JAIRO ROTAVA

Índices de resiliência hídrica e de perigo para gestão do risco de inundações urbanas

VERSÃO CORRIGIDA

São Carlos 

JAIRO ROTAVA

\section{Índices de resiliência hídrica e de perigo para gestão do risco de inundações urbanas}

Dissertação apresentada à Escola de Engenharia de São Carlos, da Universidade de São Paulo, como parte dos requisitos para obtenção do título de Mestre em Ciências: Engenharia Hidráulica e Saneamento

Orientador: Prof. Dr. Eduardo Mario Mendiondo

VERSÃO CORRIGIDA

São Carlos 
AUTORIZO A REPRODUÇÃO TOTAL OU PARCIAL DESTE TRABALHO, POR QUALQUER MEIO CONVENCIONAL OU ELETRÓNICO, PARA FINS DE ESTUDO E PESQUISA, DESDE QUE CITADA A FONTE.

Rotava, Jairo

R8421 Í Indices de resiliência hídrica e de perigo para gestão do risco de inundações urbanas / Jairo Rotava; orientador Eduardo Mario Mendiondo. São Carlos, 2014.

Dissertação (Mestrado) - Programa de Pós-Graduação e Área de Concentração em Hidráulica e Saneamento -Escola de Engenharia de São Carlos da Universidade de São Paulo, 2014.

1. índice. 2. perigo. 3. resiliência. 4. inundação. I. Título. 


\section{FOLHA DE JULGAMENTO}

Candidato: Engenheiro JAIRO ROTAVA.

Título da dissertação: "Índices de resiliência e de perigo para gestão do risco de inundações urbanas".

Data da defesa: 24/04/2014

\section{Comissão Julgadora:}

Prof. Dr. Eduardo Mario Mendiondo (Orientador)

(Escola de Engenharia de São Carlos/EESC)

Prof. Dr. Vladimir Caramori Borges de Souza

(Universidade Federal de Alagoas/UFAL)

Dr. José Antonio Marengo Orsini

(Instituto Nacional de Pesquisas Espaciais/INPE)
Resultado:

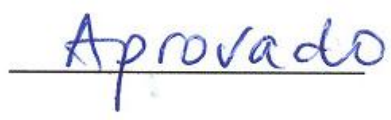

APROVADO

AlROVADO

Coordenadora do Programa de Pós-Graduação em Engenharia Hidráulica e Saneamento:

Profa. Associada Maria Bernadete A. Varesche Silva

Presidente da Comissão de Pós-Graduação:

Prof. Titular Denis Vinicius Coury 



\section{AGRADECIMENTOS}

Agradeço ao Mario pela oportunidade de conhecer uma nova área, pela paciência e ajuda.

À Andréia pela oportunidade de realizar o mestrado.

Aos amigos do NIBH pelas risadas e diversão.

Aos amigos do SHS.

Agradeço à minha família. 



\section{RESUMO}

ROTAVA, J. Índices de resiliência hídrica e de perigo para gestão do risco de inundações urbanas. 2014. Dissertação (Mestrado) - Escola de Engenharia de São Carlos, Universidade de São Paulo, São Carlos, 2014.

Inundações são eventos cada vez mais freqüentes e a cada ano os prejuízos são maiores. Inicialmente o combate dos prejuízos das inundações se deu na forma de evitá-las através de medidas estruturais. Hoje esta forma de combate vem sendo substituída, ou complementada, por medidas chamadas resilientes, geralmente medidas não estruturais, onde o objetivo é evitar as conseqüências e prejuízos da inundação, e não a própria inundação. Índices para avaliação do risco e conseqüências de inundações são ferramentas importantes para o gerenciamento do risco, eles permitem avaliar o risco, suas conseqüências, e auxiliam no desenvolvimento de planos de combate. Neste trabalho é proposto um índice de perigo (IP) e um índice de resiliência (PWRI): o primeiro lida com a vulnerabilidade de pessoas expostas à corrente de água devido inundação, e o segundo tem o objetivo de avaliar a resiliência de uma região com relação a eventos extremos hidrológicos, onde o risco de inundação e a capacidade de gerenciamento de suas conseqüências são determinados. 0 índice de resiliência (PWRI), que avalia qualitativamente a resiliência de uma região, é composto por seis fatores: o evento natural causador do risco (Ameaça), a probabilidade de inundação devido ao evento natural (Vulnerabilidade), a quantidade de pessoas expostas (Exposição), avaliação das medidas de prevenção e preparação contra a inundação e suas conseqüências (Antes), medidas de combate direto (Durante) e medidas de reconstrução após o evento (Depois). Os fatores são agrupados em dois grupos, o primeiro envolve a avaliação do Risco (Ameaça, Vulnerabilidade e Exposição) e o segundo a avaliação do Gerenciamento do Risco (Antes, Durante e Depois). Os fatores Ameaça, Vulnerabilidade e Exposição são obtidos a partir da previsão de escoamento superficial, modelo digital de elevação e densidade populacional. Os fatores Antes, Durante e Depois são obtidos a partir de hipóteses estabelecidas para o ano em questão. Os resultados são apresentados em uma nova forma de visualização do índice e são realizadas comparações dos resultados obtidos com eventos de inundação recentes. O índice de resiliência identifica pontos com problemas de inundações, e sugere novos pontos que podem sofrer inundação e perdas com o aumento da impermeabilização do solo e alteração do padrão de precipitação. Para o índice de perigo (IP) é desenvolvido um modelo teórico, onde os resultados são comparados e validados com dados experimentais encontrados na literatura. São apresentadas algumas recomendações e formas de utilização para o índice de perigo. Esta pesquisa forma parte do projeto temático Assessment of Impacts and Vulnerability to Climate Change in Brazil and Strategies for Adaptation Options, FAPESP 2008/58161-1 pela componente Mitigation and adaptation measures of vulnerable communities to cope with water-related risks derived from climate change scenarios at river basins of Sao Carlos.

Palavras-Chave: índice, perigo, resiliência, inundação. 


\begin{abstract}
ROTAVA, J. Hazard and resilience indexes for urban flood risk management. 2014. Dissertação (Mestrado) - Escola de Engenharia de São Carlos, Universidade de São Paulo, São Carlos, 2014.

Floods are becoming more frequent and each year the losses are greater. Initially it was used structural measures to avoid the floods and consequently avoid the losses. Today this is being replaced or supplemented by resilient measures generally in form of non-structural measures where the goal is to avoid the losses and damages and not the flood itself. Indexes for assessing the hazard and flooding losses are important tools in the risk management and allow the assessment of the flooding consequences and development of action plans. This work proposes the hazard index and the resilience index: the first one deals with the vulnerability of people exposed to flooding water flow and the second evaluates the resilience of a region with respect hydrological events. The resilience index (PWRI) is formed by six factors: a natural event which causes the threat (Hazard), the flooding probability due the hazard (Vulnerability), exposed people (Exposure), assessment of preflood measures (Before), emergency management (During) and post flood reconstruction measures (After). These factors are grouped into two groups: Risk assessment (Hazard, Vulnerability and Exposure) and the Risk Management (Before, During and After). The Hazard, Vulnerability and Exposure factors are obtained from the predicted runoff, digital elevation model and population density. Before, During and After factors are obtained from hypothesis. The resilience index is developed and compared with known flooding points map. It is shown that new flooding points are expected with the increase of the urbanization and land impermeabilization. The second part of the work is the hazard index (IP). A theoretical model is developed to evaluate the forces and limit conditions where people are dragged by water flow. The critical points of velocity and water depth are determined with the model and compared to experimental data found in the literature. In the end some suggestion and recommendation are present.
\end{abstract}

Keywords: index, hazard, resilience, flood. 


\section{LISTA DE FIGURAS}

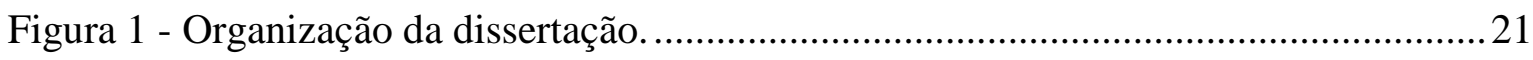

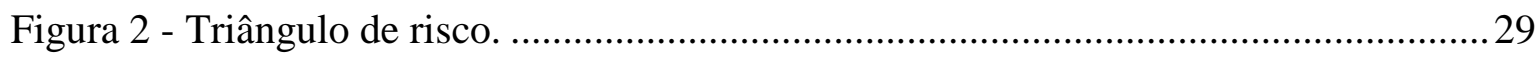

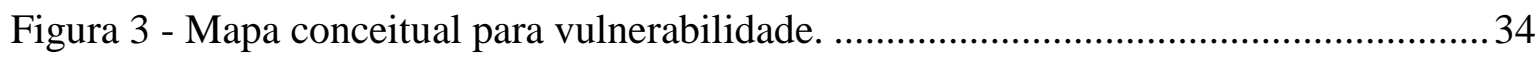

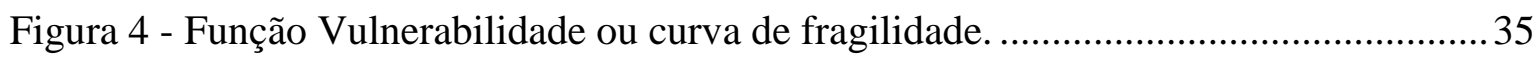

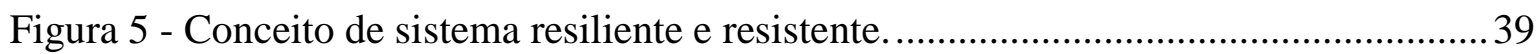

Figura 6 - Quinze anos de urbanização em Jakarta, em 1994 e 2009................................. 39

Figura 7 - Exemplos de estratégias resilientes................................................................ 41

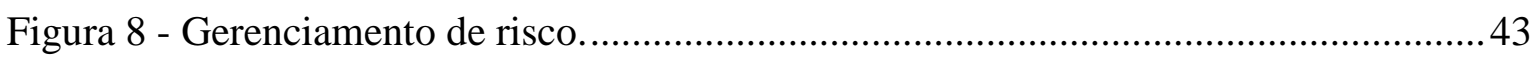

Figura 9 - Ciclo de gerenciamento de risco integrado. ................................................. 44

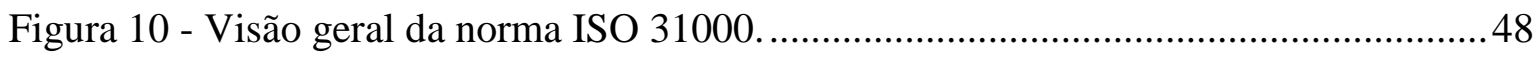

Figura 11 - Ciclo de gerenciamento de desastre. ........................................................ 49

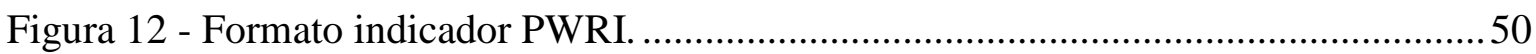

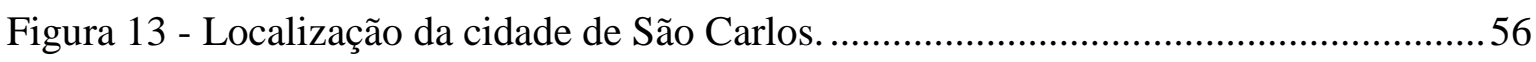

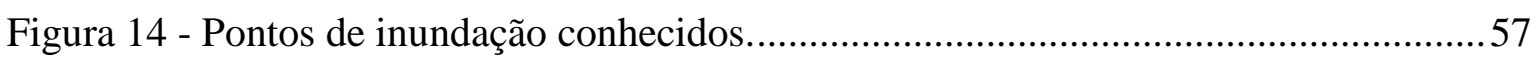

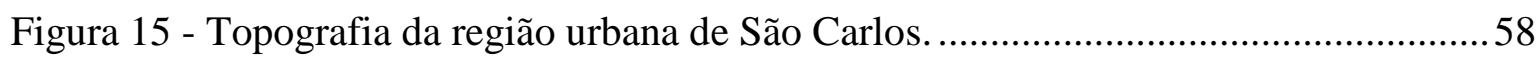

Figura 16 - Bacia urbana de São Carlos e sub-bacias..........................................................59

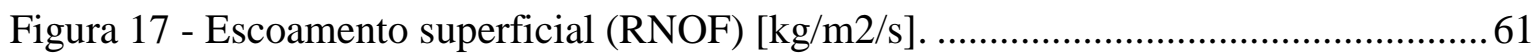

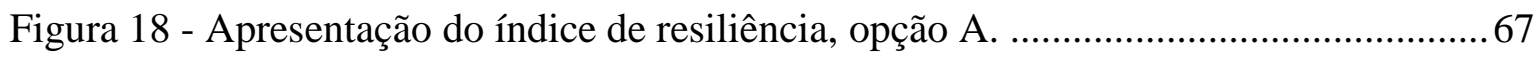

Figura 19 - Apresentação do índice de resiliência, opção B................................................6 68

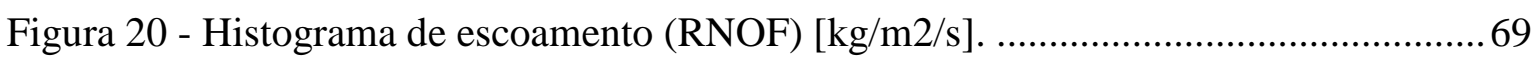

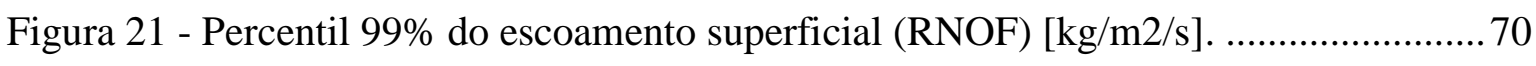

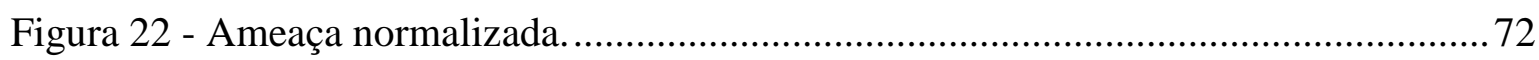

Figura 23 - Mapa de Ameaça para o presente - ano 2003 ............................................. 75

Figura 24 - Fluxo de água acumulado em células. ............................................................ 76

Figura 25 - Mapa de fluxo acumulado após filtro espacial gaussiano............................... 77

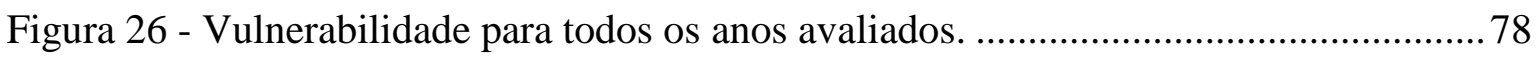

Figura 27 - Mapa de Vulnerabilidade e pontos conhecidos de inundação. .......................... 79

Figura 28 - Mapa de densidade populacional $[\mathrm{hab} / \mathrm{m} 2]$................................................. 80

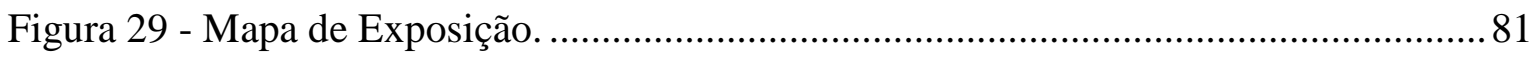

Figura 30 - Mapa de risco para o presente - ano 2003 - e pontos conhecidos de inundação.

Figura 31 - Mapa de risco para futuro - ano 2100 - e pontos conhecidos de inundação. .... 83 


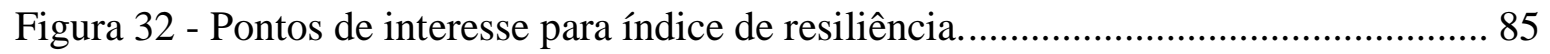

Figura 33 - Pontos de interesse no mapa de risco para futuro - ano 2100 ........................ 86

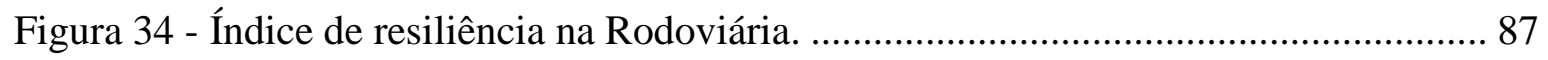

Figura 35 - Índice de resiliência no Mercado Municipal. ................................................ 87

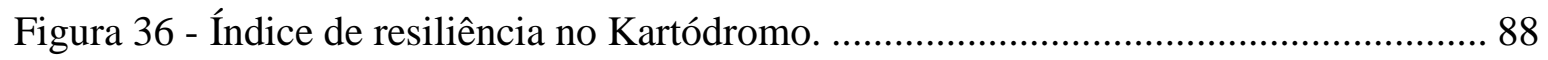

Figura 37 - Índice de resiliência na Rotatória do Shopping, ou Cristo. ............................. 88

Figura 38 - Índice de resiliência no Alto do Monjolinho.................................................. 89

Figura 39 - Índice de resiliência para rotatória do Cristo.................................................. 90

Figura 40 - Modelo de corpo humano para estudo de instabilidade. ................................ 95

Figura 41 - Coeficiente de atrito para diferentes superfícies........................................... 98

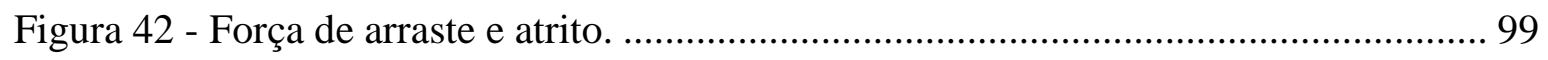

Figura 43 - Produto crítico $\boldsymbol{h} \boldsymbol{v}$ teórico e experimental....................................................... 100

Figura 45 - Produto $\boldsymbol{h} \boldsymbol{v}^{\mathbf{2}}$ com a profundidade relativa............................................. 101

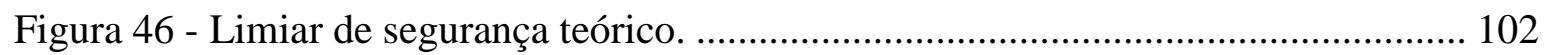

Figura 47 - Limiar de segurança empírico. ................................................................... 102

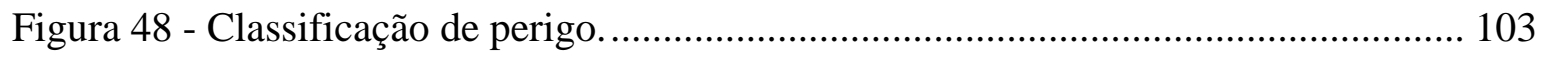

Figura 49 - Índice de perigo no Tijuco Preto/USP - São Carlos. ....................................... 104

Figura 50 - Forma de indicação de perigo por profundidade relativa. .............................. 105

Figura 51 - Escoamento superficial simulado pelo INPE. .............................................. 123

Figura 52 - Histograma do escoamento superficial simulado pelo INPE. ....................... 124

Figura 53 - Índice de resiliência para Kartódromo........................................................... 125

Figura 54 - Índice de resiliência para Mercado Municipal. ........................................... 126

Figura 55 - Índice de resiliência para Alto do Monjolinho............................................ 127

Figura 56 - Índice de resiliência para Rodoviária. ........................................................ 128 


\section{LISTA DE TABELAS}

Tabela 1 - Vantagens e desvantagens de indicadores compostos. ......................................25

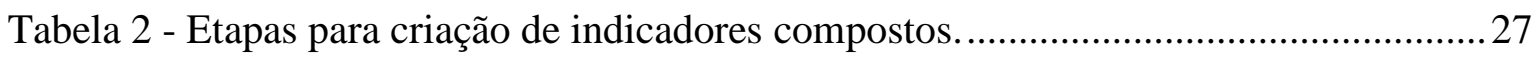

Tabela 3 - Tabela com definições de risco na literatura. ...................................................... 30

Tabela 4 - Desafios na definição de Vulnerabilidade. .......................................................... 31

Tabela 5 - Compilação de definições para Vulnerabilidade............................................... 32

Tabela 6 - Fases do processo de prevenção de desastres naturais. .....................................42

Tabela 7 - Valores dos parâmetros $\mathrm{CN}$ para diferentes tipos de ocupação urbana...............55

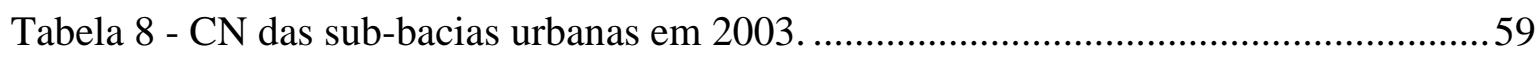

Tabela 9 - Condições de CN e armazenamento de água no solo.........................................63

Tabela 10 - Compilação de medidas de gerenciamento de Risco........................................66

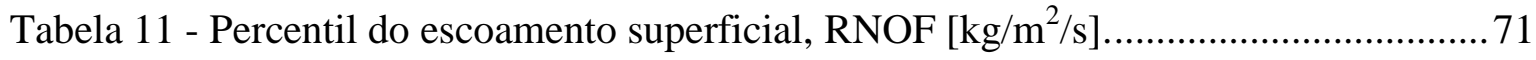

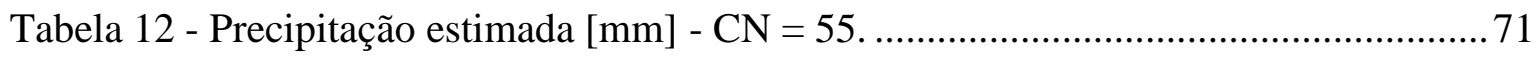

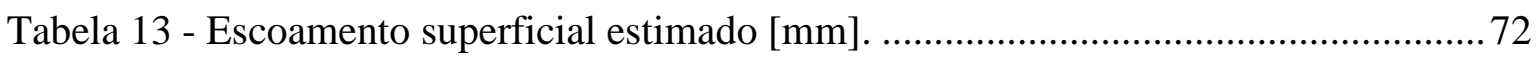

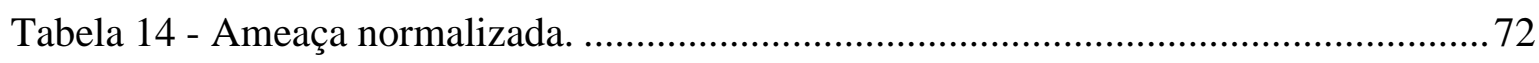

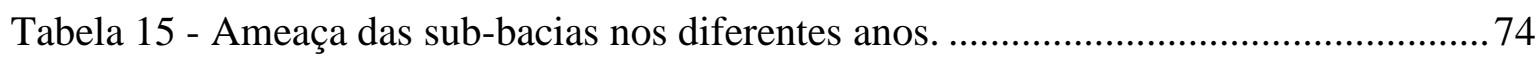

Tabela 16 - Hipóteses de medidas de Gerenciamento de Risco. ......................................... 84

Tabela 17 - Tabela com resumo de indicadores de Gerenciamento de Risco. .....................85

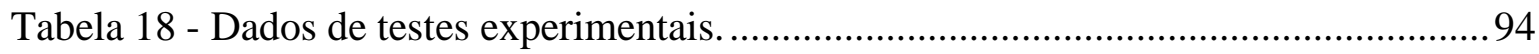

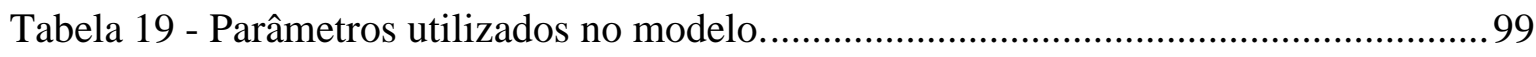

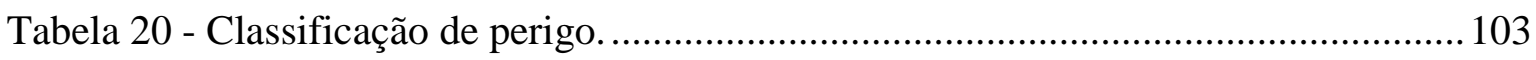

Tabela 21 - Datas com ocorrência de precipitação diária maior que 70 mm para São Carlos. 


\section{LISTA DE ABREVIATURAS E SIGLAS}

ASI

Agenzia Spaziale Italiana

CPTEC

Centro de Previsão de Tempo e Estudos Climáticos

DLR

Deutsches Zentrum für Luft und Raumfahrt

HADCM3

Hadley Centre Coupled Model, version 3

HAND

Height Above the Nearest Drainage

IBGE

Instituto Brasileiro de Geografia e Estatística

INPE

Instituto Nacional de Pesquisa Espacial

IP

Indicador de Perigo

IPCC

Intergovernmental Panel on Climate Change

NASA

National Aeronautics and Space Administation

NIMA

National Imagery and Mapping Agency

PWRI

Participative Water Resilience Index

SCS

Soil Conservation Service

SIGRH

Sistema Integrado de Gerenciamento de Recursos Hídricos

SRTM

Shuttle Radar Topography Mission 


\section{LISTA DE SÍMBOLOS}

$\theta$

$\mathrm{CN}$

CNTRL

$F_{\text {person }}$

$F_{\text {buoy }}$

$F_{\text {friction }}$

$F_{\text {flow }}$

$\mathrm{HIGH}$

$h v$

$h v^{2}$

$I_{a}$

$k$

LOW

MIDI

RNOF

$P$

$Q$

$S$
Profundidade relativa, altura da água / altura da pessoa

Curve Number

Rodada de controle modelo Eta

Peso da pessoa

Força de empuxo

Força de Atrito

Força de Arraste devido escoamento de água

Rodada de alta sensibilidade modelo Eta

Indicador de perigo, produto da altura e velocidade da lâmina da água

Indicador de Perigo, produto da altura e o quadrado da velocidade da lâmina de água

Perdas iniciais [mm]

Constante de calibração, envolve constantes físicas e algumas simplificações

Rodada de baixa sensibilidade modelo Eta

Rodada de média sensibilidade modelo Eta

Runoff, Escoamento superficial

Precipitação total acumulada [mm]

Escoamento superficial acumulado [mm]

Armazenamento do solo [mm] 



\section{SUMÁRIO}

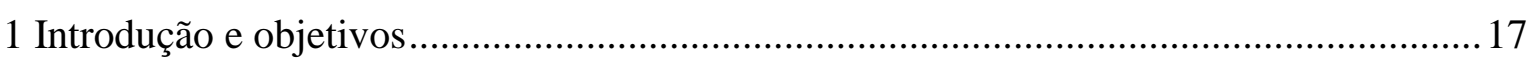

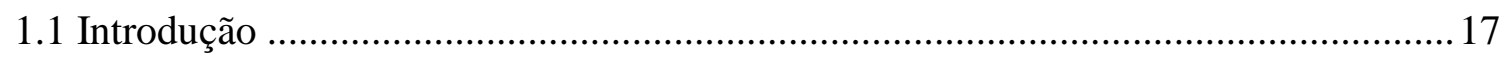

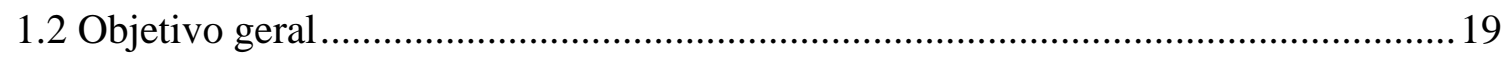

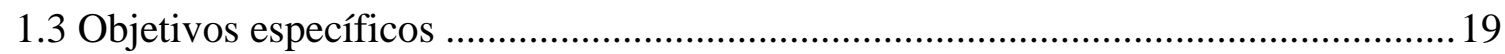

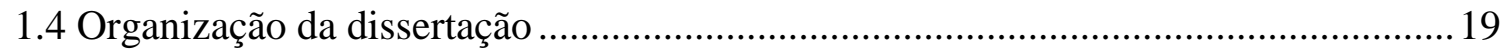

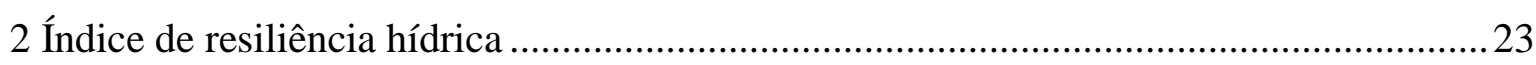

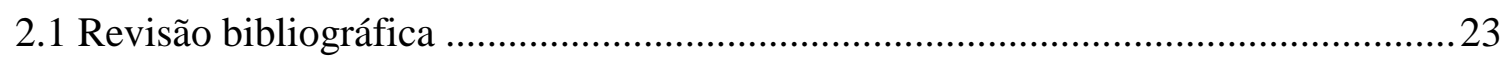

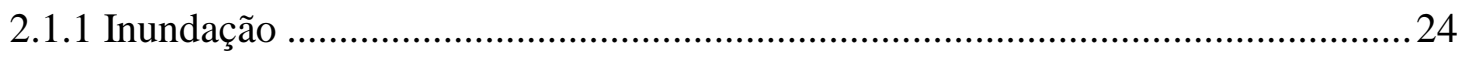

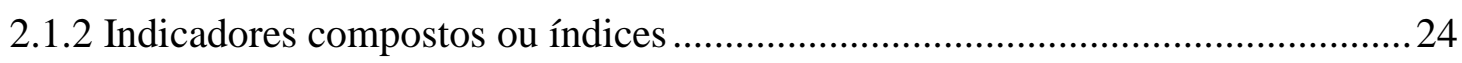

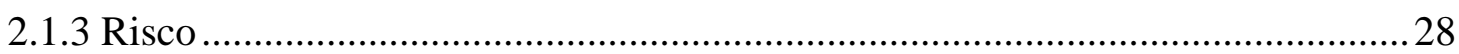

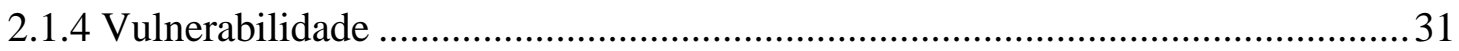

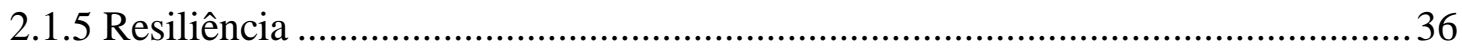

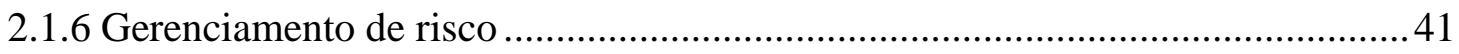

2.1.7 Índice de resiliência hídrica com base participativa (PWRI) .............................49

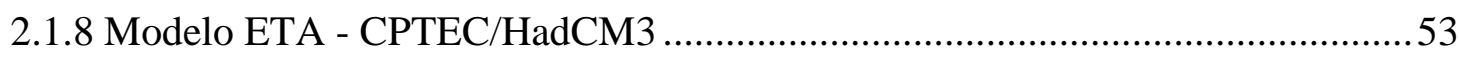

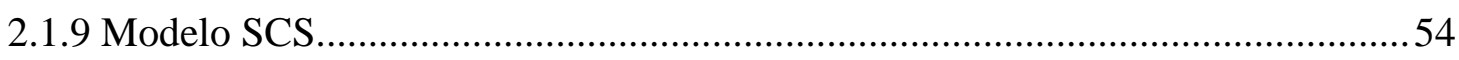

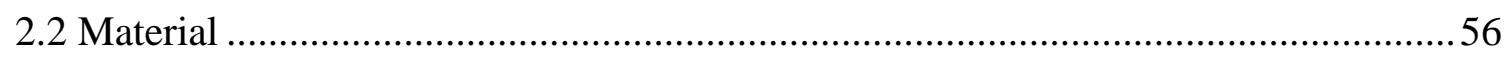

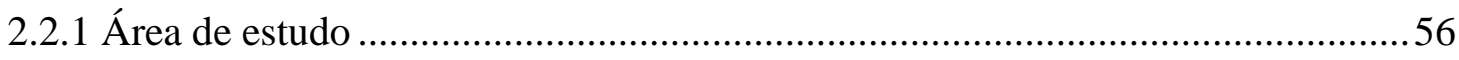

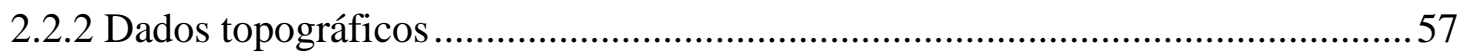

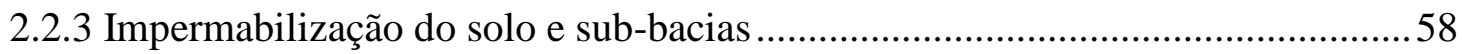

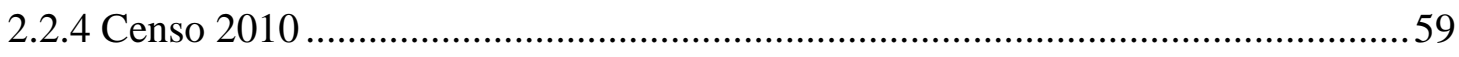

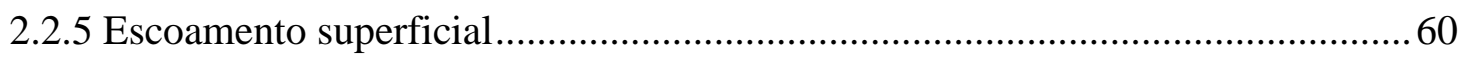

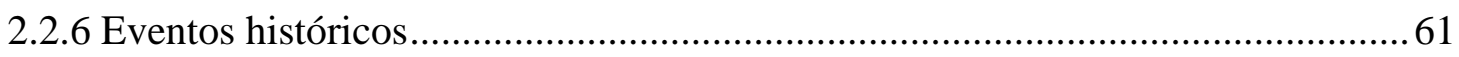

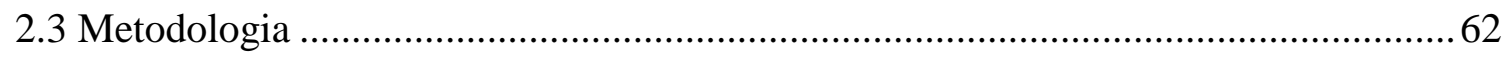

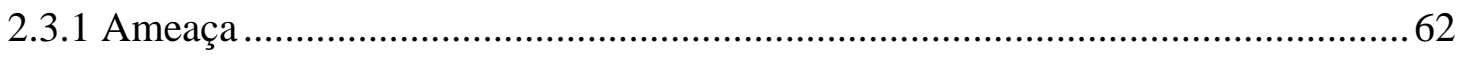

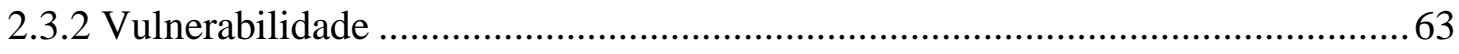

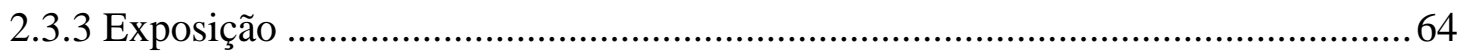

2.3.4 Mapa de risco \{Ameaca, Vulnerabilidade, Exposição\} ………………...............6 65

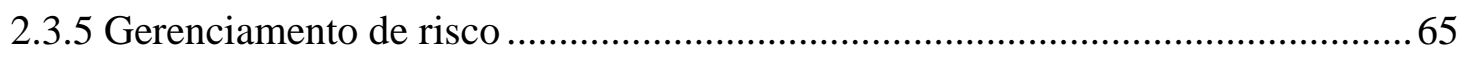

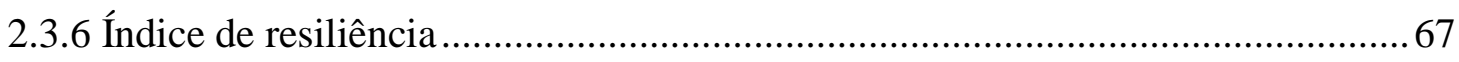

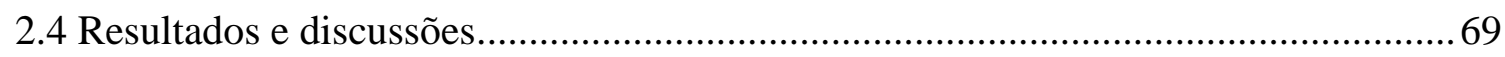

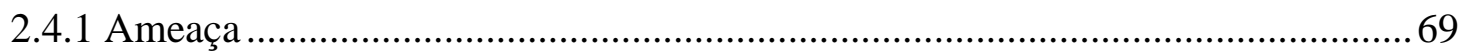

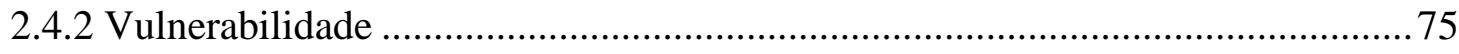

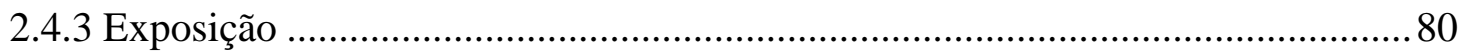

2.4.4 Mapa de risco \{Ameaça, Vulnerabilidade, Exposição\} ..................................... 81 
2.4.5 Gerenciamento de risco \{Antes, Durante, Depois \} ....................................... 83

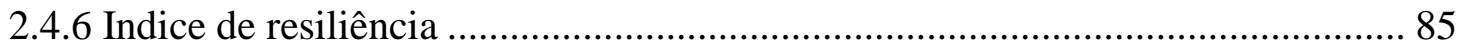

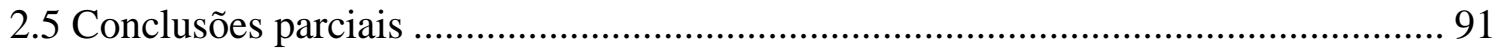

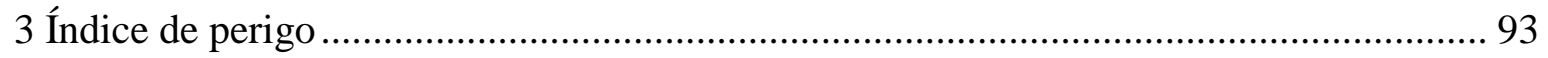

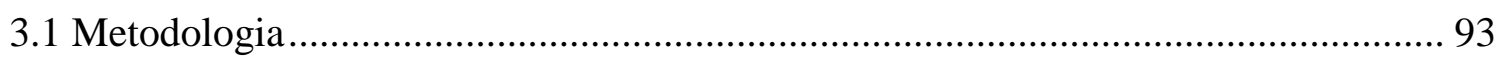

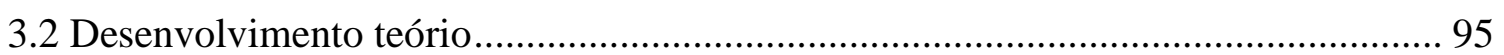

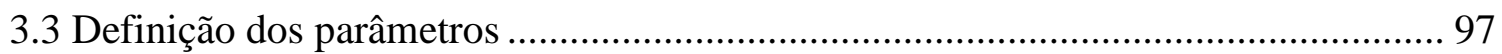

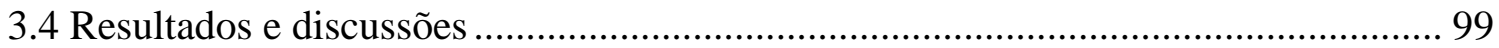

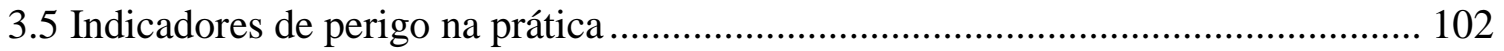

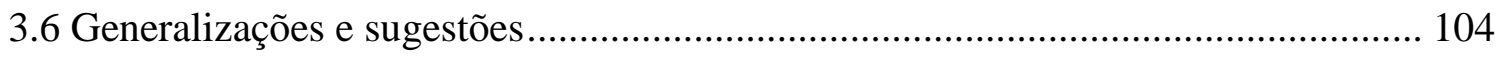

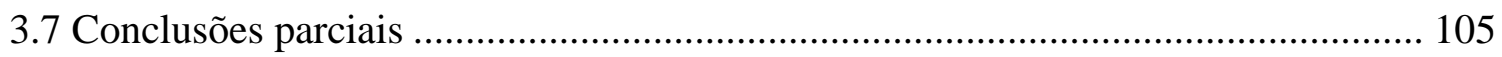

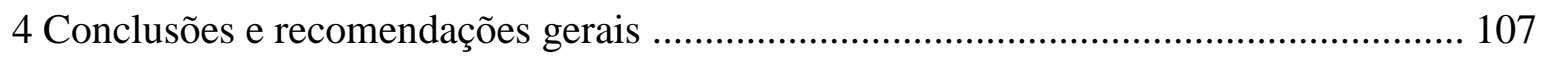

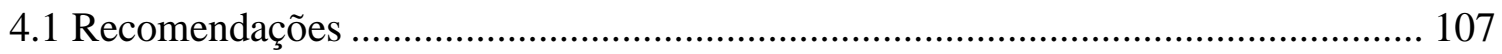

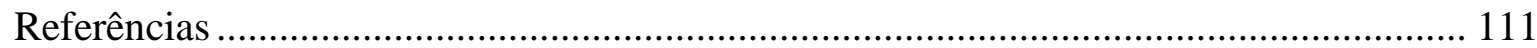

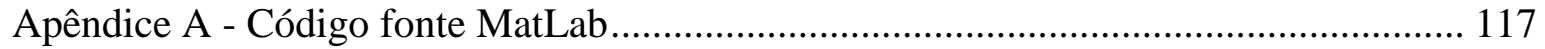

Apêndice B - Escoamento superficial e histograma....................................................... 123

Apêndice C - Índice de resiliência ........................................................................... 125

Anexo A - Tabela de precipitação histórica .................................................................... 129 


\section{INTRODUÇÃO E OBJETIVOS}

A proposta deste capítulo é realizar uma breve introdução e oferecer uma visão geral sobre o trabalho desenvolvido nesta dissertação. Os objetivos são formulados na forma de um objetivo geral e alguns objetivos específicos, que resumem as etapas do trabalho. No final é apresentado um diagrama da organização geral da dissertação.

\subsection{INTRODUÇÃO}

Riscos naturais são inevitáveis. Entre os riscos naturais a inundação é o risco mais freqüente e com conseqüências mais severas. Inundações destroem vidas e causam danos para terras, propriedades e infra-estrutura. Para garantir a sustentabilidade de uma comunidade, a identificação do risco de inundação deve ser um dos mais importantes passos no planejamento e prevenção (GANOULIS, 1994). A engenharia de análise de risco e confiabilidade oferece uma metodologia para quantificação de incertezas e por isso deve ser utilizada para avaliar a segurança de um sistema (AHMAD; SIMONOVIC, 2011). Identificar e medir riscos e vulnerabilidade antes que o desastre ocorra é uma tarefa essencial para redução efetiva do risco em longo prazo (BIRKMANN, 2007)

Este trabalho consiste de duas partes independentes: o desenvolvimento de uma metodologia para um Índice de Resiliência e o desenvolvimento teórico de um Índice de Perigo para avaliação de vulnerabilidade humana em escoamentos de água. Cada parte do trabalho é apresentada em um capítulo diferente.

Mudanças climáticas tendem a aumentar a freqüência e intensidade de eventos de inundações assim como o risco associado (SCHOLZ; YANG, 2010). Além do aumento da frequiência e intensidade das chuvas, o aumento da urbanização, da população e economia em áreas vulneráveis também aumentam os prejuízos. Uma ferramenta capaz de identificar regiões com chances de sofrer inundação, assim como estimar seus prejuízos, é de grande valia para gerenciamento do crescimento urbano e convívio com inundações.

O estudo parte da premissa que, antes mesmo de questões como aumento de intensidade e freqüência de precipitação devido a mudanças climáticas ou problemas devidos à urbanização e impermeabilização do solo, existem regiões naturalmente mais propensas a sofrer inundação. Isto é suposto como uma característica natural do local que pode ou não ser agravada por fatores externos. A partir de características físicas como topografia, tipo de solo e precipitação é possível estimar quais pontos em determinada região são mais susceptíveis a 
inundação. Além das características naturais também é possível adicionar as informações relativas à urbanização e identificar novos pontos susceptíveis a inundação. Estes aspectos estão relacionados na avaliação do risco de inundação e suas consequiências, e compõem parte do Indicador de Resiliência Hídrica Participativo (PWRI) através dos termos: Ameaça, Vulnerabilidade e Exposição.

O termo Ameaça neste trabalho é definido como a escoamento superficial previsto através de simulações do modelo Eta CPTEC/HadCM3 (MARENGO et al., 2011). A Vulnerabilidade é tratada como a probabilidade de um local ser atingido por uma inundação e a Exposição como a densidade populacional de pessoas em domicilio na região, obtido a partir do CENSO 2010. O mapa de Vulnerabilidade apresenta os pontos com maiores chances de inundação, o mapa Exposição mostra as regiões mais densamente habitadas, e o produto do mapa Vulnerabilidade pelo mapa de Exposição, o mapa de Risco, apresenta os pontos que apresentam o potencial número de pessoas atingidas por inundação.

É suposto duas formas de combate a inundação: resistente e resiliente. A opção resistente tem objetivo de evitar as inundações com obras estruturais, enquanto a opção resiliente utiliza medidas não estruturais para minimizar as perdas.

A quantificação da capacidade de gerenciamento do risco é a segunda parte do índice de resiliência. Os termos Antes, Durante e Depois refletem a capacidade e ferramentas de gerenciamento disponíveis na região para lidar com eventos de inundação. O fator Antes avalia as ferramentas e medidas que podem ser utilizadas antes de uma inundação, Durante corresponde as medidas emergenciais que podem ser utilizadas durante a inundação e Depois se refere às estruturas administrativas responsáveis pela recuperação após a inundação.

O trabalho propõe uma metodologia para criação de mapas de Vulnerabilidade e Risco e uma forma de apresentação visual do índice de resiliência, aplicados na zona urbana de São Carlos. Posteriormente é feita uma comparação entre os mapas e índice em alguns pontos de interesse. Um evento de inundação real é utilizado para avaliar a validade e limitação da metodologia.

Na segunda parte do trabalho é realizado o desenvolvimento teórico do Índice de Perigo (IP) para avaliação de vulnerabilidade humana em escoamento de água devido inundação. Inundações podem produzir escoamentos de água nas ruas da cidade que, dependendo de suas características, podem ser perigosas para pessoas. O desenvolvimento teórico visa estimar as forças que atuam sobre uma pessoa exposta em um escoamento e definir os limites seguros para travessia do mesmo para diferentes pessoas. Este tipo de estudo permite fornecer uma base teórica para posterior elaboração de mapas de pontos perigosos. Os pontos perigosos 
devem ser evitados por pessoas e automóveis a fim de evitar que sejam levados pela força da água. São discutidas as duas formas mais comum de representação do escoamento para avaliação do perigo, $h v$ e $h v^{2}$, e são propostas algumas formas de utilização do índice na prática.

\subsection{OBJETIVO GERAL}

O objetivo deste trabalho é desenvolver e aplicar índices que possam auxiliar na gestão do risco de inundação para bacia urbana da cidade de São Carlos.

\subsection{OBJETIVOS ESPECÍFICOS}

Os objetivos específicos são:

1. Reunir informações e avaliar criticamente os conceitos utilizados na análise e gerenciamento de risco como: indicadores, índices, ameaça, vulnerabilidade, exposição, resiliência, resistência, gerenciamento de risco, etc.

2. Propor e aplicar uma metodologia para um índice de resiliência baseado no formato do índice de resiliência hídrica com base participativa (PWRI) na bacia urbana da cidade de São Carlos.

3. Organizar um estudo teórico para avaliação da vulnerabilidade de uma pessoa exposta em escoamentos de água de forma a estimar forças e limiares de segurança com base hidráulica.

4. Comparar criticamente os resultados e conclusões teóricas com dados e informações da literatura.

\subsection{ORGANIZAÇÃO DA DISSERTAÇÃO}

A dissertação é organizada em duas partes: a primeira trata do índice de resiliência aplicado em toda bacia urbana, avaliado no período dos anos de 1960 a 2100. Trata-se de um índice de longo prazo aplicado na escala espacial da ordem das bacias hidrográficas. Este índice abrange um panorama mais amplo e é uma ferramenta de gerenciamento em longo prazo. A segunda parte trata de um índice mais específico, que avalia a vulnerabilidade de uma pessoa exposta em escoamento de água, que pode ou não ser devido a uma inundação.

Os dois índices se complementam, sendo que o primeiro oferece uma visão macro, ou geral, que avalia a capacidade de gerenciamento e resiliência, enquanto o segundo é destinado 
à avaliação de pontos e condições bem específicas de uma inundação quanto à segurança das pessoas com relação a escoamento de água. 


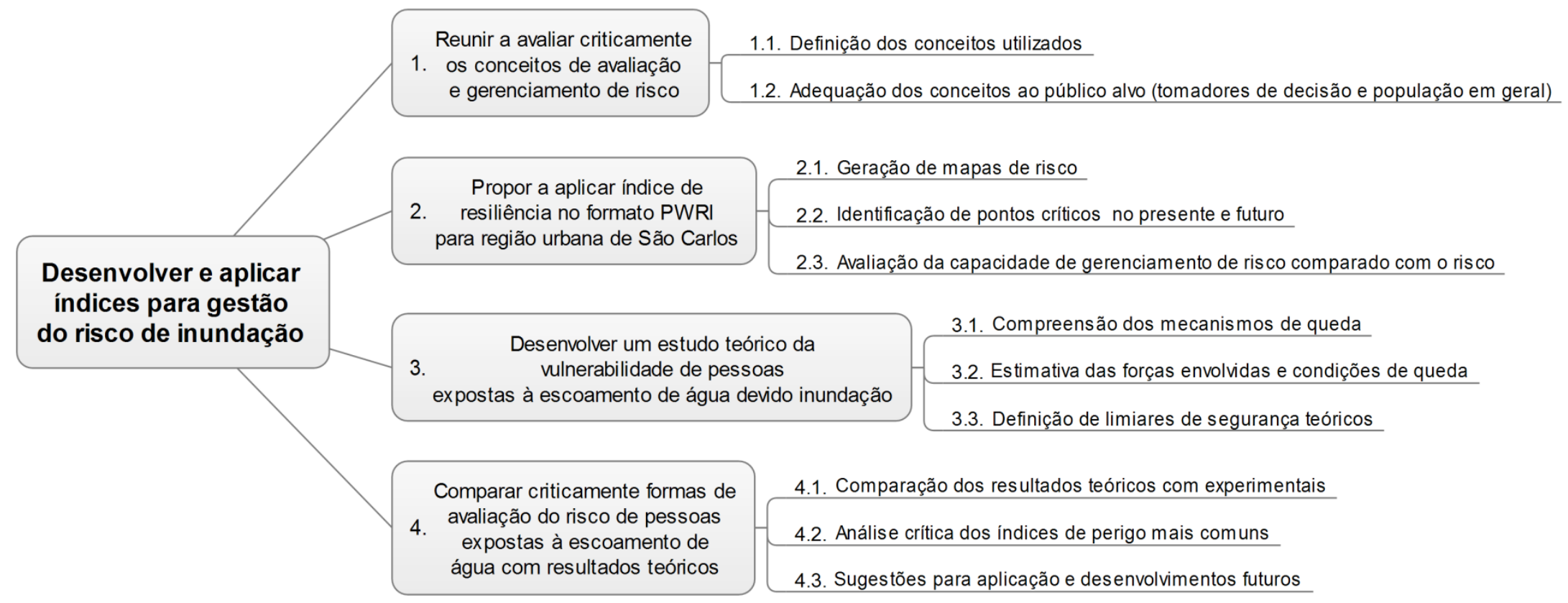

Figura 1 - Organização da dissertação.

De acordo com a Figura 1, o objetivo geral é dividido em quatro objetivos específicos, sendo que os dois primeiros são relacionados com o índice de resiliência no capítulo 2. Os objetivos específicos três e quatro correspondem ao desenvolvimento do índice de perigo no capítulo 3 . 


\section{2 ÍNDICE DE RESILIÊNCIA HÍDRICA}

O objetivo deste capítulo é estudar a construção de índice para avaliação da resiliência frente a fatores de risco de uma região a partir de conceitos como risco e gerenciamento de risco. Inicialmente é realizada a revisão bibliográfica onde são discutidos os princípios básicos e mais aceitos para índices ou indicadores compostos, seguindo por uma pesquisa das definições de termos como vulnerabilidade, resiliência, gerenciamento de risco, etc., e apresentação de alguns conceitos de gerenciamento de risco atuais. É apresentado o formato do Índice de Resiliência Hídrica com base Participativa, do inglês Participatory Based Water Resilience Index (PWRI) (MENDIONDO, 2010; MENDIONDO et al., 2013).

Em seguida é desenvolvida a metodologia, apresentados os dados e os resultados.

\subsection{REVISÃO BIBLIOGRÁFICA}

A revisão bibliográfica é organizada da seguinte maneira:

1. Inundação: definição de inundação.

2. Índices (ou indicadores compostos): uma breve discussão sobre indicadores compostos, boas práticas e metodologias mais aceitas. Alguns dos conceitos apresentados são utilizados posteriormente.

3. Conceitos básicos de termos utilizados no estudo: risco, resiliência, vulnerabilidade, estratégias resistentes e resilientes de combate à inundação, etc. O objetivo é apresentar a variedade de definições que estes termos podem assumir, geralmente utilizados por especialistas na área, e mostrar como estas podem ser confusas e contra intuitivas para a maioria das pessoas, e estabelecer as definiçõoes a serem utilizadas neste trabalho.

4. Gerenciamento de risco: compilação de diferentes proposta para gerenciamento de risco e avaliação de semelhanças e diferenças.

5. Índice de resiliência: descrição do formato do índice de resiliência hídrica com base participativa (PWRI), que é utilizado no desenvolvimento do índice de resiliência.

6. Modelo ETA-CPTEC/HadCM3: visão geral do modelo utilizado pelo INPE para previsão de precipitação e escoamento superficial no período de 1960-2100.

7. Modelo SCS: uma breve descrição. O modelo é utilizado para ajuste do escoamento superficial para diferentes condições de impermeabilização do solo. 


\subsubsection{INUNDAÇÃO}

A inundação, popularmente tratada como enchente, é o aumento do nível dos rios além do seu nível normal, ocorrendo o transbordamento de suas águas sobre as áreas próximas a ele. Quando não ocorre o transbordamento, apesar do rio praticamente cheio, tem-se uma enchente e não uma inundação. Por esta razão, no mundo científico, os termos inundação e enchente devem ser usados com diferenciação (KOBIYAMA et al., 2006).

A freqüência das inundações é alterada devido a modificações na bacia hidrográfica e padrão de precipitação. Este tipo de problema é comumente presenciado nas áreas urbanas. Assim devem ser introduzidos novos conceitos e práticas para uma melhor convivência com este fenômeno (KOBIYAMA et al., 2006).

\subsubsection{INDICADORES COMPOSTOS OU ÍNDICES}

Em termos gerais, um indicador é uma medida quantitativa ou qualitativa derivada de uma série de fatos observados que podem revelar posições relativas em uma dada área. Quando avaliado em intervalos regulares um indicador consegue apontar a direção das mudanças com o tempo. No contexto de análise política os indicadores são úteis para identificação de tendências e chamar a atenção para problemas particulares. Eles podem ser úteis na definição de prioridades e na avaliação de desempenho dos programas implementados. Um indicador composto, ou índice, é formado quando indicadores individuais são compilados em um único número. Um indicador composto deve idealmente medir conceitos multidimensionais que não podem ser capturados por um único indicador, como por exemplo: competitividade, nível de industrialização, sustentabilidade, integração de mercado (Organisation for economic cooperation and development - OECD, 2008). As principais vantagens e desvantagens na utilização de índices ou indicadores compostos são apresentadas na Tabela 1. 
Tabela 1 - Vantagens e desvantagens de indicadores compostos.

\begin{tabular}{lll}
\hline Vantagens & Desvantagens \\
\hline - & Resume realidades complexas e & Se mal construído ou interpretado \\
multidimensionais com objetivo de & pode ser utilizado em mensagens \\
auxiliar tomadores de decisão. & políticas duvidosas. \\
indicadores separados. & Pode ser um convite a conclusões \\
- Permite avaliar o progresso com o & simplistas. \\
tempo. & Pode ser mal utilizado para apoiar \\
Reduz o número de indicadores sem & decisão política, no caso do processo \\
descartar informações. & de construção do indicador não ser \\
Coloca assuntos como performance e & transparente e não ter base conceitual \\
progresso no centro da discussão & e estatística sólida. \\
política. & A seleção dos indicadores e pesos pode \\
Facilita a discussão com público em & estar sujeita a disputa política. \\
geral. & Podem ter falhas graves em algumas \\
Permite usuários comparar dimensões & dimensões, e aumentar a dificuldade \\
complexas. & de identificar a ação corretiva se o \\
& processo de construção não for \\
& adequado. \\
& Pode ser utilizado para políticas \\
& impróprias se a importância de \\
& dimensões difíceis de serem medidas \\
& for ignorada. \\
\hline
\end{tabular}

Fonte: OECD (2008).

Existem duas correntes de pensamento com relação a indicadores compostos, que questionam se esse tipo de indicador é adequado:

Agregadores acreditam que existem duas razões principais na combinação de indicadores para produzir de alguma forma uma linha inferior. Eles acreditam que este resumo estatístico pode mesmo capturar a realidade e tem algum significado, e afirmam que uma linha inferior é extremamente útil para obter atenção da mídia e políticos. A segunda escola, os não agregadores, acredita que se deve parar assim que um conjunto apropriado de indicadores é criado e não seguir em diante e produzir um indicador composto. A principal objeção deste grupo é o que a forma como os indicadores são combinados é um processo de natureza arbitrária (SHARPE ${ }^{1}, 2004$ apud OECD, 2008, p.14).

Ou ainda:

[...] é difícil imaginar quando o debate entre uso de indicadores compostos vai encerrar [...] estatísticos oficiais tem a tendência de não gostar de indicadores compostos, onde muito trabalho em coletar e editar dados é desperdiçado ou escondido atrás de um único número de significado duvidoso. Por outro lado, a tentação de resumir processos complicados em um único número e utilizá-lo na política parece ser irresistível (SAISANA et al. ${ }^{2}, 2005$ apud OECD, 2008, p.14).

\footnotetext{
${ }^{1}$ Sharpe A. (2004), Literature Review of Frameworks for Macro-indicators, Centre for Study of Living Standards, Ottawa, CAN

${ }^{2}$ Saisana M., Tarabtika S. e Saktelli A. (2005), Uncertainty and sensitivity techniques as tools for the analysis and validation of composite indicators, Journal of the Royal Statistical Society A, 168(2), 307-323
} 
Um indicador fornece um nível ou estado da informação que está sendo avaliada. Os indicadores são uma maneira de se observar objetivamente a realidade e um passo importante é escolher indicadores apropriados para cada fenômeno em estudo. Portanto, para a escolha do indicador que retrata com maior fidelidade a condição real devem ser observados os seguintes atributos (DE BONNIS ${ }^{3}, 2006$ e OLAVE ${ }^{4}, 2003$ apud ZONENSEIN, 2007):

- Validade: se efetivamente mede aquilo que pretende.

- Confiabilidade: se sua medição repetida em condições similares reproduz os mesmos resultados.

- Clareza: se tem significado claro para todos seus usuários.

- Especificidade: se mede somente o fenômeno de interesse.

- Sensibilidade: se consegue representar as mudanças no fenômeno de interesse.

- Mensurabilidade: se é baseado em dados disponíveis ou fáceis de serem obtidos.

- Custo-benefício: se justifica os investimentos de tempo e recursos.

São exemplos de indicadores: nível do rio, altitude, velocidade, etc.

Um índice, ou indicador composto, é uma forma de agregar informações de diferentes indicadores na tentativa de apresentar um único valor representativo de uma situação real. Este resultado tem por objetivo refletir o efeito conjunto do grupo de indicadores, permitindo assim comparações no tempo e no espaço. Sendo assim a construção de índices é um passo a frente na observação de indicadores, pois o índice relaciona matematicamente os indicadores em estudo. São destacadas as seguintes propriedades para elaboração de um índice (ZONENSEIN, 2007):

- Constituição: é o grupo de indicadores que compõe o índice.

- Domínio: é a esfera espacial de aplicabilidade do índice (local, regional, nacional, global).

- Formulação: é a expressão matemática que representa a relação entre os indicadores considerados.

- Escala: é definida pelos extremos máximo e mínimo, entre os quais estão compreendidos todos os valores que o índice pode assumir.

\footnotetext{
${ }^{3}$ DE BONIS, A., IDU - Índice de Drenagem Urbana, Monografia, Curso de Pós Graduação Lato Sensu de Gerenciamento de Recursos Hídricos Integrado ao Planejamento Municipal, Universidade Federal do Rio de Janeiro, Rio de Janeiro, 2007.

${ }^{4}$ OLAVE, D.C.S, "Sumário de indicador de índices relacionados con la evaluacíon de la vulnerabilidad, la amenaza y el riesgo por eventos naturales, In: Programa de Información e Indicadores de Gestión de Riesgo de Desastres Naturales, BID - CEPAL - IDEA, Operación ATB/JF-7907-RG, Manizales, Colombia, 2003.
} 
$\mathrm{Na}$ Tabela 2 são apresentadas recomendações para o desenvolvimento de uma estrutura teórica até a apresentação e disseminação de um índice ou indicador composto. Cada passo é extremamente importante, mas coerência em todo o processo é igualmente importante (OECD, 2008).

Tabela 2 - Etapas para criação de indicadores compostos.

\begin{tabular}{|c|c|}
\hline Etapa & Motivo \\
\hline $\begin{array}{l}1 \text { - Estrutura teórica: define uma base para a } \\
\text { seleção e combinação das variáveis em um indicador } \\
\text { composto. }\end{array}$ & $\begin{array}{l}\text { - } \quad \text { Para obter uma compreensão e definição da } \\
\text { multidimensionalidade do fenômeno a ser medido. } \\
\text { - } \quad \text { Para estruturar os vários subgrupos do fenômeno. } \\
\text { - } \quad \text { Para compilar uma lista de seleção de critérios } \\
\text { para variáveis, como entrada, saída, processos. }\end{array}$ \\
\hline $\begin{array}{l}\text { 2 - Seleção de dados: deve ser baseada no valor } \\
\text { analítico, mensurabilidade, cobertura nacional e } \\
\text { relevância dos indicadores com relação ao fenômeno a } \\
\text { ser medido. }\end{array}$ & $\begin{array}{l}\text { Para avaliar a qualidade dos indicadores } \\
\text { disponíveis. } \\
\text { Para discutir os pontos fortes e fracos de cada } \\
\text { indicador selecionado. } \\
\text { Para criar uma tabela de resumo sobre a } \\
\text { característica dos dados como disponibilidade, } \\
\text { fontes, tipo. }\end{array}$ \\
\hline $\begin{array}{l}3 \text { - Estimativa de dados indisponíveis: necessário } \\
\text { para estimar os dados que faltam para completar as } \\
\text { informações. }\end{array}$ & $\begin{array}{l}\text { - Para estimar valores que faltam ou estão } \\
\text { indisponíveis. } \\
\text { Para disponibilizar a medida de confiabilidade de } \\
\text { cada valor estimado, assim como avaliar o } \\
\text { impacto das estimativas no resultado do indicador } \\
\text { composto. }\end{array}$ \\
\hline $\begin{array}{l}\text { 4 - Análise multivariável: deve ser utilizada para } \\
\text { estudar a estrutura geral dos dados analisados, } \\
\text { disponibilidade, e subseqüente escolha de metodologia } \\
\text { de agregação. }\end{array}$ & $\begin{array}{l}\text { - } \quad \text { Para verificar a estrutura dos dados. } \\
\text { Para identificar grupos de indicadores que são } \\
\text { estatisticamente similares e oferecer uma } \\
\text { interpretação dos resultados. } \\
\text { - } \quad \text { Para comparar estruturas estatisticamente } \\
\text { definidas dos dados com a estrutura teórica e } \\
\text { discutir possíveis diferenças. }\end{array}$ \\
\hline $\begin{array}{l}5 \text { - Normalização: deve ser utilizada para permitir } \\
\text { comparação das variáveis. }\end{array}$ & $\begin{array}{l}\text { - Para selecionar uma forma adequada de } \\
\text { normalização com relação estrutura teórica e as } \\
\text { propriedades dos dados. } \\
\text { - } \quad \text { Para realizar ajuste de escala. }\end{array}$ \\
\hline $\begin{array}{l}\text { 6 - Pesos e combinação: a combinação dos } \\
\text { indicadores e os pesos utilizados devem ser } \\
\text { subsidiados pela estrutura teórica. }\end{array}$ & $\begin{array}{l}\text { - Para selecionar pesos e procedimentos de } \\
\text { combinação adequados com a estrutura teórica e a } \\
\text { propriedades dos dados. } \\
\text { - } \quad \text { Para discutir a questão de correlação entre } \\
\text { indicadores. } \\
\text { - } \quad \text { Para discutir quando deve ser permitida } \\
\text { compensação entre indicadores. }\end{array}$ \\
\hline $\begin{array}{l}7 \text { - Análise de incertezas e sensibilidade: deve ser } \\
\text { utilizada para avaliar a robustez do indicador composto } \\
\text { e escolha de pesos e métodos de combinação. }\end{array}$ & $\begin{array}{l}\text { - Para considerar o modelo a ser utilizado na } \\
\text { construção do indicador composto, e se } \\
\text { disponível, cenários alternativos para seleção dos } \\
\text { indicadores. } \\
\text { - Para identificar as possíveis fontes de incertezas } \\
\text { no desenvolvimento do indicador composto e } \\
\text { avaliar os valores dos indicadores compostos com } \\
\text { os contornos devido incertezas. } \\
\text { Para conduzir analises de sensibilidade da } \\
\text { interferência. }\end{array}$ \\
\hline
\end{tabular}




\begin{tabular}{|c|c|}
\hline $\begin{array}{l}8 \text { - Novamente os dados: é necessário para revelar } \\
\text { os fatores importantes para um desempenho bom ou } \\
\text { ruim. Transparência é primordial para uma boa análise } \\
\text { e decisão política. }\end{array}$ & $\begin{array}{l}\text { - Para avaliar o desempenho em nível de indicador } \\
\text { para determinar o que esta influenciando o } \\
\text { indicador composto. } \\
\text { - } \quad \text { Para avaliar a correlação e casualidade. } \\
\text { - Para identificar se o comportamento do indicador } \\
\text { composto é dominado por alguns poucos } \\
\text { indicadores e explicar a importância relativa entre } \\
\text { os sub componentes do indicador composto. }\end{array}$ \\
\hline $\begin{array}{l}9 \text { - Links para outros indicadores: deve ser feita } \\
\text { para correlacionar indicadores compostos com outros } \\
\text { indicadores existentes assim como identificar } \\
\text { conexões. }\end{array}$ & $\begin{array}{l}\text { Para correlacionar o indicador composto com } \\
\text { outras medidas relevantes, levando em } \\
\text { consideração os resultados da análise de } \\
\text { sensibilidade. } \\
\text { - Para desenvolver narrativas baseadas nos } \\
\text { resultados. }\end{array}$ \\
\hline $\begin{array}{l}10 \text { - Visualização dos resultados: deve receber } \\
\text { atenção adequada, dado que a visualização pode } \\
\text { influenciar e ajudar na interpretação. }\end{array}$ & $\begin{array}{l}\text { - Para identificar a coerência das ferramentas de } \\
\text { apresentação e audiência. } \\
\text { - Para selecionar as técnicas de visualização que } \\
\text { permitem comunicar de melhor forma a } \\
\text { informação. } \\
\text { - Para apresentar os resultados do indicador } \\
\text { compostos de uma forma clara e precisa. }\end{array}$ \\
\hline
\end{tabular}

Fonte: OECD (2008).

\subsubsection{RISCO}

A definição de risco, de uso cotidiano, encontrada em dicionários e utilizada pela maioria de população é:

- Situação envolvendo exposição ao perigo.

- Possibilidade de alguma coisa desagradável ou indesejada acontecer.

Por outro lado, nos estudos de avaliação de perigo é comum utilizar o termo risco com definições diferentes, dependo do campo de pesquisa e corrente de pensamento. Uma das definições conhecidas para risco foi proposta inicialmente por Crichton (1999), com foco em seguros, Figura 2. O autor afirma que o risco é a probabilidade de perda, e depende de três elementos: Ameaça, Exposição e Vulnerabilidade. Por exemplo: uma propriedade segurada requer que avaliemos a frequiência e severidade da Ameaça, como inundação ou tempestade; a Vulnerabilidade da propriedade para aquela Ameaça, que é qual a extensão que vai sofrer danos ou perdas, e a Exposição da propriedade à ameaça, por exemplo, o valor e localização. 


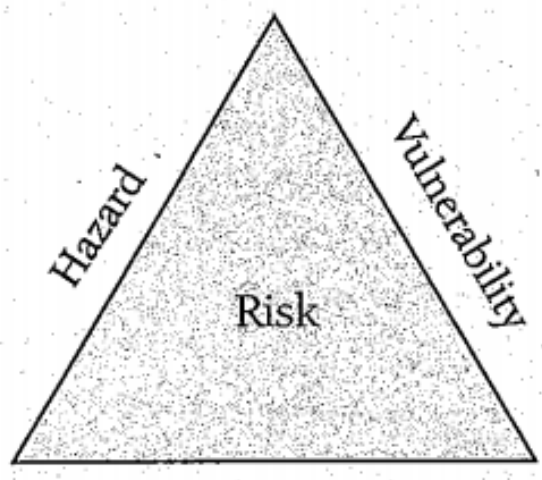

Exposure

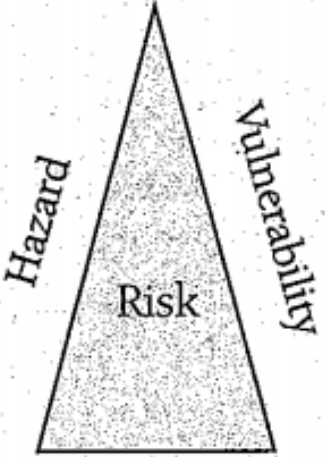

Exposure

Figura 2 - Triângulo de risco.

Fonte: Crichton (1999).

Se pensarmos o tamanho do risco como a área de um triângulo, então por simples geometria sabemos que a mesma depende do tamanho dos três lados. Se um dos lados é zero, o risco também será. É possível, por exemplo, diminuir o risco reduzindo a exposição (CRICHTON, 1999).

O triângulo de risco é conceitualmente válido, e de fácil entendimento, mas parece esconder algumas incompatibilidades encontradas também nas outras definições de risco. Alguns pontos que merecem ser observados:

1. O risco é utilizado e tem unidade diferente de como ele é entendido pela maioria da população, o que pode trazer dificuldades na compreensão do termo. O sinônimo mais utilizado para risco no dicionário de línguas é "probabilidade" / "possibilidade" de algum evento acontecer, ou seja, um evento estatístico, enquanto que nesta proposta ele parece ter dimensão de área, e depende de termos como Ameaça, Vulnerabilidade e Exposição.

2. Não está claro como se pode estimar o risco e cada um de suas componentes Ameaça, Vulnerabilidade e Exposição.

A Tabela 3 apresenta outras definições de risco utilizadas em estudos de avaliação de perigo. 
Tabela 3 - Tabela com definições de risco na literatura.

\begin{tabular}{|c|c|}
\hline Fonte & Definição \\
\hline Blong (1996) & $\begin{array}{l}\text { Risco total = Impacto do perigo } * \text { Elementos em risco * } \\
\text { Vulnerabilidade dos elementos em risco }\end{array}$ \\
\hline Crichton (1999) & $\begin{array}{l}\text { "Risco é a probabilidade de perda, e depende de três } \\
\text { elementos: ameaça, vulnerabilidade e exposição". Se } \\
\text { qualquer um destes elementos aumenta ou diminui, } \\
\text { então o risco aumenta ou diminui respectivamente. }\end{array}$ \\
\hline de la Cruz-Reyna (1996) & $\begin{array}{l}\text { Risco = Perigo * Vulnerabilidade * Valor (da área } \\
\text { ameaçada) / Prevenção }\end{array}$ \\
\hline Granger et al. (1999) & $\begin{array}{l}\text { Risco ('risco total') significa o número esperado de perda } \\
\text { de vidas, pessoas feridas, danos a propriedades e } \\
\text { interrupção da atividade econômica devido a um } \\
\text { fenômeno natural particular, e conseqüentemente o } \\
\text { produto do risco específico e elementos em risco. O risco } \\
\text { total pode ser expresso na forma: } \\
\text { Risco (total) = Perigo * Elemento em Risco } * \\
\text { Vulnerabilidade }\end{array}$ \\
\hline Helm (1996) & Risco $=$ Probabilidade* Conseqüências \\
\hline Sayers et al. (2002) & $\begin{array}{l}\text { Risco é a combinação das chances de um evento } \\
\text { particular, com o impacto que esse evento pode gerar. } \\
\text { Portanto risco é composto por dois componentes: a } \\
\text { chance (ou probabilidade) de um evento ocorrer e o } \\
\text { impacto (ou conseqüência) associado a esse evento. A } \\
\text { conseqüência de um evento pode ser desejada ou não. } \\
\text { Em alguns casos, mas não todos, o risco pode ser dados } \\
\text { por: } \\
\text { Risco = Probabilidade*Conseqüência }\end{array}$ \\
\hline Smith (1996) & $\begin{array}{l}\text { Risco é a exposição atual de alguma coisa de valor } \\
\text { humano a um perigo e geralmente pode ser entendido } \\
\text { como a combinação da probabilidade e perda. }\end{array}$ \\
\hline Stenchion (1997) & $\begin{array}{l}\text { Risco pode ser definido com a probabilidade da } \\
\text { ocorrência de um evento indesejável, mas pode ser } \\
\text { melhor descrito como a probabilidade de um perigo } \\
\text { contribuir para um desastre potencial importante, ele } \\
\text { envolve considerar a vulnerabilidade ao perigo. }\end{array}$ \\
\hline $\begin{array}{l}\text { United Nation Department of } \\
\text { Humanitarian Affairs - UN DHA, (1992) }\end{array}$ & $\begin{array}{l}\text { Risco é a perda esperada (vidas, pessoas feridas, danos a } \\
\text { propriedades, e economia) devido a um perigo particular } \\
\text { para uma dada área e período. Baseado em cálculo } \\
\text { matemático, risco é o produto do perigo e } \\
\text { vulnerabilidade. }\end{array}$ \\
\hline
\end{tabular}

Fonte: Adaptado de Kelman (2003).

O número de diferentes definições para risco pode trazer dificuldade na utilização e na compreensão do mesmo quando apresentado para um grupo grande e não homogêneo de pessoas, como por exemplo, população em geral. Também não está claro na maioria das definições como aplicar e medir o risco e suas componentes na prática. Algumas definições 
ainda citam vulnerabilidade, que ainda não foi definida, e pode ter uma interpretação subjetiva.

\subsubsection{VULNERABILIDADE}

O conceito de vulnerabilidade é de grande importância no contexto de mudanças climáticas (WOLF et al., 2013). Entretanto o conceito de vulnerabilidade contém inúmeras contribuições de diferentes disciplinas, o que leva a um diferente entendimento do que vulnerabilidade significa (SOARES; GAGNON; DOHERTY, 2012).

Soares; Gagnon e Doherty (2012) e Wolf et al. (2013) apresentam as dificuldades encontradas na definição de Vulnerabilidade. A Tabela 4 reúne alguns dos desafios e implicações em se obter uma definição geral para Vulnerabilidade.

Tabela 4 - Desafios na definição de Vulnerabilidade.

\begin{tabular}{ll}
\hline Desafio & Implicação \\
\hline Enorme quantidade de definições. & Dificuldade em obter uma visão geral. \\
\hline Níveis teóricos e operacionais não são & Diferenças entre como a vulnerabilidade é \\
claramente distinguidos no trabalho teórico. & definida e medida não é apontado. \\
\hline Definições teóricas são vagas. & Pequenas diferenças escondem semelhanças. \\
\hline Definições teóricas semelhantes acompanham & A lacuna existente entre os níveis teóricos e \\
diferentes formas de avaliação. & operacionais devem ser levados de forma séria. \\
\hline Apenas na avaliação da Vulnerabilidade as & O trabalho conceitual deve ser focado no nível \\
diferenças se tornam aparentes. & operacional. \\
\hline Trabalho conceitual foca nas definições & A confusão não pode ser realmente esclarecida. \\
teóricas. & \\
\hline
\end{tabular}

Fonte: Wolf et al. (2013).

Lewis (1999) observa "Considerando a vulnerabilidade, esta parece ser o processo que trabalha entre os fatores de perigo e risco. É o reverso do ponto de vista convencional, e focado na localização e condição do elemento em risco e razões para esta localização e condição". Risco é estático e hipotético, mas vulnerabilidade é acretiva, morfológica e tem real aplicação a qualquer perigo (KELMAN, 2003).

A Tabela 5 apresenta diferentes definições para o termo vulnerabilidade. $\mathrm{O}$ número elevado de definições do termo sugere dificuldade na compreensão, na sua medida e na comunicação com tomadores de decisão e população em geral. As definições de 
vulnerabilidade às vezes também se confundem com definições anteriores de risco, e da mesma forma, parece ter problema na conexão entre o nível teórico e operacional do conceito.

Tabela 5 - Compilação de definições para Vulnerabilidade.

\begin{tabular}{|c|c|}
\hline Fonte & Definição \\
\hline Gabor e Griffith (1980) & $\begin{array}{l}\text { Vulnerabilidade é a ameaça (de materiais perigosos) a qual } \\
\text { pessoas são expostas. Vulnerabilidade é o contexto de risco. }\end{array}$ \\
\hline Timmerman (1981) & $\begin{array}{l}\text { Vulnerabilidade é o grau a qual um sistema age } \\
\text { inadequadamente a ocorrência de um evento de perigo. O } \\
\text { grau e qualidade da reação adversa é condicionada pela } \\
\text { resiliência do sistema (a medida da capacidade do sistema de } \\
\text { absorver e recuperar de um evento). }\end{array}$ \\
\hline UNDRO (1982) & $\begin{array}{l}\text { Vulnerabilidade é o grau da perda de um elemento em risco } \\
\text { resultante da ocorrência de um fenômeno natural de uma } \\
\text { dada magnitude. }\end{array}$ \\
\hline Susman, O’Keefe; Wisner (1983) & $\begin{array}{l}\text { Vulnerabilidade é o grau que diferencia diferentes classes em } \\
\text { risco. }\end{array}$ \\
\hline Varnes (1984) & $\begin{array}{l}\text { Vulnerabilidade significa o grau de perda de um dado } \\
\text { elemento em risco devido à ocorrência de um fenômeno } \\
\text { natural de uma dada magnitude. É expressa na escala de } 0 \\
\text { (zero, sem danos) a } 1 \text { (um, dano total). }\end{array}$ \\
\hline Kates (1985) & $\begin{array}{l}\text { Vulnerabilidade é a capacidade de sofrer dano e reagir } \\
\text { adversamente. }\end{array}$ \\
\hline Pijawka e Radwan (1985) & $\begin{array}{l}\text { Vulnerabilidade é a interação entre risco e prevenção. É o } \\
\text { grau com o qual um material perigoso ameaça uma } \\
\text { população (risco) e a capacidade de uma comunidade de } \\
\text { reduzir o risco ou as conseqüências adversas. }\end{array}$ \\
\hline Bogard (1989) & $\begin{array}{l}\text { Vulnerabilidade é operacionalmente definida como a falta de } \\
\text { habilidade em tomar medidas efetivas contra perdas. Quando } \\
\text { aplicado em indivíduos, vulnerabilidade é a conseqüência da } \\
\text { impossibilidade ou improbabilidade de uma mitigação efetiva } \\
\text { e é função de nossa habilidade de detectar perigo. }\end{array}$ \\
\hline Mitchel (1989) & Vulnerabilidade é o potencial de perda. \\
\hline Downing (1991) & $\begin{array}{l}\text { Vulnerabilidade tem três conotações: ela refere-se a } \\
\text { conseqüência (exemplo fome) ao invés da causa (exemplo } \\
\text { seca); ela implica na conseqüência adversa e é um termo } \\
\text { relativo que diferencia grupos ou regiões socioeconômicas, } \\
\text { não é uma medida absoluta. }\end{array}$ \\
\hline $\begin{array}{l}\text { United Nations Disasters Relief Co- } \\
\text { ordination - UNDRO (1991) }\end{array}$ & $\begin{array}{l}\text { Vulnerabilidade é o grau de perda de um dado elemento em } \\
\text { risco resultante da ocorrência de um fenômeno natural de } \\
\text { uma dada magnitude expresso da escala de } 0 \text { (zero, sem } \\
\text { dano) a } 1 \text { (um, dano total). Significa o grau que cada } \\
\text { indivíduo, família, comunidade, classe ou região em risco } \\
\text { sofre com o acontecimento de um evento natural extremo. }\end{array}$ \\
\hline Dow (1992) & $\begin{array}{l}\text { Vulnerabilidade é a diferente capacidade de grupo ou } \\
\text { indivíduos de lidar com ameaças, baseado em suas posições } \\
\text { físicas e sociais. }\end{array}$ \\
\hline Alexander (1993) & $\begin{array}{l}\text { Vulnerabilidade humana é função dos custos e benefícios de } \\
\text { áreas habitadas em risco de desastres naturais. }\end{array}$ \\
\hline
\end{tabular}




\begin{tabular}{ll}
\hline Watts e Bohle (1993) & Vulnerabilidade é definida em termos de exposição, \\
& capacidade e potencial. Portanto as forma de responder a \\
& vulnerabilidade é reduzir a exposição, aumentar capacidade \\
& de lidar e se recuperar de um evento extremo e minimizar as \\
& conseqüências destrutivas. \\
\hline Bohle, Downing, Watts (1994) & Vulnerabilidade é mais bem definida como medidas \\
& ambientais, sociais, econômicas e políticas contra \\
& perturbações potencialmente danosas. \\
\hline Gilard e Givone (1997) & Vulnerabilidade representa a sensibilidade da ocupação de \\
& terra a um fenômeno de perigo. \\
\hline Comfort et al. (1999) & Vulnerabilidade são aquelas circunstâncias que colocam \\
& pessoas em risco enquanto diminui suas chances de resposta \\
& e proteção. \\
\hline Weichselgartner, Bertens (2000) & $\begin{array}{l}\text { Vulnerabilidade é definida como a condição de uma dada } \\
\text { área a respeito de uma ameaça, exposição, prevenção e } \\
\text { características de resposta para lidar com eventos de certa } \\
\text { característica física. }\end{array}$ \\
\hline Smith (2001) & Sensibilidade Humana a ambientes de perigo representa a \\
& Combinação de exposição física e vulnerabilidade humana. \\
\hline Wulnerabilidade é definida como a característica de uma \\
pessoa ou grupo em termos da sua capacidade de lidar, \\
resistir e recuperar de um impacto natural. Esta envolve \\
combinação de fatores que determinam o grau em que a vida \\
de cada um é colocada em risco por um evento natural ou \\
social discreto e identificável.
\end{tabular}

Fonte: Adaptado de Fuchs, Heiss, Hübl (2007).

A Figura 3 é a representação de um mapa conceitual que representa o que é a vulnerabilidade de acordo com INCLINE (2013). Ele fornece visualmente todas as relações entre o conceito vulnerabilidade e suas componentes. 


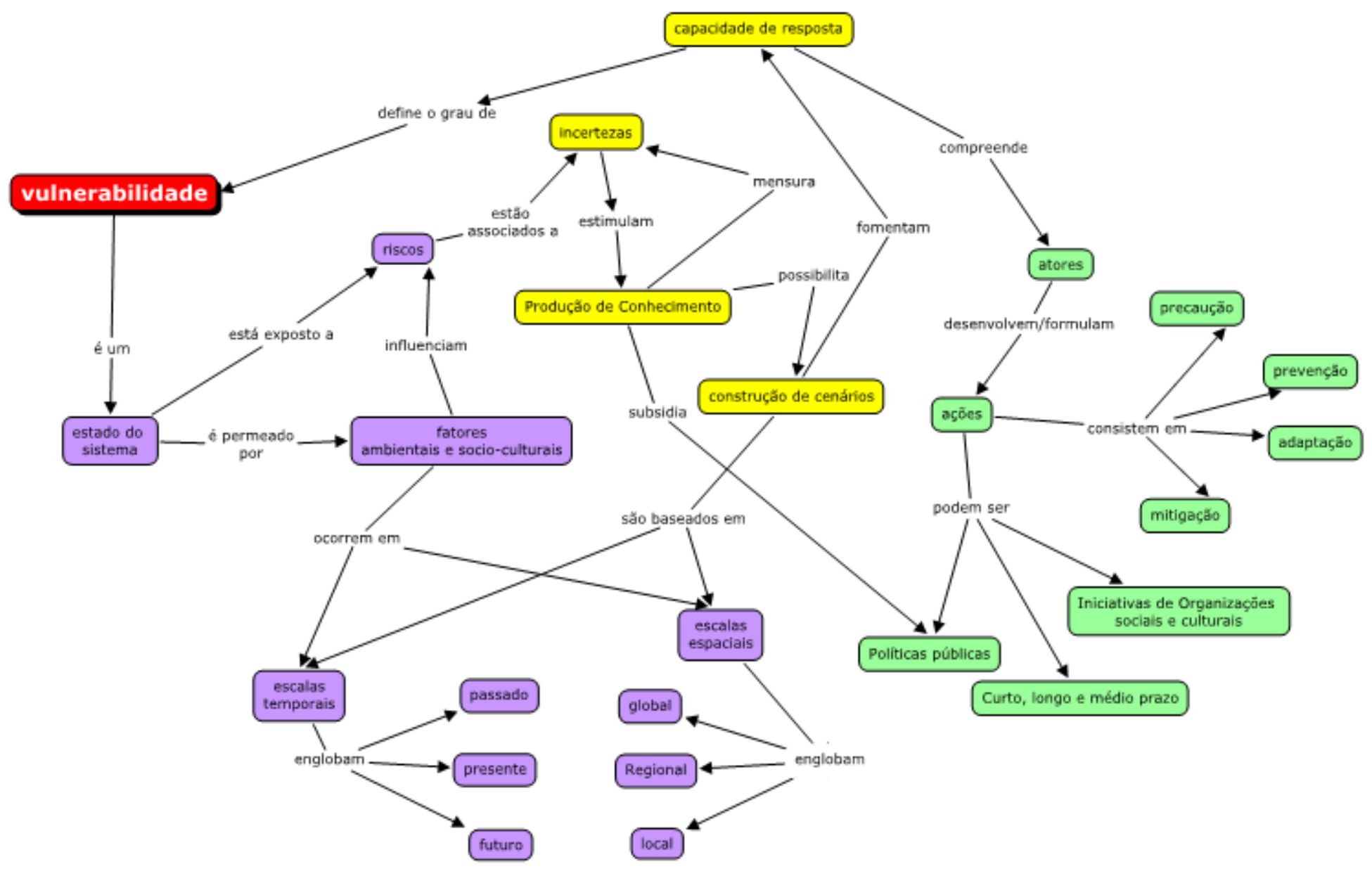

Figura 3 - Mapa conceitual para vulnerabilidade.

Fonte: INCLINE (2013). 
Todas estas definições parecem ter um núcleo, uma idéia em comum, algo que relaciona o comportamento de uma região à presença de determinada ameaça ou perigo. Mas são bastante subjetivas e não respondem bem a questões do tipo: como a vulnerabilidade se relaciona com risco? Como avaliar se a vulnerabilidade de um indivíduo é maior ou menor que de outro? Todas as definições até agora apresentadas para vulnerabilidade tem uma deficiência de ordem prática, não fornecem pistas de como a vulnerabilidade pode ser medida ou representada.

Outra linha de pensamento é encontrada na Engenharia de Risco. Na engenharia de risco a vulnerabilidade é compreendida como uma função que relaciona a intensidade de um evento com a probabilidade de perda, com escala de 0 (zero, não existe perda) e 1 (um, perda certa) (WEN et al., 2004).

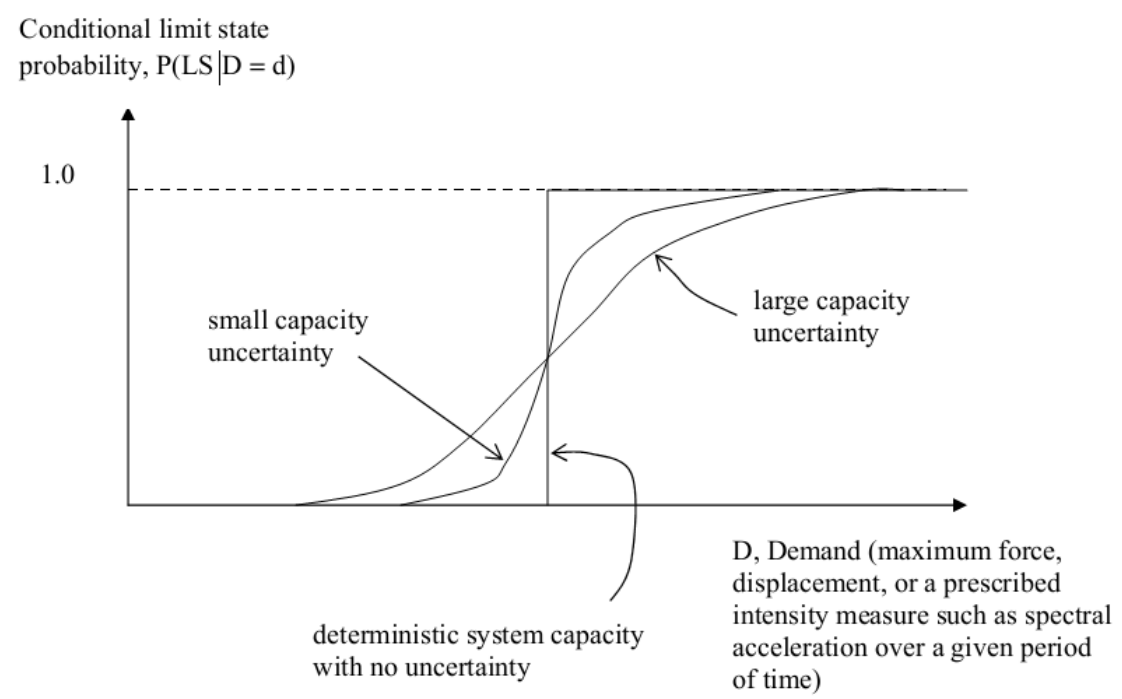

Figura 4 - Função Vulnerabilidade ou curva de fragilidade.

Fonte Wen et al. (2004).

Segundo esta definição a função vulnerabilidade fica explícita, representa uma probabilidade e assume valores entre 0 e 1 (ou 0 a 100\%). Esta definição também especifica que a vulnerabilidade relaciona a magnitude de uma demanda ou evento com a probabilidade que o mesmo leve o elemento a atingir o estado limite condicional avaliado (WEN et al., 2004). Isso pode ser o equivalente a definir uma função que determine a probabilidade de um determinado local ser atingido por uma inundação devido a uma precipitação. Essa representação ainda permite trabalhar com as incertezas tão comuns em análise de risco: caso não existam incertezas a curva da função vulnerabilidade é uma função degrau, ou seja, é conhecido e claro que após certa demanda a condição limite é atingida. No caso de incertezas 
a curva fica mais suave, e não fica claro a partir de qual demanda (precipitação) a condição limite (inundação) pode ser atingida.

\subsubsection{RESILIÊNCIA}

Segundo United Nations International Strategy for Disaster Reduction- UNISDR (2012), resiliência significa a habilidade de um sistema, comunidade ou sociedade exposta a uma ameaça de resistir, absorver, acomodar e se recuperar dos efeitos das ameaças de maneira eficiente, incluindo a preservação e restauração das suas estruturas básicas e funcionais. Resiliência foca no investimento do aumento da habilidade geral da cidade para suportar uma sociedade e economia saudável exposta a uma grande variedade de circunstâncias.

\subsubsection{ORIGEM DO TERMO RESILIÊNCIA NA ECOLOGIA}

O conceito de resiliência vem emprestado de sistemas ecológicos (HOLLING, 1973) e refere-se à preservação do funcionamento de um ecossistema na presença de uma mudança imprevista.

É útil distinguir dois comportamentos. Um pode ser chamado de estabilidade, que representa a habilidade de um sistema para retornar a um estado de equilíbrio após um distúrbio temporário; quanto mais rápido o retorno e menores as flutuações, mais estável é o sistema. Mas também existe outra propriedade, chamada resiliência, que mede a persistência de um sistema e sua habilidade de absorver distúrbios e mudanças e ainda manter as mesmas relações entre população e variáveis de estado (HOLLING, 1973).

Um gerenciamento baseado em resiliência enfatiza manter as opções em aberto, a necessidade de ver os eventos em um contexto regional, não local, e a necessidade de enfatizar a heterogeneidade. Partindo deste ponto não é presunção de conhecimento suficiente, mas o reconhecimento de nossa ignorância; não é assumir que eventos futuros são esperados, mas sim que eles são inesperados. A resiliência pode acomodar essa visão, pois não requer uma capacidade precisa de prever o futuro, apenas uma capacidade qualitativa para avaliar sistemas que conseguem absorver e acomodar eventos futuros e de qualquer natureza inesperada (HOLLING, 1973).

\subsubsection{RESILIÊNCIA EM SISTEMAS SOCIAIS E ECONÔMICOS}

Como sociedade confrontamos com uma variedade de catástrofes e problemas ambientais irreversíveis para os quais os métodos tradicionais não oferecem solução. Os problemas são caracterizados por serem imprevisíveis. Em geral é difícil detectar sinais de mudanças cedo o 
suficiente para motivar soluções efetivas ou até mesmo desenvolver consenso científico a tempo de permitir uma solução efetiva (LEVIN et al., 2013).

Em sistemas ecológicos e socioeconômicos, atividades humanas podem levar a mudanças qualitativas em estrutura e função, evidencia que o sistema em questão perdeu resiliência: ele não é mais capaz de absorver o estresse e choques impostos pela atividade humana sem passar por uma mudança e perdas de função e, geralmente, perda de produtividade. Resiliência, a habilidade de experimentar mudanças e distúrbios sem alteração catastrófica qualitativa na função básica organizacional, é a medida da integridade do sistema (HOLLING, 1973).

É importante entender o potencial e limitação para resiliência, e desenvolver mecanismos que aumentem a resiliência em sistemas como biosfera é essencial para a sobrevivência humana. De certo modo, competição pode ajudar na construção de resiliência e sistemas por meio de mecanismos de realimentação comuns nos mercados. Isto coordena a atividade de milhões de pessoas de forma que, após a economia estar sujeita a uma mudança de parâmetros, recursos são realocados até que a possibilidade de ganhos mútuos seja exaurida. No evento de mudança climática, por exemplo, a força de mercado força os agricultores a utilizar novas matérias primas e incentiva empresas a desenvolver novas sementes mais resistentes às mudanças (LEVIN et al., 2013).

Se aceitarmos a resiliência como um conceito útil mesmo no contexto de sistemas socioeconômicos, então precisamos responder a questão: "Quão resiliente é um dado sistema?" Não existe uma forma de responder esta questão sem medir a resiliência (AMITRAJEET, 1998).

Hanley (2013) questiona a validade do conceito de resiliência apresentado por Levin (2013). Ele afirma que o conceito é muito vago, e que embora possa fazer sentido o termo resiliência em sistemas ecológicos onde se avalia a resistência à extinção das espécies, em sistemas socioeconômicos não está claro quais são os itens que devem ser preservados. Resiliência é um conceito muito vago para ser útil para análise de sistemas socioeconômicos. É particularmente assim quando se tenta estabelecer as condições necessárias para a existência de um sistema econômico resiliente. Por exemplo, considere a seguinte afirmativa: "em sistemas econômicos, resiliência depende de... governo e instituições efetivos... por efetivo nós entendemos... uma grande variedade de instituições que sustentem, através de diversos mecanismos, múltiplos produtos". Esta é dificilmente uma linguagem política recomendável ou uma hipótese teórica irrefutável (HANLEY, 2013). 


\subsubsection{ESTRATÉGIAS RESISTENTES E RESILIÊNTES DE COMBATE A INUNDAÇÕES}

É possível definir dois tipos de estratégia de gerenciamento de risco de inundação: resistente e resiliente. A estratégia resistente foca em prevenir a inundação, enquanto a estratégia resiliente objetiva minimizar e aperfeiçoar a recuperação dos impactos. Uma estratégia resiliente é entendida como uma estratégia melhor para lidar com as incertezas (DE BRUIJN, 2004).

Tradicionalmente o gerenciamento de risco de inundação foi focado na prevenção da inundação. A maior parte da atenção está em determinar a probabilidade de descarga e construir estruturas de defesa. Entretanto, risco de inundação consiste de dois elementos: ameaça, na forma dos picos de descarga, e nas conseqüências, que resultam nos danos e problemas sociais. As estratégias tradicionais, focadas apenas na prevenção da inundação, podem ser consideradas como uma estratégia resistente. Em contraste uma estratégia resiliente é focada em conviver com as inundações ao invés de preveni-las. Minimizar a conseqüência da inundação, ou aprender a viver com as inundações, ao invés de reduzir sua ocorrência, é uma alternativa para diminuir as conseqüências. Esta estratégia, diminuir os custos de uma inundação ao invés de diminuir a inundação, é chamada de "estratégia resiliente" (DE BRUIJN, 2004).

Embora existam algumas definições de resiliência no contexto de gerenciamento de água, uma definição clara para gerenciamento de risco de inundação ainda não existe. Devido ao fato que dados sobre inundação e seus danos são geralmente incompletos, é muito difícil ou impossível derivar dados sobre o impacto e recuperação dos eventos. Portanto, indicadores para resiliência podem ser necessários (DE BRUIJN, 2004).

De Bruijn (2004) apresenta as seguintes definições de resiliência:

1. Resiliência é a habilidade do sistema em manter seus processos e características mais importantes quando sujeitos a distúrbios. Resiliência é então medida pela magnitude do distúrbio que esta pode absorver antes que o sistema redefina sua estrutura alterando as variáveis e processos que controlam seu comportamento. Esta definição é utilizada para descrever a dinâmica de uma variedade de ecossistemas. É baseada na idéia que, em sistemas resilientes, nenhuma mudança repentina ou colapsos devem ocorrer.

2. Resiliência é a habilidade de um sistema em retornar para um equilíbrio ou estágio de desenvolvimento anterior a uma perturbação. Sistemas resilientes reagem a um 
distúrbio e se recuperam, enquanto que sistemas resistentes não reagem de qualquer forma.

Na Figura 5 é apresentada uma representação de um sistema resiliente e resistente. O cilindro no sistema resiliente pode mover para os lados e para cima, mas retorna para centro após um distúrbio. O cilindro no sistema resistente não pode mover. Se o cilindro for empurrado acima de um limiar ele ultrapassa a borda do sistema e seu retorno é incerto (DE BRUIJN, 2004).

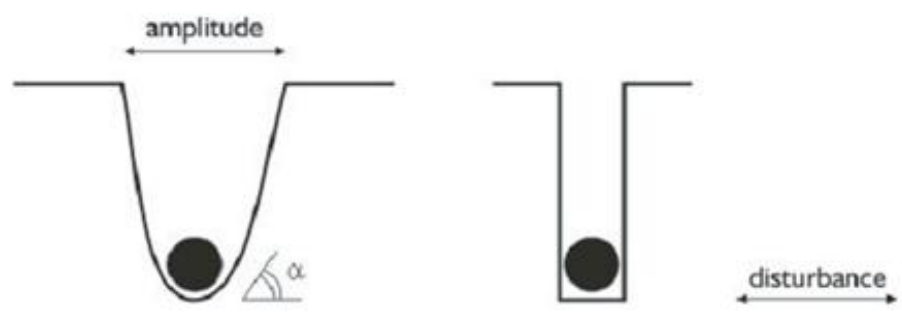

Figura 5 - Conceito de sistema resiliente e resistente.

Fonte: De Bruijn (2004)

É necessário enfatizar que o controle de risco de inundação não é o mesmo que controle de inundação. Risco de inundação resulta de uma inundação em uma área vulnerável. Sem uma sociedade ou ecossistema vulnerável, a inundação é apenas um fenômeno natural que não pode ser qualificado como "risco" (KLIJN; VAN BUUREN; VAN ROOIJ, 2004).
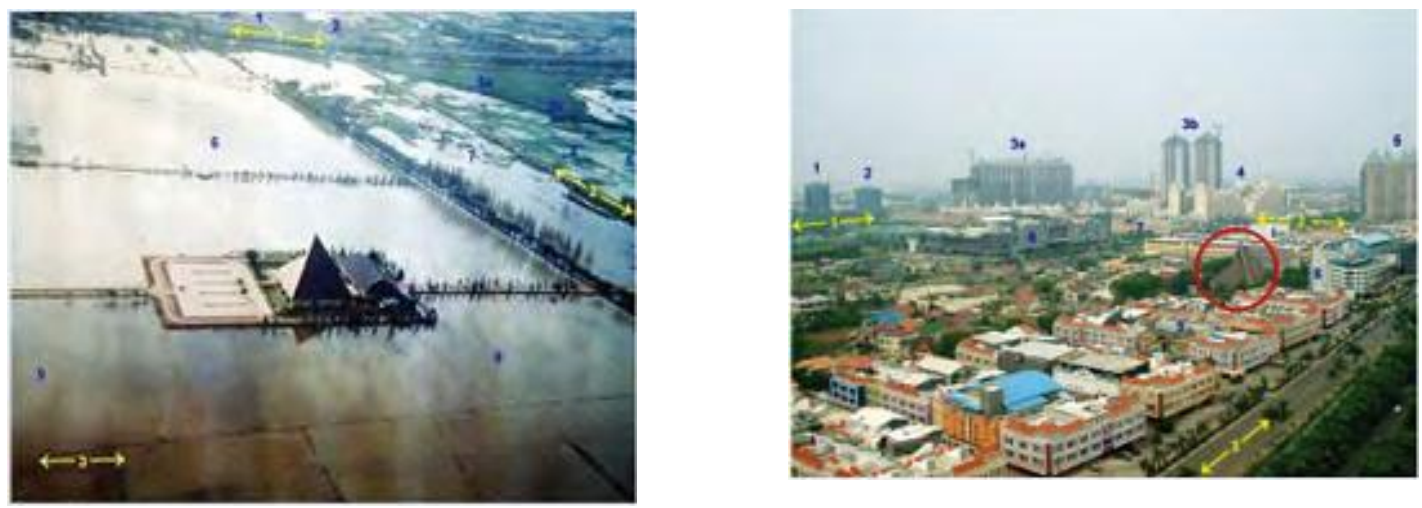

Figura 6 - Quinze anos de urbanização em Jakarta, em 1994 e 2009.

Fonte: United Nations - UN, (2010).

A Figura 6 é um exemplo de uma área susceptível a inundação que posteriormente foi ocupada. Em 1994 é possível ver a ocorrência de inundação, mas sem consequiências muito severas, pois a área não era ocupada. Após 15 anos de urbanização o cenário foi alterado e a região urbanizada. É muito provável que, independente de medidas e adaptações ao risco de inundação que possam ter sido tomadas, a região deva apresentar prejuízos e danos bem 
maiores hoje do que em 1994. Este é apenas um exemplo de que os prejuízos decorrentes de uma inundação dependem também da exposição de pessoas e bens em áreas susceptíveis.

Resumindo: estratégia resiliente de combate de risco de inundação pode ser definida como a facilidade com que o sistema, consistindo de aspectos socioeconômicos e físicos de uma área, tem de se recuperar de uma inundação. Em contraste, a estratégia resistente pode ser definida como a habilidade de permitir grandes descargas sem eventos de inundação. Em outras palavras, gerenciamento resiliente permite a inundação, mas seus impactos serão facilmente recuperados. Na estratégia resistente não ocorrerá inundação (DE BRUIJN, 2004).

Outra diferença importante entre as duas estratégias é como elas lidam com as incertezas. Em gerenciamento de risco é necessário lidar com muitas incertezas. Primeiramente a probabilidade de descarga é uma incerteza. Depois as descargas precisam ser convertidas em nível de água em cada secção do rio. A relação descarga-altura para eventos extremos é outra incerteza, visto que eventos extremos são raros e não podem ser facilmente verificados. Além disso, em situações extremas a divisão da descarga nos diferentes braços do rio também adiciona incertezas. E ainda quando uma inundação ocorre, nem o padrão da inundação nem o comportamento das pessoas é definido (DE BRUIJN, 2004). A estratégia resistente lida com estas incertezas incluindo as mesmas na probabilidade de inundação ou super dimensionando as estruturas. Neste caso os habitantes geralmente estão desavisados das incertezas e do fato que existe uma pequena probabilidade de ocorrer uma inundação maior que a utilizada no projeto. Em contraste, a estratégia resiliente é desenvolvida para explicitamente lidar com a incerteza. Ela baseia-se na noção que a inundação não pode ser evitada a qualquer custo e propõe medidas para limitar os impactos e otimizar a recuperação (DE BRUIJN, 2004)

A estratégia resistente baseada em descarga de projeto torna incerto qual área vai ser inundada primeiro caso o valor de projeto for ultrapassado. Isto significa que todas as áreas ao redor do rio têm o mesmo nível de proteção, independente do dano potencial de cada área. Isto economicamente não faz sentido (DE BRUIJN, 2004). Outra estratégia é permitir que áreas com menor valor econômico absorvam parte da descarga e inundem antes. 

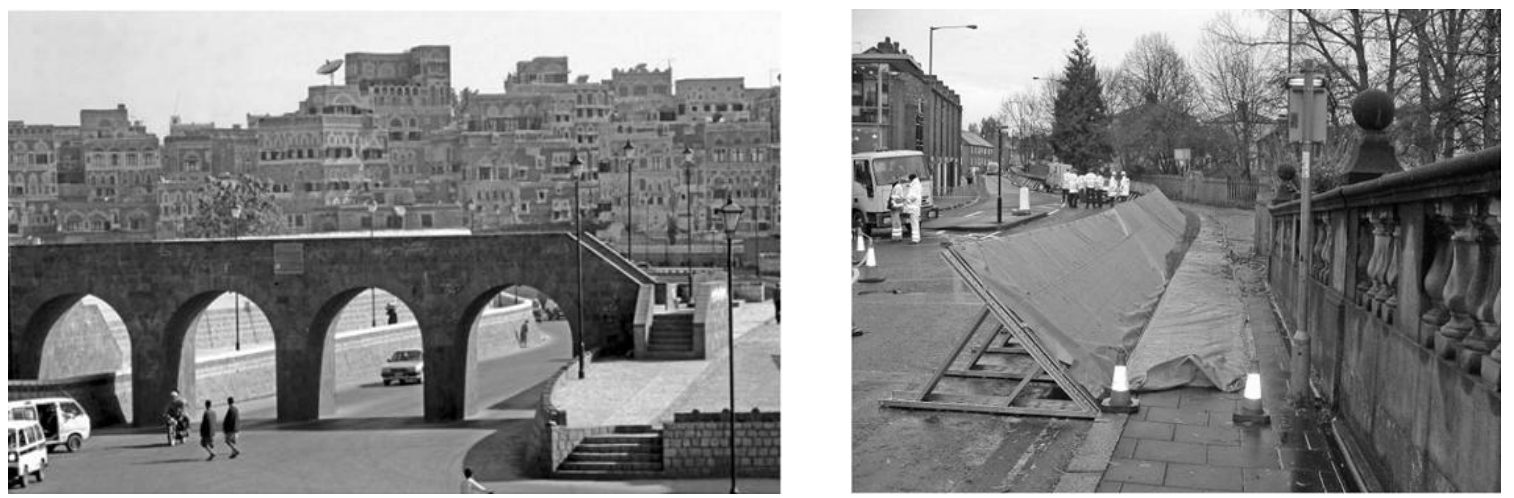

Figura 7 - Exemplos de estratégias resilientes.

Fonte: Jha, Bloch, Lamond (2012).

A Figura 7 mostra exemplos de estratégias que podem ser compreendidas como resilientes. Na figura da esquerda uma estrada é utilizada também como um canal de escoamento de água de inundação, ou seja, uma área que apresenta menos danos é utilizada para escoar e inundar primeiro que áreas mais nobres. A segunda imagem mostra barreiras temporárias para manter a água longe de áreas mais importantes.

\subsubsection{GERENCIAMENTO DE RISCO}

É chamado gerenciamento de risco o conjunto de ações que tem como objetivo mitigar os efeitos negativos de eventos extremos (DE ANDRADE, 2006). Questões técnicas e sociais são consideradas, por alguns países, de grande importância para uma eficaz compreensão e gerenciamento de inundações. Segundo Mendiondo (2010), as propostas modernas de gestão de riscos de inundação contêm três etapas principais: "Antes" (estágio de preparo, como sistemas de alerta e prevenção), "Durante" (ações de controle e manejo, medidas de proteção) e "Depois" (Reconstrução e reabilitação das áreas atingidas). A Tabela 6 apresenta alguns exemplos de atividades relacionadas às fases do Gerenciamento do Risco segundo Kobiyama et al., (2006). 
Tabela 6 - Fases do processo de prevenção de desastres naturais.

\begin{tabular}{|c|c|}
\hline Fator & Atividades \\
\hline $\begin{array}{l}\text { Antes } \\
\text { (preparação) }\end{array}$ & $\begin{array}{l}\text { - } \quad \text { Levantar, com base científica, perigos e riscos de desastres naturais. } \\
\text { - } \quad \text { Identificar as potencialidades da sociedade para prevenção de desastres naturais (PDN). } \\
\text { - } \quad \text { Realizar o mapeamento e zoneamento de áreas de perigos e riscos. } \\
\text { - } \quad \text { Estabelecer uma legislação pertinente para a PDN. } \\
\text { - } \quad \text { Criar órgão fiscalizador, com funcionários exclusivos e permanentes para a PDN, integrando aos diferentes setores institucionais. } \\
\text { - } \quad \text { Criar centros para integração de estações telemétricas, sistema de previsão e de alerta. } \\
\text { - } \quad \text { Planejar medidas emergenciais. } \\
\text { - } \quad \text { Desenvolver tecnologia com baixo custo para reforçar a infra-estrutura existente e obras de engenharia para contenção dos desastres. } \\
\text { - } \quad \text { Promover a educação e o desenvolvimento de uma cultura de PDN. } \\
\text { - } \quad \text { Organizar sistema de seguro de vida, propriedade e atividades. } \\
\text { - } \quad \text { Promover adequações no setor agrícola. } \\
\text { - } \quad \text { Estabelecer medidas para fixação da população em sua cidade de origem, evitando o processo de migração e favelização. } \\
\text { - } \quad \text { Puscar a integração entre população, os técnicos e os cientistas para um melhor esclarecimento sobre a PDN e o auxílio nas tomadas de decisão. } \\
\text { - } \quad \text { Campanha com a população para não ocupar áreas de risco. } \\
\text { - Preparar a população através de simulações. }\end{array}$ \\
\hline $\begin{array}{l}\text { Durante } \\
\text { (resposta) }\end{array}$ & $\begin{array}{ll}\text { - } & \text { Levantar rapidamente os danos e prejuízos. } \\
\text { - } & \text { Fortalecer os sistemas para a coleta, processamento e divulgação de dados. } \\
\text { - } & \text { Estabelecer rede de informações (imprensa, radio amadores, líderes comunitários, etc.). } \\
\text { - } & \text { Adminisistrar adequadamente o uso comum de espaços (abrigos). } \\
\text { - } & \text { Distribuição justa dos auxílios (financeiro, material, etc.) às comunidades afetadas. } \\
\text { - } & \text { Mobilizar equipes de saúde e alimentação, assim como máquinas e caminhões. } \\
\end{array}$ \\
\hline $\begin{array}{l}\text { Depois } \\
\text { (recuperação) }\end{array}$ & $\begin{array}{l}\text { - } \quad \text { Identificar a situação anterior e atual das vítimas dos desastres. } \\
\text { - } \quad \text { Orçar os prejuízos e a reconstrução. } \\
\text { - } \quad \text { Revisar o Plano Diretor do local destruído. } \\
\text { - } \quad \text { Fortalecer a rede pública de saúde e assistência social. } \\
\text { - } \quad \text { Orientar processo de limpeza e higienização. }\end{array}$ \\
\hline
\end{tabular}

Fonte: adaptado de Kobiyama et al. (2006) 


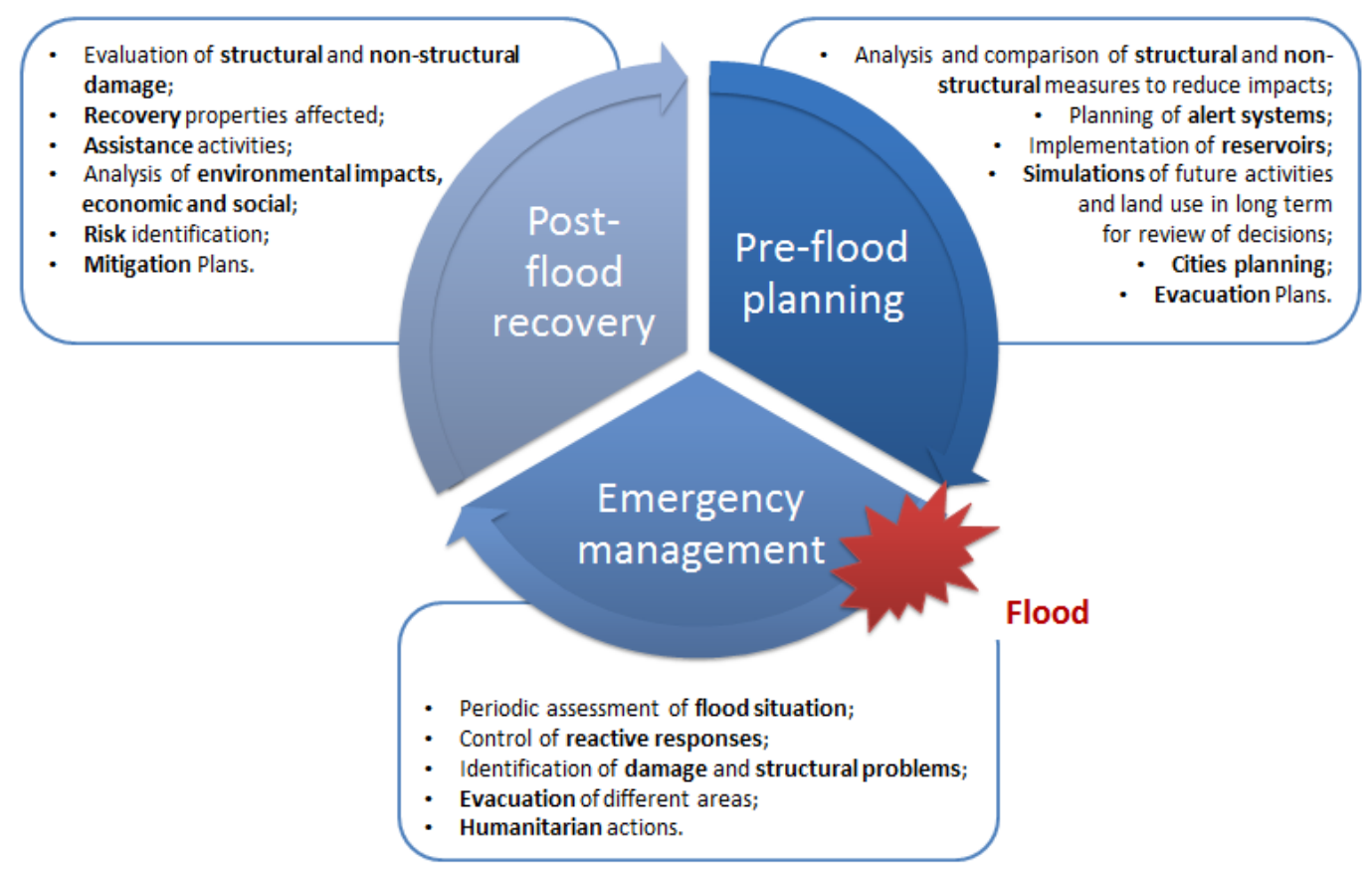

Figura 8 - Gerenciamento de risco.

Fonte: Ahmad e Simonovic (2006).

Ahmad e Simonovic (2006) entendem o gerenciamento de risco como apresentado na Figura 8, e definem as etapas como: planejamento antes da inundação, gerenciamento de emergência e recuperação após a inundação. O planejamento antes da inundação é o conjunto de medidas no sentido de planejar e se preparar para lidar com eventuais eventos. Entre as medidas estão:

- Análise e comparação de medidas estruturais e não estruturais para redução de impactos.

- Planejamento do sistema de alerta.

- Implementação de reservatórios.

- Simulação de futuras atividades de uso e ocupação de solo em longo prazo.

- Planejamento de cidade.

- Planos de evacuação.

$\mathrm{Na}$ etapa de gerenciamento de emergência estão as medidas de combate direto à inundação; são os mecanismos utilizados durante o acontecimento do evento:

- Avaliação periódica da inundação.

- Controle das respostas reativas.

- Identificação de danos e problemas estruturais.

- Evacuação de áreas. 
- Ações humanitárias.

A etapa de recuperação após a inundação consiste das medidas tomadas após o evento, e que contribuem para a recuperação da área e atividades da região:

- Avaliação dos danos estruturais e não estruturais.

- Recuperação das propriedades afetadas.

- Analise de impactos ambientais, econômicos e sociais.

- Identificação de risco.

- Planos de mitigação

\subsubsection{CICLO DE GERENCIAMENTO DE RISCO INTEGRADO}

Um gerenciamento holístico e integrado de risco, na Figura 9, assume que todos os tipos de medidas para redução de desastres naturais são considerados. Geralmente medidas de preparação, resposta e recuperação são igualmente aplicadas. O conceito foi originalmente desenvolvido para proteção civil e adaptado para gerenciamento de perigos naturais (Federal Office for Civil Protection - FOCP, 2013).

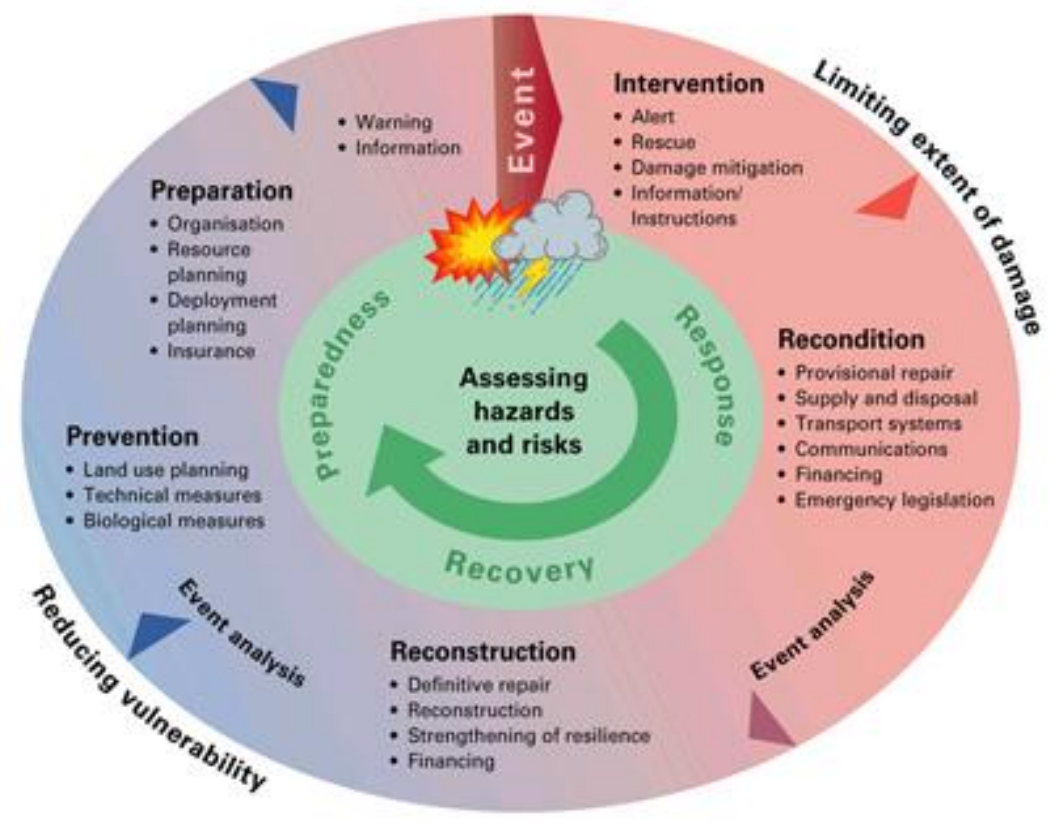

Figura 9 - Ciclo de gerenciamento de risco integrado.

Fonte: FOCP (2013).

Aumento da densidade populacional, do tráfego e várias outras necessidades modernas aumentaram consideravelmente o risco de desastres naturais nas últimas décadas. É impossível garantir $100 \%$ de segurança. Portanto a cultura do risco é necessária, é a cultura do 
risco que nos permite avaliar e mostrar os principais riscos e suas mudanças, assim como a necessidade de medidas de proteção. Com esse propósito é particularmente importante desenvolver a habilidade de lidar com incertezas (FOCP, 2013).

Existem três grandes campos no gerenciamento de risco de desastre integrado:

1. Preparação

2. Resposta

3. Recuperação

\subsection{PREPARAÇÃO}

A preparação consiste em medidas de prevenção e preparação. O objetivo é minimizar a vulnerabilidade das pessoas e materiais expostos a riscos naturais. Enquanto a prevenção tem como objetivo evitar danos primários com uso apropriado da terra ou medidas estruturais, a preparação tenta gerenciar e lidar com as catástrofes (FOCP, 2013).

A prevenção de perigos naturais consiste primeiramente de um uso adequado do espaço. Quando não é possível evitar o perigo, medidas estruturais, técnicas e biológicas devem ser tomadas com o objetivo de minimizar a intensidade do processo natural. Prevenção basicamente consiste (FOCP, 2013):

- Avaliação e mapas de risco: a avaliação dos perigos é utilizada para determinação da magnitude e freqüência com que o processo atinge as áreas afetadas, levando em conta as medidas de proteção já existentes.

- Planejamento do uso de terra: o planejamento de desenvolvimento divide o espaço de solo em diferentes zonas de acordo com o mapa de perigo. Em zonas de alto risco geralmente é proibida a construção. Em zonas de médio risco é permitido construções, mas somente com condições especiais como paredes reforçadas. Nas zonas de baixo risco a construção é permitida sem nenhuma condição particular.

- Medidas técnicas: medidas estruturais para proteção, e também instalação de sistema de monitoramento e de aviso de perigo.

A preparação é muito importante para redução do risco de desastre natural. Ela é composta de planejamento dos recursos assim como das operações e treinamento de equipe de resgate (FOCP, 2013):

- Planejamento de recursos: recursos para gerenciar e lidar com catástrofes e crises são limitados tanto em material quanto em pessoal. É tarefa do planejamento de recursos 
otimizar os recursos de forma a estarem no local de emergência para serem utilizados da forma mais rápida e eficiente possível.

- Treinamento de equipes de resgate: para salvar vidas e oferecer primeiros socorros as equipes de resgate devem chegar ao local de emergência o mais rápido possível e estarem preparadas para lidar com a situação.

\subsection{RESPOSTA}

O foco de todas as medidas de resposta é limitar o efeito e duração de uma catástrofe. Resposta inclui alertas, atendimento a vítimas, assim como medidas imediatas para prevenção de danos futuros como recondicionamento da estrutura e documentação do evento. Em caso de desastres naturais é importante minimizar a extensão dos danos com um sistema de alerta, resgate e atendimento rápidos às vítimas (FOCP, 2013). Como forma de intervenção temos:

- Sistema de alerta: dependendo da severidade de um desastre natural, é possível que o processo natural altere seu comportamento usual. As pessoas que vivem em área de perigo devem se alertadas e evacuadas em tempo.

- Resgate e atendimento às vítimas: a primeira ação em caso de desastre natural é resgatar as pessoas e mantê-las a salvo de perigo. Equipes especiais cuidam das vítimas e seus parentes.

- Medidas imediatas e limitação dos danos: durante e depois do desastre é importante prevenir um aumento da área afetada.

Em caso de emergência, construções vitais como ruas e hospitais devem ser reparados o mais rápido possível para garantir seu funcionamento. Isso significa reparo temporário. A maior diferença com relação à recuperação é que durante o processo de recuperação a solução temporária é trocada pela solução definitiva (FOCP, 2013). O recondicionamento, ou reparo temporário, consiste:

- Reparos provisórios: é importante que construções vitais, equipamentos e estradas sejam reparados provisoriamente o mais rápido possível após o desastre natural. Isso inclui itens com fornecimento de água, esgoto, eletricidade, ruas e telecomunicação.

- Avaliação e documentação do desastre: as marcas deixadas pelos desastres naturais geralmente são removidas e limpas imediatamente. Mas para permitir reconstruir e analisar o desastre é importante documentar as marcas. Além de documentar o desastre é importante documentar as operações de resgate também, para otimizar estas operações no futuro. 


\subsection{RECUPERAÇÃO}

Durante a recuperação, a reconstrução de prédios e infra-estrutura são prioridades, assim como a análise do desastre. A principal tarefa é converter corretamente os resultados da análise de desastre e integrá-los no planejamento. Soluções sustentáveis são preferidas sobre solução fáceis e baratas (FOCP, 2013):

- Análise do desastre: avaliar o desastre deve ajudar a entender a evolução do evento e os processos envolvidos (como chuva, descarga e transporte de solo e rochas), assim como classificá-lo para comparação com eventos anteriores. Avaliação inclui análise das atividades de gerenciamento e serviços de emergência para identificar possíveis melhorias nas operações futuras.

- Análise da vulnerabilidade: se pessoas ou animais são machucados ou prédios e infra-estrutura são destruídos durante um evento natural, então é necessário encontrar a causa dos danos. A análise da vulnerabilidade oferece informações importantes para definição de regulamentos e condições para construções e objetos em zonas de perigo.

- Reconstrução: a análise da vulnerabilidade oferece base para as mudanças necessárias durante a reconstrução. Simples mudanças construtivas na reconstrução (exemplo porta um pouco mais altas que o nível do solo) podem efetivamente diminuir danos futuros.

- Adaptação do plano de uso de solo: no caso de danos severos após um evento natural, a avaliação de perigo e o mapa de perigo devem ser reavaliados e adaptados.

\subsubsection{NORMA INTERNACIONAL PARA GERENCIAMENTO DE RISCO ISO 31000:2009}

A ISO 31000:2009 define um conjunto de princípios, um formato e um processo para gerenciamento de risco que é aplicável a qualquer tipo de organização, seja no setor público ou privado. A norma não estabelece uma única solução para todos os casos, mas enfatiza o fato que o gerenciamento de risco precisa ser adaptado para necessidade e estrutura específica de uma organização em particular (UNISDR, 2012). 
A norma oferece guias importantes quanto à complexidade do gerenciamento de risco e disponibiliza formatos para diálogo entre diferentes agentes e setores envolvidos. Estas recomendações são aplicáveis, independente do tamanho e tipo de organização, setor e país (MARSH, 2011).

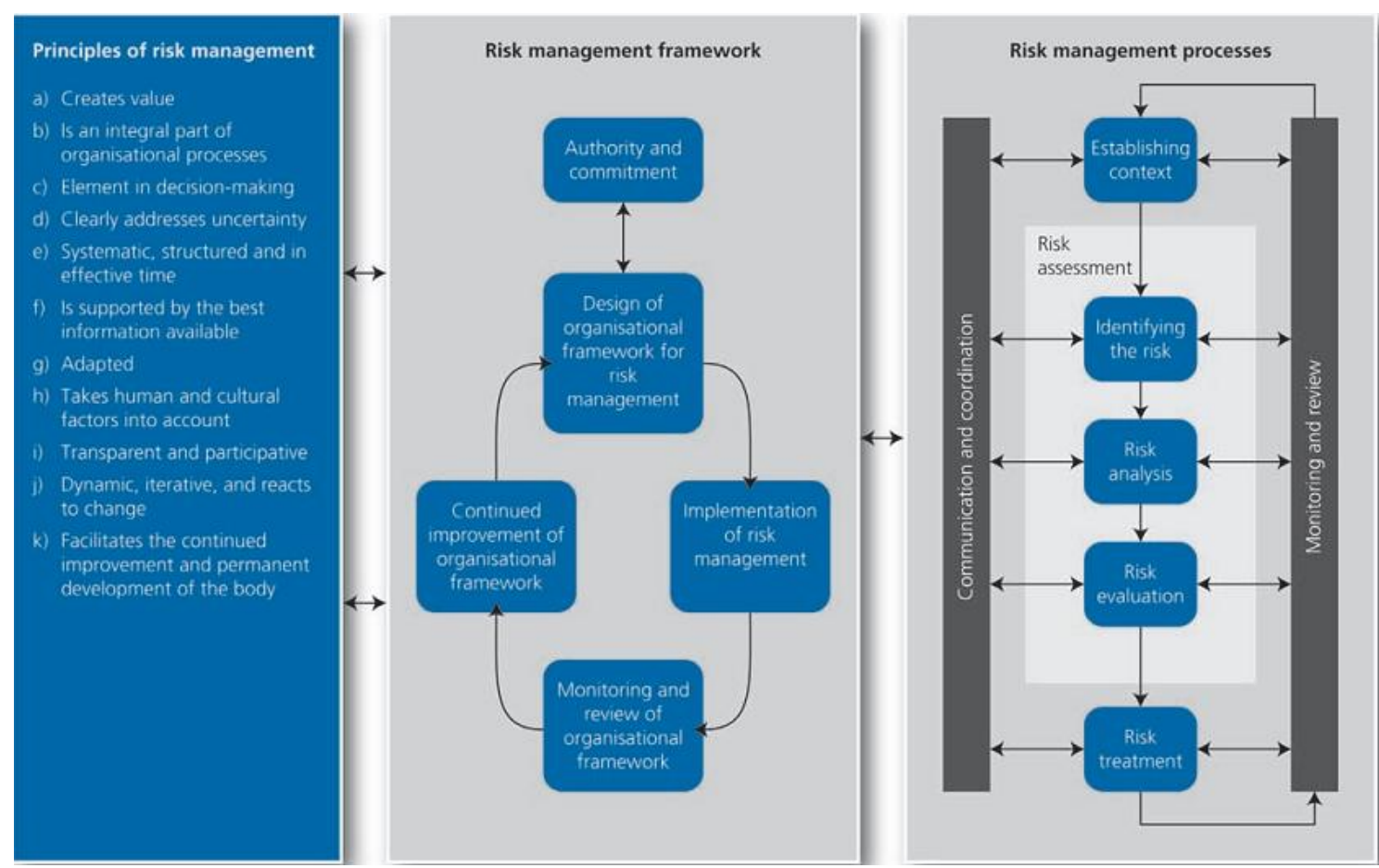

Figura 10 - Visão geral da norma ISO 31000.

Fonte: MARSH (2011).

A base da ISO 31000 consiste de um conjunto de atividades de gerenciamento de risco que controlam o processo de governança, organização, gerenciamento e formas de implementação. A Figura 10 apresenta uma visão geral do que a norma ISO 31000 oferece. São apresentados desde os princípios básicos até como devem ser organizados a estrutura e os processos para gerenciamento de risco.

Segundo a ISO 31000, gerenciamento de risco é:

1. Criar valor.

2. Integrado dentro do processo organizacional.

3. Integrado dentro dos processos de tomada de decisão.

4. Lida explicitamente com incertezas.

5. Sistemático, estruturado e utilizado de maneira efetiva.

6. Baseado na melhor informação disponível.

7. Adaptativo.

8. Inclui fatores humanos e culturais. 
9. Transparente e participativo.

10. Dinâmico, iterativo e reage a mudanças.

11. Facilita o melhoramento contínuo da organização

A Figura 11 apresenta o ciclo de gerenciamento de desastres adotado pela União Européia, que tem muitos pontos em comum com as outras propostas de gerenciamento de risco apresentadas anteriormente, onde também é possível identificar as etapas Antes, Durante e Depois.

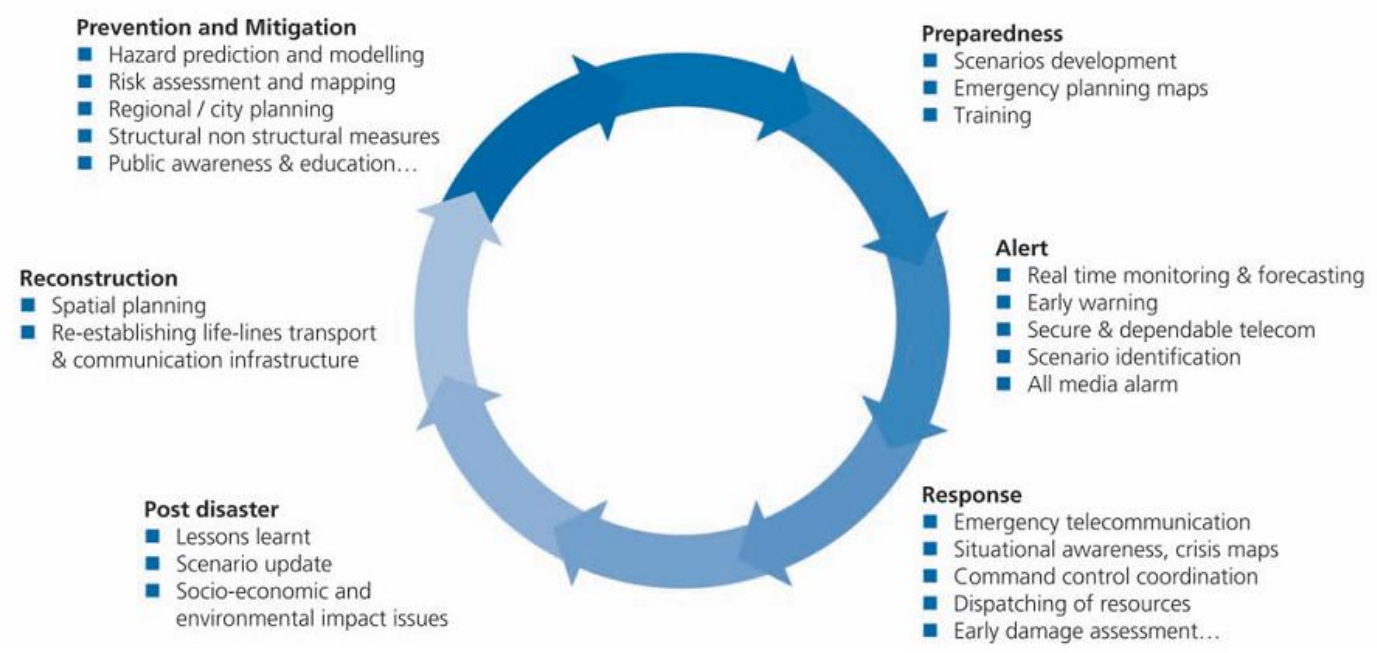

Figura 11 - Ciclo de gerenciamento de desastre.

Fonte: MARSH (2011).

\subsection{7 ÍNDICE DE RESILIÊNCIA HÍDRICA COM BASE PARTICIPATIVA (PWRI)}

Conceitos como vulnerabilidade, impacto e adaptação auxiliam na avaliação do grau de resiliência de sistemas complexos sob riscos múltiplos. Mudanças de uso de solo e do clima podem aumentar a vulnerabilidade desses sistemas aos padrões de freqüência e intensidade de eventos extremos, e até manifestação destes como desastres. Em sistemas como bacias hidrográficas, essas mudanças progressivas mudam a probabilidade de eventos extremos como inundações, secas e deslizamentos. Seus riscos são avaliados e gerenciados com estratégias de adaptação e de mitigação, inclusive na forma de índices, que facilitam a comunicação e o preparo de comunidades. Por um lado, um índice de risco é a representação da chance de ocorrência e cujo cálculo avalia a Ameaça, a Vulnerabilidade, a Exposição aos riscos. Por outro lado, a hipótese da pesquisa afirma que um índice de resiliência estende o 
cálculo anterior, ao incorporar elementos da gestão desses riscos com medidas a adotar Antes, Durante e Depois a ocorrência de eventos extremos (MENDIONDO et al., 2013).

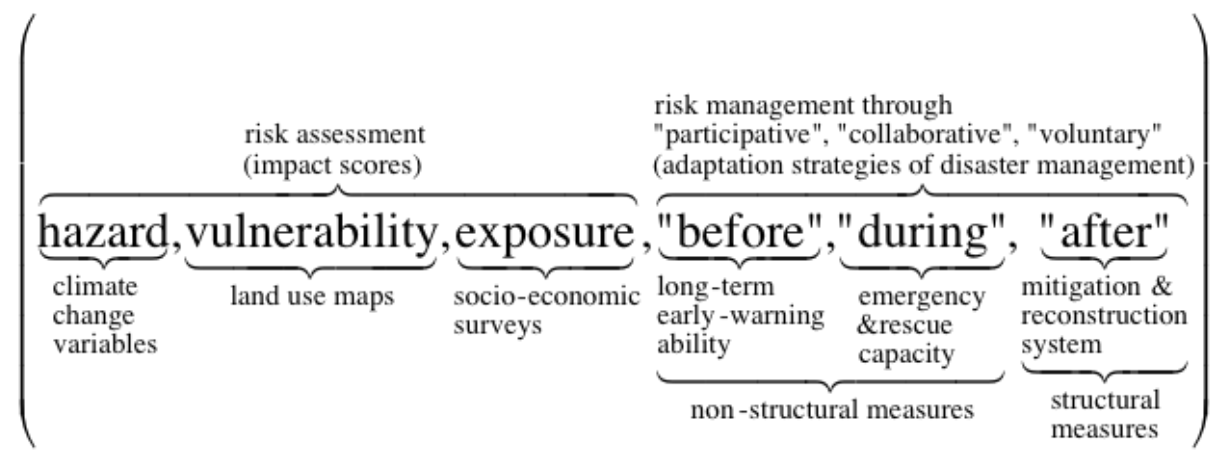

Figura 12 - Formato indicador PWRI.

Fonte: Mendiondo et al. (2013).

O Índice de Resiliência Hídrica com Base Participativa (Participative Water Resilience Index - PWRI) apresentado na Figura 12 é composto de duas partes: avaliação do risco e gerenciamento do risco. Esta estrutura permite utilizar variáveis de diferentes tipos e fontes, além de oferecer um layout flexível de maneira que cada grupo possa redefinir seu próprio índice (MENDIONDO et al., 2013). O índice PWRI é definido pelos seguintes termos:

- Avaliação do Risco: define probabilidade e tamanho dos danos.

- Ameaça ou Perigo: corresponde a medida do evento causador do perigo ou risco.

○ Vulnerabilidade: corresponde quão vulnerável é um local à ocorrência de perdas e danos devido a Ameaça.

○ Exposição: corresponde aos danos potenciais do local. Pode representar número de vida, valor econômico, número de empresas, etc.

- Gerenciamento de risco: avalia a capacidade do local ou comunidade de lidar com o risco:

○ Antes: pode ser entendida como a etapa de preparação. Representa como a comunidade esta preparada para lidar com o evento de risco.

○ Durante: corresponde às capacidades de lidar com o problema durante seu acontecimento, é a capacidade de resposta.

- Após: é a capacidade de reconstrução após evento de desastre, de forma a retomar a vida como era antes do desastre. É a capacidade de recuperação.

A avaliação do risco é compreendida como uma combinação dos termos Ameaça, Exposição e Vulnerabilidade: 


\section{Avaliação de Risco $=\{$ Ameaça,Vulnerabilidade, Exposiç̧ão $\}$}

Este conjunto tem como objetivo avaliar os riscos e danos que um local pode vir a enfrentar. Avalia o conjunto de condições que provocam o risco, assim como os danos e prejuízos.

O gerenciamento do risco é a combinação dos termos Antes, Durante e Depois:

$$
\text { Gerenciamento de Risco }=\{\text { Antes, Durante }, \text { Depois }\}
$$

A estrutura do índice PWRI não explicita como cada termo deve ser calculado, normalizado e agrupado. Isso permite que o mesmo seja adaptado às diferentes realidades encontradas em diferentes estudos.

Um exemplo de índice PWRI é apresentado na Equação 1. O índice proposto por Giuntoli (2008) e Mendiondo (2010) é originalmente chamado de índice de risco pelos autores. Esta formulação segue o formato sugerido para o PWRI, e trabalha no longo prazo com componentes adimensionais e concentrados em sub-bacias. $\mathrm{O}$ resultado permite apresentar e comparar riscos em diferentes sub-bacias.

Equação 1 - Exemplo de índice PWRI.

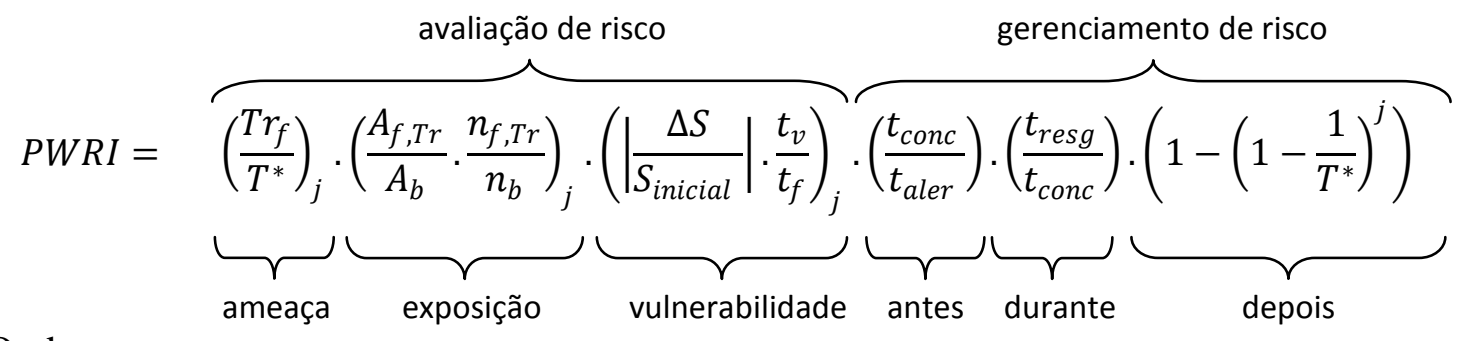

Onde:

- $\operatorname{Tr}_{f}$ é o tempo de retorno na inundação;

- $T^{*}$ é o tempo de retorno de projeto do canal referente à altura de extravasamento (bankfull);

- $A_{f, T r}$ é á área inundável segundo o tempo de retorno $\operatorname{Tr}_{f}$;

- $A_{b}$ é a área total da bacia hidrográfica;

- $n_{f, T r}$ é a população que vive na área inundável $A_{f, T r}$;

- $n_{b}$ é a população total da bacia; 
- $\Delta S$ é a diferença entre o armazenamento atual de água no solo e inicial anterior a urbanização;

- $t_{v}$ é a duração média que um indivíduo vulnerável (portador de deficiência ou idoso) leva para atravessar o fundo de vale inundável;

- $t_{f}$ é a duração média que um indivíduo não vulnerável leva para atravessar o fundo de vale inundável;

- $t_{\text {conc }}$ é o tempo de concentração da bacia;

- $\quad t_{\text {aler }}$ é o tempo de previsão de alerta;

- $t_{\text {resg }}$ é o tempo de resgate necessário para atender a emergência em caso de inundação;

- $\quad N$ é o tempo de vida útil das obras;

- $j$ é o tempo de adequação relativo;

No trabalho de Giuntoli (2008) a Ameaça é dada pelo tempo de retorno da inundação e é expressa pela razão de tempos de projeto e de inundação. A Exposição quantifica o número de pessoas expostas à inundação. Chega-se nesta expressão pelas razões entre as áreas, sujeita à inundação e total da bacia, e o número de habitantes, que ocupam áreas sujeitas à inundação e número total (GIUNTOLI, 2008). A Vulnerabilidade exprime a propensão a sofrer dano por inundação. Neste caso a expressão considera o lado físico da vulnerabilidade, com a evolução do armazenamento potencial de água no solo, e social por meio da razão entre tempo ocorrido para se deslocar, por parte de cidadãos com bons níveis de saúde e outros mais vulneráveis como idosos ou portadores de deficiência (GIUNTOLI, 2008).

Para o gerenciamento de risco, a componente Antes é a razão de tempo de concentração do curso de água com o tempo de alerta. A componente Durante refere-se ao momento em que o evento ocorre, considerando-se neste caso, além do tempo de concentração do curso de água, o tempo de resgate à população atingida (GIUNTOLI, 2008). O último componente do gerenciamento de risco, Depois, é constituído pela equação que relaciona o risco hidrológico ao tempo de retorno, e segundo a qual os prejuízos causados por uma falha de funcionamento da estrutura diminuem com o aumento do tempo de retorno adotado em projeto (GIUNTOLI, 2008).

A metodologia adotada por Giuntoli (2008) utiliza indicadores físicos para todas as componentes avaliadas, mesmo para o gerenciamento do risco. Ao invés de avaliar se existem medidas gerenciais implementadas, ele optou por utilizar indicadores como tempo de 
atendimento, tempo de retorno e outros, que podem ser compreendidos como uma medida indireta do resultado das políticas de gerenciamento de risco.

\subsubsection{MODELO ETA - CPTEC/HADCM3}

O desenvolvimento de cenários de mudanças climáticas é talvez o primeiro passo para o entendimento dos impactos climáticos sob condições de um aquecimento global, proporcionando informações para avaliação de vulnerabilidade e para desenvolvimento de medidas e estratégias de adaptação para mudanças do clima (MARENGO et al., 2011).

O Centro de Previsão de Tempo e Estudos Climáticos (CPTEC) vem utilizando o modelo Eta desde 1996 para gerar as previsões de tempo para América do Sul (MARENGO et al., 2011).

O clima regional foi simulado utilizando o modelo regional Eta-CPTEC, que é derivado do modelo Eta desenvolvido na Universidade de Belgrado e implementado operacionalmente pelo Centro Nacional de Previsão Ambiental. O modelo Eta foi escolhido porque existem poucas investigações utilizando o Modelo Eta em longas integrações sobre a América do Sul e porque o sistema de coordenadas vertical utilizado neste modelo é recomendado para uso na América do Sul devido à presença da cordilheira dos Andes (MARENGO et al., 2011).

As projeções foram geradas para o presente (1961-1990) e futuro (2010-2100) para o cenário IPCC SRES A1B (MARENGO et al., 2011).

As condições de contorno de HadCM3 passados ao modelo Eta-CPTEC são as seguintes: aenwh/aenwl; aexso/aeyjo; aexsj/aeyjj e aexsb/aeyjb. O par de nomes refere-se às partes históricas e futuras da rodada. O primeiro par é o membro sem perturbações (CNTRL), o segundo é o membro de alta sensibilidade (HIGH), o terceiro de média sensibilidade (MIDI) e o último de baixa sensibilidade (LOW). O membro sem perturbação localiza-se entre os membros MIDI e LOW (MARENGO et al., 2011).

Embora apenas o cenário de emissão A1B esteja disponível, as diferenças na sensibilidade do modelo podem ser entendidas como fonte de dados plausíveis para representação de diferentes cenários de emissão. A rodada de alta sensibilidade HIGH pode representar as mudanças encontradas em cenários como SRES A2 ou A1FI. Da mesma forma as mudanças observadas na rodada de baixa sensibilidade LOW podem ilustrar qualitativamente as emissões mais baixas encontradas no cenário B1 (MARENGO et al., 2011). 
Enquanto o uso primário do modelo era previsão de tempo regional, ele foi utilizado com sucesso também em previsão regional de clima. A partir de várias rodadas do modelo global HadCM3, foi realizado o downscaling com o modelo regional Eta CPTEC $40 \mathrm{~km}$.

\subsubsection{MODELO SCS}

Um modelo de previsão de escoamento para solo foi apresentado pelo Soil Conservation Service (SCS) e tem sido muito utilizado para simulação de hidrogramas de cheias de projeto de obras hidráulicas, bem como para estabelecimento de risco de inundação para um determinado local (TUCCI, 1998).

O modelo, apesar de certas inconsistências apresentadas na literatura, tem sido muito utilizado em todo o mundo devido os seguintes motivos:

1. Reduzido número de parâmetros;

2. Relação entre os parâmetros e características físicas da bacia.

O modelo não foi desenvolvido com o compromisso de representar um evento específico, mas para ser utilizado para estimar (normalmente superestima) o hidrograma de projeto para uma determinada bacia (TUCCI, 1998).

O modelo utiliza uma expressão que relaciona a razão entre a precipitação total acumulada (P [mm]) com o volume superficial acumulado (Q [mm]), e a razão entre a infiltração e o escoamento da bacia. A relação é dada por (TUCCI, 1998):

$$
Q=\frac{\left(P-I_{a}\right)^{2}}{P+S-I_{a}} ; P>I_{a}
$$

Onde:

$Q$ : volume superficial acumulado [mm].

$P$ : precipitação total acumulada [mm].

$I_{a}$ : perdas iniciais $[\mathrm{mm}]$.

$S$ : armazenamento do solo [mm].

O valor $I_{a}$ é estimado para condições médias por:

$$
I_{a}=0,2 S
$$

Assim a equação pode ser simplificada para:

$$
Q=\frac{(P-0,2 S)^{2}}{(P+0,8 S)}
$$


Para determinar a capacidade máxima de armazenamento da camada superior do solo $S$, foi estabelecida uma escala onde a variável é o parametro $C N$. Este parâmetro foi classificado de acordo com o tipo e uso do solo. A expressão que relaciona $S$ com $C N$ é a seguinte: (TUCCI, 1998)

$$
S=\frac{25400}{C N}-254
$$

Esta expressão é obtida em unidades métricas, a equação original em unidades inglesas, estabelece o valor de $C N$ na escala de 1 a 100. Esta escala retrata as condições de cobertura e solo, variando desde uma cobertura muito permeável até uma cobertura completamente impermeável (limite superior) e de um solo com grande capacidade de infiltração para um de baixa infiltração (TUCCI, 1998).

Tabela 7 - Valores dos parâmetros CN para diferentes tipos de ocupação urbana.

\begin{tabular}{lllll}
\hline & \multicolumn{2}{l}{ Tipo de solo } & & \\
Descrição do uso do solo & A & B & C & D \\
\hline Espaços abertos & & & & \\
Matos ou gramas cobrem 75\% da área & 39 & 61 & 74 & 80 \\
Matos cobrem 50 a 75\% da área & 49 & 69 & 79 & 77 \\
\hline Áreas Comerciais (85\% impermeáveis) & 89 & 92 & 94 & 95 \\
\hline Distritos industriais (72\% impermeáveis) & 81 & 88 & 91 & 93 \\
\hline Áreas residenciais & & & & \\
65\% impermeável & 77 & 85 & 90 & 92 \\
38\% impermeável & 61 & 75 & 83 & 87 \\
30\% impermeável & 57 & 72 & 81 & 86 \\
25\% impermeável & 54 & 70 & 80 & 85 \\
20\% impermeável & 51 & 68 & 79 & 84 \\
\hline Parques e estacionamentos, telhados, viadutos & 98 & 98 & 98 & 98 \\
\hline Arruamentos e estradas & & & & \\
Asfaltadas e com drenagem pluvial & 98 & 98 & 98 & 98 \\
Paralelepípedos & 76 & 85 & 89 & 91 \\
Terra & 72 & 82 & 87 & 89 \\
\hline
\end{tabular}

Fonte: Tucci (1998).

Segundo o modelo, os tipos de solo identificados na tabela são:

- Solo A: solos que produzem baixo escoamento superficial e alta infiltração. Solos arenosos com pouco silte e argila.

- Solo B: solos menos permeáveis do que o anterior, solos arenosos menos profundos do que do tipo A e com permeabilidade superior à média. 
- Solo C: solos que geram escoamento superficial acima da média e com capacidade de infiltração abaixo da média, contendo percentagem considerável de argila e pouco profundo.

- Solo D: solos contendo argilas expansivas e pouco profundos com baixa capacidade de infiltração, gerando maior proporção de escoamento superficial.

\subsection{MATERIAL}

\subsection{1 ÁREA DE ESTUDO}

A área de estudo é a região urbana da cidade de São Carlos. A cidade está localizada na região centro-norte do Estado São Paulo, a 240 km da cidade de São Paulo. A região urbana pertence à bacia hidrográfica do rio Monjolinho, afluente do rio Jacaré-Guaçu que, por sua vez, deságua no rio Tietê. Na área urbana da São Carlos, o rio Monjolinho tem como principais tributários os córregos Tijuco Preto, Mineirinho e Gregório. O município de São Carlos está em processo acelerado de crescimento da população urbana. De acordo com a Prefeitura Municipal de São Carlos (2008), a população atual do município é de 220.425 habitantes (GRACIOSA, 2010).

Coordenadas:

- 4730’ e 4830' Longitude Oeste

- 2130’ e 22ํㅜㅇ' Latitude Sul

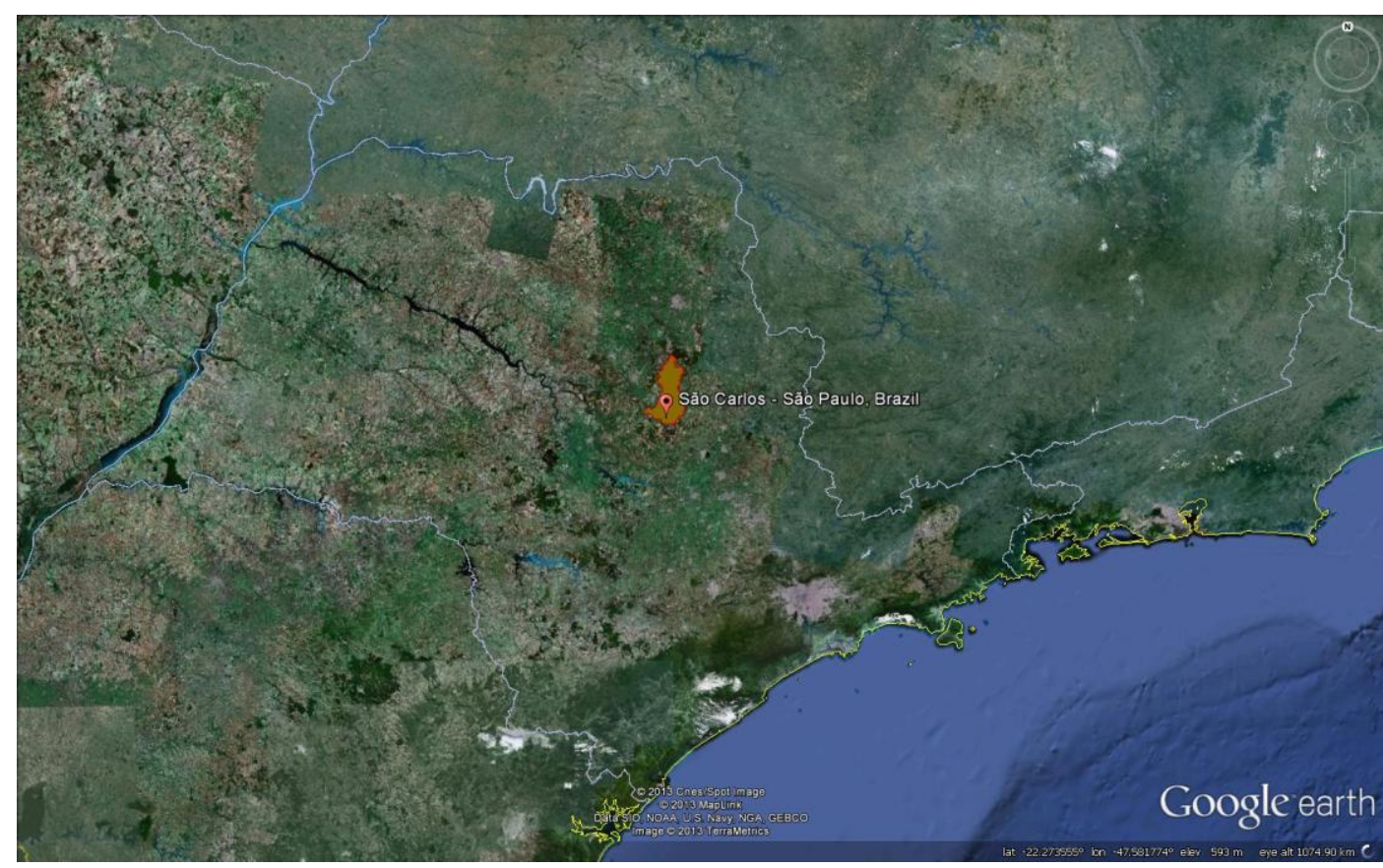

Figura 13 - Localização da cidade de São Carlos. 
O município de São Carlos está inserido em duas grandes bacias hidrográficas, a MojiGuaçu e Tietê-Jacaré. O município é caracterizado por solos de alta permeabilidade, sendo constituído por zonas de latossolo-vermelho-amarelo e de areia quartzosa profunda com características arenosas (MARTINS, 2012).

São Carlos apresenta problemas de inundações recorrentes, de periodicidade quase anual. A região do Mercado Municipal é conhecida pelas inundações. Existem relatos de inundações desde 1947 (DECINA, 2012). Apesar de sabido que a região era sujeita a inundações freqüentes, isso não foi levado em conta no processo de ocupação do solo, e a região foi intensamente ocupada e impermeabilizada. Deste modo o problema de inundações tem se acentuado com o passar dos anos e os prejuízos econômicos são cada vez maiores. As inundações que afetam a área ocorrem de forma muito rápida, de 15 a 30 minutos (DECINA, 2012).

A Figura 14 apresenta alguns dos pontos de inundação conhecidos. Os pontos marcados são locais que sofreram inundação no ano de 2013, sendo que a maioria ocorreu em um evento de precipitação extrema no dia 22 de outubro de 2013.

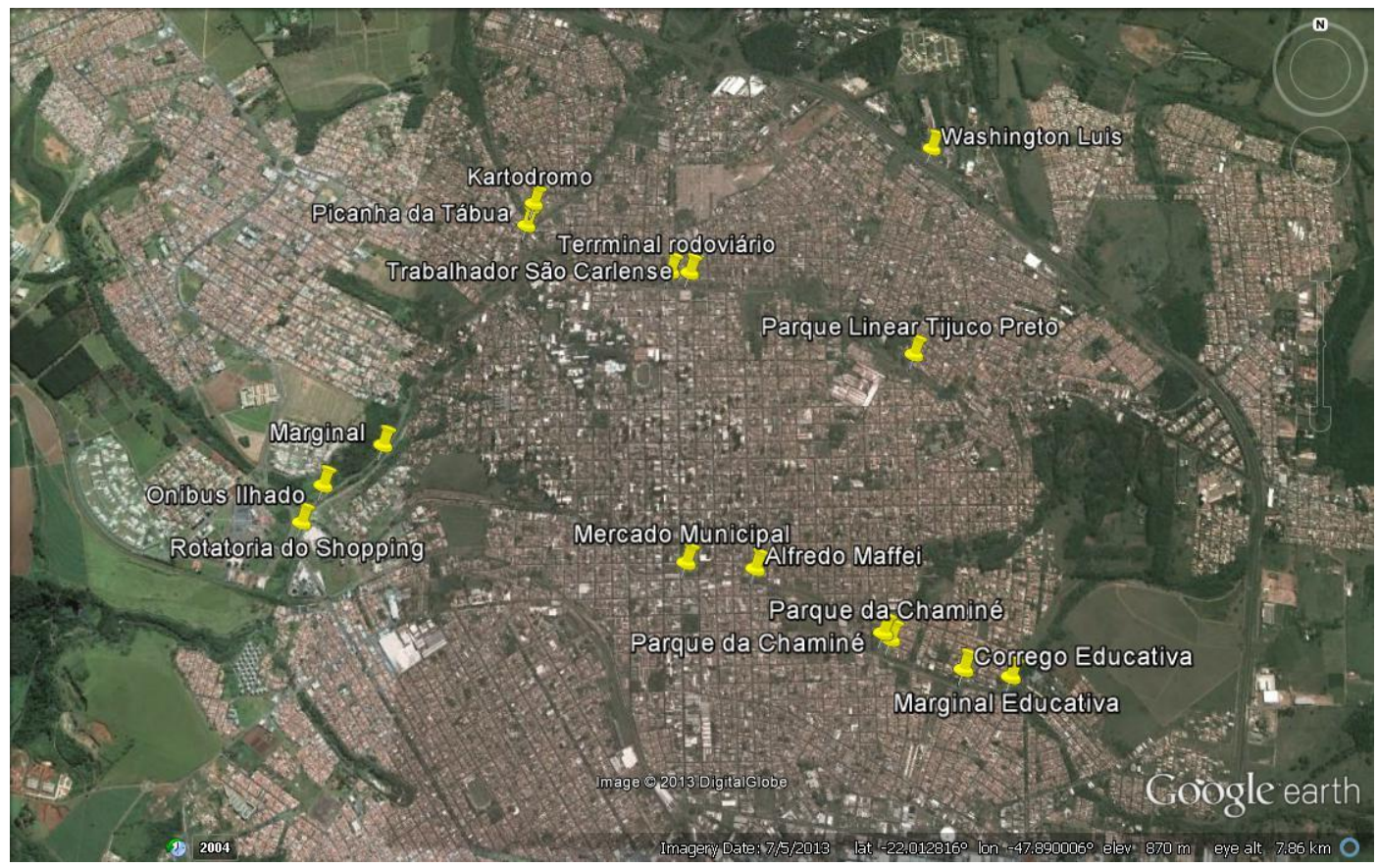

Figura 14 - Pontos de inundação conhecidos.

\subsubsection{DADOS TOPOGRÁFICOS}

Os dados topográficos foram obtidos no site da Embrapa. A Embrapa Monitoramento por Satélite disponibiliza uma série de imagens do Brasil visto do espaço, com detalhes de relevo 
e da topografia. A topografia foi gerada a partir dos dados de radar, obtidos de sensores a bordo do ônibus espacial Endeavour, no projeto SRTM (Shuttle Radar Topography Mission), uma parceria das agências espaciais dos Estados Unidos (NASA e NIMA), Alemanha (DLR) e Itália (ASI) (MIRANDA, 2005).

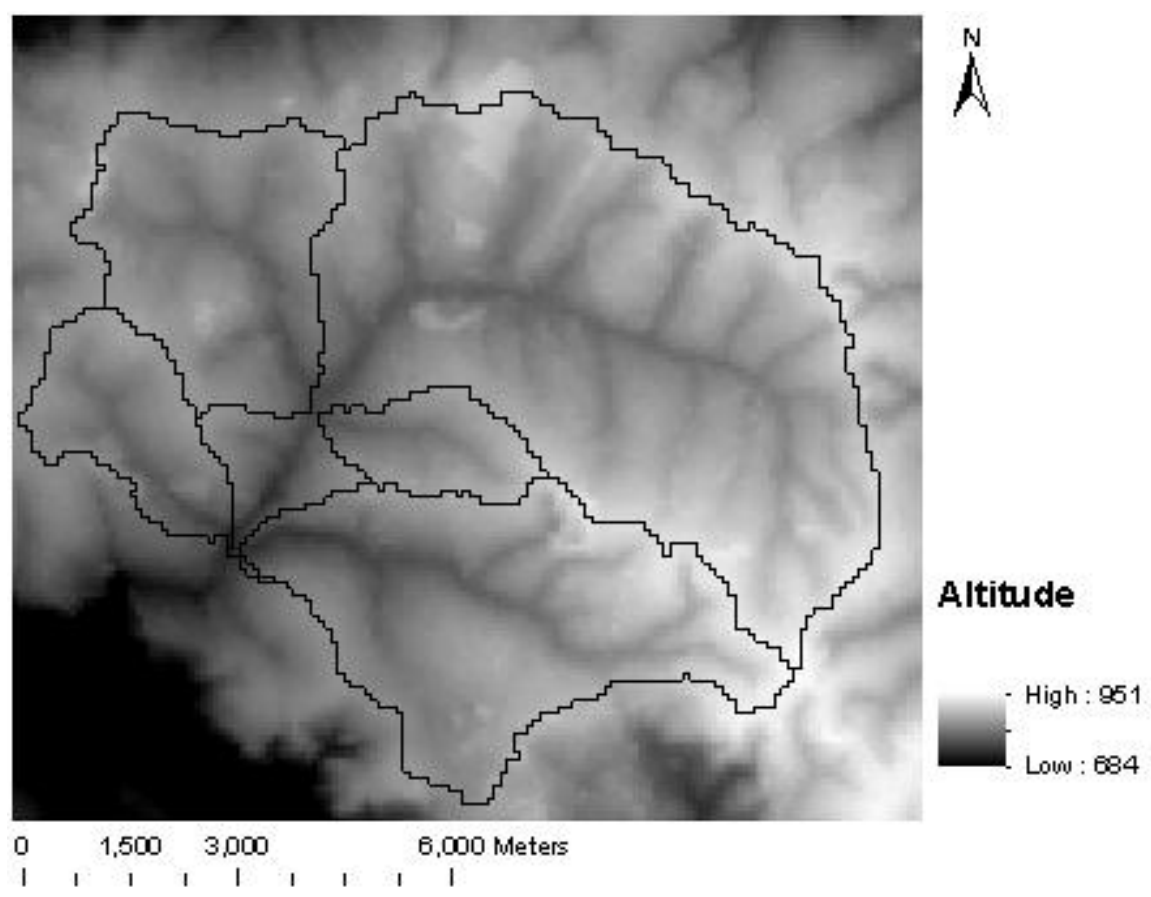

Figura 15 - Topografia da região urbana de São Carlos.

Os pesquisadores da Embrapa Monitoramento por Satélite processaram os dados brutos do SRTM e realizaram um trabalho de correção e padronização, eliminando falhas, sombras e distorções. A resolução é de aproximadamente 90 metros (MIRANDA, 2005).

\subsubsection{IMPERMABILIZAÇÃO DO SOLO E SUB-BACIAS}

A área urbana de cidade foi dividida em bacias menores, e para cada sub-bacia foi adotado um valor médio de impermeabilização do solo, que varia de acordo com os anos segundo as hipóteses estabelecidas. 


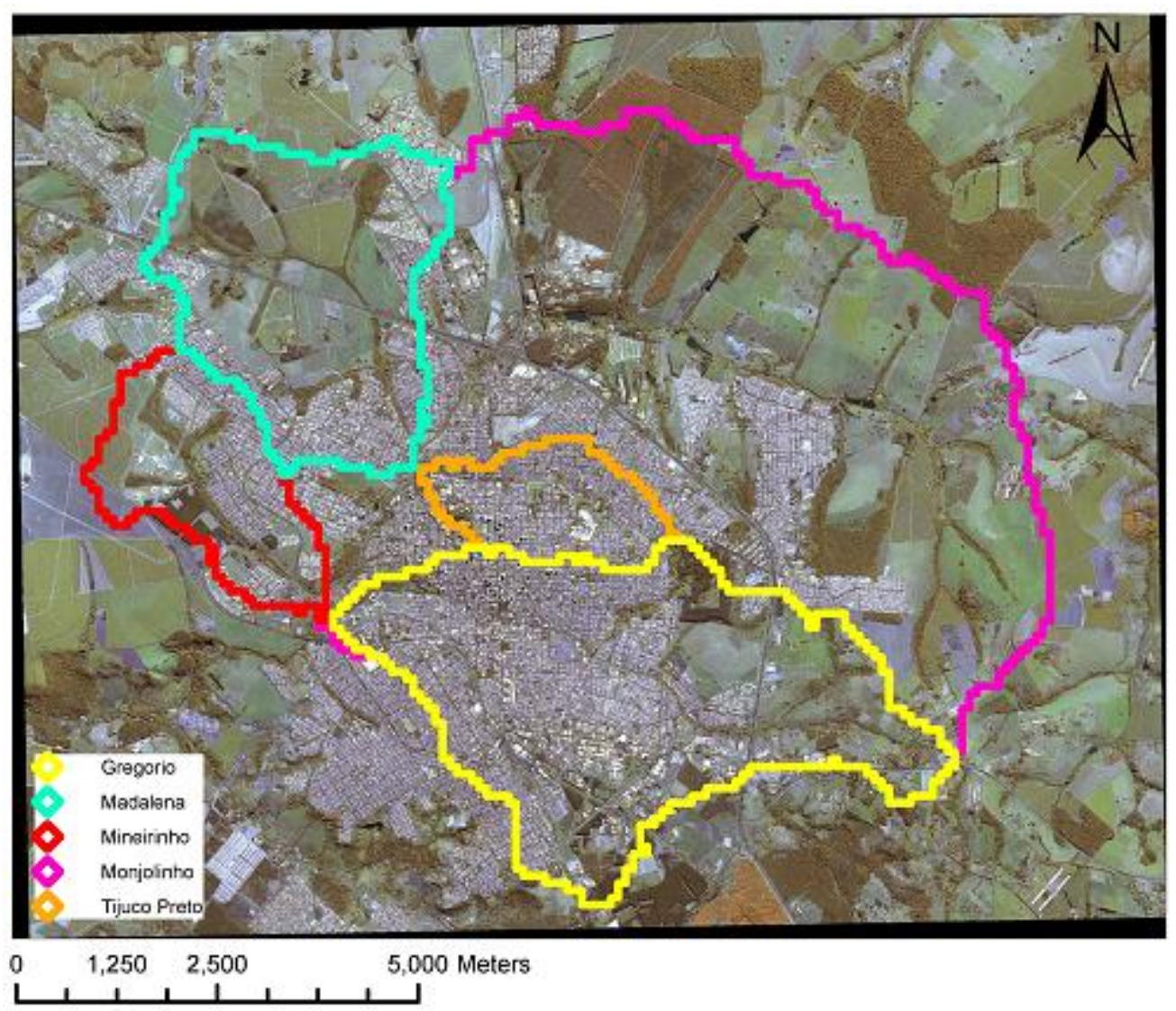

Figura 16 - Bacia urbana de São Carlos e sub-bacias.

As sub-bacias utilizadas são as mesmas utilizadas no trabalho de Giuntoli (2008). Elas foram geradas com o software Arcgis 10 a partir da informação de topografia.

Tabela 8 - CN das sub-bacias urbanas em 2003.

\begin{tabular}{ll}
\hline Bacia & CN SCS [adm] \\
\hline Santa Maria Madalena & 76,1 \\
Mineirinho & 84,5 \\
Tijuco Preto & 89,3 \\
Gregório & 83 \\
Monjolinho & 71 (estimado pelo autor) \\
\hline
\end{tabular}

Fonte: adaptado de Giuntoli (2008).

A Tabela 8 apresenta os valores de $\mathrm{CN}$ estimados para cada sub-bacia.

\subsubsection{CENSO 2010}

O Censo Demográfico é a mais complexa operação estatística realizada por um país, quando são investigadas as características de toda a população e dos domicílios do Território Nacional. Os Censos, por pesquisarem todos os domicílios do país, constituem a única fonte de referência para o conhecimento das condições da população em todos os municípios e em 
seus recortes territoriais internos e classificação de acordo com a localização dos domicílios em áreas urbanas ou rurais. Os dados, por setor censitário, compreendem características dos domicílios particulares e das pessoas que foram investigadas para a totalidade da população e são denominados, por convenção, resultados do universo. Estes dados foram obtidos reunindo informações captadas por meio da investigação das características dos domicílios e das pessoas, que são comuns aos dois tipos de questionários utilizados para o levantamento do Censo Demográfico 2010.

O mapa dos setores censitários e informações da população foram obtidos através de IBGE (2013a, b).

\subsubsection{ESCOAMENTO SUPERFICIAL}

Os dados simulados pelo INPE tiveram como origem as projeções climáticas para América do Sul simuladas pelo modelo regional Eta-CPTEC. O modelo global foi rodado no século 21 de acordo com os cenários de emissão SREX A1B, cada membro contendo diferente sensibilidade climática (MARENGO et al., 2011).

Foi escolhida a variável RNOF, ou escoamento superficial, pois ele representa diretamente o volume de água superficial. Para cálculo do escoamento superficial é necessário fornecer informação sobre a capacidade de infiltração do solo em questão. A urbanização é levada em conta posteriormente através de correções deste valor. 


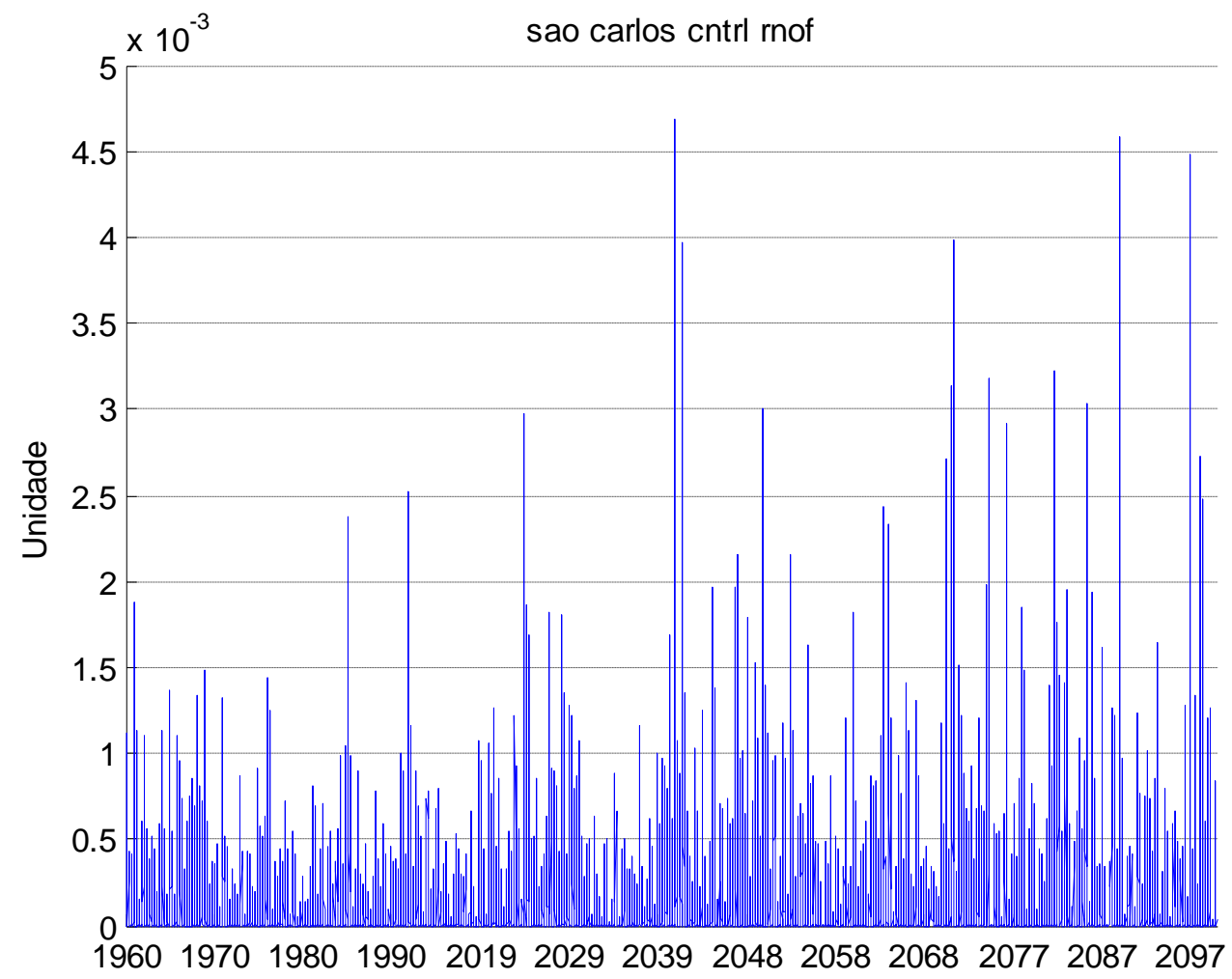

Figura 17 - Escoamento superficial (RNOF) [kg/m2/s].

As previsões utilizadas são para a variável de RNOF, períodos de 1960-1990, 2010-2040, 2040-2070 e 2070-2100. A rodada escolhida é a de controle, CNTRL, que apresentou uma variabilidade de temperatura mediana, ou seja, pode ser compreendida como um cenário intermediário, não sendo nem o mais otimista, nem o mais pessimista com relação às mudanças climáticas.

\subsubsection{EVENTOS HISTÓRICOS}

Analisando dados obtidos junto ao SIGRH - Sistema Integrado de Gerenciamento de Recursos Hídricos, foi possível identificar as datas que ocorreram as maiores precipitação totais diárias próximas à sub-bacia do Gregório, de 1939 a 1996. Foram selecionadas as datas em que a precipitação diária foi superior a $70 \mathrm{~mm}$, totalizando 58 eventos (MENDES et al., 2004).

Segundo a Tabela 21, no anexo A, a ocorrência de problema de inundação está associada aos dias com precipitação diária maiores que $70 \mathrm{~mm}$. Esta informação é utilizada posteriormente para validar a precipitação estimada a partir dos cálculos do modelo SCS. 


\subsection{METODOLOGIA}

\subsubsection{AMEAÇA}

O termo Ameaça é obtido a partir da previsão de escoamento superficial, RUNOFF, gerada pelo INPE. Primeiramente, a partir de um histograma, é investigado se existe alguma tendência na frequiência e intensidade dos eventos. Ainda com o objetivo de identificar algum tipo de tendência temporal no comportamento do escoamento superficial é calculado o percentil $99 \%$, para uma janela de 10 anos (5 anos anteriores e 5 anos posteriores a data de análise) para todo o período de 1960 a 2100 . O objetivo é identificar algum tipo de tendência no número de eventos extremos do universo de análise. O histograma e gráfico de percentil são gerados com auxílio de rotinas específicas criadas pelo autor no software Matlab.

Descartada qualquer evidência clara no comportamento do escoamento superficial, foi optado por trabalhar com o percentil $99 \%$ de cada período de simulação disponível, 19601990, 2010-2040, 2040-2070 e 2070-2100, que é a forma como os dados são disponibilizados pelo INPE.

O próximo passo é estimar qual seria o escoamento superficial para diferentes condições de urbanização da zona urbana, ou seja, diferentes coeficientes de impermeabilização do solo. Os dados simulados admitem $\mathrm{CN}$ do solo sem urbanização, que devem ser corrigidos para refletir o uso e ocupação do solo.

Sabendo-se os valores de escoamento superficial $Q[\mathrm{~mm}]$ e armazenamento potencial $S$ [mm], é possível encontrar o valor da precipitação $\mathrm{P}$ [mm] através da solução da equação de escoamento SCS, dada pela equação abaixo:

$$
P=\frac{S}{5}+\frac{Q}{2}+\frac{\sqrt{Q *(4 * S+Q)}}{2}
$$

A partir do valor da precipitação, é possível estimar qual seria escoamento superficial para uma nova condição de impermeabilização solo.

Adotou-se para o armazenamento de água no solo pré-urbanização $\left(\mathrm{S}_{0}\right)$, o valor de $\mathrm{S}_{0}=207.8 \mathrm{~mm}$, correspondente ao $\mathrm{CN}$ de 55 . O CN varia da faixa de 55 para condições préurbanização até 80-90 para o presente na região de São Carlos (GIUNTOLI, 2008).

$\mathrm{O}$ valor de $\mathrm{CN}$ igual a 55 equivale a um potencial de armazenamento de água de aproximadamente $207 \mathrm{~mm}$, o que é admitido como $100 \%$ da capacidade inicial de armazenamento do solo. Caso o local seja urbanizado e impermeabilizado, admite-se que o potencial de armazenamento diminui. Assim, para regiões densamente urbanizadas, com um $\mathrm{CN} 90, \mathrm{~S}$ igual a $28.2 \mathrm{~mm}$, o potencial de armazenamento do solo equivale a somente $13.6 \%$ 
da capacidade inicial. É assumida uma simplificação, onde o potencial de armazenamento diminui linearmente com a porcentagem de impermeabilização do solo, ou seja, um solo 100 $\%$ impermeabilizado equivale a $0 \%$ de $\mathrm{S}_{0}$, e $0 \%$ impermeabilizado é o mesmo que $100 \%$ de $\mathrm{S}_{0}$.

Tabela 9 - Condições de CN e armazenamento de água no solo.

\begin{tabular}{llll}
\hline Condições & CN estimado & S [mm] & Porcentagem de $\mathbf{S}_{\mathbf{0}}$ \\
\hline Pré urbanização & 55 & 207.8 & 100 \\
Urbanização densa & 90 & 28.2 & 13.6 \\
\hline
\end{tabular}

Uma tabela é criada a partir dos valores de escoamento corrigidos para diferentes condições de impermeabilização e estimativas de precipitação. Esta tabela é normalizada através do método de máximo e mínimo e apresentada na forma de gráfico para avaliação do comportamento da Ameaça no período de avaliação e porcentagem de impermeabilização.

Foram geradas sete hipóteses, de acordo com o ano base de avaliação, admitindo uma hipótese inicial com um mínimo de impermeabilização do solo, até uma hipótese futura de total impermeabilização, junto do aumento de precipitação. A cada ponto da bacia foi atribuído o peso de Ameaça calculado nesta etapa.

\subsubsection{VULNERABILIDADE}

Neste trabalho é utilizada a função vulnerabilidade, ou seja, é uma função que a partir de uma Ameaça retorna a probabilidade do ponto ser atingido por uma inundação. Se for impossível o ponto ser atingido por uma inundação o valor de vulnerabilidade é zero (0), e se é certo o valor é um (1).

$$
\text { Vulnerabilidade }=f(\text { Ameaça })
$$

Um mapa de vulnerabilidade pode ser desenvolvido de formas mais simples, que exigem poucos cálculos e dados, ou de formas mais complexas com auxílio de modelos físicos e dados específicos que podem oferecer maior precisão na previsão. Trabalhos como de Graciosa (2010) e Decina (2012), utilizam dados topográficos de alta resolução e modelo hidráulicos e hidrológicos sofisticados para identificar áreas vulneráveis à inundação, enquanto trabalhos como Rennó et al. (2008) propõem metodologias alternativas para identificação de áreas vulneráveis a partir do indicador HAND - Height Above the Nearest Drainage - onde são identificadas áreas susceptíveis a inundação somente a partir do modelo digital de elevação com resolução limitada e sem uso de modelos físicos complexos. 
Neste trabalho foi optado por obter a Vulnerabilidade a partir de dados amplamente disponíveis e fáceis de obter. A partir do modelo digital de elevação obtido da Embrapa (MIRANDA, 2005) é calculado o fluxo acumulado para cada ponto do mapa, ou seja, é calculada a área drenada por cada ponto da bacia. Valor muito alto de fluxo acumulado sugere regiões onde existe maior volume de água devido precipitação, e que, portanto, são boas candidatas a terem problema de inundação.

Inundação não é um evento pontual, portanto, a vizinhança dos pontos com alto fluxo acumulado também tem uma probabilidade maior de sofrer com inundação. Existe uma influência entre as células, ou seja, um ponto exerce influência sobre seus vizinhos, o que pode ser entendido como um campo de influência. Neste trabalho, o campo é simulado com ajuda de um filtro espacial gaussiano.

As etapas para geração do mapa de Vulnerabilidade são resumidas como:

1. Preparação do modelo digital de elevação (software Arcgis).

2. Atribuição dos pesos do mapa de Ameaça para cada ponto da bacia para cada hipótese (software ArcGis).

3. Determinação de fluxo acumulado (software Arcgis).

4. Aplicação de filtro espacial gaussiano (software Matlab).

5. Normalização através do método de classificação Natural Breaks Jenks (software Arcgis).

As etapas são repetidas para cada hipótese definida.

A normalização por classificação Natural Breaks Jenks foi escolhida por apresentar os melhores resultados na visualização e diferenciação da vulnerabilidade dos pontos. Este é um método desenvolvido para otimizar a separação dos valores em classes "naturais". Isto é feito procurando minimizar o desvio médio da média da classe, enquanto maximiza o desvio da média dos outros grupos. Ou seja, o método reduz a variância dentro da classe e maximiza a variância entre as classes (JENKS, 1967).

\subsubsection{EXPOSIÇÃO}

Como indicador de Exposição é adotada a densidade populacional, ou seja, quantas pessoas por área vivem em domicílio permanente $\left[\mathrm{hab} / \mathrm{m}^{2}\right]$. O mapa é gerado a partir das informações obtidas do CENSO 2010, no software ArcGis 10. O IBGE fornece os mapas com a representação dos setores censitários, assim como as planilhas com diferentes informações sobre cada setor censitário. Sabendo-se o contorno de cada setor censitário e sua população total é possível calcular a densidade populacional $\left[\mathrm{hab} / \mathrm{m}^{2}\right]$. 
A normalização adotada utiliza o método de classificação por categorias. Neste tipo de normalização é atribuído um peso que varia de zero a um, de acordo com uma classificação definida.

$$
I=\left\{\begin{array}{c}
0 \text { se } x<P^{15} \\
0,2 \text { se } P^{15} \leq x<P^{25} \\
0,4 \text { se } P^{25} \leq x<P^{65} \\
0,6 \text { se } P^{65} \leq x<P^{85} \\
0,8 \text { se } P^{85} \leq x<P^{95} \\
1 \text { se } P^{95} \leq x
\end{array}\right\}
$$

A partir do mapa de densidade populacional, é realizada uma estatística sobre os setores censitários, e determinado os percentis 15, 25, 65, 85 e $95 \%$. Estes valores são utilizados na classificação do mapa de acordo com a equação (8). Setores que têm densidade menor que percentil $15 \%$ recebem peso zero, setores com densidade entre percentil 15 e $25 \%$ recebem peso 0,2, e assim por diante, de acordo com o apresentado na equação (8).

\subsubsection{MAPA DE RISCO \{AMEACA, VULNERABILIDADE, EXPOSIÇÃO\}}

Ao combinar os três termos de risco: Ameaça, Vulnerabilidade e Exposição, é possível gerar um mapa de Risco, onde os pontos que apresentam maior probabilidade de inundação associado ao maior número de pessoas atingidas fica evidenciado. Ao adotar a Vulnerabilidade como a probabilidade de um ponto sofrer inundação, e multiplicar esse mapa pelo mapa de Exposição, é possível ter uma idéia do risco (no sentido de prejuízo). É importante deixar claro que o tipo de prejuízo avaliado neste caso é definido pela dimensão do termo Exposição, ou seja, no caso deste trabalho é a densidade populacional [hab $\left./ \mathrm{m}^{2}\right]$.

Em resumo, a Vulnerabilidade, que é dada na faixa [0,1], multiplicada pela Exposição, é igual ao mapa de Risco, que identifica pontos que devem ter maiores prejuízos (neste caso pessoas atingidas) devido inundações.

\subsubsection{GERENCIAMENTO DE RISCO}

O índice de resiliência é composto da avaliação do risco e do gerenciamento de risco. Os três termos do risco - Ameaça, Vulnerabilidade e Exposição - foram definidos anteriormente, agora falta definir os aspectos relacionados ao gerenciamento de risco, definidos pelos termos Antes, Durante e Depois.

Comparado com a avaliação do risco, a análise do gerenciamento de risco parece ser mais subjetiva, pois trata de medidas administrativas e questões gerenciais. Outro ponto é que ferramentas administrativas estão sempre associadas a unidades administrativas, como 
comunidade, bairros, cidades. Medidas como alertas antecipados, estruturação de cadeia de resgate, preparação de equipes de socorro e mapas de ocupação são todas medidas tomadas de alguma forma localizada, em forma de contorno do município ou similares. Neste trabalho são adotados valores escalares representativos para toda a zona urbana de São Carlos avaliada, ou seja, é adotado um único valor para toda cidade, ao contrário dos termos utilizados na etapa de avaliação de risco.

A partir de uma compilação de diversas fontes, são apresentadas na Tabela 10 diversas medidas de gerenciamento de risco, agrupadas nas categorias Antes, Durante e Depois. O objetivo não é fazer uma avaliação muito sofisticada, portanto é atribuído o mesmo peso para cada medida de forma que a soma de todos os itens sob uma mesma categoria seja igual a um. Para cada medida implementada na política de gerenciamento de risco é somado o peso correspondente no termo correspondente.

Tabela 10 - Compilação de medidas de gerenciamento de Risco.

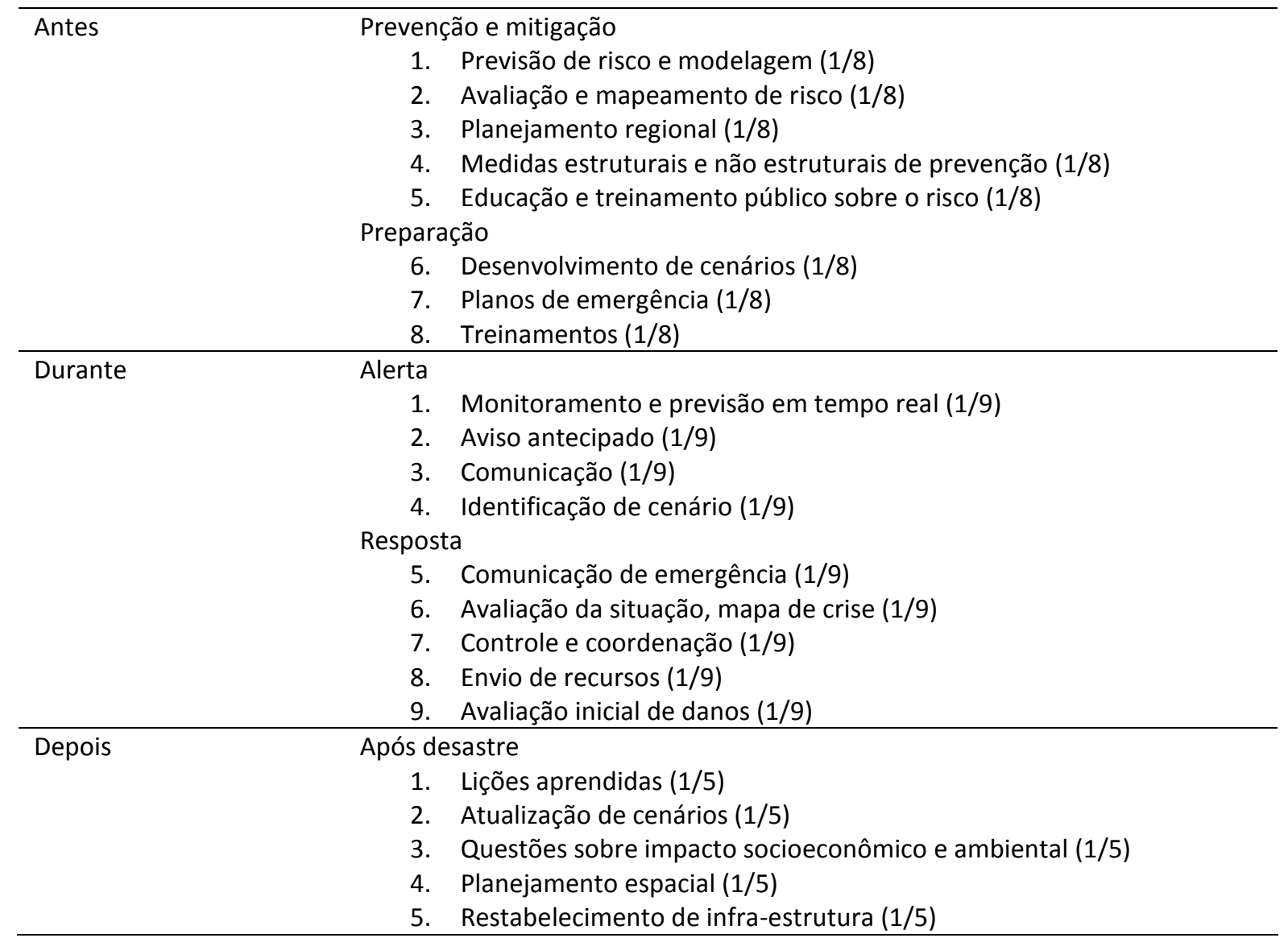

Um metodologia de avaliação de resiliência mais sofisticada pode ser encontrada em (UNISDR, 2012). 


\subsection{6 ÍNDICE DE RESILIÊNCIA}

A apresentação do índice de resiliência deve ser clara e objetiva, e apresentar os seis termos: Ameaça, Vulnerabilidade, Exposição, Antes, Durante e Depois. Foi optado por não aglomerar os seis termos na forma de um único índice de forma a evitar adicionar mais subjetividade e evitar questões como qual é a melhor forma de combinar os termos e como evitar perdas das informações.

São propostas duas formas de visualização do índice, Figura 18 e Figura 19. Todas as dimensões são apresentadas simultaneamente, sendo que na parte superior, na cor vermelha, é destacado o grupo de avaliação de risco, e na parte inferior, na cor verde, o grupo do gerenciamento do risco.

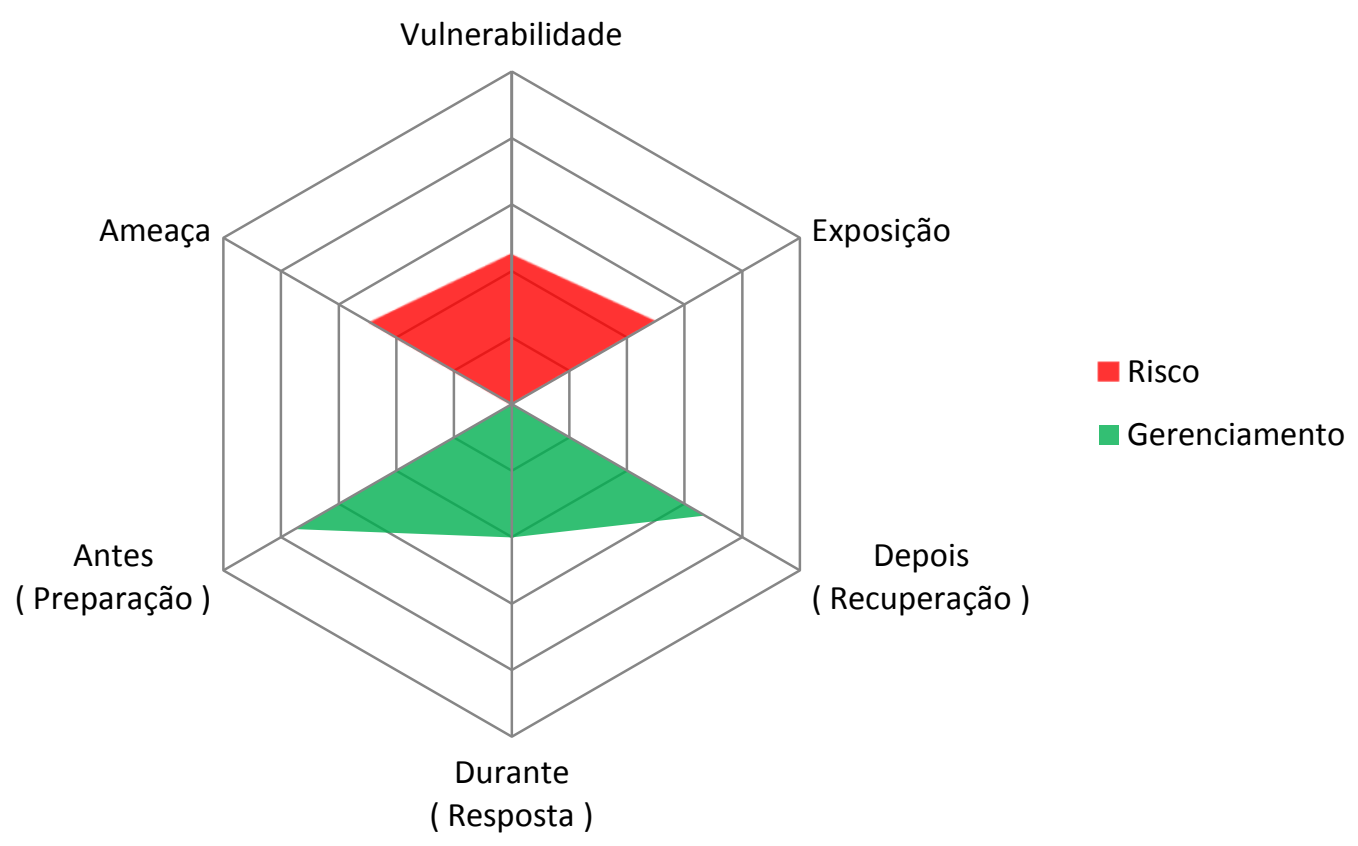

Figura 18 - Apresentação do índice de resiliência, opção A.

A diferença entre a forma de apresentação A e B é a divisão da figura ao meio com um eixo central, e que as áreas preenchidas em vermelho e verde iniciam a partir desde eixo e não somente entre os eixos das variáveis. A inclusão da divisão central, opção B, aumenta a sensibilidade visual da área preenchida, assim como utiliza melhor todo o espaço visual disponível. Por outro lado o eixo central desacoplado que qualquer termo original do índice parece trazer alguma dificuldade na compreensão do indicador para algumas pessoas. A informação transmitida nas duas opções é essencialmente a mesma, apesar de ainda existir 
dúvida sobre qual das duas opções seria mais fácil de compreender. Nesta dissertação foi optado por trabalhar com a opção B.

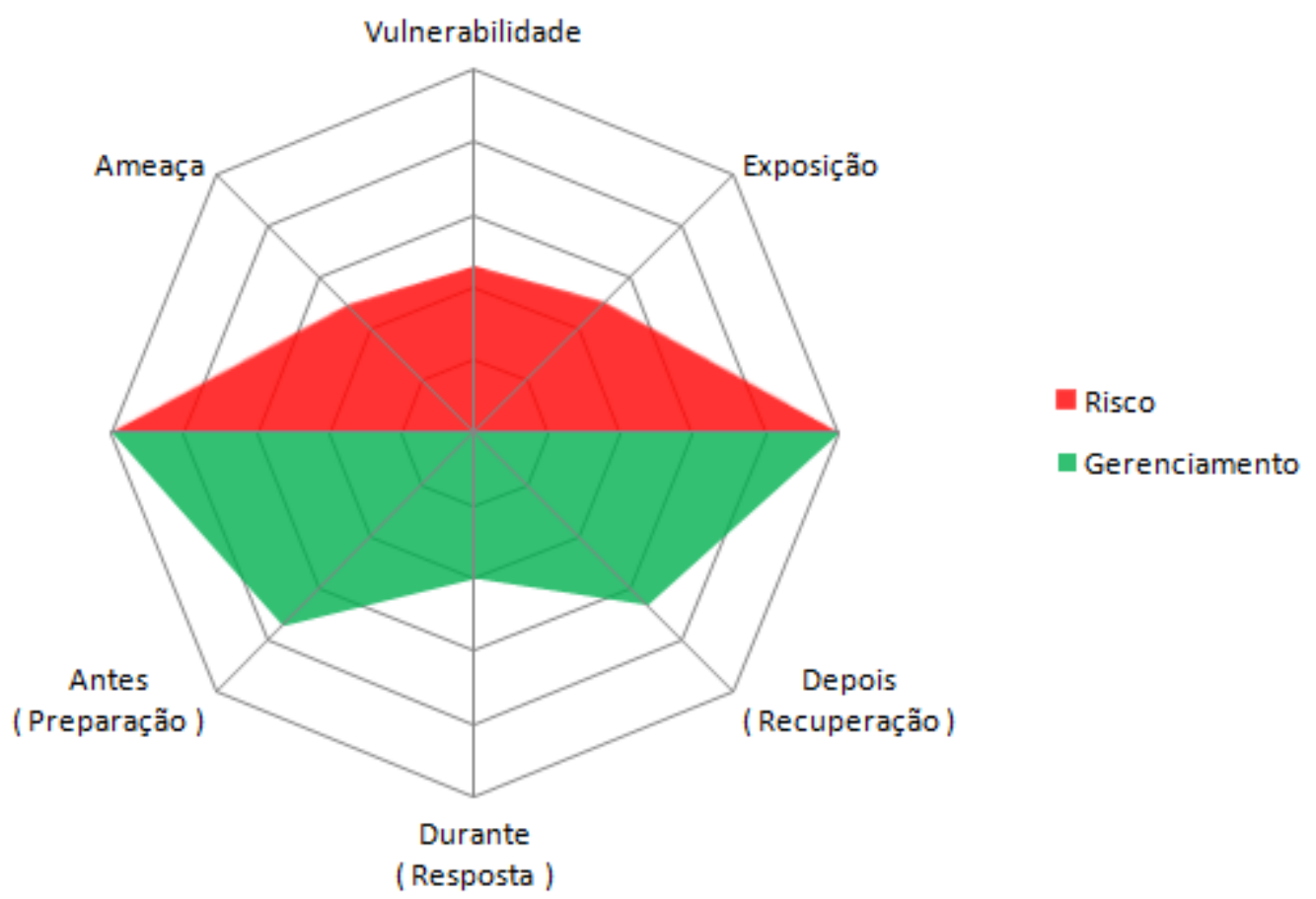

Figura 19 - Apresentação do índice de resiliência, opção B.

Todos os termos são normalizados entre [0,1]. Quando um termo é pequeno, ou inexistente, o valor é zero, e quando é máximo ou implantado o valor é um. Por exemplo: na avaliação de risco uma Ameaça muito alta tem valor um (1). No gerenciamento de risco, se não existe nenhuma medida adotada o valor é zero (0), e caso existam boas medidas implantadas o peso é próximo de um (1).

A figura permite uma avaliação rápida e intuitiva de três tipos de informações:

1. O tamanho de cada termo: Ameaça, Vulnerabilidade, Exposição, Antes, Durante e Depois.

2. Uma idéia qualitativa do risco através da área vermelha e uma idéia qualitativa da capacidade de gerenciamento de risco na área verde.

3. Comparação do risco e do gerenciamento de risco, por meio da razão da área geométrica entre as regiões vermelha e verde.

Embora não exista uma relação estabelecida entre a área geométrica de risco e gerenciamento, qualitativamente é possível observar qual é o "tamanho" do risco a ser 
enfrentado e se os aspectos gerenciais são do "tamanho" adequado. Risco pequeno exige gerenciamento de risco pequeno. Risco grande exige grandes medidas.

O índice de resiliência tem como base os valores de Ameaça, Vulnerabilidade e Exposição desenvolvidos na etapa de geração do mapa de Risco. Para gerenciamento de risco é adotado um único valor para toda a bacia urbana avaliada, admitindo que todas as medidas de gerenciamento de risco se aplicam igualmente por toda a bacia urbana.

O índice é gerado somente para alguns pontos de interesse: a rotatória do shopping (ou Cristo), Mercado Municipal, antigo Kartódromo, Terminal rodoviário e para um ponto pouco urbanizado no Monjolinho, chamado neste trabalho de Alto do Monjolinho. Os pontos são apresentados adiante na Figura 32.

\subsection{RESULTADOS E DISCUSSÕES}

\subsubsection{AMEAÇA}

Para realizar uma análise qualitativa da evolução do comportamento dos eventos extremos, foi construído um histograma dos valores do escoamento (RNOF).

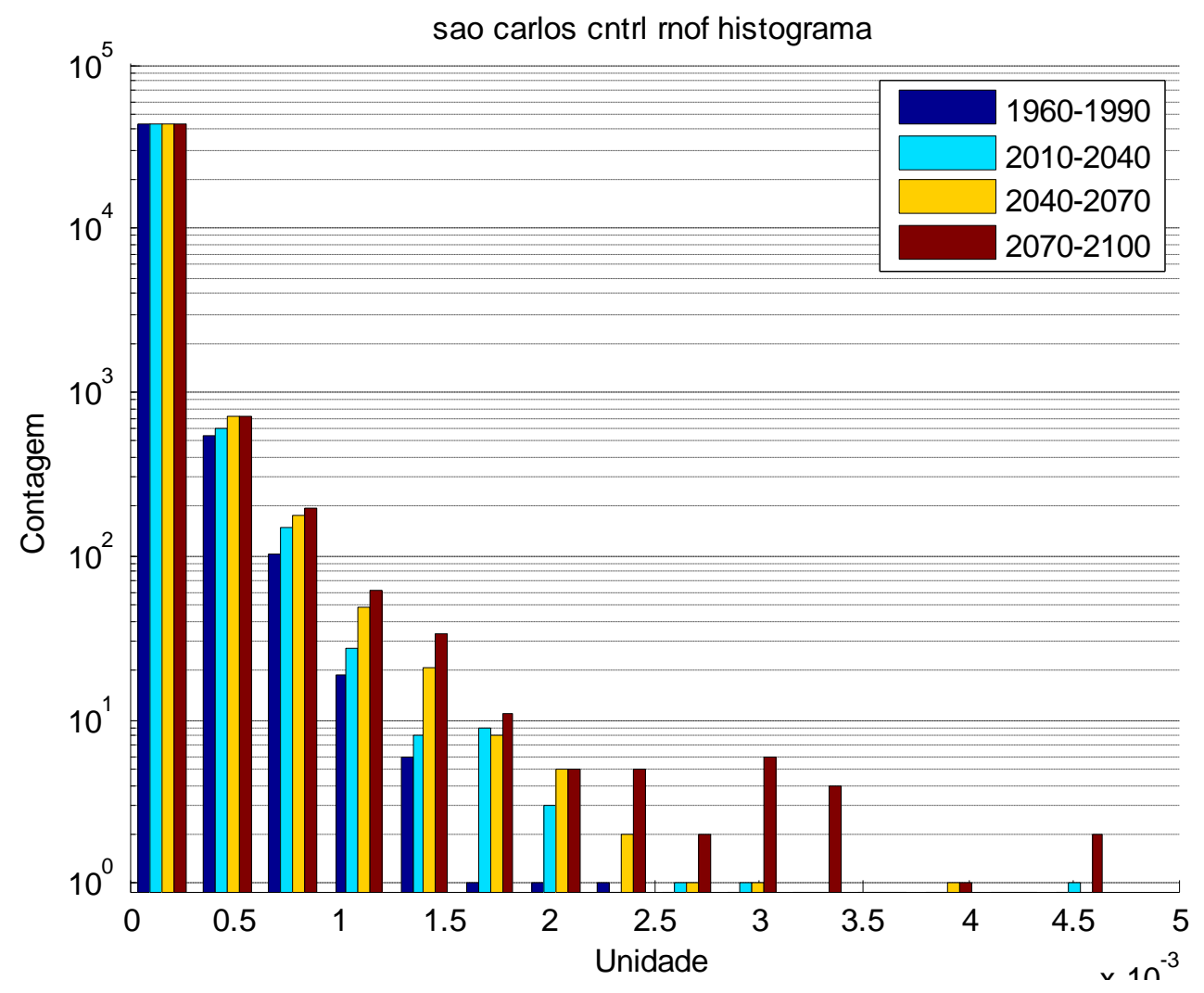

Figura 20 - Histograma de escoamento (RNOF) $[\mathrm{kg} / \mathrm{m} 2 / \mathrm{s}]$. 
A Figura 20 é o histograma do escoamento superficial, rodada de controle (CNTRL) separado nos período de 1970-1990, 2010-2040, 2040-2070 e 2070-2100. O histograma é apresentado com escala logarítmica para comportar a faixa dinâmica das contagens de eventos. O histograma mostra claramente um aumento no número de eventos extremos. $\mathrm{O}$ período de 2010-2040 tem um maior número de eventos extremos que o período de 19601990. O período de 2040-2070 apresenta mais eventos extremos que 2010. A freqüência e intensidade de eventos extremos parece aumentar de acordo com esta simulação.

Primeiramente foi calculado o valor do percentil $99 \%$ por década centrada no ano, calculada de ano em ano. Os 5 primeiros e últimos anos são inconsistentes pela falta de informação da série, portanto os valores nesses períodos são copiados do ano válido mais próximo. O resultado é apresentado na Figura 21. Nota-se que o valor do percentil aumenta e diminui sem um padrão claro e que seu valor médio parece aumentar ligeiramente no futuro.

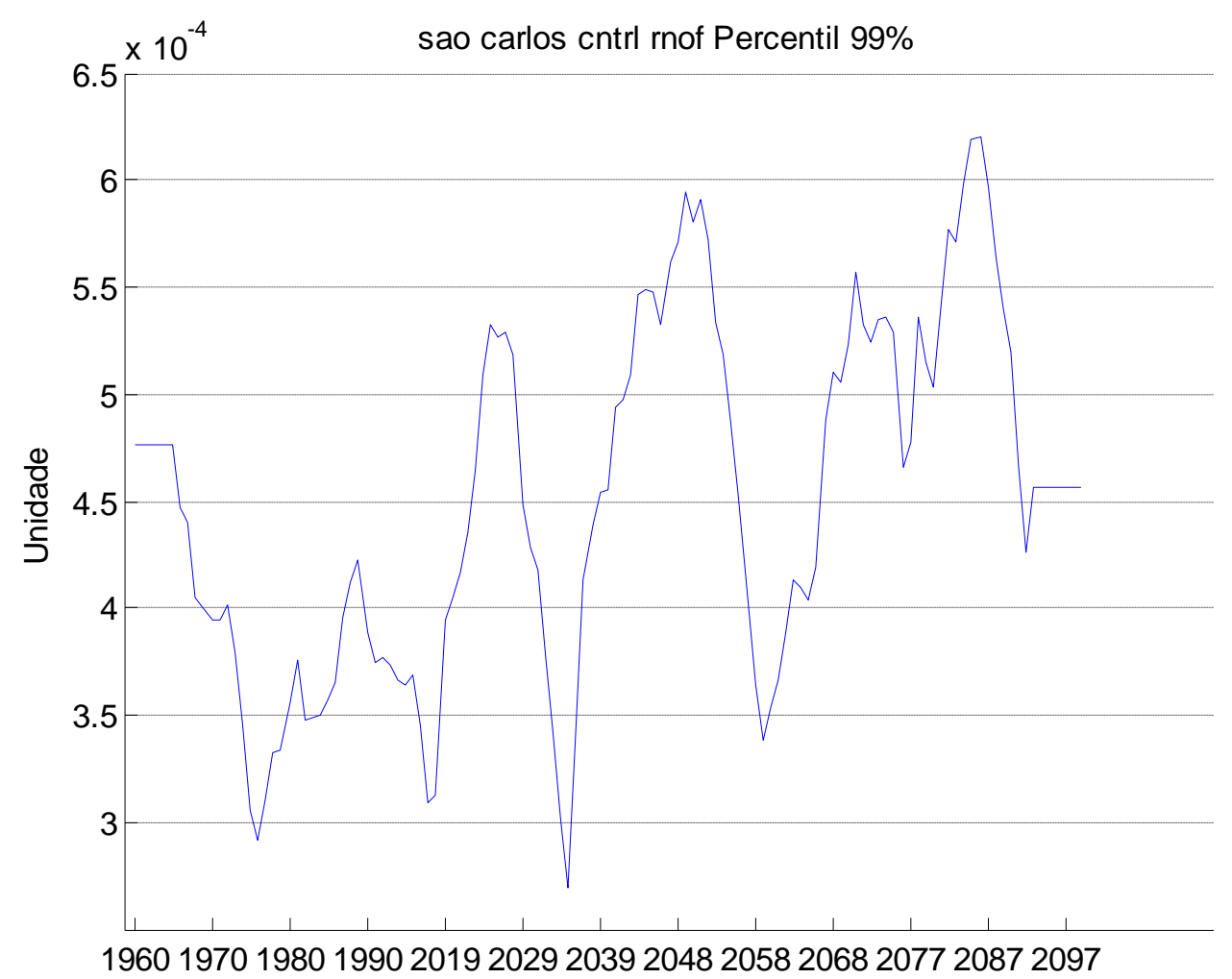

Figura 21 - Percentil 99\% do escoamento superficial (RNOF) [kg/m2/s].

O percentil $99 \%$ identifica qual é o escoamento para o qual $1 \%$ das ocorrências é maior, ou seja, é o menor valor dos $1 \%$ maiores eventos previstos. Assim é possível ter uma idéia da magnitude dos eventos extremos esperados. Foi observado que estes valores se alteram bastante com o valor do percentil e com o tamanho da janela de análise; inclusive a forma da curva é diferente com a variação desses parâmetros sugerindo que tal informação não é 
adequada ou robusta para uso em previsões. A partir da Figura 21: não é correto afirmar que no ano de 2058 os eventos extremos serão menores que no ano de 2087, o modelo e a metodologia de análise não parecem ser adequados para esse tipo de conclusão. Portanto optou-se por trabalhar somente com os períodos completos de simulação, tais como fornecidos pelo INPE, em quatro intervalos de 30 anos. A Tabela 11 apresenta o valor do percentil $99 \%$ para cada período.

Tabela 11 - Percentil do escoamento superficial, RNOF $\left[\mathrm{kg} / \mathrm{m}^{2} / \mathrm{s}\right]$.

\begin{tabular}{clllll}
\hline Rodada & Percentil & $\mathbf{1 9 6 0 - 1 9 9 0}$ & $\mathbf{2 0 1 0 - 2 0 4 0}$ & $\mathbf{2 0 4 0 - 2 0 7 0}$ & $\mathbf{2 0 7 0 - 2 1 0 0}$ \\
\hline CNTRL & $99 \%$ & 0,00038 & 0,00042 & 0,00048 & 0,00053 \\
\hline O modelo & não utilizou & informações & sobre urbanização para cálculo & do escoamento,
\end{tabular}

somente informações médias sobre o tipo de solo. É necessário corrigir estes valores para a região urbana onde a alteração da ocupação do solo altera os valores de escoamento superficial. Admitindo como valor inicial de CN=55 (GIUNTOLI, 2008) e utilizando a equação do SCS, pode-se estimar a precipitação efetiva, apresentada na Tabela 12.

Mas antes é necessário realizar uma conversão de unidades: enquanto os valores de escoamento superficiais são gerados em $\left[\mathrm{kg} / \mathrm{m}^{2} / \mathrm{s}\right]$, o modelo SCS requer $[\mathrm{mm}]$. Tal conversão é feita multiplicando o valor original por 21600. Este valor se deve ao fato dos dados do INPE serem apresentados para passos de 6 horas, equivalente a 21600 segundos, fator que converte a unidade do escoamento superficial para $[\mathrm{mm}]$.

Tabela 12 - Precipitação estimada $[\mathrm{mm}]$ - CN = 55 .

\begin{tabular}{llll}
\hline $\mathbf{1 9 6 0 - 1 9 9 0}$ & $\mathbf{2 0 1 0 - 2 0 4 0}$ & $\mathbf{2 0 4 0 - 2 0 7 0}$ & $\mathbf{2 0 7 0 - 2 1 0 0}$ \\
\hline 87,31 & 89,82 & 93,40 & 96,57 \\
\hline
\end{tabular}

Observa-se que a precipitação estimada para $\mathrm{CN}=55$ é próxima dos valores apresentados na tabela de chuvas históricas maiores que $70 \mathrm{~mm}$, Tabela 21 no Anexo A, sugerindo que a metodologia apresenta resultados razoáveis.

A partir da precipitação estimada é calculado o novo escoamento superficial, para diferentes valores de CN. É feita uma estimativa até uma redução para $15 \%$ do valor original da capacidade de armazenamento do solo (equivalente a $85 \%$ de impermeabilização, ou algo como $\mathrm{CN}=90$ ), Tabela 13. 
Tabela 13 - Escoamento superficial estimado [mm].

\begin{tabular}{lllll}
\hline$\% \mathbf{S}_{\mathbf{0}}$ & $\mathbf{1 9 6 0 - 1 9 9 0}$ & $\mathbf{2 0 1 0 - 2 0 4 0}$ & $\mathbf{2 0 4 0 - 2 0 7 0}$ & $\mathbf{2 0 7 0 - 2 1 0 0}$ \\
\hline 100 & 8,25 & 9,09 & 10,35 & 11,51 \\
85 & 11,82 & 12,85 & 14,37 & 15,77 \\
50 & 25,97 & 27,56 & 29,88 & 31,97 \\
15 & 58,56 & 60,88 & 64,20 & 67,16 \\
\hline
\end{tabular}

Posteriormente os valores são normalizados, onde o valor mínimo assume peso zero e o valor máximo assume peso um. Os demais valores são mapeados linearmente dentro da nova escala, Tabela 14.

Tabela 14 - Ameaça normalizada.

\begin{tabular}{lllll}
\hline$\% \mathbf{S}_{\mathbf{0}}$ & $\mathbf{1 9 6 0 - 1 9 9 0}$ & $\mathbf{2 0 1 0 - 2 0 4 0}$ & $\mathbf{2 0 4 0 - 2 0 7 0}$ & $\mathbf{2 0 7 0 - 2 1 0 0}$ \\
\hline 100 & 0,00 & 0,01 & 0,04 & 0,06 \\
85 & 0,06 & 0,08 & 0,10 & 0,13 \\
50 & 0,30 & 0,33 & 0,37 & 0,40 \\
15 & 0,85 & 0,89 & 0,95 & 1,00 \\
\hline
\end{tabular}

A Tabela 14 é apresentada em forma de gráfico na Figura 22. Um eixo do gráfico corresponde ao período de simulação: 1960-1990, 2010-2040, 2040-2070 e 2070-2100, enquanto o outro eixo corresponde ao nível de impermeabilização do solo, apresentado como a porcentagem do potencial de armazenamento inicial $S_{0}$. A figura mostra um leve crescimento da Ameaça com relação ao período de simulação, e um aumento muito acentuado no sentido do aumento da impermeabilização do solo.

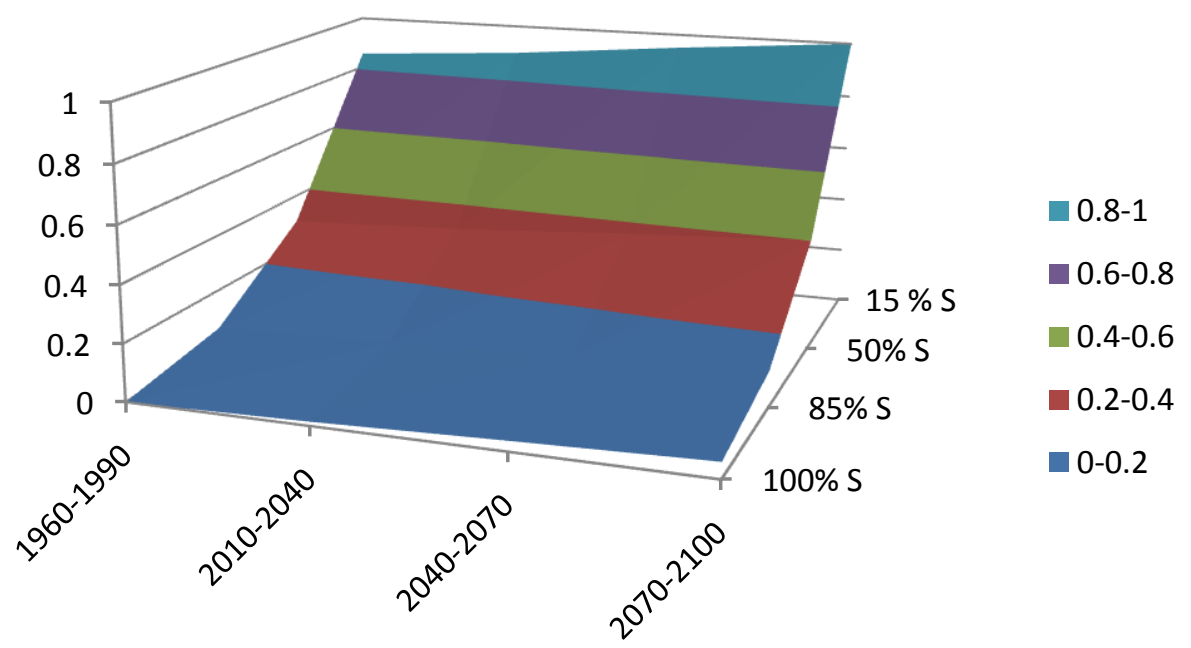

Figura 22 - Ameaça normalizada. 
Segundo a Figura 22, o aumento da Ameaça, ou escoamento superficial em pequenas bacias neste caso, deve-se principalmente a diminuição do potencial de armazenamento do solo, ou seja, a impermeabilização.

A partir destes resultados foram criadas sete hipóteses diferentes, Tabela 15, onde o valor da Ameaça é ajustado de acordo com a sub-bacia e ano avaliado. Segundo as hipóteses assumidas, a Ameaça era mínima (0) no passado, ano de 1960, e máxima (1) no futuro, ano de 2100. O ano de referência, que representa o presente, é o ano 2003, e tem os valores de Ameaça calculados a partir dos valores de $\mathrm{CN}$ apresentados anteriormente na Tabela 8. Para os demais os valores de Ameaça são interpolados. 
Tabela 15 - Ameaça das sub-bacias nos diferentes anos.

\begin{tabular}{|c|c|c|c|c|c|c|c|c|}
\hline Hipótese & Ano & $\begin{array}{l}\text { Período de } \\
\text { simulação }\end{array}$ & $\begin{array}{l}\text { Santa Maria } \\
\text { Madalena }\end{array}$ & Mineirinho & Tijuco-Preto & Gregório & Monjolinho & Comentário \\
\hline 1 & 1960 & $1960-1990$ & 0,00 & 0,00 & 0,00 & 0,00 & 0,00 & Passado - condição inicial \\
\hline 2 & 1975 & $1960-1990$ & 0,18 & 0,27 & 0,30 & 0,25 & 0,12 & \\
\hline 3 & 2003 & $2010-2040$ & 0,52 & 0,78 & 0,85 & 0,73 & 0,33 & $\begin{array}{l}\text { Presente - cenário de } \\
\text { referência }\end{array}$ \\
\hline 4 & 2025 & $2010-2040$ & 0,63 & 0,83 & 0,88 & 0,79 & 0,48 & \\
\hline 5 & 2055 & $2040-2070$ & 0,78 & 0,90 & 0,93 & 0,87 & 0,69 & \\
\hline 6 & 2085 & $2070-2100$ & 0,93 & 0,97 & 0,98 & 0,96 & 0,90 & \\
\hline 7 & 2100 & $2070-2100$ & 1,00 & 1,00 & 1,00 & 1,00 & 1,00 & $\begin{array}{l}\text { Futuro - densamente } \\
\text { urbanizado }\end{array}$ \\
\hline
\end{tabular}


Para cada ano avaliado é gerado um mapa de Ameaça correspondente onde cada pixel assume o peso da Ameaça, como na Figura 23, que posteriormente é utilizado como dado de entrada para cálculo da Vulnerabilidade.

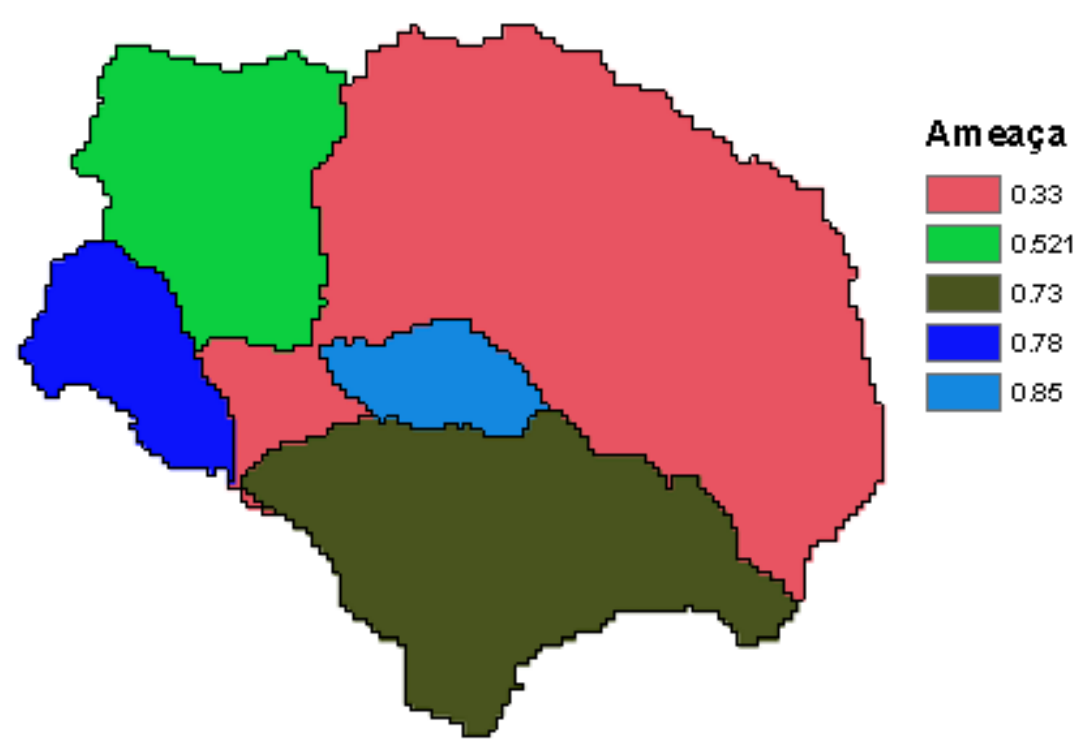

Figura 23 - Mapa de Ameaça para o presente - ano 2003.

\subsubsection{VULNERABILIDADE}

O mapa de Vulnerabilidade tem como base a topografia e cálculo do fluxo acumulado, realizado com ajuda do software Arcgis. A resolução do mapa é limitada pela resolução do modelo digital de elevação, neste caso 90 metros.

A Figura 24 é o mapa de fluxo acumulado, que representa qual é a área drenada por cada ponto. O mapa é gerado em nível de pixel, ou células. Para saber a área drenada aproximada basta multiplicar o valor da célula pela área de cada célula, aproximadamente 90 x $90=8100$ $\mathrm{m}^{2}$. A área drenada no exutório da bacia é de 9254 x $8100 \sim 75 \mathrm{~km}^{2}$, que corresponde à área total da bacia urbana avaliada. 


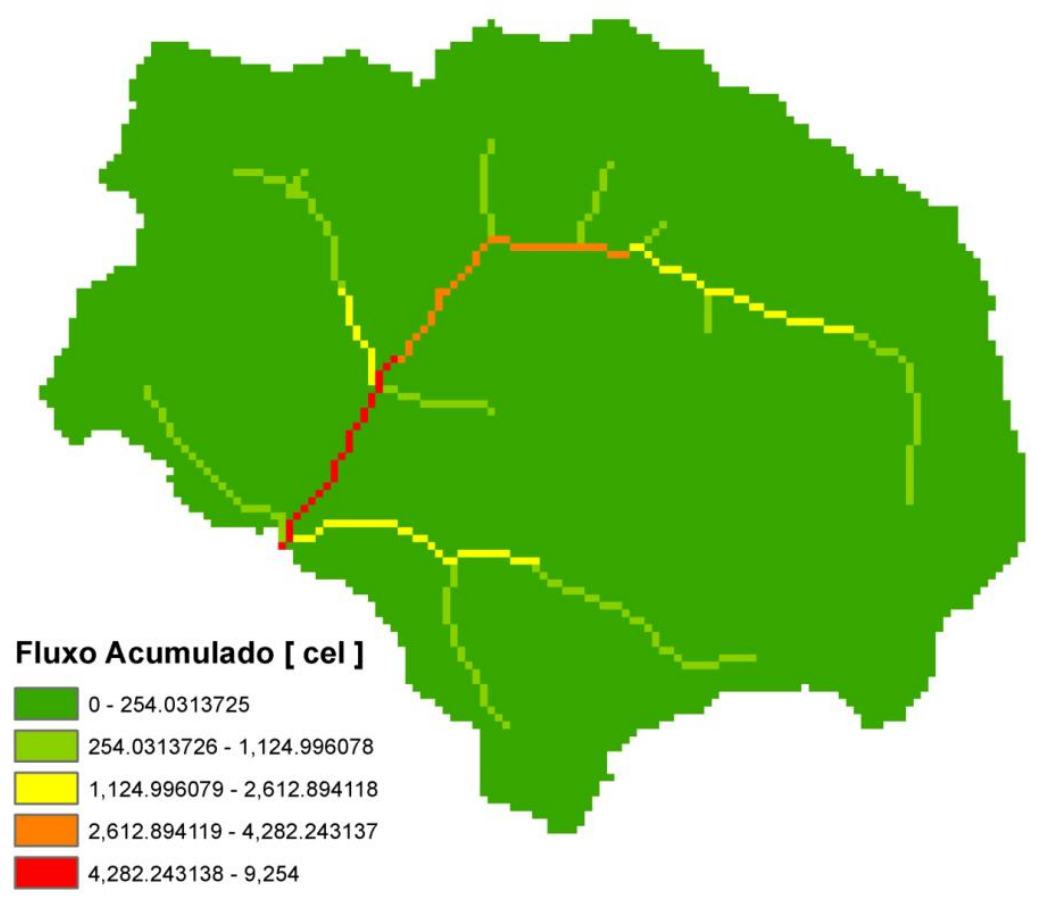

Figura 24 - Fluxo de água acumulado em células.

Para cada uma das sete hipóteses ou anos avaliados é gerado um mapa de fluxo acumulado. O modelo digital de elevação utilizado nos diferentes anos é o mesmo, mas o peso de contribuição de cada célula é alterado pelo mapa de Ameaça definido para cada ano.

Em seguida o mapa de fluxo acumulado sofre uma filtragem espacial com o objetivo de simular a influência que um ponto exerce sobre os vizinhos. O filtro utilizado é da forma gaussiana e a operação é realizada no software Matlab. A grade do filtro é 20 células, com sigma igual 2. 


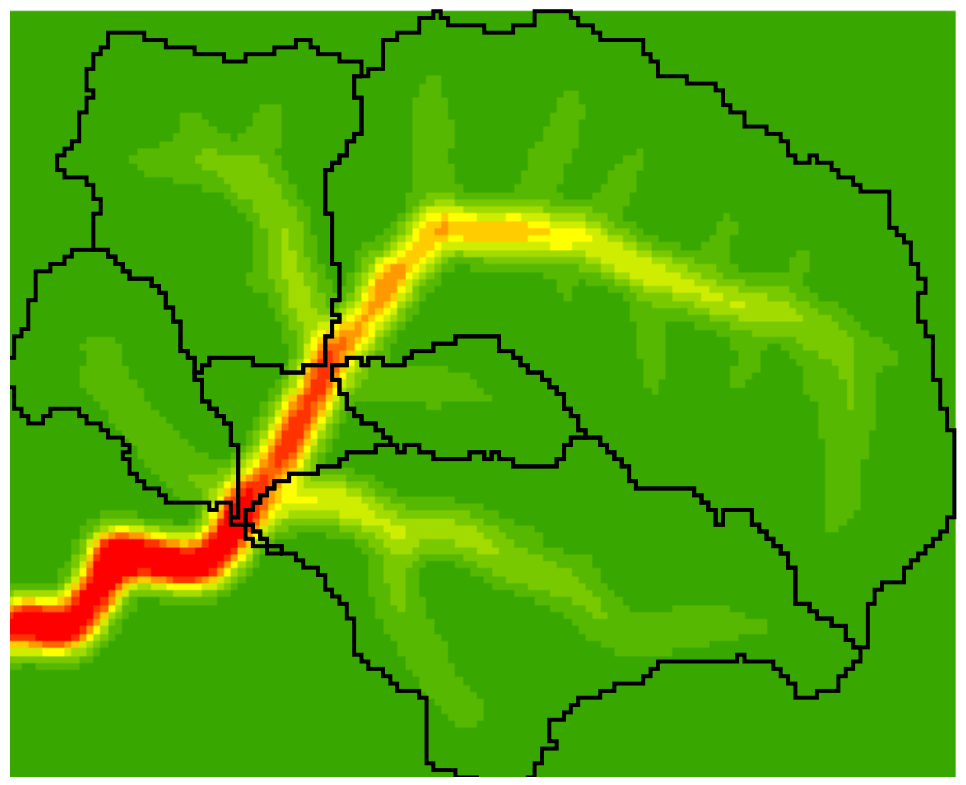

Figura 25 - Mapa de fluxo acumulado após filtro espacial gaussiano.

A próxima etapa é a normalização do mapa. A classificação é através do método de Natural Breaks e foi realizada no mapa de Vulnerabilidade correspondente ao ano 2100. A equação (9) foi utilizada na classificação e normalização dos mapas de vulnerabilidade.

$$
I=\left\{\begin{array}{c}
0 \text { se } x<26,87 \\
0,1 \text { se } 26,87 \leq x<93,10 \\
0,2 \text { se } 93,10 \leq x<192,44 \\
0,3 \text { se } 192,44 \leq x<305,03 \\
0,4 \text { se } 305,03 \leq x<430,86 \\
0,5 \text { se } 430,86 \leq x<563,32 \\
0,6 \text { se } 563,32 \leq x<689,15 \\
0,7 \text { se } 689,15 \leq x<834,85 \\
0,8 \text { se } 834,85 \leq x<987,18 \\
0,9 \text { se } 987,18 \leq x<1218,98 \\
1 \text { se } 1218,98 \leq x
\end{array}\right\}
$$

Ao todo foram gerados sete mapas de Vulnerabilidade, onde foi alterado o valor de Ameaça para cada ponto de acordo com os anos. Em resumo o ano de 1960 representa uma situação de ameaça zero para toda a área analisada, enquanto o ano de 2100 assume a hipótese onde toda a bacia assume o valor de Ameaça máxima de um. Os demais anos utilizam valores intermediários de Ameaça, Tabela 15. 


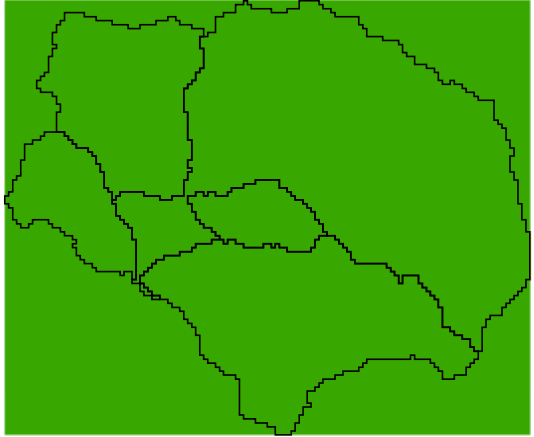

1960

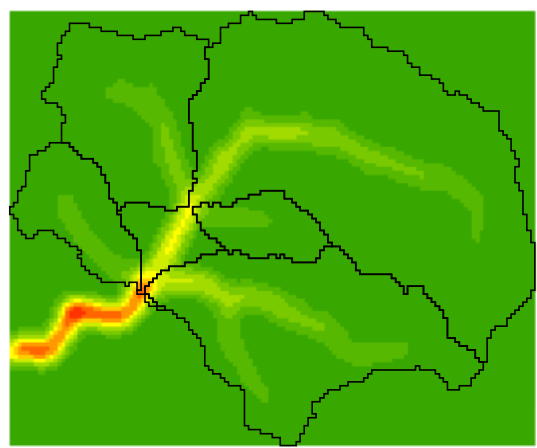

2003

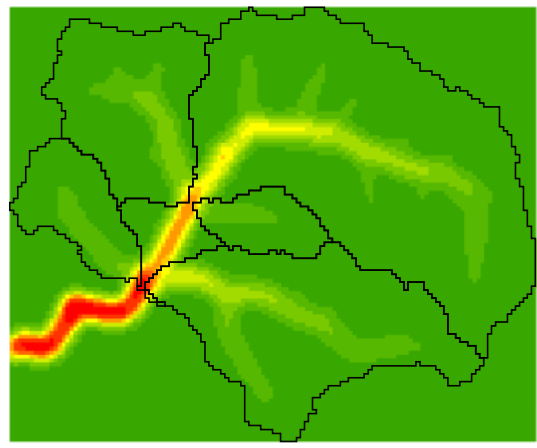

2055

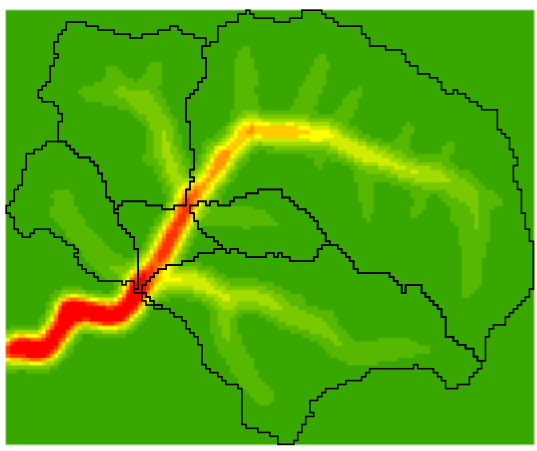

2100

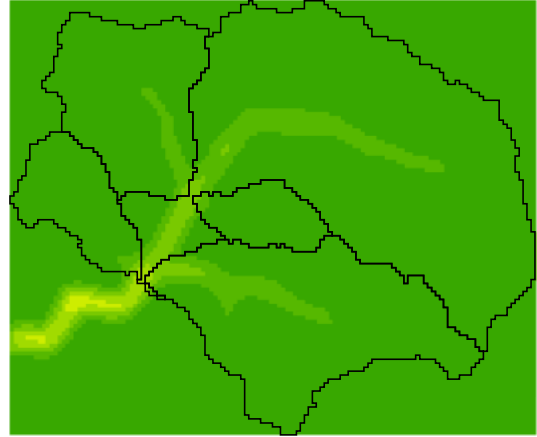

1975

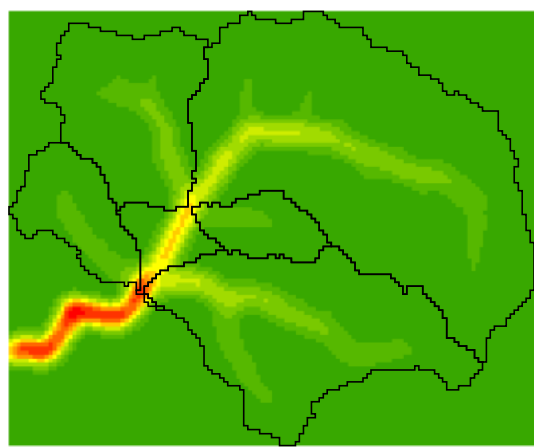

2025

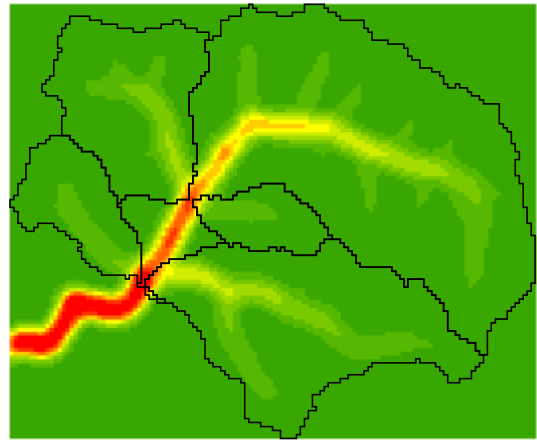

2085

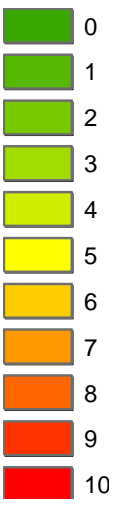

Figura 26 - Vulnerabilidade para todos os anos avaliados.

Os mapas de Vulnerabilidade são apresentados na Figura 26. Na legenda o valor 10 equivale a probabilidade 1 ou $100 \%$. O primeiro mapa, que representa algo como uma época 
anterior a urbanização, tem valores de Vulnerabilidade muito baixos. Por outro lado o último mapa, pior caso, onde é considerado aumento da precipitação devido mudança climática e alto valor de impermeabilização do solo, apresenta regiões com alta probabilidade de inundação. Os pontos mais vulneráveis são também os mais próximos aos rios da região, apesar da metodologia de cálculo não ter nenhum tipo de informação da presença dos rios.

Para efeito de verificação, na Figura 27 temos o mapa de Vulnerabilidade para o presente (2003) e futuro (2100), junto com os pontos de inundação (em azul) conhecidos na data presente, apresentados anteriormente na Figura 14.

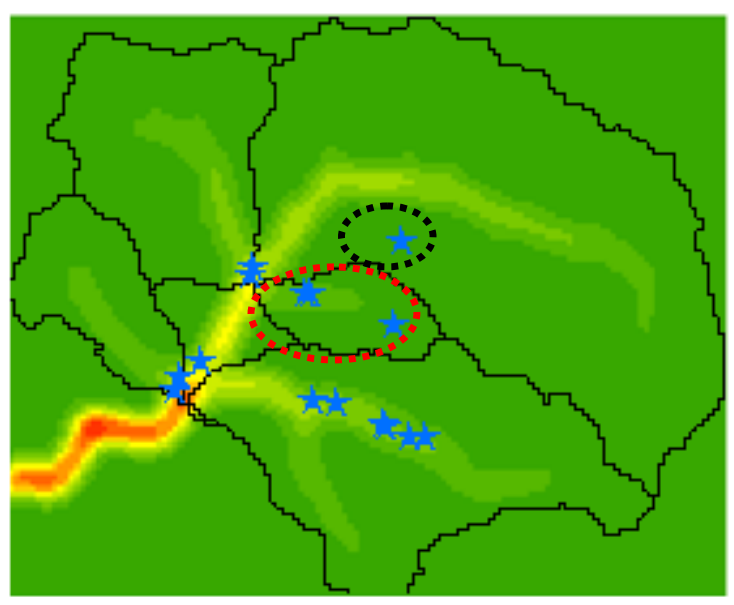

2003

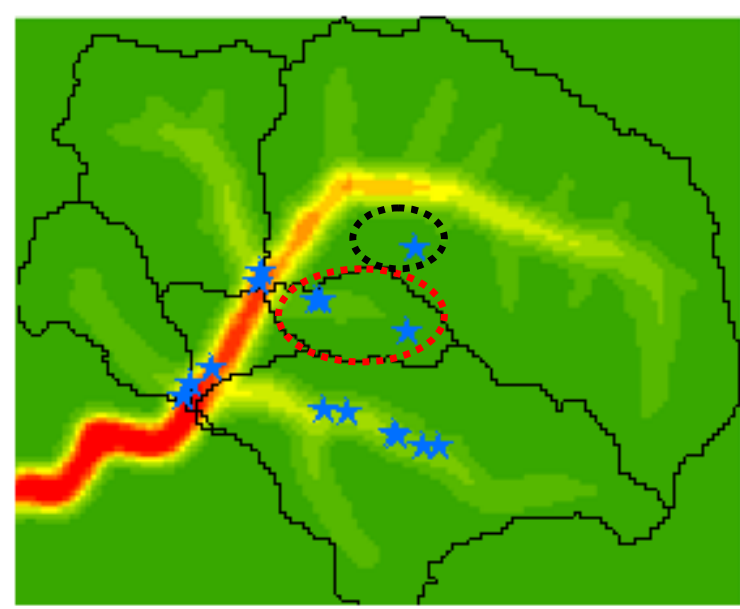

2100

Figura 27 - Mapa de Vulnerabilidade e pontos conhecidos de inundação.

Existe razoável coerência entre os pontos de inundação e o mapa de Vulnerabilidade. Apesar disso a Vulnerabilidade na sub-bacia do Tijuco Preto parece subestimada (destacada com linha tracejada e vermelha). Mesmo para a hipótese do ano de 2100 a Vulnerabilidade na sub-bacia de Tijuco Preto continua subestimada.

O ponto de inundação mais acima (destacado com linha tracejada preta) trata de um ponto de alagamento sob um viaduto. Esta metodologia não deve ter sucesso na identificação de pontos de alagamento pequenos. Um dos fatores é que a resolução do modelo digital de elevação utilizado é da ordem de grandeza do viaduto, 90 m, o que impede sua representação de forma adequada, além de outros fatores que envolvem o algoritmo de cálculo do escoamento acumulado. 


\subsubsection{EXPOSIÇÃO}

O mapa de densidade populacional para zona urbana de São Carlos é apresentado na Figura 28. O mapa foi gerado a partir dos dados obtidos do CENSO 2010, com software Arcgis.

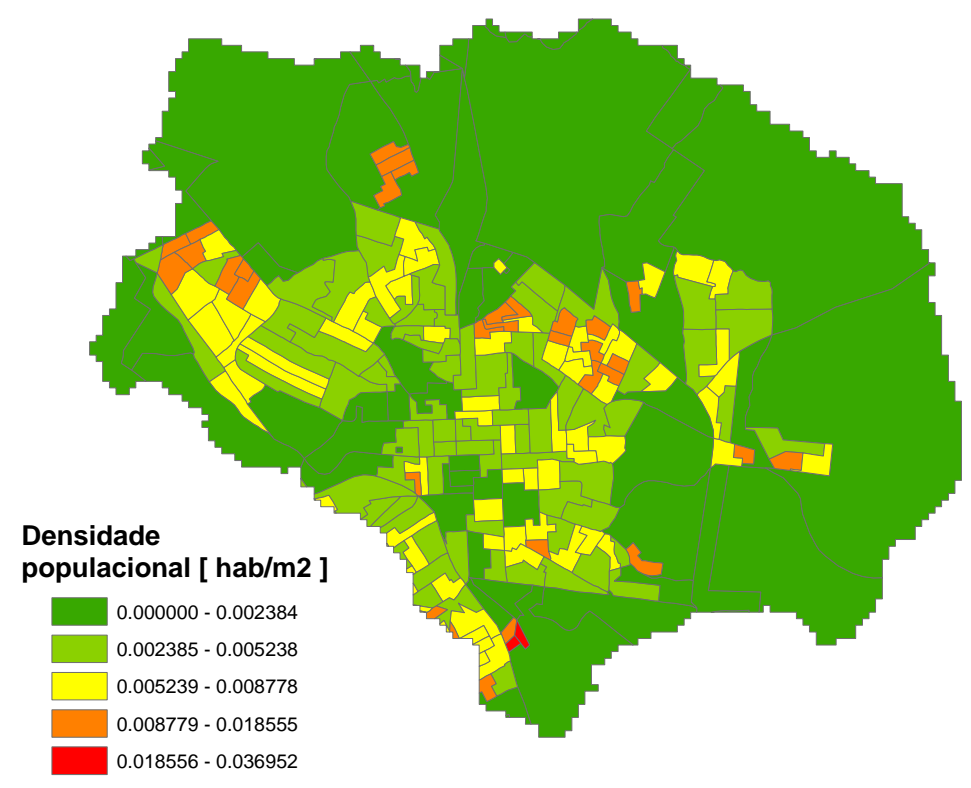

Figura 28 - Mapa de densidade populacional [hab/m2].

O mapa de densidade populacional é normalização através de categorias de acordo com a equação (10), onde as categorias equivalem aos percentis 15, 25, 65, 85 e 95\% do universo analisado.

$$
I=\left\{\begin{array}{c}
0 \text { se } x<0,0015 \\
0,2 \text { se } 0,0015 \leq x<0,0026 \\
0,4 \text { se } 0.0026 \leq x<0,0060 \\
0,6 \text { se } 0,0060 \leq x<0,0087 \\
0,8 \text { se } 0,0087 \leq x<0,0109 \\
1 \text { se } 0,0109 \leq x
\end{array}\right\}
$$

Após a classificação é criado o mapa de Exposição, Figura 29. 


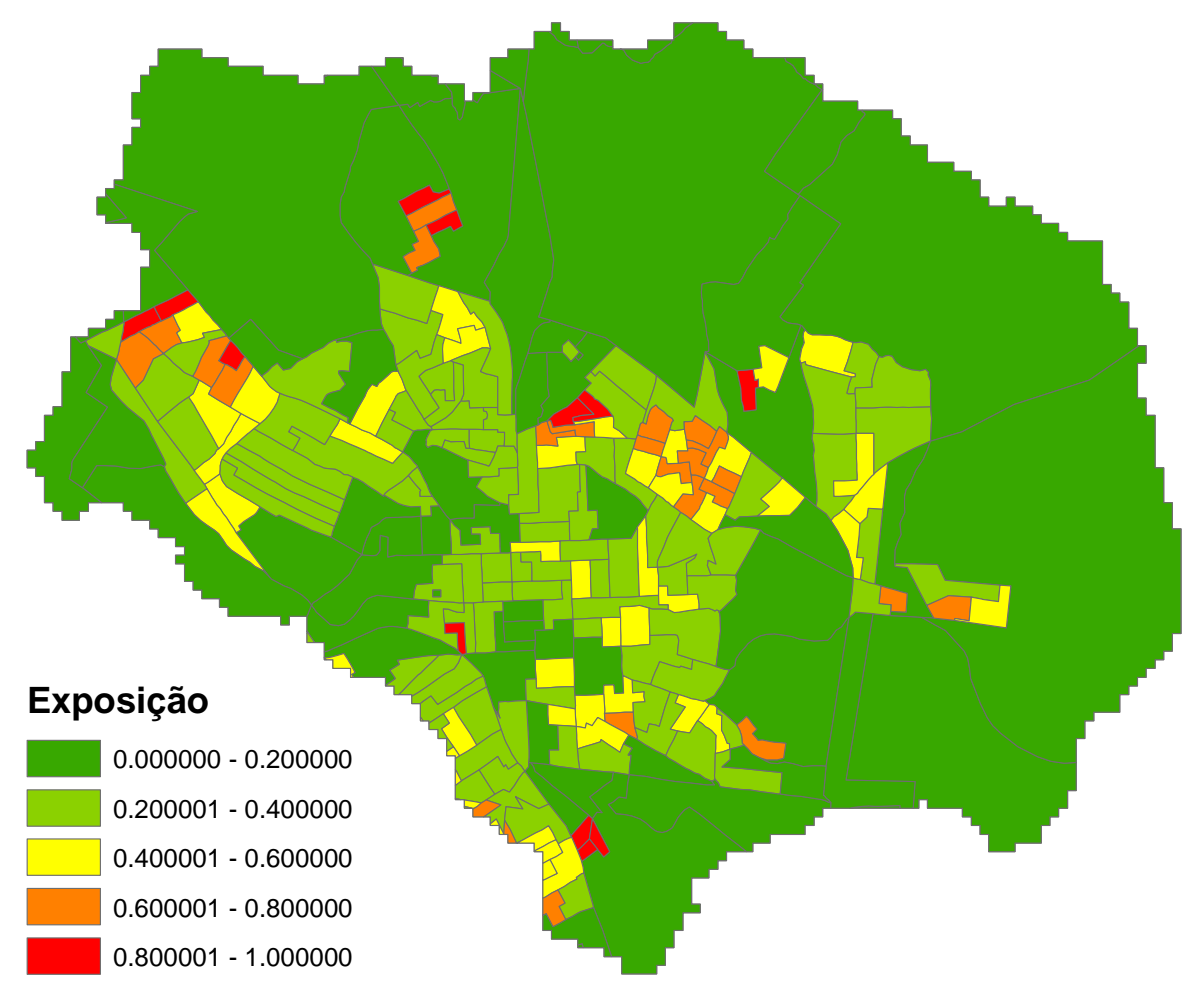

Figura 29 - Mapa de Exposição.

São Carlos ainda possui poucas regiões com alta densidade populacional e muitos espaços para expansão. É interessante notar que boa parte da bacia ainda não urbanizada contribui para a área de drenagem, evidenciando que no caso da impermeabilização do restante da bacia os eventos de inundação no exutório devem se agravar.

\subsubsection{MAPA DE RISCO \{AMEAÇA, VULNERABILIDADE, EXPOSIÇÃO\}}

A partir dos termos de Ameaça, Vulnerabilidade e Exposição é possível gerar um mapa qualitativo apontando as regiões com maior potencial de perdas devido inundação. O mapa de Risco é obtido multiplicando o mapa de Vulnerabilidade pelo mapa de Exposição, ponto a ponto. O termo Ameaça já esta embutido dentro do mapa de Vulnerabilidade, portanto não é utilizado explicitamente no cálculo do risco.

Diferente do mapa de Vulnerabilidade, que apresenta os pontos com maior probabilidade de inundação, ou o mapa de Exposição, que mostra os pontos com maior população, o mapa de risco mostra os pontos onde o produto da probabilidade de inundação e densidade populacional é maior. Isto é interessante, pois separa as áreas com grande probabilidade de 
inundação, mas sem nenhuma perda, das áreas que realmente podem apresentar perdas devido a inundação, mesmo que a probabilidade seja baixa.

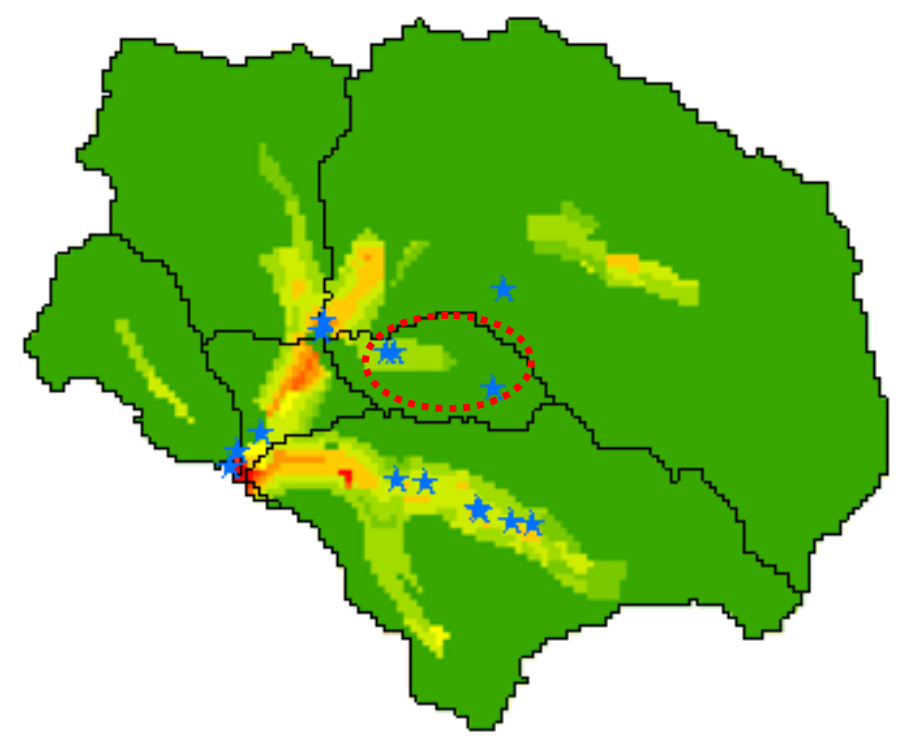

\section{Risco normalizado}

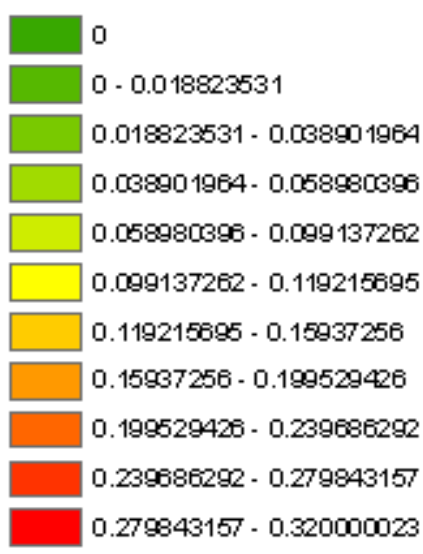

Figura 30 - Mapa de risco para o presente - ano 2003 - e pontos conhecidos de inundação.

A Figura 30 é o mapa de risco para o presente, ano 2003, com o mapa de Exposição referente ao ano de 2010. No mapa estão também os pontos conhecidos por sofrerem inundação periodicamente (marcas azuis). Diferente do mapa de Vulnerabilidade que acompanhava os vales e rios, os pontos com maiores perdas devido inundação se concentram nas regiões com maior densidade populacional e próximo dos rios. 

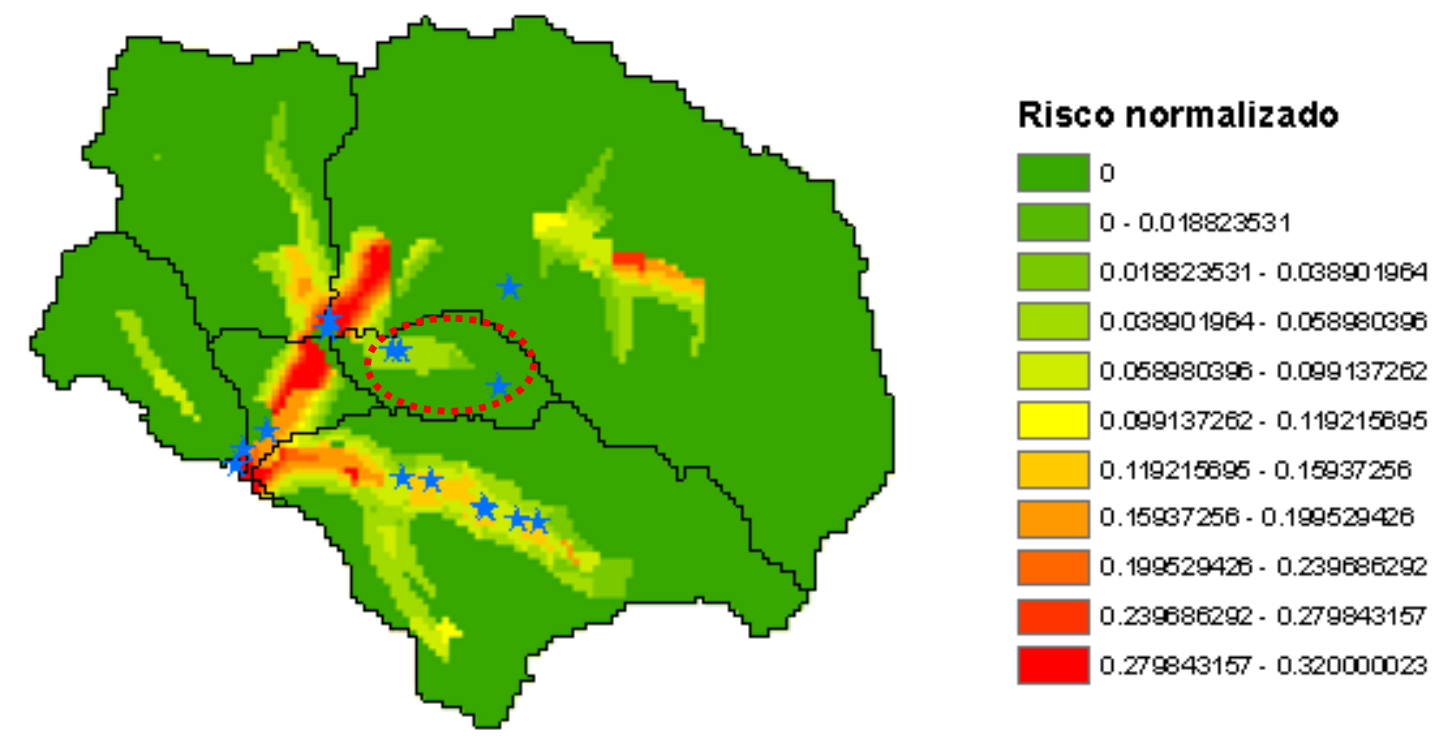

Figura 31 - Mapa de risco para futuro - ano 2100 - e pontos conhecidos de inundação.

A Figura 31 é o mapa de risco para o futuro, ano 2100, mas ainda utilizando o mapa de Exposição para 2010. No mapa fica claro que os pontos atuais de inundação permanecem com valores de risco quase estáveis, mas o risco em outros pontos aumenta consideravelmente. A região do Kartódromo tem o risco aumentado. Estas são áreas que tem grande potencial de perdas por inundação no futuro.

\subsubsection{GERENCIAMENTO DE RISCO \{ANTES, DURANTE, DEPOIS\}}

Para as sete anos avaliados foram criadas hipóteses quanto às medidas de Gerenciamento de Risco. Como o paradigma de gerenciamento de risco é uma tendência recente, é suposto que no passado existia pouca ou nenhuma preocupação com os aspectos resilientes de combate a inundação, e que o número de medidas resilientes deve aumentar no futuro. A Tabela 16 apresenta as medidas de combate aos danos e conseqüências de inundações de acordo com as hipóteses para cada ano. 
Tabela 16 - Hipóteses de medidas de Gerenciamento de Risco.

\begin{tabular}{|c|c|c|c|}
\hline $\begin{array}{l}\text { Ano } \\
\text { Base }\end{array}$ & Antes & Durante & Depois \\
\hline 1960 & Nenhuma & Nenhuma & Nenhuma \\
\hline 1975 & Nenhuma & Nenhuma & Nenhuma \\
\hline 2003 & - $\quad$ Medidas estruturais & - $\quad$ Comunicação de emergência & Nenhuma \\
\hline 2025 & $\begin{array}{ll}\text { - } & \text { Medidas estruturais e não } \\
\text { - } & \text { estruturais } \\
& \text { Previsão de risco e } \\
\text { - } & \text { Avaliação e mapeamento de } \\
\text { risco } \\
\text { - }\end{array}$ & $\begin{array}{l}\text { - } \quad \text { Comunicação de emergência } \\
\text { - } \quad \text { Controle e coordenação } \\
\text { - } \quad \text { Monitoramento e previsão em } \\
\text { tempo real }\end{array}$ & $\begin{array}{ll}\text { - } & \text { Lições aprendidas } \\
\text { - } & \text { Atualização de cenários }\end{array}$ \\
\hline 2055 & 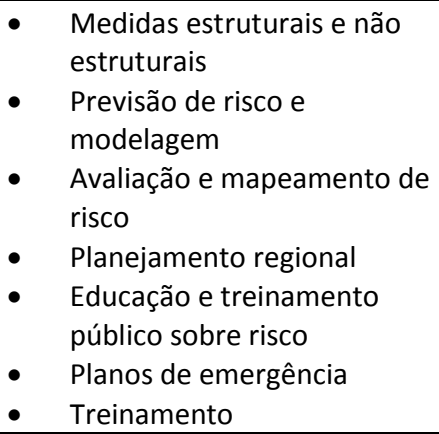 & $\begin{array}{ll}\text { - } & \text { Comunicação de emergência } \\
\text { - } & \text { Controle e coordenação } \\
\text { - } & \text { Monitoramento e previsão em } \\
\text { - } & \text { tempo real } \\
\text { - } & \text { Comiso antecipado } \\
& \text { Comicação }\end{array}$ & $\begin{array}{ll}\text { - } & \text { Lições aprendidas } \\
\text { - } & \text { Atualização de cenários } \\
\text { - } & \text { Questões sobre impacto } \\
\text { socioeconômico e } \\
\text { ambiental }\end{array}$ \\
\hline 2085 & 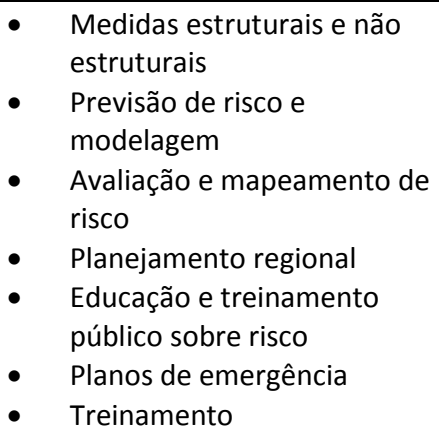 & $\begin{array}{ll}\text { - } & \text { Comunicação de emergência } \\
\text { - } & \text { Controle e coordenação } \\
\text { - } & \text { Monitoramento e previsão em } \\
\text { - } & \text { Aviso antecipado } \\
\text { - } & \text { Comunicação } \\
\text { - } & \text { Identificação de cenário }\end{array}$ & $\begin{array}{ll}\text { - } & \text { Lições aprendidas } \\
\text { - } & \text { Atualização de cenários } \\
\text { Questões sobre impacto } \\
\text { socioeconômico e } \\
\text { - } \quad \text { Planbiental } \\
\text { - } \\
\text { Restabelecimento de infra- } \\
\text { estrutura }\end{array}$ \\
\hline 2100 & 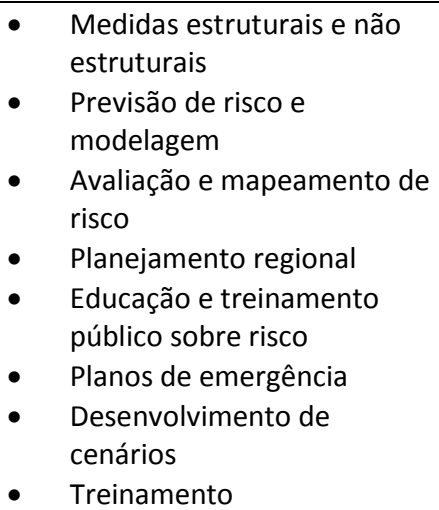 & $\begin{array}{ll}\text { - } & \text { Comunicação de emergência } \\
\text { - } & \text { Controle e coordenação } \\
\text { - } & \text { Monitoramento e previsão em } \\
\text { - } & \text { tempo real } \\
\text { - } & \text { Comunico antecipado } \\
\text { - } & \text { Identificação de cenário } \\
\text { - } & \text { Envio de recursos } \\
\text { - } & \text { Avaliação inicial de danos }\end{array}$ & $\begin{array}{ll}\text { - } & \text { Lições aprendidas } \\
\text { - } & \text { Atualização de cenários } \\
\text { Questões sobre impacto } \\
\text { socioeconômico e } \\
\text { - } \\
\text { - } \\
\text { Planbiental } \\
\text { Restabelecimento de infra- } \\
\text { estrutura }\end{array}$ \\
\hline
\end{tabular}

A soma dos pesos de cada cenário é resumida na tabela abaixo. Estes são os valores adotados no Gerenciamento de Risco. O universo de medidas de gerenciamento do risco utilizado é apresentado anteriormente na tabela Tabela 10. 
Tabela 17 - Tabela com resumo de indicadores de Gerenciamento de Risco.

\begin{tabular}{llll}
\hline Ano Base & Antes & Durante & Depois \\
\hline 1960 & 0,00 & 0,00 & 0,00 \\
1975 & 0,00 & 0,00 & 0,00 \\
2003 & $1 / 8=0,13$ & $1 / 9=0,11$ & 0,00 \\
2025 & $5 / 8=0,63$ & $3 / 9=0,33$ & $2 / 5=0,40$ \\
2055 & $7 / 8=0,88$ & $5 / 9=0,56$ & $3 / 5=0,60$ \\
2085 & $7 / 8=0,88$ & $6 / 9=0,67$ & $5 / 5=1,00$ \\
2100 & $8 / 8=1,00$ & $8 / 9=0,89$ & $5 / 5=1,00$ \\
\hline
\end{tabular}

\subsubsection{INDICE DE RESILIÊNCIA}

Os pontos escolhidos para avaliação do índice de resiliência foram: rotatória do shopping (ou Cristo), Kartódromo, Mercado Municipal, estação rodoviária e Alto do Monjolinho. Entre estes pontos é reconhecido que o Cristo, mercado municipal e o Kartódromo são pontos que sofrem inundação freqüentemente. No ponto próximo a Rodoviária inundações não são comum, embora tenham ocorrido um evento em outubro de 2013. Não são conhecidos eventos de inundação no Alto do Monjolinho até a data atual, seja pela ausência ou por falta de documentação dos mesmos.

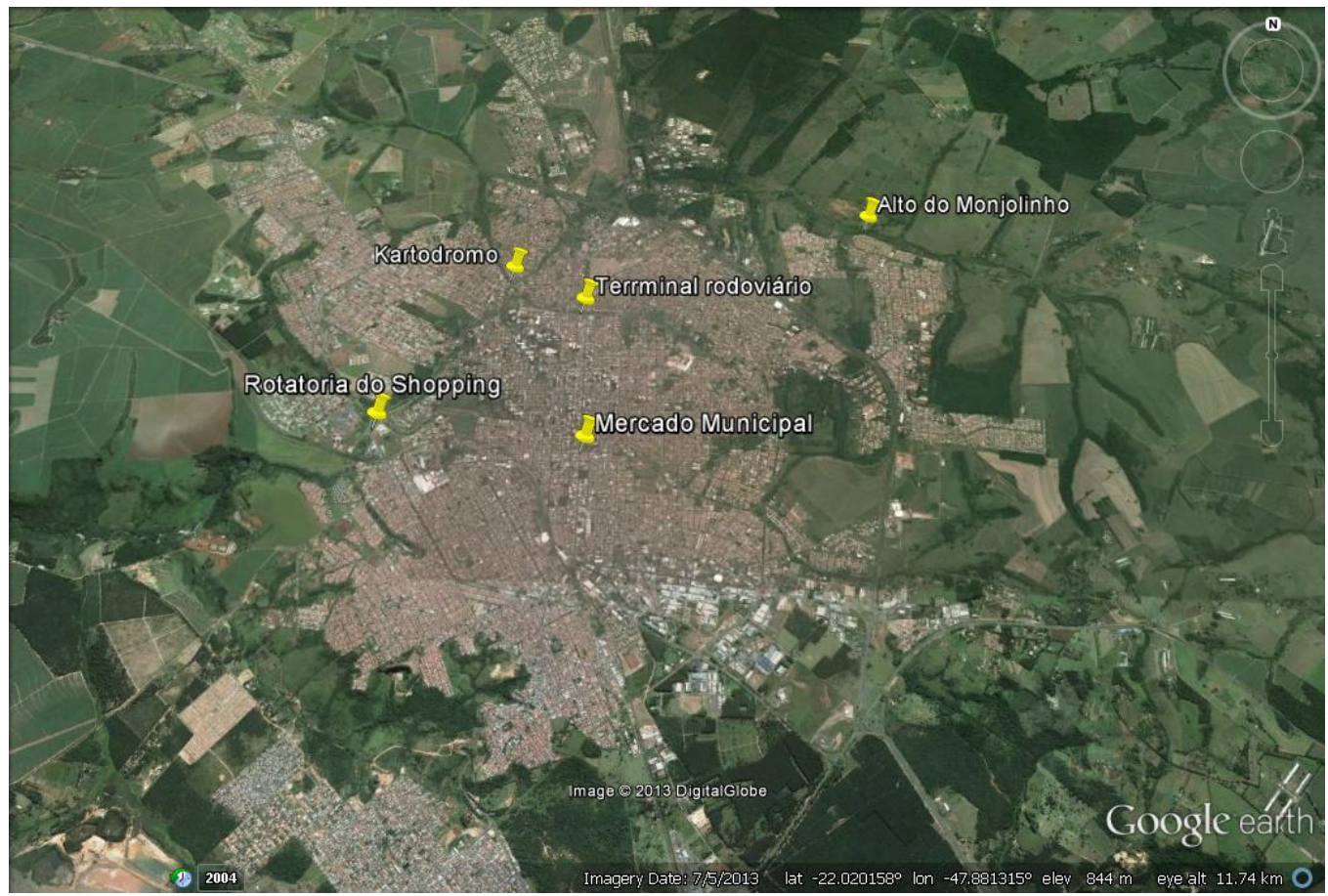

Figura 32 - Pontos de interesse para índice de resiliência.

Na Figura 32 são apresentados os pontos de interesse sobre uma imagem de satélite da zona urbana de São Carlos, e na Figura 33 estão os mesmos pontos sobre o mapa de Risco 
gerado anteriormente. Todos os pontos encontram-se na região urbana, com exceção do Alto do Monjolinho que está em uma área pouco urbanizada.

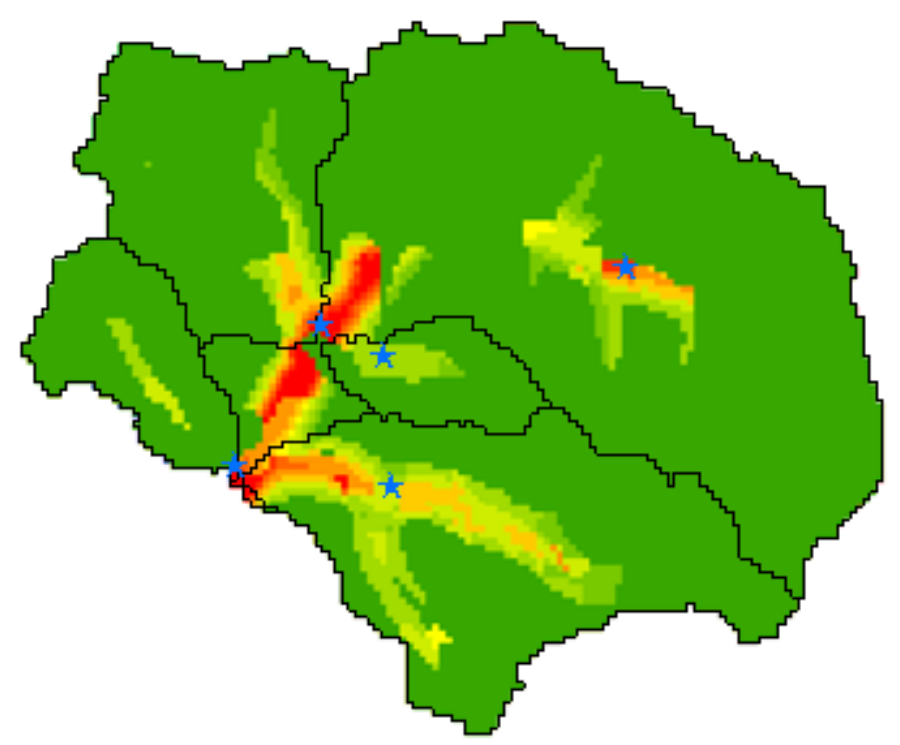

Figura 33 - Pontos de interesse no mapa de risco para futuro - ano 2100.

Foram gerados índices de resiliência para os cinco pontos de interesse. Para cada ponto são apresentados dois índices, referentes ao presente - ano 2003 - e futuro - ano 2100. A população é suposta como a mesma para os dois cenários, baseada nos dados de 2010 . Embora supor que a população na cidade seja constante possa não ser correto, é razoável assumir que o crescimento da cidade se dará nas áreas menos populosas e livres, e que não deve refletir em um grande aumento, ou diminuição, na densidade populacional nos pontos de interesse. 

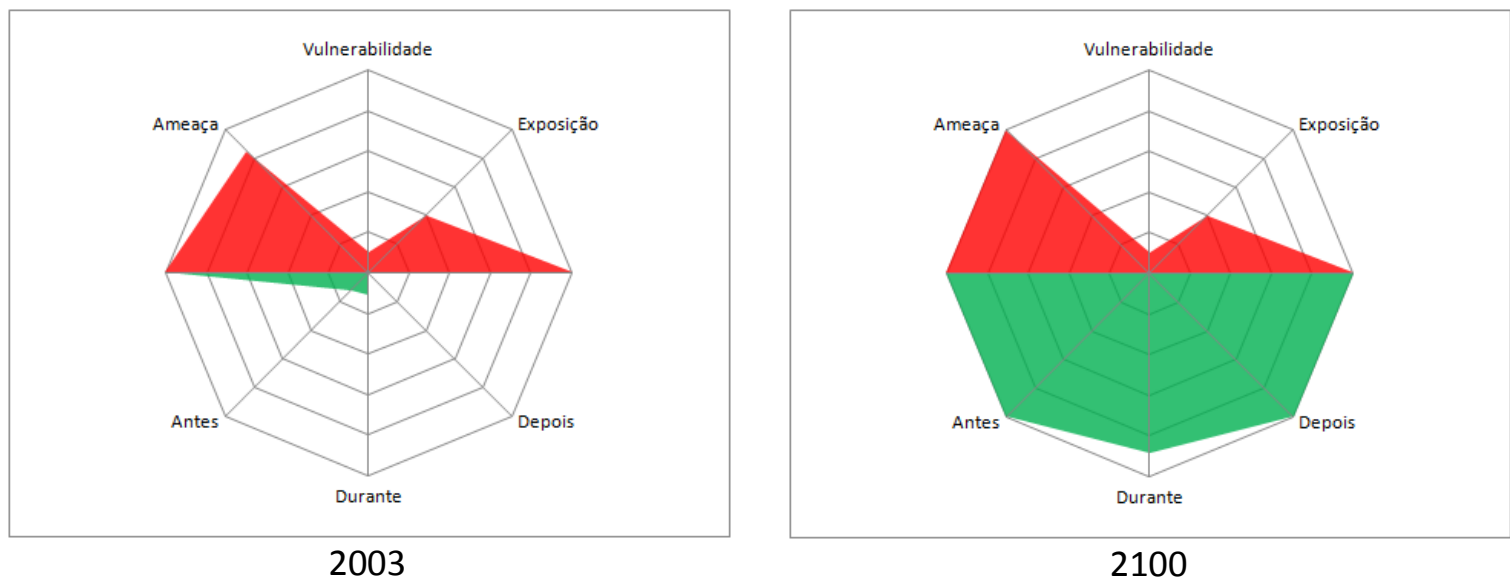

Figura 34 - Índice de resiliência na Rodoviária.

A Figura 34 mostra o índice de resiliência para o ponto próximo a rodoviária, presente à esquerda e futuro à direita. $\mathrm{O}$ termo Ameaça aumenta pouco do presente para o futuro, e a Vulnerabilidade é similar para os dois períodos. A conclusão é que este ponto não deve apresentar aumento na freqüência de inundação no futuro. Uma hipótese é que a sub-bacia já está plenamente urbanizada e que não deve ocorrer nenhuma alteração significativa da impermeabilização do solo. O pequeno aumento na Ameaça deve ser basicamente devido às mudanças climáticas, e deve provocar pouco impacto. Atualmente não é comum evento de inundação neste ponto.
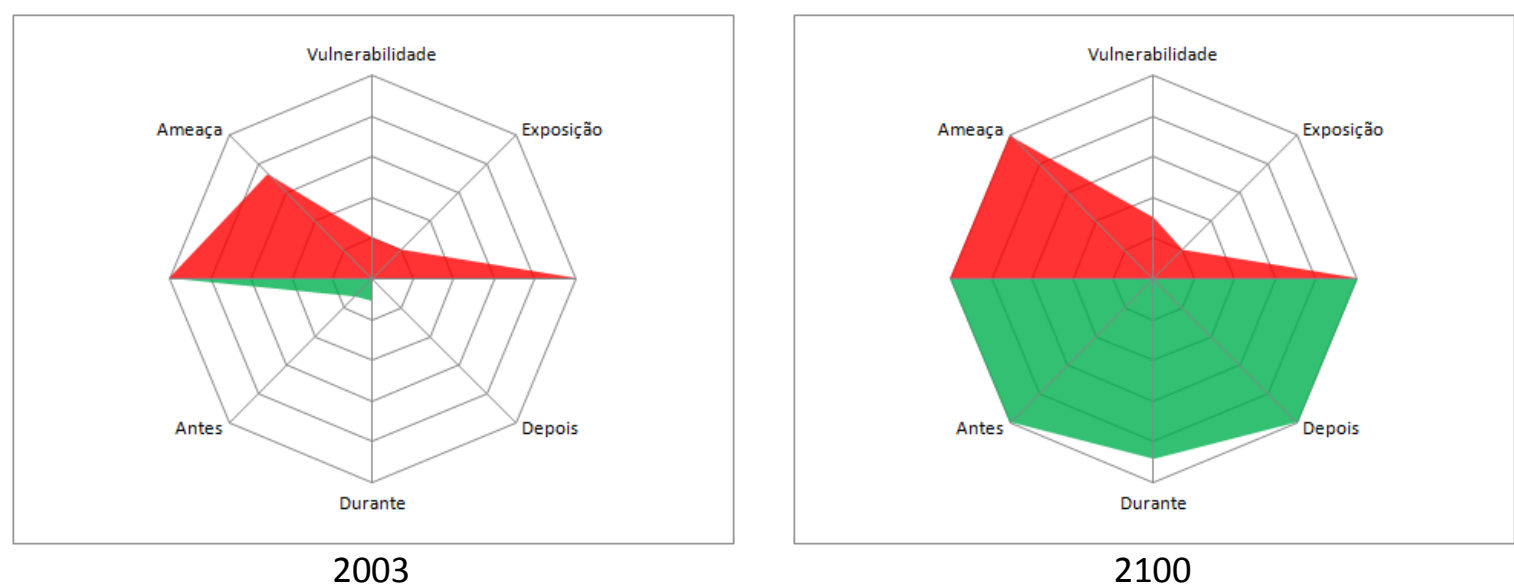

Figura 35 - Índice de resiliência no Mercado Municipal.

O índice de resiliência para o Mercado Municipal é apresentado na Figura 35, presente à esquerda, e futuro a direita. Este ponto sofre constantemente com eventos de inundação. Comparado com o ponto anterior, a Ameaça é menor, enquanto a Vulnerabilidade é um pouco maior. A Exposição neste ponto também é maior, devido uma urbanização mais densa. Para o futuro, urbanização e impermeabilização extrema, a Ameaça e Vulnerabilidade aumentam um 
pouco. Embora a Vulnerabilidade, ou probabilidade de inundação, aumente um pouco é esperado um comportamento similar entre o padrão de inundação atual e futuro.

O ponto do Kartódromo, Figura 36, é o ponto que tem maior alteração da Vulnerabilidade entre os dois cenários. A freqüência e magnitude das inundações neste ponto devem aumentar.

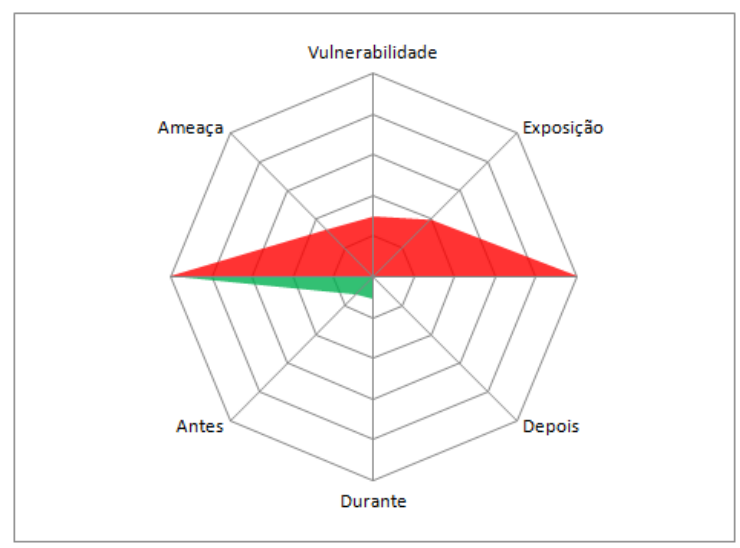

2003

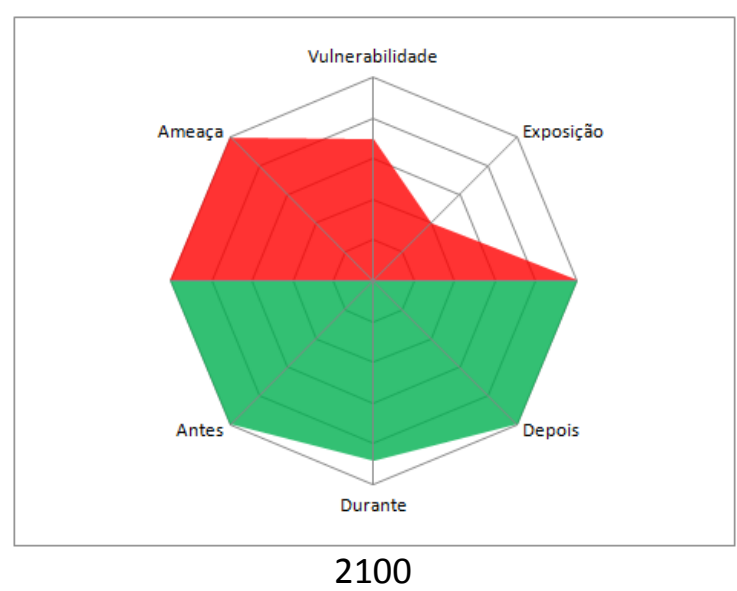

2100

Figura 36 - Índice de resiliência no Kartódromo.

Os pontos que mais sofrem com inundação em São Carlos são Mercado Municipal e a rotatória do Cristo. O índice para a rotatória do Cristo é apresentado na Figura 37. Mesmo no presente a Vulnerabilidade deste ponto já é alta. Espera-se que a Vulnerabilidade seja ainda maior no futuro, quando a maioria da bacia urbana deve estar impermeabilizada.
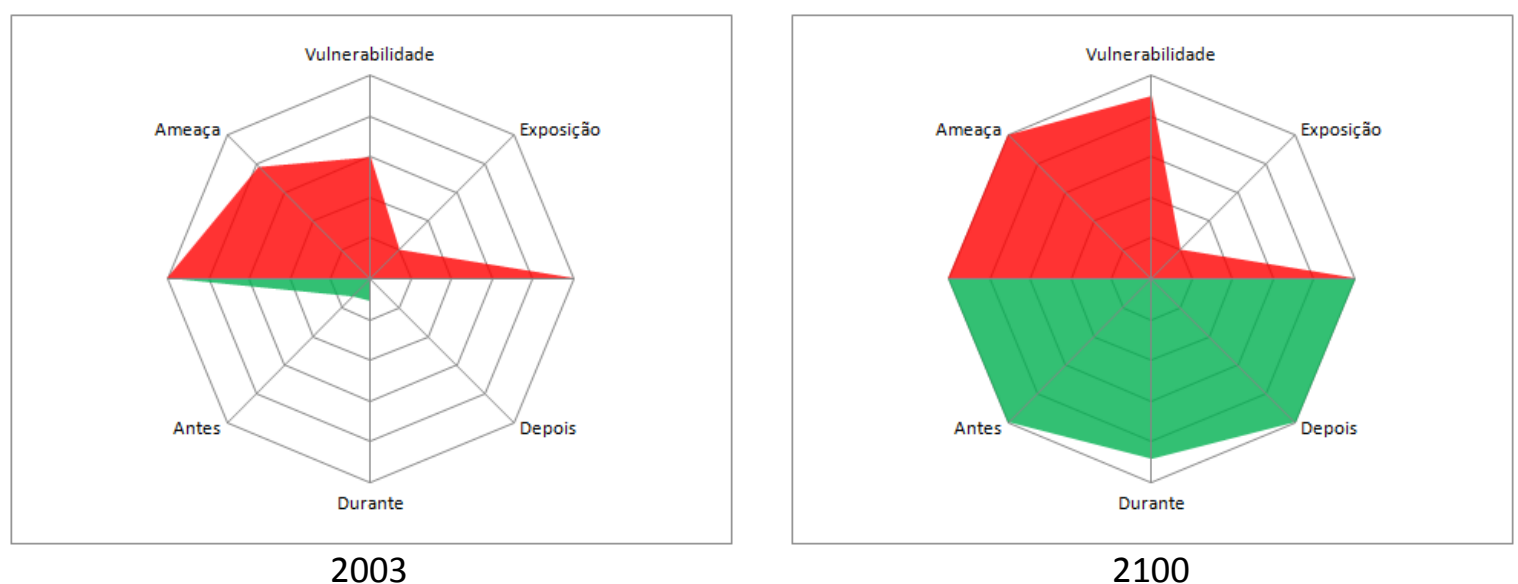

Figura 37 - Índice de resiliência na Rotatória do Shopping, ou Cristo.

O último ponto avaliado é o Alto do Monjolinho. Até a presente data não foram encontradas notícias de inundação neste ponto. Através da foto de satélite da cidade é possível observar que o ponto tem uma mata ciliar, e que a urbanização é afastada do córrego. Caso existam eventos de inundação neste ponto eles não devem ser documentadas pelo fato de não atingirem a zona urbana e provocarem perdas. $\mathrm{O}$ índice de resiliência para este ponto apresenta ligeiro aumento da Vulnerabilidade, e grande aumento da Ameaça. O valor da 
Existe uma limitação na representação da Exposição, pois existe mata ciliar ao redor do rio neste ponto, não existe nenhuma pessoa residente próximo ao rio. Isso se deve ao fato que os setores censitários não excluem os rios e mata ciliares de seus contornos, alterando a densidade populacional na região de maneira incorreta.
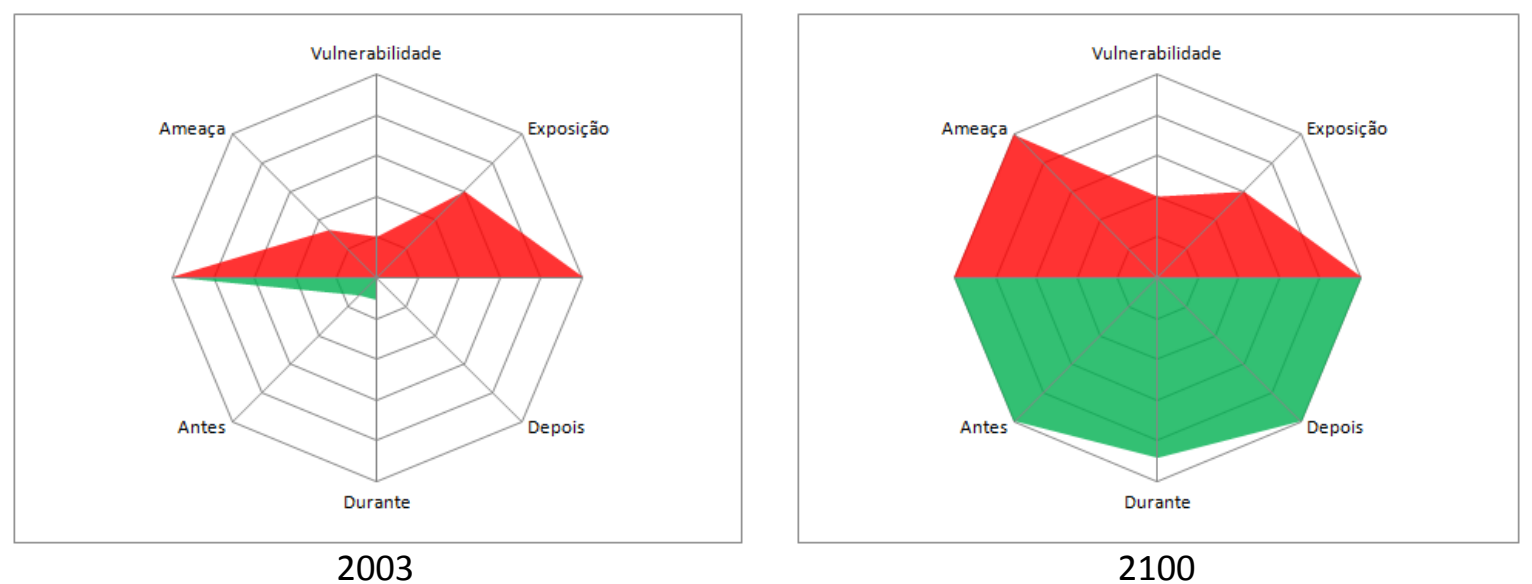

Figura 38 - Índice de resiliência no Alto do Monjolinho.

Para todos os índices apresentados o comportamento do Gerenciamento de Risco é o mesmo, pois foi suposto um único valor para toda a bacia urbana. No presente existe um mínimo de medidas contra inundação, somente medidas de combate, ou seja, aplicadas Durante o evento. É suposto que não existam medidas de preparação e prevenção (Antes), nem mecanismos para reconstrução, suporte e avaliação após o evento (Depois). Para o futuro acredita-se que grande parte das medidas de gerenciamento de risco de inundação tenha sido adotada. Pode-se afirmar que este é um cenário bastante otimista.

Para uma análise mais detalhada do gerenciamento de risco é apresentado o índice de resiliência no ponto da rotatória do Cristo, Figura 39. 

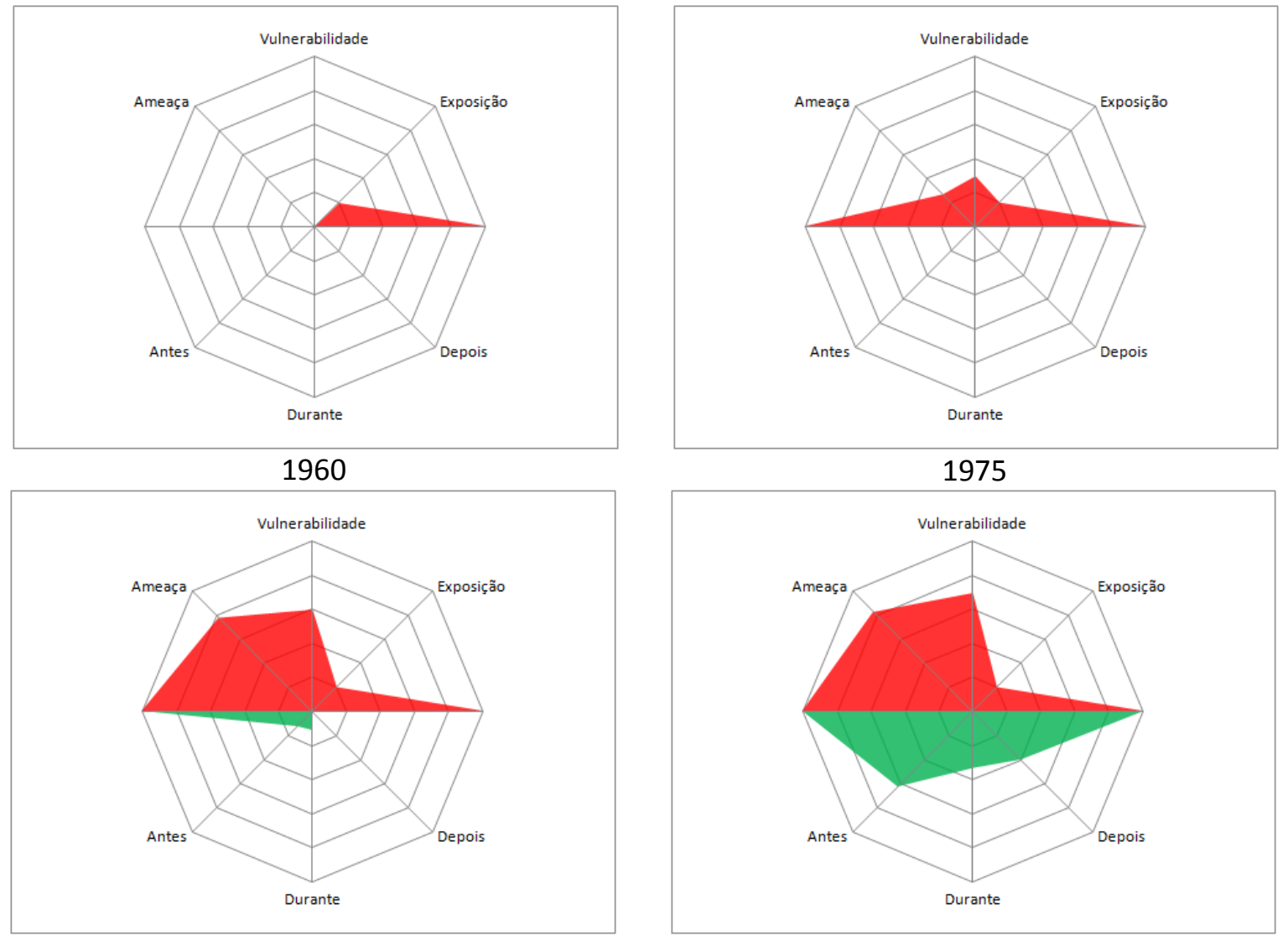

2003

2025

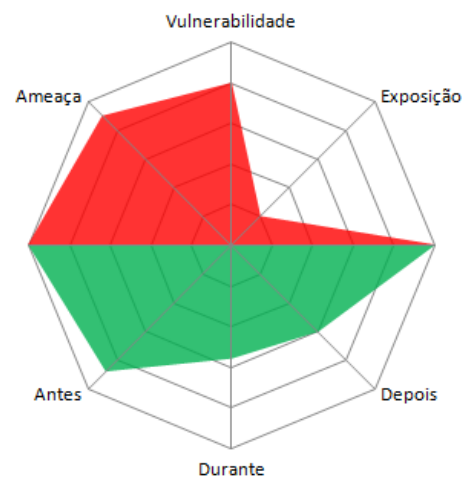

2055

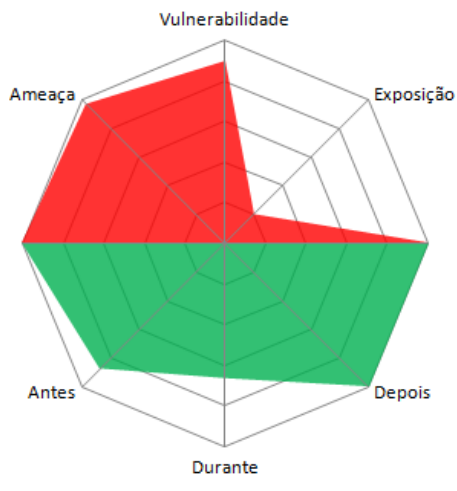

2085

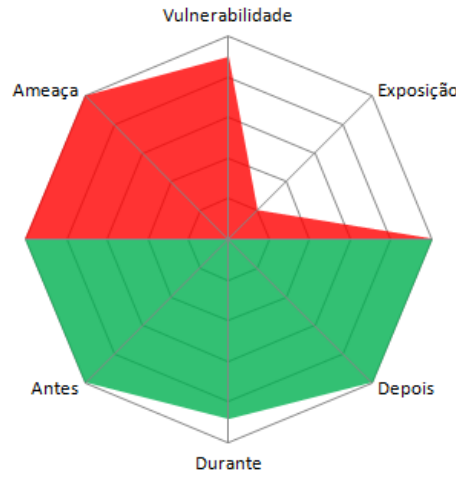

2100

Figura 39 - Índice de resiliência para rotatória do Cristo. 
De acordo com as hipóteses assumidas, um pouco otimistas, espera-se um aumento gradual das habilidades do município no gerenciamento de risco. $\mathrm{O}$ aumento do risco de inundação do ponto é acompanhado por um aumento na capacidade de lidar com as conseqüências da inundação.

Inicialmente devem ser implementadas medidas reativas, de combate ao evento, correspondentes ao termo Durante. Posteriormente os tomadores de decisão devem aceitar a opção de medidas de preparação e prevenção (Antes) como forma de evitar prejuízos. Como último passo, os tomadores de decisão devem perceber que mesmo com medidas de preparação, prevenção e combate à inundação, ainda podem existir perdas que são muito difíceis ou economicamente inviáveis de serem evitadas. Neste momento devem ser desenvolvidas medidas para auxiliar a reconstrução e recuperação, correspondentes ao termo Depois.

Vale lembrar que se optou por manter a Exposição constante em todos os anos avaliados, devido à ausência de dados e metodologia para estimar a variação da densidade populacional.

\subsection{CONCLUSÕES PARCIAIS}

O estudo apresentou a construção de mapas distribuídos para avaliação do risco e de seus termos. Foi demonstrado como identificar áreas vulneráveis à inundação a partir do modelo de elevação digital disponibilizado pela Embrapa. O mapa de exposição foi gerado a partir de informações disponibilizadas livremente pelo IBGE.

O termo Ameaça foi derivado a partir do escoamento superficial obtido a partir de previsões disponibilizado pelo INPE, e corrigido para diferentes níveis de impermeabilização do solo. Segundo os dados obtidos o aumento do número e tamanho das inundações é devido principalmente ao aumento da impermeabilização do solo, enquanto as mudanças climáticas têm importância secundária.

Os mapas de risco desenvolvidos apresentaram resultados satisfatórios e indicaram as regiões de pontos reconhecidamente problemáticos.

Com relação ao índice de resiliência e sua forma de apresentação: o formato proposto foi capaz de mostrar todas as dimensões de maneira simultânea de forma clara e organizada. Foi proposta uma forma de apresentação onde é possível avaliar diretamente todos os seis termos, assim como o conjunto de avaliação de risco e do conjunto de gerenciamento de risco. A forma de apresentação também associa cores e ordem na apresentação das informações de 
forma a favorecer comunicação e entendimento de tomadores de decisão e população em geral.

Foi realizada análise em cinco pontos de interesse, sendo que dois sofrem inundação freqüentemente, dois em raros episódios, e um ponto que atualmente parece não sofrer inundação.

Foram adotadas definições para Ameaça, Vulnerabilidade e Exposição com objetivo de serem intuitivos e naturais para o público alvo, composto pela população e tomadores de decisão em geral, e não conceitos específicos naturais somente para comunidade de pesquisa da área.

Uma vez definidos os pontos mais críticos com relação ao risco de inundação, pode-se utilizar índices mais específicos e locais para avaliação de questões como vulnerabilidade dos indivíduos em si. No capítulo 3 é desenvolvida a base teórica de um índice de perigo para avaliação da vulnerabilidade de pessoas expostas à escoamento de água que pode estar presente durante uma inundação. 


\section{3 ÍNDICE DE PERIGO}

No capítulo 2 foi apresentado um índice de resiliência, utilizado de uma forma mais ampla e geral, oferecendo um panorama sobre os riscos e questões para gerenciamento de risco de inundações em escalas espaciais da ordem das bacias hidrográficas e escalas temporais de dezenas de anos. Depois de identificadas as regiões com maior risco podem ser necessários estudos mais detalhados com relação aos diferentes aspectos que envolvem as consequiências de uma inundação. Este capítulo trata do estudo de um índice de perigo (IP) para avaliação da vulnerabilidade de pessoas expostas e submersas parcialmente em escoamento de água. É realizado o desenvolvimento teórico para determinação de condição limite de estabilidade, quando a pessoa é levada pela correnteza, e o resultado é comparado com resultados experimentais e recomendações de diferentes fontes na literatura. No final são feitas algumas recomendações e sugestões para uso do índice.

\subsection{METODOLOGIA}

A construção de uma metodologia para simulação das forças e mecanismos que agem sobre uma pessoa exposta em escoamento de água, como no caso de uma inundação, requer primeiramente um modelo matemático representativo que possa oferecer ao menos os valores de forças presentes nesta situação e quais são as condições a partir do qual é fisicamente impossível uma pessoa permanecer em equilíbrio estável.

Muitos autores propõem uma relação entre profundidade $h$ e velocidade $v$, através de uma combinação que indica a possibilidade de uma pessoa ser levada à instabilidade (JONKMAN; PENNING-ROWSELL, 2008). A relação geralmente é representada pelo produto das duas variáveis $(h v)$.

O primeiro estudo experimental sobre assunto foi apresentado por Abt et al. (1989) em uma série de testes nos quais pessoas e blocos eram colocados em um experimento de laboratório para determinação da velocidade e profundidade da água que provocavam sua queda. A partir deste estudo foi derivada uma equação empírica, equação (11), para estimar o valor crítico de $h v$ para o qual uma pessoa teria comportamento instável.

$$
h v=0,0929\left(e^{0,001906 L m+1,09}\right)^{2}
$$

Onde $h v$ é o produto crítico de velocidade $v[\mathrm{~m}]$ e profundidade $h[\mathrm{~m}]$ onde existe grandes chances de queda, $L$ é a altura da pessoa [m] e $m$ é o peso [kg]. 
Outros estudos (KARVONEN et al., 2000; LIND; HARTFORD; ASSAF, 2004; SUETSUGI, 1996) também avaliaram o produto $h v$ e concluíram que os valores críticos variam de $0,6 \mathrm{~m}^{2} / \mathrm{s}$ até $2 \mathrm{~m}^{2} / \mathrm{s}$. Abt et al. (1989) chegou a valores muito mais conservadores de $0,3 \mathrm{~m}^{2} / \mathrm{s}$ quando utilizando blocos monolíticos.

Tabela 18 - Dados de testes experimentais.

\begin{tabular}{|c|c|c|c|c|}
\hline Referência & Superfície & Condições & Pessoas & Resultados \\
\hline $\begin{array}{l}\text { Abt et al. } \\
\text { (1989) }\end{array}$ & $\begin{array}{l}\text { Grama, } \\
\text { concreto, aço. }\end{array}$ & $\begin{array}{l}v=0,36 \sim 3,05 \mathrm{~m} / \mathrm{s} \\
h=0,42 \sim 1,2 \mathrm{~m}=0\end{array}$ & $\begin{array}{l}m=41 \sim 91 \mathrm{~kg} \\
L=1,51 \sim 1,91 \mathrm{~m}\end{array}$ & $\begin{array}{l}\text { Média } h v=1,33 \mathrm{~m}^{2} / \mathrm{s} \\
\text { Desvio padrão } h v=0,28 \mathrm{~m}^{2} / \mathrm{s}\end{array}$ \\
\hline $\begin{array}{l}\text { Karvonen et } \\
\text { al. (2000) }\end{array}$ & $\begin{array}{l}\text { Grade de aço } \\
\text { escorregadia }\end{array}$ & $\begin{array}{l}v=0,6 \sim 2,75 \mathrm{~m} / \mathrm{s} \\
h=0,3 \sim 1,1 \mathrm{~m}\end{array}$ & $\begin{array}{l}m=48 \sim 100 \mathrm{~kg} \\
L=1,60 \sim 1,95 \mathrm{~m}\end{array}$ & $\begin{array}{l}\text { Média } h v=0,96 \mathrm{~m}^{2} / \mathrm{s} \\
\text { Desvio Padrão } h v=0,16 \mathrm{~m}^{2} / \mathrm{s}\end{array}$ \\
\hline
\end{tabular}

Fonte: adaptado de Jonkman e Penning-Rowsell (2008)

As chances de uma pessoa ser desequilibrada e arrastada por uma corrente de água dependem de diferentes variáveis como terreno, visibilidade, condições da pessoa, etc. (LIND; HARTFORD; ASSAF, 2004).

A literatura identifica dois mecanismos que podem causar instabilidade humana em correntes de água: instabilidade de momento (tombamento) e instabilidade por fricção. Tombamento acontece quando a força de arrasto excede o momento devido ao peso do corpo e gira a pessoa provocando a queda. Instabilidade de fricção ocorre quando a força de arraste é maior que a força de atrito entre o pé e a superfície de apoio, arrastando a pessoa (JONKMAN; KELMAN; BAIN, 2005), conforme apresentado na Figura 40.

Para efeito de simplificação o corpo humano é modelado como um bloco retangular com dimensões e pesos similares ao de uma pessoa. Entretanto, enquanto o bloco é passivo, uma pessoa pode se mover e alterar as distâncias e ângulos do problema. Abt et al. (1989) consideram o bloco monolítico uma estrutura extremamente conservadora para estimativa da vulnerabilidade um corpo humano em um escoamento de água. 
Instabilidade por momento

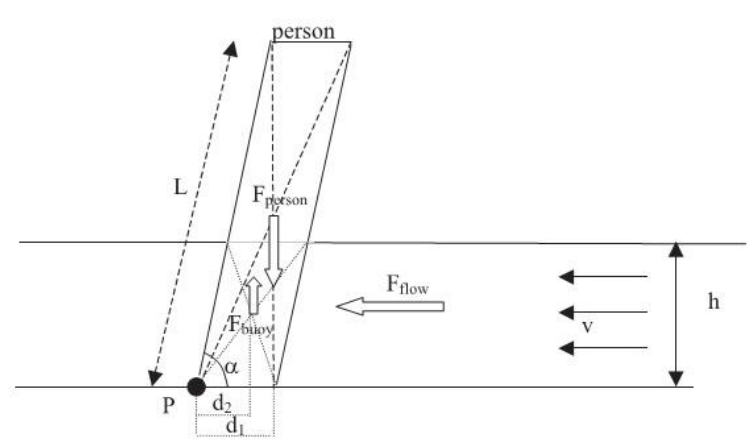

Instabilidade por fricção

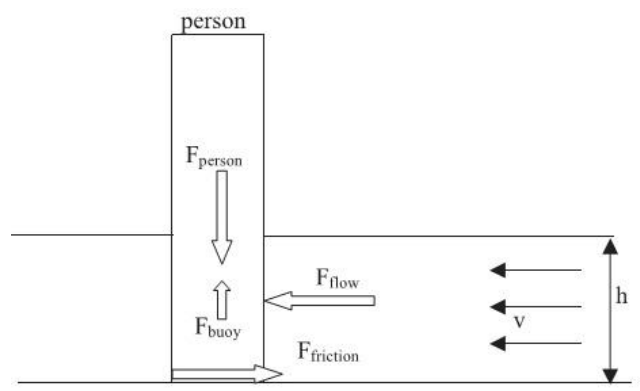

Figura 40 - Modelo de corpo humano para estudo de instabilidade.

Fonte: Jonkman e Penning-Rowsell (2008).

A partir da Figura 40, a distância $d 1$ é a distância entre o ponto de apoio $(P)$ e o centro de massa $[m]$ (igual a $\cos (\propto) L)$ ); $d 2$ é a distância do ponto de apoio $(P)$ até o ponto de aplicação da força de empuxo $[m] ; F_{\text {buoy }}$ é a força vertical realizada pelo empuxo $[N]$. $F_{\text {flow }}$ é a força horizontal de arrasto causada pelo fluxo do fluído $[N] ; F_{\text {friction }}$ é a força de atrito entre a pessoa e a superfície $[N] ; F_{\text {person }}$ é a força vertical realizada pelo peso da pessoa $[N] ; h$ é a profundidade da água $[\mathrm{m}] ; L$ é a altura da pessoa $[\mathrm{m}] ; P$ é o ponto de apoio da pessoa; $v$ é a velocidade da água $[\mathrm{m} / \mathrm{s}]$ e $\propto$ é o angulo entre a pessoa e o fluxo de água [graus].

A estrutura de equações adotada neste trabalho baseia-se na proposta de Jonkman; Penning-Rowsell (2008), com modificações, e o mecanismo de queda avaliado é exclusivamente o de instabilidade por fricção. A principal modificação aqui proposta é a inclusão da força de empuxo no modelo. Foi escolhido o modelo de instabilidade por fricção por ser mais simples, e por ser a condição extrema, ou seja, qualquer outro mecanismo de queda deve necessariamente ocorrer antes da perda de estabilidade por falta de atrito.

\subsection{DESENVOLVIMENTO TEÓRIO}

O desenvolvimento teórico é baseado na Figura 40, modelo instabilidade por fricção. Definimos as forças do peso $F_{\text {person }}$ e empuxo $F_{\text {buoy }}$ como:

$$
\begin{aligned}
& F_{\text {person }}=m g \\
& F_{\text {buoy }}=\rho V_{c} g
\end{aligned}
$$


Onde $\rho$ é o peso específico do fluído em questão $\left[\mathrm{kg} / \mathrm{m}^{3}\right] ; V_{C}$ é o volume submerso da pessoa $\left[\mathrm{m}^{3}\right] ; g$ é a aceleração devido à gravidade $\left[\mathrm{m} / \mathrm{s}^{2}\right]$.

A força de atrito é uma relação entre o peso, empuxo e coeficiente de atrito $\mu$ [adimensional]. A inclusão do termo $F_{b u o y}$ na equação é a principal modificação no equacionamento se comparado com o trabalho original de Jonkman; Penning-Rowsell (2008), que utiliza somente o peso no cálculo do atrito:

$$
F_{\text {friction }}=\mu\left(F_{\text {person }}-F_{\text {buoy }}\right)
$$

A força de arrasto, que já engloba as componentes de força devidas as diferença de pressão e arrasto por viscosidade do fluído, é dada por:

$$
F_{\text {flow }}=0,5 \rho C_{D} B h v^{2}
$$

Onde $B$ é a largura média do corpo exposto na normal do fluxo $[m] ; C_{D}$ é o coeficiente de arrasto [adimensional]:

O volume de corpo submerso pode ser estimado por (válido para $h \leq L$ ):

$$
V_{C}=\frac{h m}{L \rho_{\text {person }}}
$$

Onde $\rho_{\text {person }}$ é a densidade média de uma pessoa $\left[\mathrm{kg} / \mathrm{m}^{3}\right]$. A equação (16) foi derivada supondo o corpo como um bloco retangular homogêneo, de forma que o centro de massa está na metade da altura da pessoa, o que é razoável visto que o centro de massa de uma pessoa está aproximadamente a 55\% da altura (HELLEBRANDT; TEPPER; BRAUN, 1938). Supondo uma distribuição de massa uniforme e densidade do corpo constante, o volume do corpo submerso nada mais é que a proporção entre a parte submersa pela a altura da pessoa ou bloco $(h / L)$, multiplicado pelo volume total da pessoa, o mesmo que sua massa dividia pela densidade do corpo $\left(m / \rho_{\text {person }}\right)$.

A condição crítica ocorre quando a força de arraste é igual ou maior que a força de atrito disponível. A partir deste ponto existe escorregamento e eventual queda da pessoa. A curva de pontos é gerada determinando a velocidade máxima $v$ para dada altura $h$, na qual a força de arrasto $F_{\text {flow }}$ é igual à força de atrito $F_{\text {friction }}$, equação (17). Esta curva pode ser adotada como o caso extremo, visto que sem atrito suficiente é fisicamente impossível permanecer parado na corrente de água. A equação (17) é similar a apresentada em Jonkman e PenningRowsell (2008), mas com a inclusão do termo de empuxo:

$$
0,5 \rho C_{D} B h v^{2}=\mu\left(F_{\text {person }}-F_{\text {buoy }}\right)
$$


$\mathrm{Na}$ equação (17), os termos $h$ e $v$ são características do escoamento, altura e velocidade respectivamente, enquanto as demais variáveis são constantes físicas ou características da pessoa. É conveniente isolar o termo $h v^{2}$, de forma a ter um indicador que depende somente das características do escoamento, sem influência das características da pessoa. Com o objetivo de isolar o termo $h v^{2}$, continuamos:

$$
\begin{gathered}
0,5 \rho C_{D} B h v^{2}=\mu\left(m g-\rho V_{c} g\right) \\
0,5 \rho C_{D} B h v^{2}=\mu g\left(m-\rho \frac{h m}{L \rho_{\text {person }}}\right)
\end{gathered}
$$

Admitindo que a densidade do corpo $\rho_{\text {person }}$ é muito próxima a densidade da água $\rho$ :

$$
0,5 \rho C_{D} B h v^{2}=\mu g m\left(1-\frac{h}{L}\right)
$$

Reorganizando:

$$
h v^{2}=\frac{g}{0,5 \rho C_{D} B} \mu m\left(1-\frac{h}{L}\right)
$$

Definindo profundidade relativa (profundidade/altura pessoa):

$$
\theta=\frac{h}{L}
$$

Definindo a constante de calibração $k$ como:

$$
k=\frac{g}{0,5 \rho C_{D} B}
$$

Utilizando as novas definições a equação pode ser resumida como:

$$
h v^{2}=\mu m k(1-\theta)
$$

Onde $\theta$ é a profundidade relativa e $k$ é uma constante de calibração.

A equação (24) mostra que o termo $h v^{2}$ é proporcional ao produto da constante de calibração $k$, coeficiente de atrito do solo $\mu$, peso $m$ e a profundidade relativa, ou fração do corpo submerso no escoamento, $\theta$.

\subsection{DEFINIÇÃO DOS PARÂMETROS}

Para cálculo das forças geradas pelo escoamento na pessoa é necessário estimar o valor de alguns parâmetros. Além de valores como peso e altura da pessoa, velocidade e altura da água, outros fatores como o coeficiente de atrito $\mu$, coeficiente de arrasto $C_{D}$, largura equivalente $B$ e as densidades $\rho$ e $\rho_{\text {person }}$ precisam ser definidos. 
Endoh e Takahashi (1995) apresentam a medida do coeficiente de atrito $\mu$ para diferentes tipos de superfície. Os valores variam de 0,38 para concreto coberto por lama até 1,12 para concreto rugoso. Eles sugerem $\mu=0,4$ como um valor conservador para uma primeira análise. Jonkman e Penning-Rowsell (2008) utilizam $\mu=0,5$ em seus cálculos, valor que representa concreto escorregadio devido presença de lama, ou aço escorregadio.

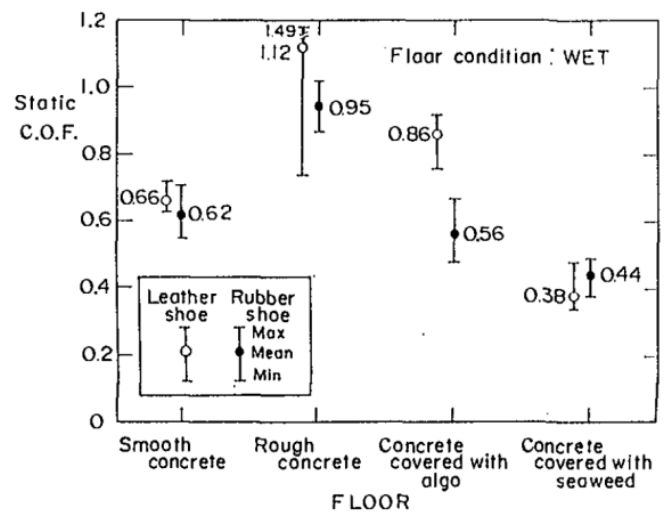

Figura 41 - Coeficiente de atrito para diferentes superfícies.

Fonte: Endoh e Takahashi (1995)

O valor de $C_{D}$ adotado por Jonkman e Penning-Rowsell (2008) é de 1,1, que é o mesmo valor médio utilizado por Endoh e Takahashi (1995). Fox e McDonald (1988) apresentam um gráfico com a variação do coeficiente de arrasto com a razão de uma placa finita, normal ao escoamento, para número de Reynolds $\operatorname{Re}>1000$, e os valores variam na faixa de 1 a 1,5 para uma grande faixa do aspecto da placa. Portanto o valor adotado de 1,1 parece ser uma aproximação razoável.

Sabendo que o corpo humano tem uma densidade similar a da água (JONKMAN; PENNING-ROWSELL, 2008), adotou-se $\rho_{\text {person }}$ igual a $\rho$. Os demais parâmetros utilizados são os mesmos utilizados em Jonkman e Penning-Rowsell (2008) com exceção da largura média do corpo B: o valor original era de $0,4 \mathrm{~m}$ o que parece representar pessoas muito grandes. Julgou-se mais adequado utilizar o valor de $0,3 \mathrm{~m}$. Entretanto é válido pesquisar novos valores e formas de representação mais adequadas da geometria do corpo humano. 
Tabela 19 - Parâmetros utilizados no modelo.

\begin{tabular}{ll}
\hline Descrição & Valor \\
\hline Massa pessoa - m & $75 \mathrm{~kg}$ \\
Altura - L & $1,75 \mathrm{~m}$ \\
Gravidade - g & $9,81 \mathrm{~m} / \mathrm{s}^{2}$ \\
Constante de arrasto - Cd & 1,1 \\
Largura média do corpo - B & $0,3 \mathrm{~m}$ \\
Coeficiente de atrito - $\mu$ & 0,5 \\
Densidade do fluído - $\rho$ & $1000 \mathrm{~kg} / \mathrm{m}^{3}$ \\
Densidade pessoa - $\rho_{\text {person }}$ & $1000 \mathrm{~kg} / \mathrm{m}^{3}$ \\
\hline
\end{tabular}

\subsection{RESULTADOS E DISCUSSÕES}

As curvas apresentadas na Figura 42 mostram a força de arraste e atrito máximo esperados para um sistema definido pelos dados da Tabela 19. Observa-se que a força de arraste aumenta com o aumento da profundidade e da velocidade da água, e que a força de atrito disponível diminui com a profundidade.

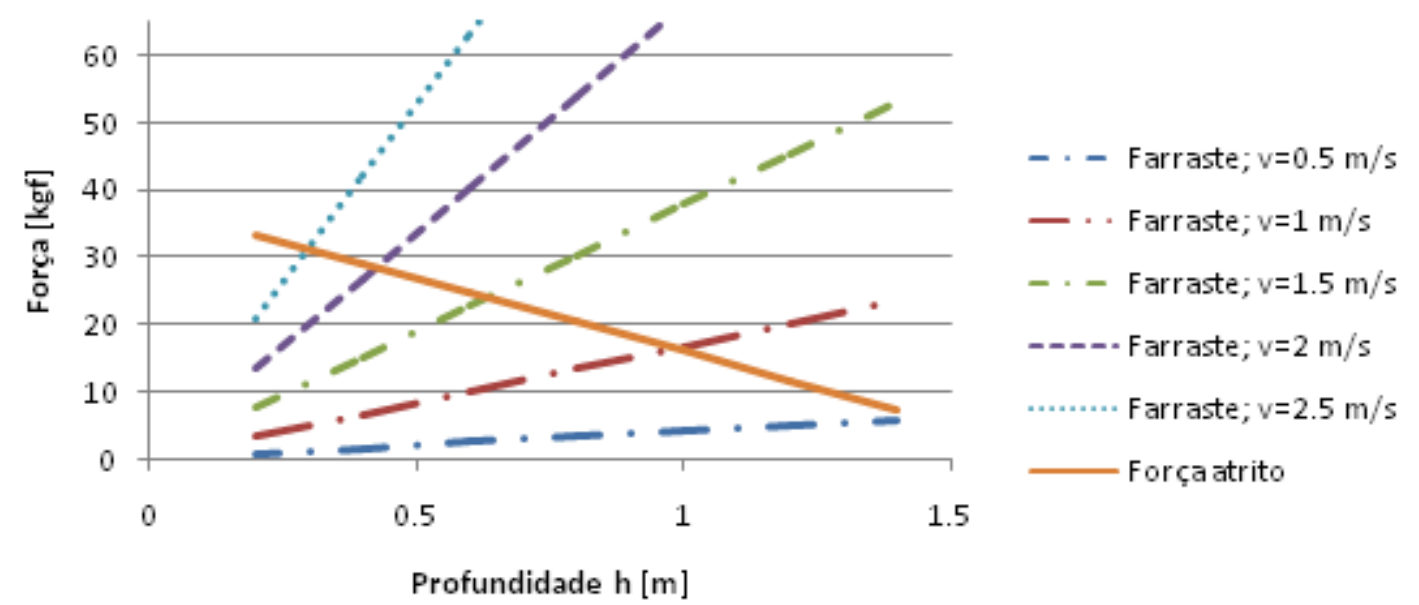

Figura 42 - Força de arraste e atrito.

A força de atrito máxima disponível é dada pela equação (14). A partir do momento que a força de arraste é maior que a força de atrito a pessoa é arrastada. Este ponto é definido como a condição crítica, ou seja, a partir deste ponto é impossível uma pessoa permanecer estável. 


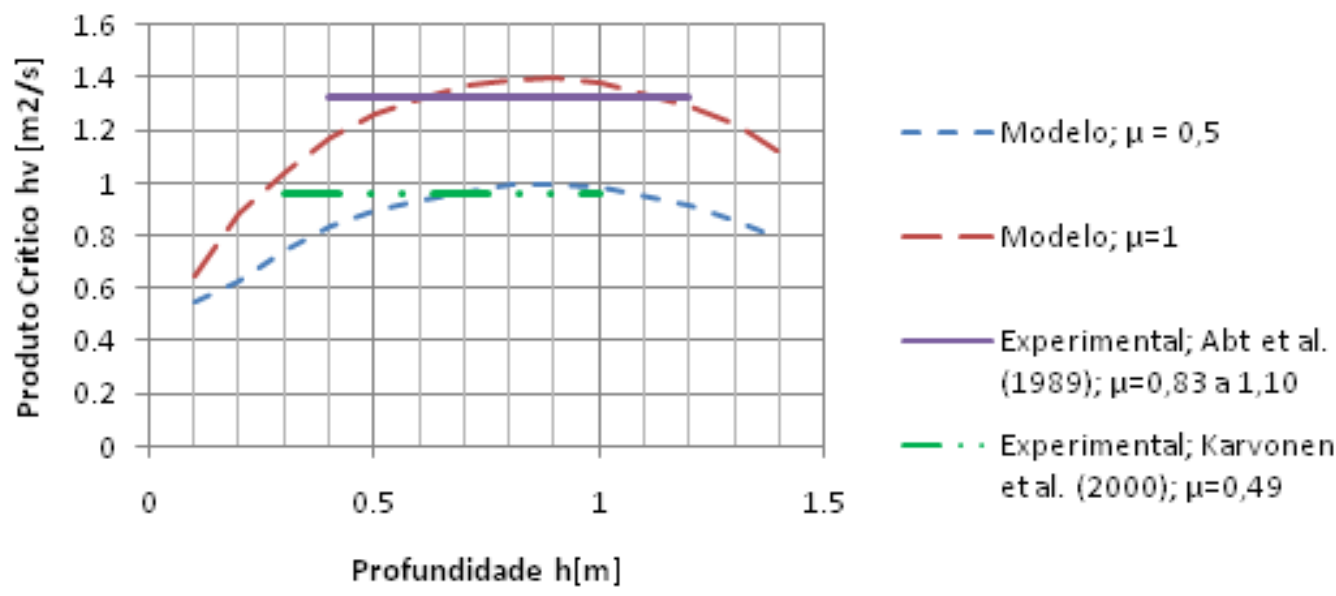

Figura 43 - Produto crítico $h v$ teórico e experimental.

A Figura 43 mostra a curva do produto crítico $h v$, ponto onde a força de arrasto $F_{\text {flow }}$ é igual à força de atrito $F_{\text {friction }}$. A utilização do produto crítico $h v$ foi escolhida para permitir a comparação entre dados teóricos e experimentais. São apresentadas as curvas do produto crítico $h v$, assim como os valores médios encontrados pelos estudos de Abt et al. (1989) e Karvonen et al. (2000). As curvas teóricas são calculadas para uma faixa de 0,2 a 1,4 m e para diferentes coeficientes de atrito $\mu$, utilizando a equação (17).

O tipo de superfície e o coeficiente de atrito têm influência na determinação da condição crítica. A diferença entre os valores de $h v$ obtidos por Abt et al. (1989) e Karvonen et al. (2000) pode ser explicada pelo coeficiente de atrito da superfície utilizada em cada experimento. Jonkman; Penning-Rowsell (2008) afirmam que no estudo de Abt et al. (1989) o coeficiente de atrito variava de 0,83 a 1,10, enquanto que em Karvonen et al. (2000) o coeficiente de atrito é 0,49 . A mesma diferença pode ser observada nas curvas teóricas com os coeficientes de atrito de 0,5 e 1 .

Os estudos experimentais anteriores sugerem que o produto $h v$ pode ser assumido constante para diferentes profundidades e velocidade da corrente de água. A Figura 43 sugere um comportamento diferente: o produto varia com a profundidade. Na região de profundidade entre 0,5 e $1 \mathrm{~m}$ os valores teóricos e experimentais são compatíveis, mas para profundidade inferior a 0,5 m e maior que $1 \mathrm{~m}$ a diferença entre a curva teórica e a constante $h v$ aumenta.

$\mathrm{Na}$ Figura 44 estão algumas curvas limite para diferentes condições, onde apenas a inclinação é diferente. 


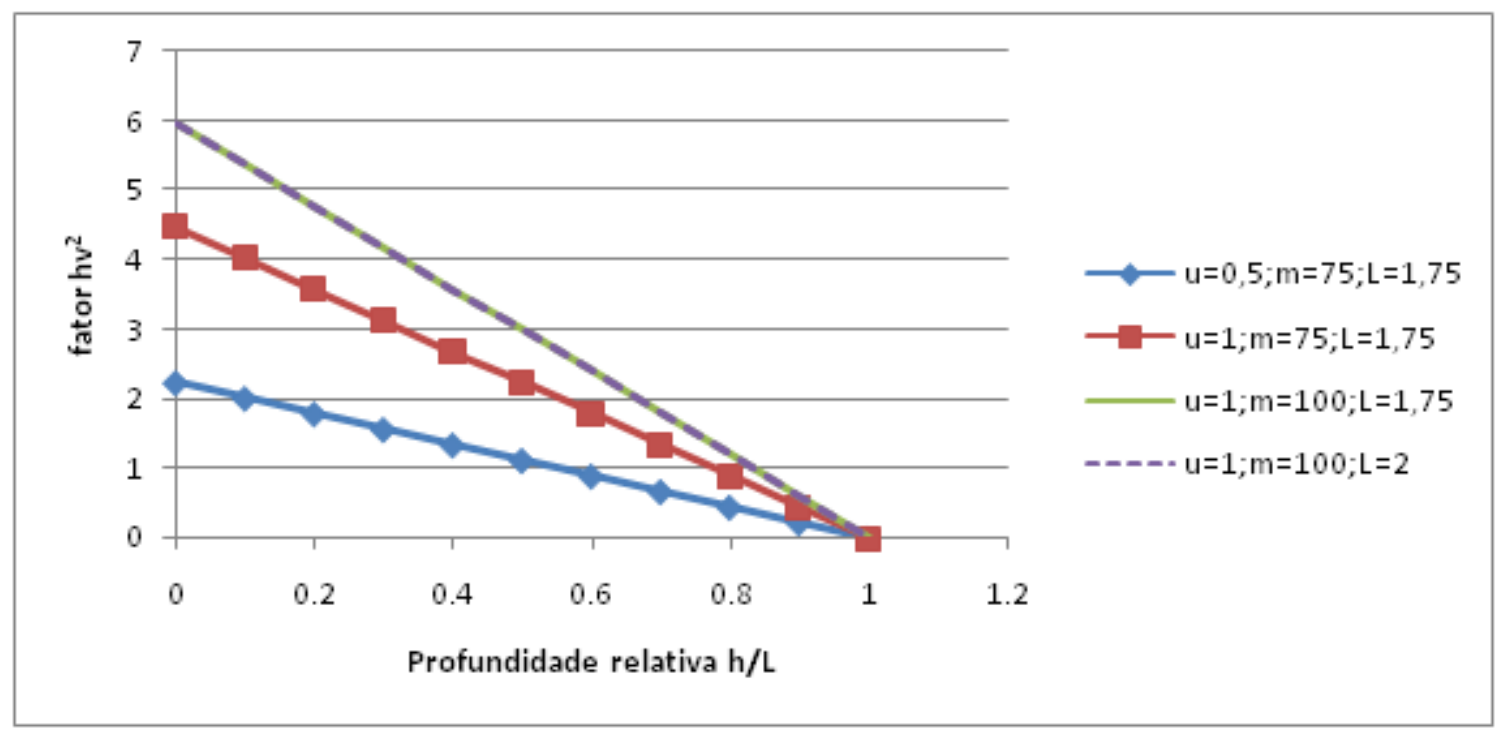

Figura 44 - Produto $h v^{2}$ com a profundidade relativa.

O fato de diferentes parâmetros alterarem somente a inclinação da curva sugere a possibilidade de utilizar somente uma curva padrão, que depois pode ser extrapolada para outros casos somente multiplicando os valores de $h v^{2}$ pelo termo $\mu m$, respectivamente o coeficiente de atrito e peso da pessoa. O valor de $h v^{2}$ tende a zero quando a profundidade relativa é igual a um. A profundidade relativa igual a um representa o caso em que a altura do escoamento é igual à altura da pessoa, ou seja, a pessoa flutua e não tem nenhum contato com o solo. Nesta condição mesmo uma pequena velocidade da água arrasta a pessoa, e não é seguro assumir que toda a população é capaz de nadar.

Na Figura 45 estão as curvas de profundidade por velocidade. Pontos profundidade por velocidade acima da curva são instáveis, e abaixo estáveis. Neste caso não é utilizada a altura relativa, mas sim a altura do escoamento. Para velocidade igual a zero a profundidade tende ao valor da altura da pessoa. Conforme a velocidade aumenta a forma da curva se aproxima de uma curva $h v$. A curva $h v=1,2$ é apresentada apenas como forma de comparação entre o resultado do modelo proposto e a forma comumente encontrada na literatura. 


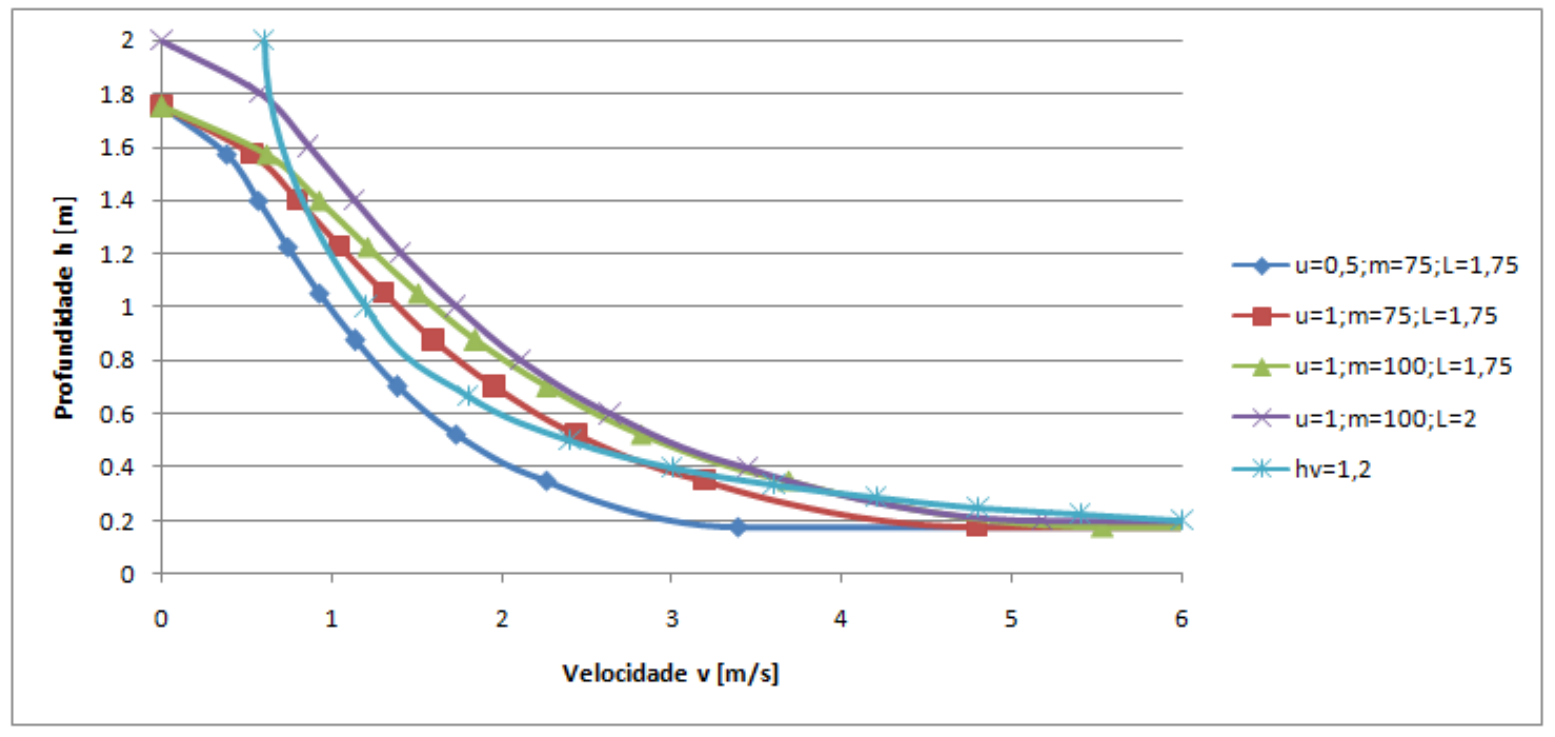

Figura 45 - Limiar de segurança teórico.

\subsection{INDICADORES DE PERIGO NA PRÁTICA}

Shand; Cox; Blacka (2011) resumem diferentes trabalhos na área de avaliação de perigo de pessoas em inundação e propõem alguns critérios de segurança baseados em medidas empíricas e estudos teóricos. Na Figura 46 é apresentado um conjunto de dados provenientes de diversos estudos sobre o assunto.

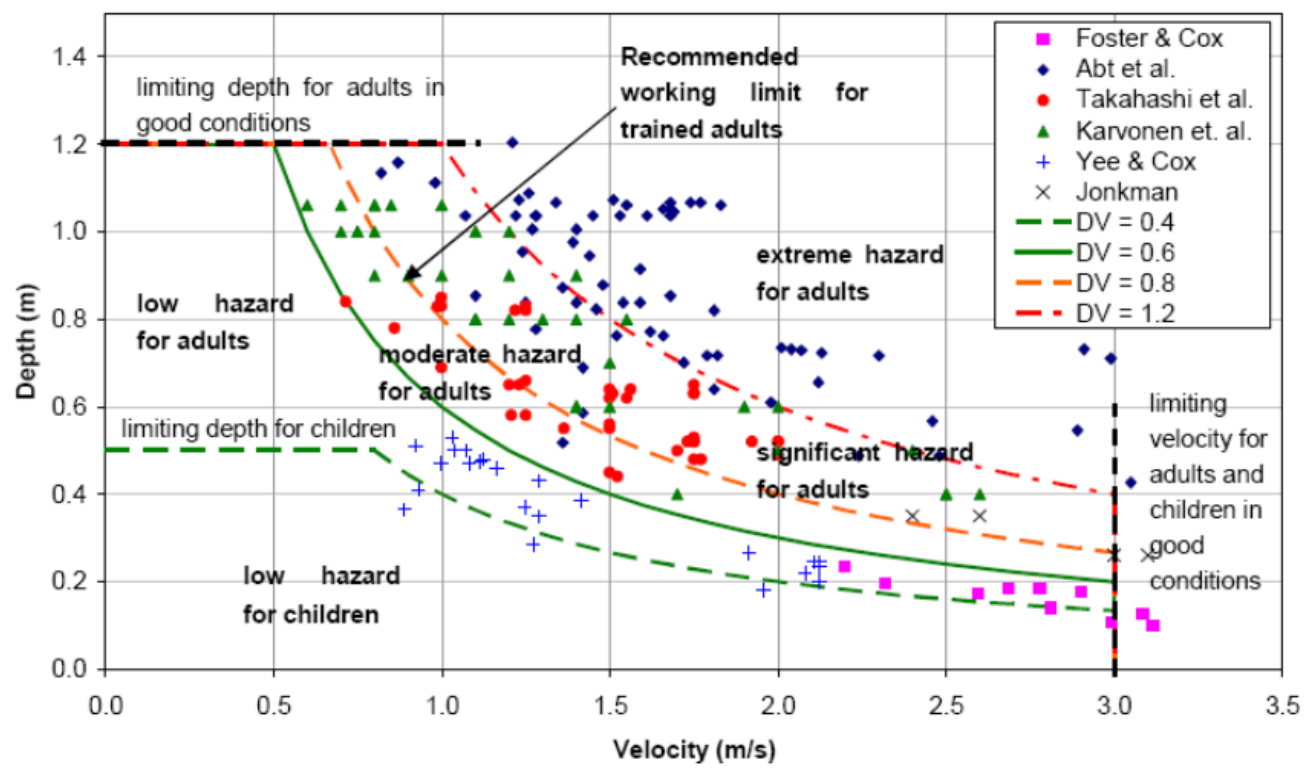

Figura 46 - Limiar de segurança empírico.

Fonte: Shand, Cox, Blacka (2011)

A partir dos dados experimentais, Shand; Cox; Blacka (2011) propõe limites de segurança de acordo com a Figura 47. O termo utilizado pelo trabalho é $h v$, e os valores deste são 
definidos através de comparação com os dados experimentais. Devido falta de dados experimentais para profundidades maiores que $1,2 \mathrm{~m}$ para adultos, 0,5 $\mathrm{m}$ para crianças e velocidades maiores que $3,2 \mathrm{~m} / \mathrm{s}$ é sugerido utilizar estes valores como condições limites. Acima de 1,2 m é aceito que a segurança depende da capacidade de nadar, algo que não pode ser assumido para toda população. Da mesma forma foi notada uma dificuldade em se manter em pé para velocidades muito altas, independente da profundidade, portanto assumir $3 \mathrm{~m} / \mathrm{s}$ como a velocidade limite é prudente (SHAND; COX; BLACKA, 2011).

\begin{tabular}{|c|c|c|c|}
\hline $\operatorname{DV}\left(\mathrm{m}^{2} \mathrm{~s}^{-1}\right)$ & $\begin{array}{c}\text { Infants, small children } \\
\text { (H.M } \leq 25) \text { and } \\
\text { frail/older persons }\end{array}$ & $\begin{array}{c}\text { Children } \\
(H . M=25 \text { to } 50)\end{array}$ & $\begin{array}{c}\text { Adults } \\
\text { (H.M }>50)\end{array}$ \\
\hline 0 & Safe & Safe & Safe \\
\hline $0-0.4$ & \multirow{5}{*}{$\begin{array}{l}\text { Extreme Hazard; } \\
\text { Dangerous to all }\end{array}$} & Low Hazard' & \multirow[b]{2}{*}{ Low Hazard ${ }^{1}$} \\
\hline $0.4-0.6$ & & $\begin{array}{l}\text { Significant Hazard; } \\
\text { Dangerous to most }\end{array}$ & \\
\hline $0.6-0.8$ & & \multirow{3}{*}{$\begin{array}{l}\text { Extreme Hazard; } \\
\text { Dangerous to all }\end{array}$} & $\begin{array}{l}\text { Moderate Hazard; } \\
\text { Dangerous to some }\end{array}$ \\
\hline $0.8-1.2$ & & & $\begin{array}{l}\text { Significant Hazard; } \\
\text { Dangerous to most }\end{array}$ \\
\hline$>1.2$ & & & $\begin{array}{l}\text { Extreme Hazard; } \\
\text { Dangerous to all }\end{array}$ \\
\hline
\end{tabular}

Figura 47 - Classificação de perigo.

Fonte: Shand, Cox, Blacka (2011)

Shand; Cox; Blacka (2011) define três classes de indivíduos: crianças, adultos e idosos. Para crianças pequenas e idosos é considerado que o risco é sempre alto. Para o caso dos adultos foram adotados os limites de DV (ou $h v$ na nossa nomenclatura) de 0 a 0,4 como risco baixo, 0,6 a 0,8 como risco moderado, 0,8 a 1,2 com risco alto, e maior de 1,2 como extremamente alto. Na Figura 46 é possível comparar esta classificação com os dados experimentais.

Tabela 20 - Classificação de perigo.

\begin{tabular}{ll}
\hline $\mathbf{h v}\left[\mathbf{m}^{2} / \mathbf{s}\right]$ & Risco \\
\hline $0-0,5$ & Baixo \\
$0,5-1,0$ & Médio \\
$1,0-1,5$ & Alto \\
$>1,5$ & Muito Alto \\
\hline
\end{tabular}

Fonte: Janine (2014)

Janine (2014) desenvolveu um trabalho para utilização de indicadores de perigo em rios distribuídos na região urbana de São Carlos. Através de uma régua de cores e o desenho de 
uma pessoa o autor tem objetivo de apresentar o risco para dada altura da água em uma secção do rio.

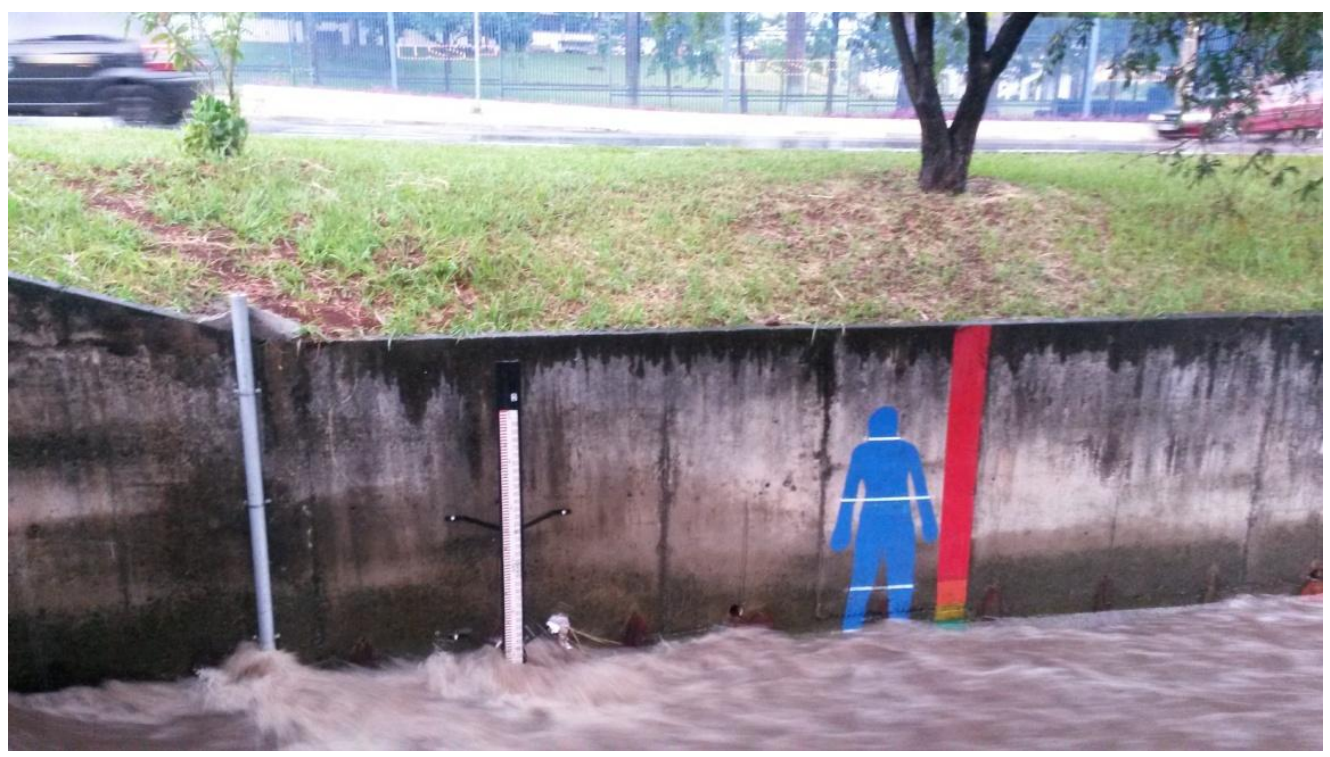

Figura 48 - Índice de perigo no Tijuco Preto/USP - São Carlos.

Janine (2014) optou por utilizar o indicador na forma $h v$ e definiu os níveis de perigo conforme apresentado na Tabela 20. Foi realizada a batimetria da secção do córrego e a velocidade da água estimada teoricamente, através de estimativas da declividade e rugosidade do canal (JANINE, 2014). A partir destes resultados foi obtido o valor de $h v$ para cada nível da água e transformado em uma escala de cores, como apresentado na Figura 48. Quando o nível da água está dentro da faixa verde é seguro atravessar o canal para a maioria das pessoas. Na faixa amarela o risco é moderado, e crianças, idosos e pessoas com problema de locomoção devem evitar atravessar o canal. Na faixa laranja o risco é alto para a grande maioria da população. Na faixa vermelha existe risco para todas as pessoas, independente de condição física e habilidade.

\subsection{GENERALIZAÇÕES E SUGESTÕES}

Enquanto Shand; Cox; Blacka (2011) utilizam três classes de pessoas, Janine (2014) trabalha com apenas uma classe: os adultos. Duas questões valem ser levantadas na utilização de indicadores de perigo:

1. Como apresentar a informação para diferentes grupos de pessoas?

2. Como generalizar da melhor forma possível a informação dentro de cada grupo?

A apresentação do risco para diferentes grupos de pessoas pode ser conseguida utilizando diferentes desenhos, conforme apresentado na Figura 49. Estes símbolos permitem apresentar 
escalas de perigo adequadas para cada grupo (crianças, adultos e idosos) e também por sexo. Tais símbolos são de fácil interpretação para a maioria da população.
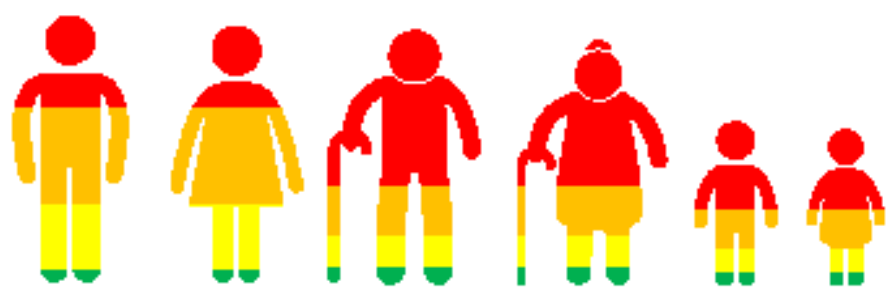

Figura 49 - Forma de indicação de perigo por profundidade relativa.

No desenvolvimento teórico chegou-se a conclusão que o perigo depende da profundidade relativa, ou seja, proporção entre a altura da água e da pessoa. Segundo esta conclusão a altura da pessoa não é importante, e o que deve ser avaliado é a proporção submersa do corpo. Ao colocar a rampa de cores dentro do desenho é possível trabalhar com a profundidade relativa. Dessa forma o usuário sabe qual é o nível de perigo ao qual esta sujeito se a água atingir, por exemplo, o joelho, cintura, etc.

Outra vantagem em utilizar uma forma humana como indicador é o fato que é mais fácil e intuitivo avaliar nível da água desta forma do que por meio de uma régua. Ao ver o nível da água na cintura do símbolo, uma pessoa tem uma idéia melhor da altura da água com relação ao seu próprio corpo do que no caso de ver uma régua mostrando uma medida como $0,9 \mathrm{~m}$.

A maioria dos estudos da literatura utiliza o termo $h v$ para indicação do perigo, embora a formulação teórica tenha chegado ao termo $h v^{2}$. Entretanto é possível encontrar alguns poucos trabalhos que utilizam o temo $h v^{2}$ (ESCOBAR, 1999; ISHIGAKI et al., 2005). Embora o resultado final apresentado por ambos os termos tende a ser muito próximo, segundo o desenvolvimento teórico aqui realizado, o termo $h v^{2}$ é mais adequado.

\subsection{CONCLUSÕES PARCIAIS}

A partir de um modelo simplificado foi obtido um equacionamento para determinação das forças as quais uma pessoa é submetida quando submersa em um escoamento de água. Também foi determinada a condição limite, quando a força de arraste da água é igual a força de atrito disponível para sustentação da pessoa. Os resultados foram comparados com dados experimentais encontrados na literatura.

O equacionamento é levado adiante chegando à conclusão que uma melhor representação do perigo de um escoamento é dada pelo termo $h v^{2}$, o que é diferente da metodologia mais 
utilizada atualmente que utiliza o termo $h v$. Também foi introduzido o conceito de altura relativa, que pode oferecer algumas vantagens na generalização do índice.

$\mathrm{Na}$ última parte foi descrita a implantação de indicadores de perigo na prática e algumas sugestões para possível melhoria dos mesmos no futuro, como o uso de figuras representativas de diferentes grupos de pessoas e a rampa de cores dentro dos símbolos para utilização do conceito de profundidade relativa. 


\section{CONCLUSÕES E RECOMENDAÇÕES GERAIS}

As conclusões gerais e recomendações são apresentadas neste capítulo. Apenas os pontos mais gerais são abordados aqui, sendo que os detalhes mais específicos podem ser encontrados nas conclusões parciais apresentadas nos capítulos correspondentes.

O objetivo geral da dissertação foi desenvolver e aplicar índices que possam auxiliar na gestão do risco de inundação para bacia urbana da cidade de São Carlos. Portanto, foi desenvolvida uma metodologia para um índice de resiliência baseado no formato do índice de resiliência hídrica com base participativa (PWRI) e um índice de perigo para avaliação da vulnerabilidade das pessoas expostas em escoamento de água. Ambos os índices podem ser utilizados de forma complementar.

Para o índice de resiliência foram analisados os conceitos mais utilizados na área, apresentados os diversos significados e possível dificuldade na utilização dos mesmos para pessoas não especialistas e acostumadas com a terminologia. Foram apresentadas as inconsistências e realizada uma tentativa de adequação dos termos ao vocabulário e universo da população em geral.

Diversos mapas e formas de apresentação dos termos do índice de resiliência foram apresentados, seja a construção dos mapas de Ameaça e Risco, até a utilização de um indicador visual para os seis termos do índice de resiliência de forma simultânea.

Com relação ao segundo índice, o índice de perigo (IP), foi desenvolvida uma nova base teórica sobre o assunto a partir da inclusão do efeito do empuxo no equacionamento disponível na literatura. A inclusão do termo do empuxo levantou pontos até então não encontrados na literatura como a profundidade relativa, e os resultados parecem adequados quando comparados com dados experimentais. $\mathrm{O}$ equacionamento teórico também levanta a hipótese que o índice de perigo é melhor representado na forma de $h v^{2}$ (altura multiplicado pelo quadrado da velocidade) e não na forma mais utilizada $h v$.

Finalmente foram apresentadas algumas formas de utilização do indicador de perigo, assim como sugestões baseadas nas novas evidências encontradas no desenvolvimento teórico, como a utilização do conceito de altura relativa.

\subsection{RECOMENDAÇÕES}

Apesar dos resultados satisfatórios, existem vários pontos que podem ser melhorados no índice de resiliência. O primeiro é com relação à metodologia para geração do mapa de Vulnerabilidade. Neste trabalho foi utilizada uma metodologia sem nenhuma base física, 
embora os resultados estejam dentro do esperado. Utilizar modelos hidráulicos e hidrológicos pode gerar mapas mais precisos, apesar destes exigirem mais trabalho e dados de entrada mais complexos, e que mesmo assim podem apresentar resultados de precisão questionável.

Outro fato que incomoda é que todos os termos relacionados ao risco sofreram normalização de forma relativa, ou seja, as escala são gerados somente para a região de estudo. Desta forma os valores normalizados podem ser utilizados somente para comparação dentro da região de estudo, mas não com outras regiões nas quais um estudo similar pode ser aplicado. Uma forma de normalização absoluta que possa ser utilizada em diferentes regiões e que permita comparação entre elas pode ser valiosa.

A avaliação do Gerenciamento de Risco é outra etapa que pode ser aperfeiçoada. A forma utilizada avaliação é, na opinião do autor, muito simplista e subjetiva. As medidas de gerenciamento propostas são um bom indicador da direção a ser tomada no gerenciamento de risco, mas parece faltar uma base teórica e metodologia de avaliação mais sólidos.

A forma de apresentação do indicador de resiliência levanta uma questão: qual seria a relação ideal entre a análise de risco e o gerenciamento de risco? É suposto que regiões com baixo risco exigem poucas medidas de gerenciamento, enquanto regiões com alto risco precisam ter muitas medidas de gerenciamento de risco implantadas para serem regiões resilientes. Desta forma parece que resiliência pode ser definida como a relação entre a Avaliação do Risco e o Gerenciamento do Risco, algo como afirmar que a resiliência seria a relação entre a área vermelha (risco) e verde (gerenciamento) do gráfico.

Como recomendações para o índice de resiliência (PWRI) destacam-se:

- Utilizar uma função para gerar o mapa de Vulnerabilidade com alguma base física mais sólida, como modelos hidráulicos e hidrológicos.

- Substituir o filtro gaussiano por um filtro que represente a declividade dos pontos ao redor, de forma a distinguir as diferentes declividades e alturas no momento de cálculo do campo de influencia.

- Utilizar uma variante do indicador HAND (RENNÓ et al., 2008) que trabalha com a distância vertical aos vales. Além da distância vertical é possível incluir também o valor da área drenada de forma a indicar melhor regiões com maior volume de água devido escoamento superficial.

- Considerar o alcance das medidas de gerenciamento de risco e tempo necessário para aplicação das mesmas nos diferentes pontos da bacia. Ao considerar o alcance e 
diferentes capacidades das medidas de gerenciamento dentro de uma mesma área urbana pode ser possível gerar mapas distribuídos de gerenciamento.

- A nomenclatura dos termos proposto pelo formato PWRI não é homogênea: enquanto Ameaça, Vulnerabilidade e Exposição são substantivos, os termos Antes, Durante e Depois são advérbios. Uma sugestão é trocar os termos Antes, Durante e Depois por substantivos como Preparação, Resposta e Recuperação.

- Durante o trabalho surgiram dúvidas quanto à facilidade de compreensão das informações na apresentação do índice. Um estudo sobre a forma da apresentação da informação e a facilidade de sua interpretação pelo público alvo é necessário.

Para o indicador de perigo (IP) as recomendações são:

- Avaliação e comparação mais cuidadosa entre os termos $h v$ e $h v^{2}$.

- A partir dos resultados teóricos desenvolver uma ferramenta, um simulador, para avaliação da vulnerabilidade das pessoas para diferentes condições de altura e velocidade da água.

- Calcular em software SIG o índice de perigo (IP) de forma distribuída, a partir de dados como topografia, mapa de ocupação e precipitação, de forma a criar um mapa de perigo devido escoamento de água para toda uma área urbana ou cidade, a fim de identificar os pontos mais perigosos. 


\section{REFERÊNCIAS $^{5}$}

ABT, S. R. et al. Human stability in a high hazard flood zone. Water Resources Bulletin, v. 25, n. 4, p. 881-890, 1989.

AHMAD, S. S.; SIMONOVIC, S. P. A three-dimensional fuzzy methodology for flood risk analysis. Journal of Flood Risk Management, v. 4, n. 1, p. 53-74, 2011.

AHMAD, S.; SIMONOVIC, S. P. An intelligent decision support system for management of floods. Water Resources Management, v. 20, n. 3, p. 391-410, jun. 2006.

ALEXANDER, D. Natural disasters. London: Routledge, 1993.

ALEXANDER, D. Vulnerability to landslides. In: GLADE, T.; ANDERSON, M.; CROZIER, M. (Ed.). Vulnerability to landslides. Chichister: John Wiley, 2005. p. 175-198.

AMITRAJEET, A. B. The concept of resilience: retrospect and prospect. Environment and Development Economics, v. 3, p. 235-239, 1998.

BIRKMANN, J. Risk and vulnerability indicators at different scales: Applicability, usefulness and policy implications. Environmental Hazards, v. 7, n. 1, p. 20-31, 2007.

BLONG, R. Volcanic hazards risk assessment. In: SCARPA, R.; TILLING, R. I. (Ed.). Monitoring and Mitigation of Volcano Hazards. New York: Springer-Verlag Berlin Heidelberg, 1996. p. 675-689.

BOGARD, W. Bringing social theory to hazards research: conditions and consequences of the mitigation of environmental hazards. Sociological Perspectives, v. 31, p. 147-168, 1989.

BOHLE, H. G.; DOWNING, T.; WATTS, M. Climate change and social vulnerability: the sociology and geography of food insecurity. Global Environmental Change, v. 4, p. 37-48, 1994.

COMFORT, L. et al. Reframing disaster policy: the global evolution of vulnerable communities. Environmental Hazards, v. 1, p. 39-44, 1999.

CRICHTON, D. The risk triangle. Natural Disaster Management, p. 102-103, 1999.

DE ANDRADE, J. P. M. Previsão hidrometeorológica visando sistema de alerta antecipado de cheias em bacias urbanas. 2006. 112 f. Dissertação (Mestrado em Hidráulica e Saneamento) - Escola de Engenharia de São Carlos, Universidade de São Paulo, São Carlos, 2006.

DE BRUIJN, K. M. Resilience and flood risk management. Water Policy, v. 6, n. 1, p. 5366, 2004.

DE LA CRUZ-REYNA, S. Long-term probabilistic analysis of future explosive eruptions. Monitoring and Mitigation of Volcano Hazards, p. 599-629, 1996.

\footnotetext{
${ }^{5}$ Referências elaboradas de acordo com a NBR 6023/2002.
} 
DECINA, T. G. T. Análise de medidas de controle de inundações a partir da avaliação de cenários de uso e ocupação do solo na bacia hidrográfica do Córrego do Gregório, São Carlos. 2012. 177 f. Dissertação (Mestrado em Hidráulica e Saneamento) — Escola de Engenharia de São Carlos, Universidade de São Paulo, São Carlos, 2012.

DOW, K. Exploring differences in our common future(s): the meaning of vulnerability to global environmental change. Geoforum, v. 23, p. 417-436, 1992.

DOWNING, T. Vulnerability to hunger and coping with climate change in Africa. Global Environmental Change, v. 1, p. 365-380, 1991.

ENDOH, K.; TAKAHASHI, S. Numerically modeling personnel danger on a promenade breakwater due to overtopping waves. In: INTERNATIONAL CONFERENCE ON COASTAL ENGINEERING, 24., 2013, Kobe. Proceedings... Kobe: [s.n.], 2013. p. 10161029.

ESCOBAR, L. S. N. Metodología numérico-experimental para el análise del riesgo asociado a la escorrentia pluvial en una red de calles. 1999. Tese (Doutorado em Engenharia Civil)) — Universitat Politècnica de Catalunya, Barcelona, 1999.

FEDERAL OFFICE FOR CIVIL PROTECTION. The cycle of integrated risk management. Disponível em: <http://www.planat.ch/en/specialists/risk-management/>. Acesso em: 30 dez. 2013.

FOX, R. W.; MCDONALD, A. T. Introdução à mecânica dos fluídos. Brasil: Guanabara, 1988.

FUCHS, S.; HEISS, K.; HÜBL, J. Towards an empirical vulnerability function for use in debris flow risk assessment. Natural Hazards and Earth System Science, v. 7, n. 5, p. 495506, 2007.

GABOR, T.; GRIFFITH, T. The assessment of community vulnerability to acute hazardous materials incidents. Journal of Hazardous Materials, v. 8, p. 323-333, 1980.

GANOUlis, P. D. J. G. Engineering Risk Analysis of Water Pollution: Probabilities and Fuzzy Sets. Weinheim: VCH, 1994.

GILARD, O.; GIVONE, P. Flood risk management: new concepts and methods for objective negotiations. In: LEAVESLEY, G. H. et al. (Ed.). Destructive water: water-caused natural disasters, their abatement and control. Oxfordshire: IAHS Press, 1997. p. 145-155.

GIUNTOLI, I. Sistema Web-GIS participativo associado a indicadores de gestão descentrelizada de risco de inundações. 2008. 110 f. Dissertação (Mestrado em Hidráulica e Saneamento) - Escola de Engenharia de São Carlos, Universidade de São Paulo, São Carlos, 2008.

GRACIOSA, M. C. P. Modelo de seguro para risco hidrológicos com base em simulação hidráulico-hidrológica como ferramenta de gestão do risco de inundações. 2010. $163 \mathrm{f}$. Tese (Doutorado em Hidráulica e Saneamento) - Escola de Engenharia de São Carlos, Universidade de São Paulo, São Carlos, 2010. 
GRANGER, K. et al. Community Risk in Cairns: A Multi-hazard risk assessment,AGSO (Australian Geological Survey Organisation) Cities Project. [s.1.] Department of Industry, Science and Resources, 1999.

HANLEY, N. Resilience in social and economic systems: a concept that fails the cost-benefit test? Environment and Development Economics, v. 18, n. 2, p. 244-249, 2013.

HELLEBRANDT, F. A.; TEPPER, R. H.; BRAUN, G. L. Location of the cardinal anatomical orientation planes passing through the center of weight in young adults women. American Journal of Physiology, v. 121, p. 465-470, 1938.

HELM, P. Integrated risk management for natural and technological disasters. Tephra, v. 15, n. 1, p. 4-13, 1996.

HOLLING, C. S. Resilience and stability of ecological systems. Annual review of ecology and systematics, v. 4, p. 1-23, 1973.

INSTITUTO BRASILEIRO DE GEOGRAFIA E ESTATÍSTICA. Setores Centitários. Disponível em: <ftp://geoftp.ibge.gov.br/malhas_digitais/censo_2010/setores_censitarios/sp.zip>. Acesso em: 30 dez. 2013a.

Resultados do Universo. Disponível em: <ftp://ftp.ibge.gov.br/Censos/Censo_Demografico_2010/Resultados_do_Universo/Agregados _por_Setores_Censitarios/Base_informacoes_setores2010_universo_SP_Exceto_Capital.zip>. Acesso em: 30 dez. 2013b.

INCLINE. I Oficina Interdisciplinar Incline.São Paulo: 4 ago. 2013

ISHIGAKI, T. et al. Experimental study on evacuation from underground space in urban flood. In: IAHR Congresson, 31, 2005, Seoul. Proceedings... Seoul: [s.n.] 2005. CD-ROM.

JANINE, A. C. . Application of Hazard Index as Reference in Floods.6th International Cofenrece on Flood Management - ICFM6: Flood in a changing Environment. Anais...São Paulo: 2014

JENKS, G. F. The Data Model Concept in Statistical Mapping. International Yearbook of Cartography, v. 7, p. 186-190, 1967.

JHA, A. K.; BLOCH, R.; LAMOND, J. Cities and flooding a guide to integrated urban flood risk management for the 21st century. Washington, D.C.: World Bank, 2012.

JONKMAN, S. N.; KELMAN, I.; BAIN, V. A Physical interpretation of Human Stability in Flowing Water. In: INTERNATIONAL SYMPOSIUM ON STOCHSTIC HYDRAULICS. Niejmegen. Proceedings... the Netherlands: [s.n.].

JONKMAN, S. N.; PENNING-ROWSELL, E. Human Instability in Flood Flows. JAWRA Journal of the American Water Resources Association, v. 44, n. 5, p. 1208-1218, 2008.

KARVOnen, R. A. et al. The Use of Physical Models in Dam Break Analysis.: RESCDAM Final Report. Helsinki, Finland: Helsinki of Technology, 2000. 
KATES, R. The interaction of climate and society. In: Climate impact assessment. New York: Kates, R., Ausubel, J. and Berberian, M., 1985. p. 3-36.

KELMAN, I. Defining Risk. FloodRiskNet Newsletter, n. 2, 2003.

KLIJN, F.; VAN BUUREN, M.; VAN ROOIJ, S. A. Flood-risk management strategies for an uncertain future: living with Rhine river floods in the Netherlands? AMBIO: A Journal of the Human Environment, v. 33, n. 3, p. 141-147, 2004.

KOBIYAMA, M. et al. Prevenção de Desastres Naturais: Conceitos Básicos. 1. ed. Curitiba: Organic Trading, 2006.

LEVIN, S. A. et al. Resilience in natural and socioeconomic systems. Environment and Development Economics, v. 18, n. 02, p. 222-235, 2013.

LEWIS, J. Development in Disaster-prone Places: Studies of VulnerabilityIntermediate Technology Publications. Anais...London: 1999

LIND, N.; HARTFORD, D.; ASSAF, H. Hydrodynamic models of human stability in a flood. JAWRA Journal of the American Water Resources Association, v. 40, n. 1, p. 89-96, 2004.

MARENGO, J. A. et al. Development of regional future climate change scenarios in South America using the Eta CPTEC/HadCM3 climate change projections: climatology and regional analyses for the Amazon, São Francisco and the Paraná River basins. Climate Dynamics, v. 38, n. 9-10, p. 1829-1848, 10 ago. 2011.

MARSH. Preparing the local public sector for risk governance: First steps towards an ISO 31000 framework. MARSH, , 2011. Disponível em: 〈www.marsh.com>

MARTINS, L. G. B. Determinação de parâmetros hidrológicos por técnicas de sensoriamento remoto em macrodrenagem urbana. 2012. 113 f. Dissertação (Mestrado em Hidráulica e Saneamento) - Escola de Engenharia de São Carlos, Universidade de São Paulo, São Carlos, 2012.

MENDES, H. C. et al. Histórico de inundações na sub-bacia do Gregório, São Carlos SP: Notícias de Jornal de 1940 a 1996, 2004.

MENDIONDO, E. M. Reducing vulnerability to water-related disasters in urban areas of the humid tropics; in Integrated Urban Water Management: Humid Tropics. In: PARKINSON, J. N.; GOLDEFUM, J. N.; TUCCI, C. E. M. (Ed.). Integrated Urban Water Management: Humid Tropics. Paris: Unesco, 2010. v. 6p. 109-127.

MENDIONDO, E. M. et al. Towards participatory-based water resilience index for coupling vulnerability, impacts and adaptation strategies at areas under land use change. In: GLOBAL WATER SYSTEM PROJECT CONFERENCE. Bonn: 2013

MIRANDA, E. E. DE. Brasil em Relevo. Campinas: Embrapa Monitoramento por Satélite. Disponível em: <www.relevobr.cnpm.embrapa.br>. Acesso em: 18 jul. 2013.

MITCHEL, J. Hazards research. In: GAILE, G.; WILLMOTT, C. (Ed.). Geography in America. Colombus: Merill, 1989. p. 410-424. 
ORGANIZATION FOR ECONOMIC CO-OPERATION AND DEVELOPMENT. Handbook on constructing composite indicators: methodology and user guide. Paris: OECD, 2008.

PIJAWKA, K.; RADWAN, A. The transportation of hazardous materials: risk assessment and hazard management. Dangerous Properties of Industrial Materials Report, p. 2-11, 1985.

RENNÓ, C. D. et al. HAND, a new terrain descriptor using SRTM-DEM: Mapping terrafirme rainforest environments in Amazonia. Remote Sensing of Environment, v. 112, n. 9, p. 3469-3481, 2008.

SAYERS, P. . et al. Risk, Performance and Uncertainty in Flood and Coastal Defence - A Review. London: Crown, 2002.

SCHOLZ, M.; YANG, Q. Guidance on variables characterising water bodies including sustainable flood retention basins. Landscape and urban planning, v. 98, n. 3, p. 190-199, 2010.

SHAND, T. D.; COX, R. J.; BLACKA, M. J. AUSTRALIAN RAINFALL AND RUNOFF PROJECT 10: APPROPRIATE SAFETY CRITERIA FOR VEHICLES. 2011.

SMITH, K. Environmental Hazards: Assessing Risk and Reducing Disaster. 2. ed. London: Routledge, 1996.

SMITH, K. Environmental hazards. London: Routledge, 2001.

SOARES, M. B.; GAGNON, A. S.; DOHERTY, R. M. Conceptual elements of climate change vulnerability assessments: a review. International Journal of Climate Change Strategies and Management, v. 4, n. 1, p. 6-35, 2012.

STENCHION, P. Development and disaster management. The Australian Journal of Emergency Management, v. 12, n. 3, p. 40-44, 1997.

SUETSUGI, K. Control of the Floodwater and Improvements of Evacuation System for Floodplain Management. In: International Workshop. 1996, Hiroshima. Proceedings...Hiroshima: 1996

SUSMAN, O.; O'KEEFE, P.; WISNER, B. Global disasters: a radical interpretation. In: HEWITT, K. (Ed.). Interpretations of calamity. Boston: Allen \& Unwin, 1983. p. 264-283.

TIMMERMAN, P. Vulnerability, resilience and the collapse of society. 1981. Environmental Monograph, 1, Institute of Environmental Studies - University of Toronto, 1981.

TUCCI, C. E. M. Modelos Hidrológicos. Porto Alegre: Editora da Universidade/UFRGS/Associação Brasileira de Recursos Hídricos, 1998.

THE UNITED NATIONS. Natural hazards, unnatural disasters: the economics of effective prevention. Washington: The World Banck e The United Nations, 2010. 
UNITED NATIONS DEPARTMENT OF HUMANITARIAN AFFAIRS. Internationally Agreed Glossary of Basic Terms Related to Disaster Management.Geneva: UN DHA (United Nations Department of Humanitarian Affairs), 1992

UNITED NATIONS DISASTER RELIEF CO-ORDINATOR. Natural disasters and vulnerability analysis. Geneva: Office of the United Nations Disaster Relief Coordinator, 1982.

. Mitigation natural disasters: phenomena, effects, and op-tions. A manual for policy makers and planners. Geneva: Office of the United Nations Disaster Relief Coordinator, 1991.

UNITED NATIONS INTERNATIONAL STRATEGY FOR DISASTER REDUCTION. How to Make Cities More Resilient: A Handbook For Local Government Leaders. Genebra: UNISDR, 2012.

VARNES, D. Landslide hazard zonation: a review of principles and practice. Paris: UNESCO, 1984.

WATTS, M.; BOHLE, H. G. The space of vulnerability: the causal structure of hunger and famine. Human Geogr., v. 17, p. 43-67, 1993.

WEICHSELGARTNER, J.; BERTENS, J. Natural disasters: acts of God, nature or society. In: Risk Analysis II. Southampton: Brebbia, C., 2000. p. 3-12.

WEN, Y. K. et al. Vulnerability function framework for consequence-based engineering. [s.1.] Mid-America Earthquake Center, 2004.

WISNER, B. et al. At risk. London: Routledge, 2004.

WOLF, S. et al. Clarifying vulnerability definitions and assessments using formalisation. International Journal of Climate Change Strategies and Management, v. 5, n. 1, p. 54$70,2013$.

ZONENSEIN, J. Índice de Risco de Cheia como Ferramenta de Gestão de Enchentes. 2007. 105 f. Dissertação (Mestrado em Engneharia Civil) - COPPE/UFRJ, Rio de Janeiro, 2007. 


\section{APÊNDICE A - CÓDIGO FONTE MATLAB}

Código fonte do arquivo vulnerabilidade.m utilizado para geração de mapa de vulnerabilidade a partir do escoamento acumulado gerado no software ArcGis:

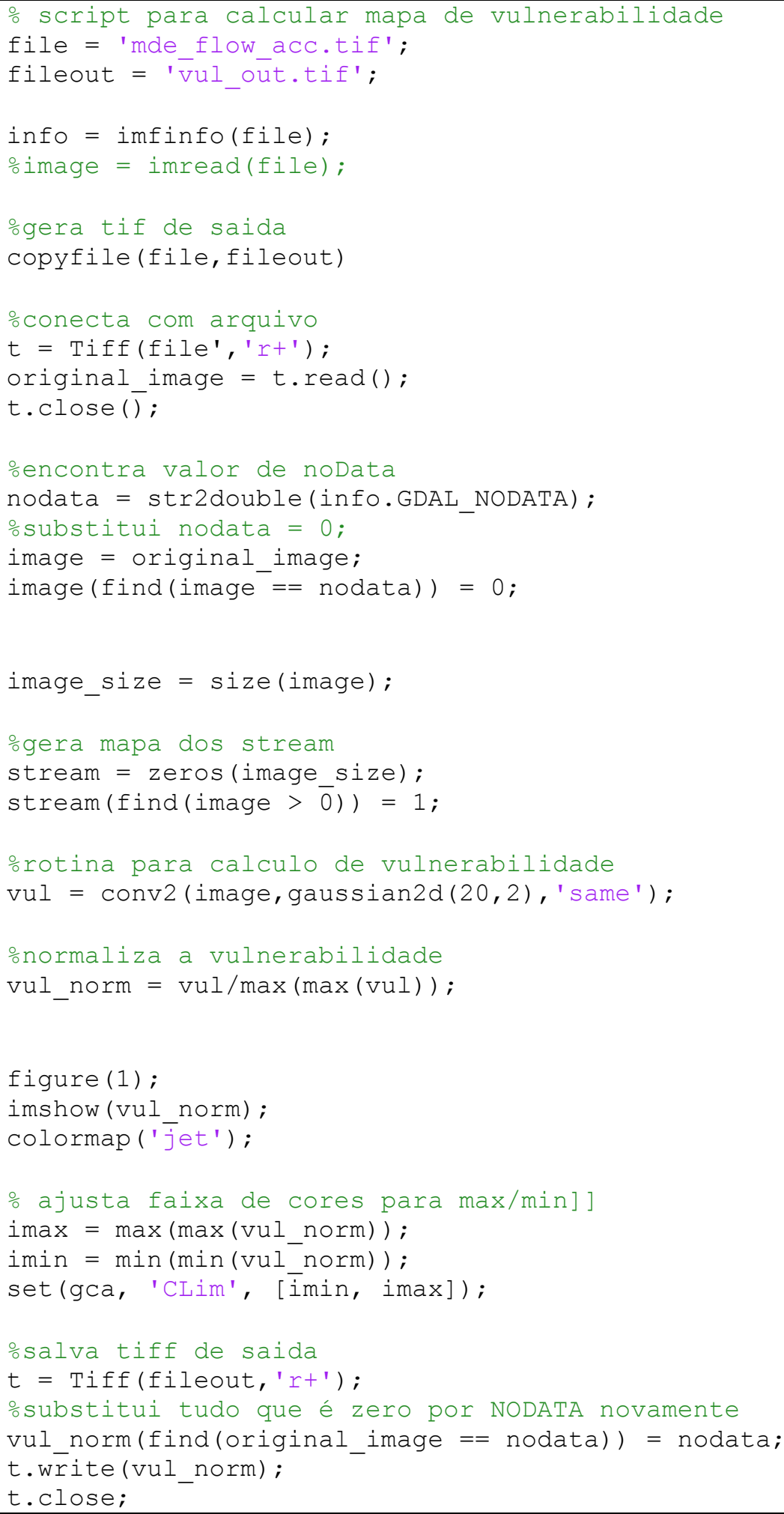


Código fonte do arquivo gaussian2d.m utilizado para geração da função gaussiana 2D utilizada na filtragem do mapa de escoamento acumulado:

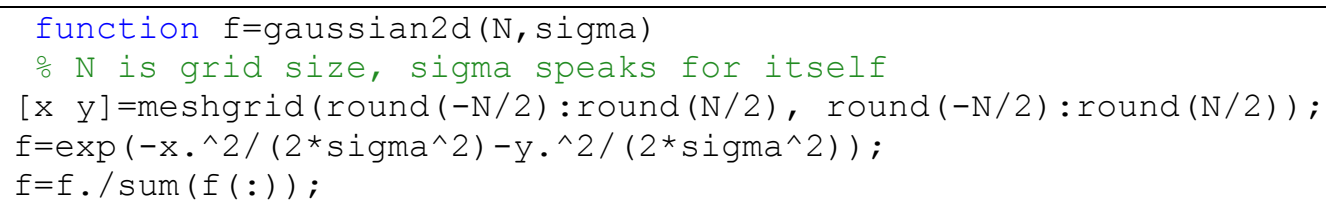

Código fonte do arquivo histPeriodos.m para geração de histograma do escoamento superficial para São Carlos a partir dos dados fornecidos pelo INPE.

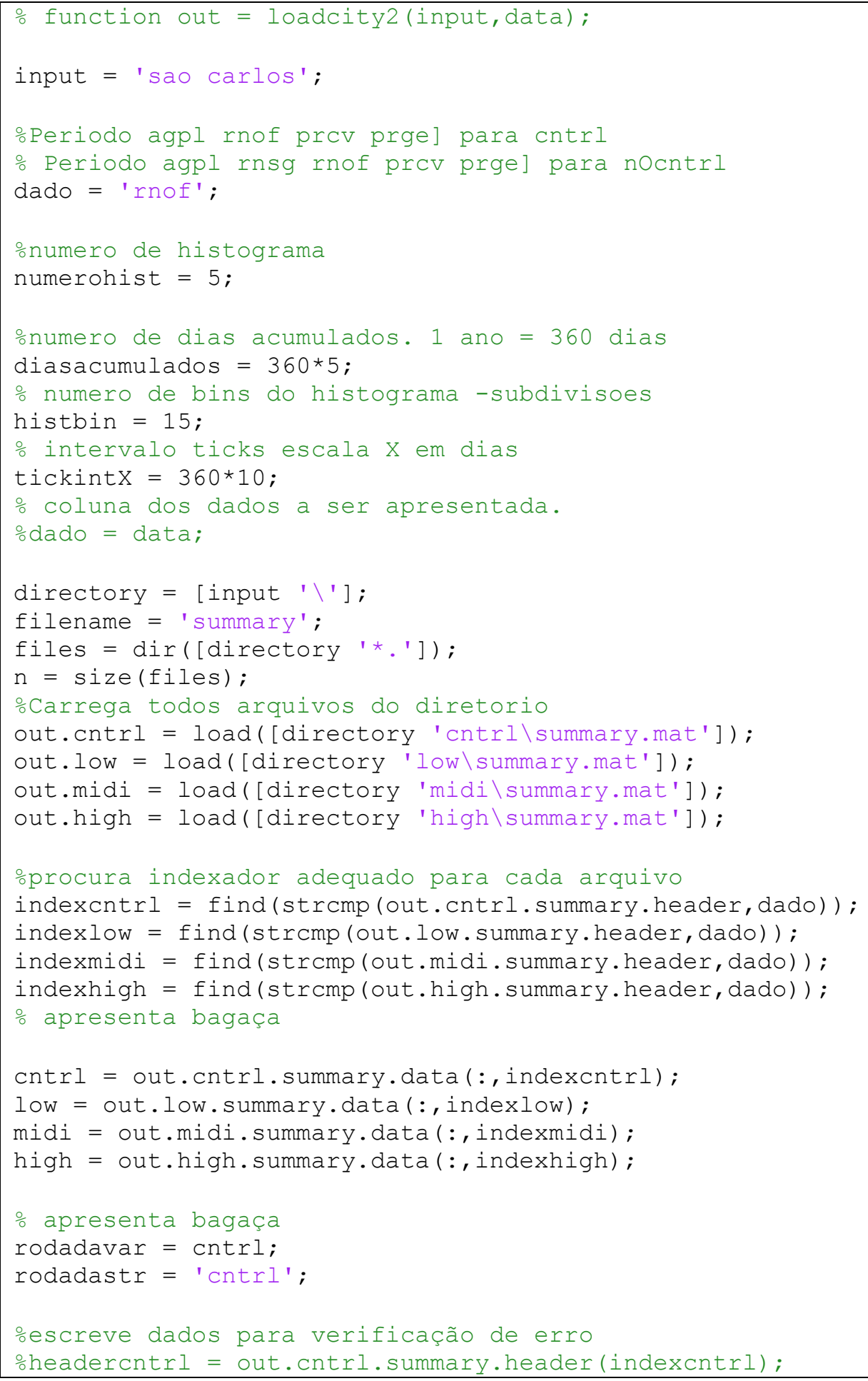




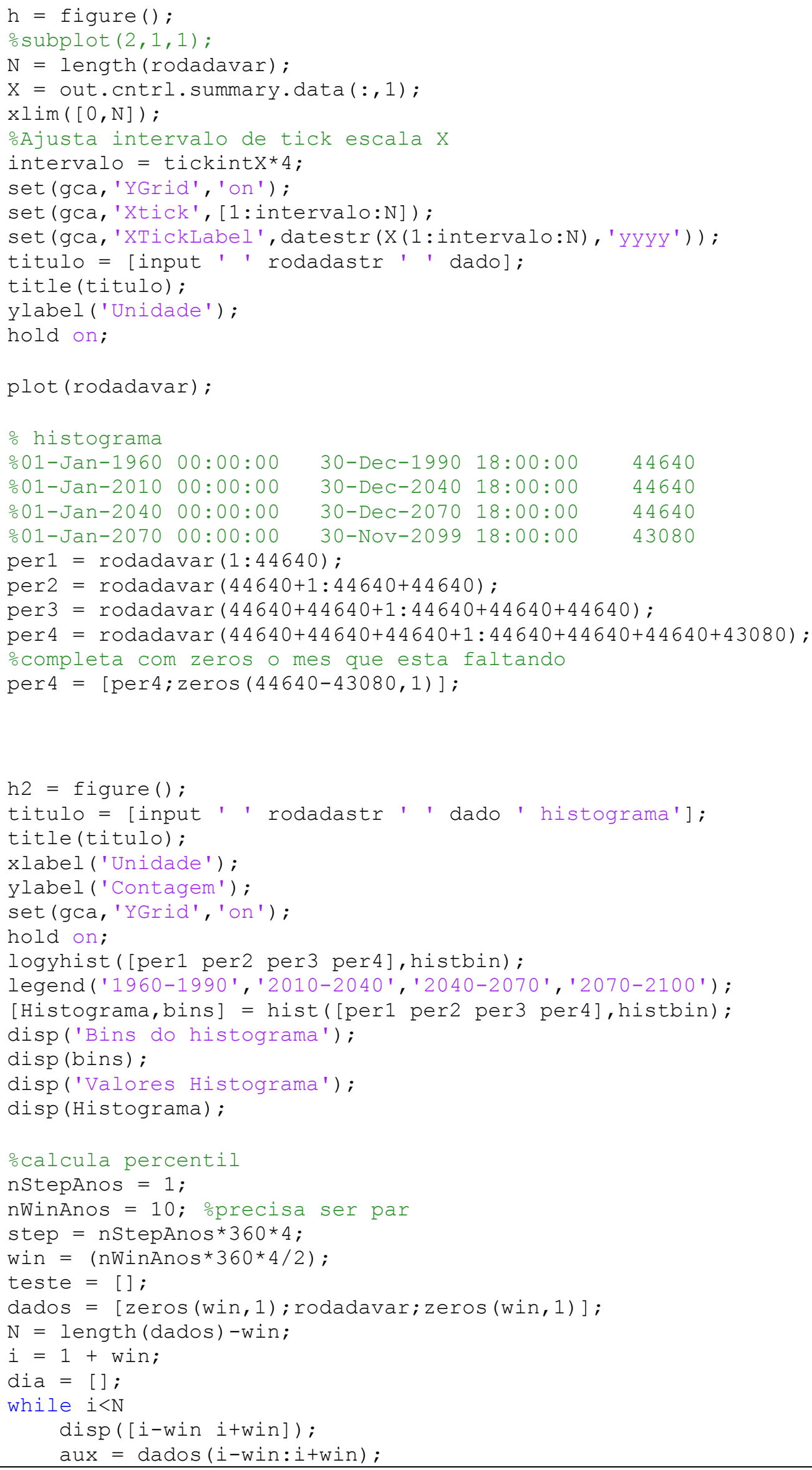




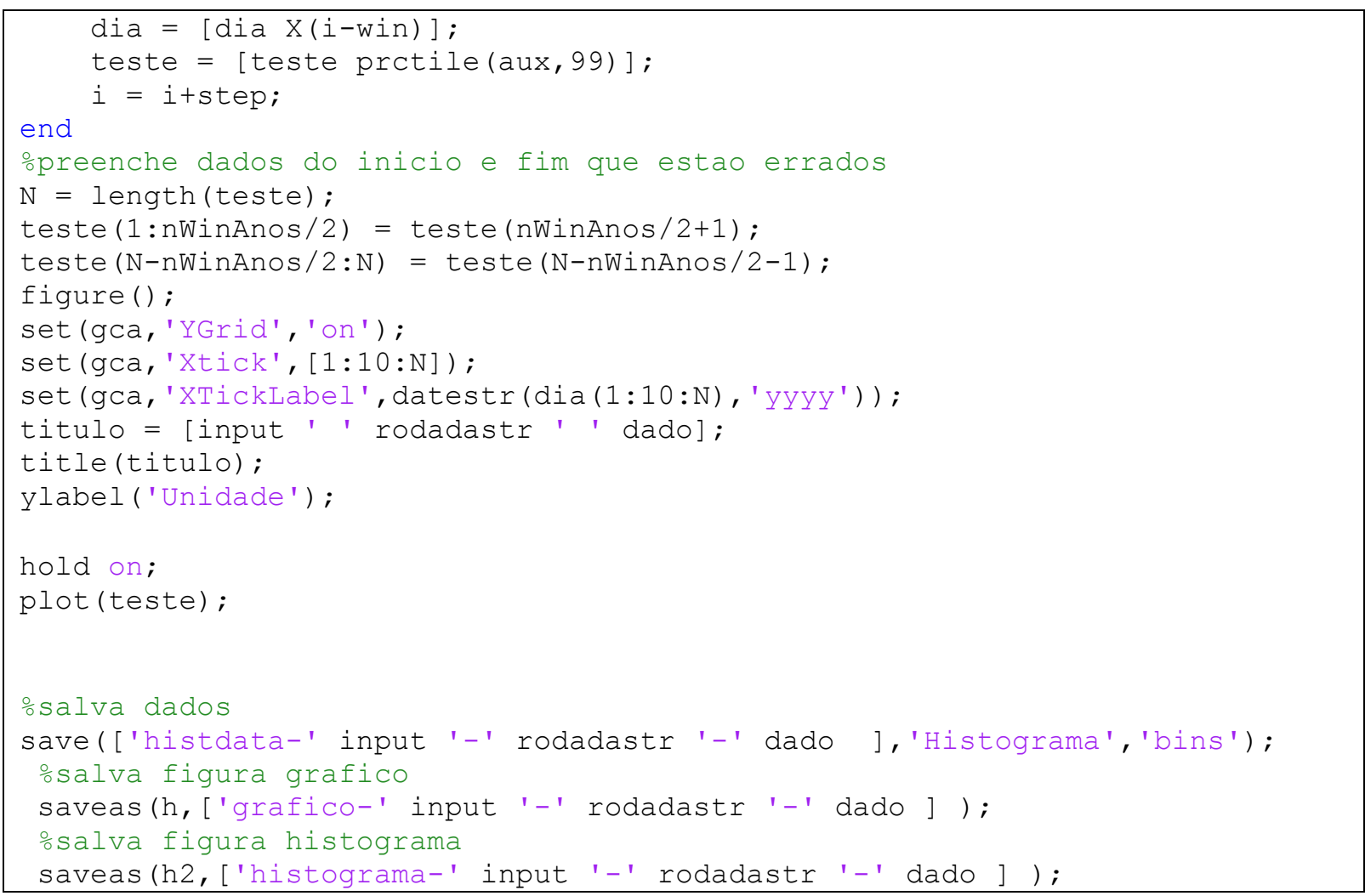

Código fonte do arquivo logyhist.m. Esta função é chamada para apresentar o gráfico do histograma em escala logarítmica, visto que a função original do MatLab contém um bug.

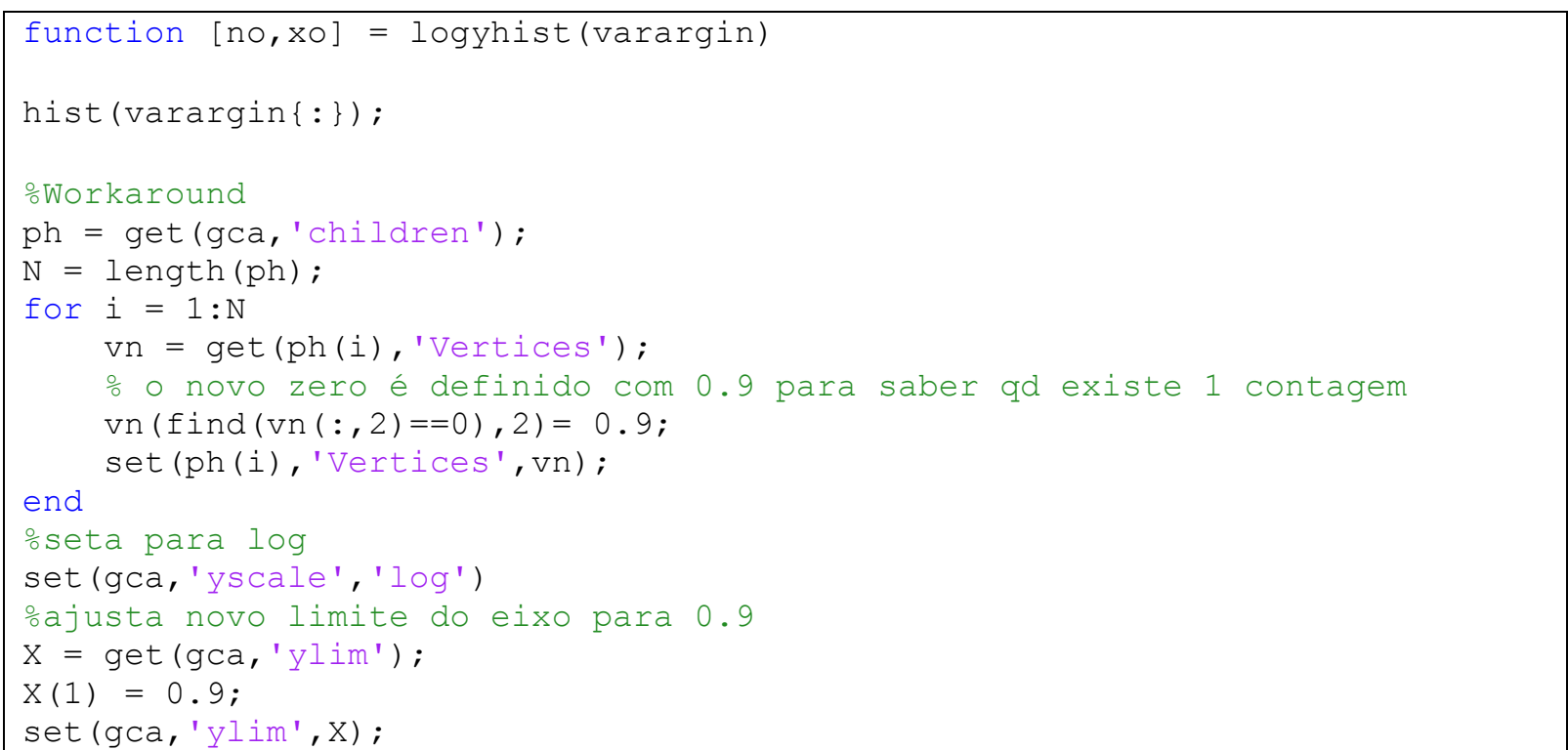

Código fonte do arquivo percentilAmeaca.m. Esta função é utilizada para cálculo do percentil e apresentação do gráfico de forma contínua no tempo. Ela calcula o percentil para uma janela determinada, em intervalos fixos.

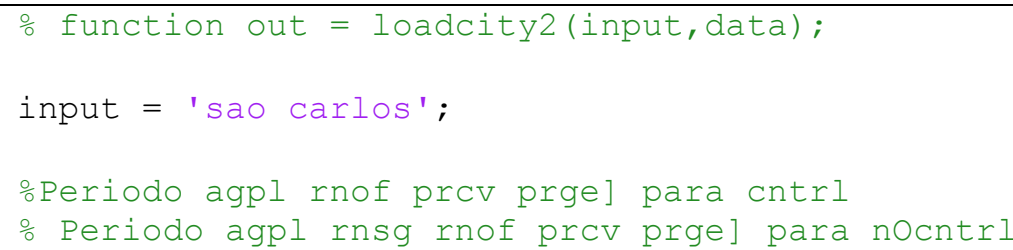




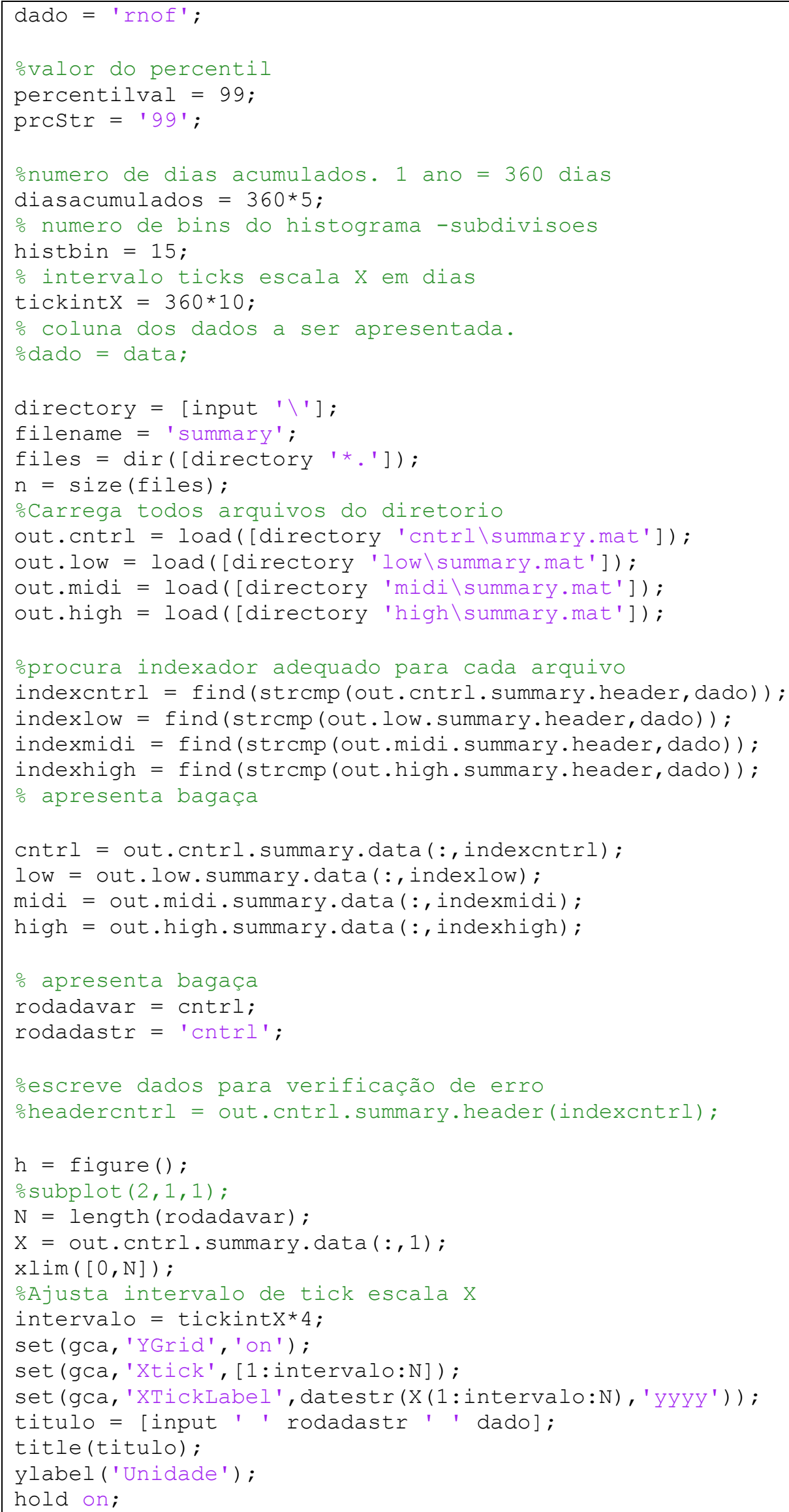




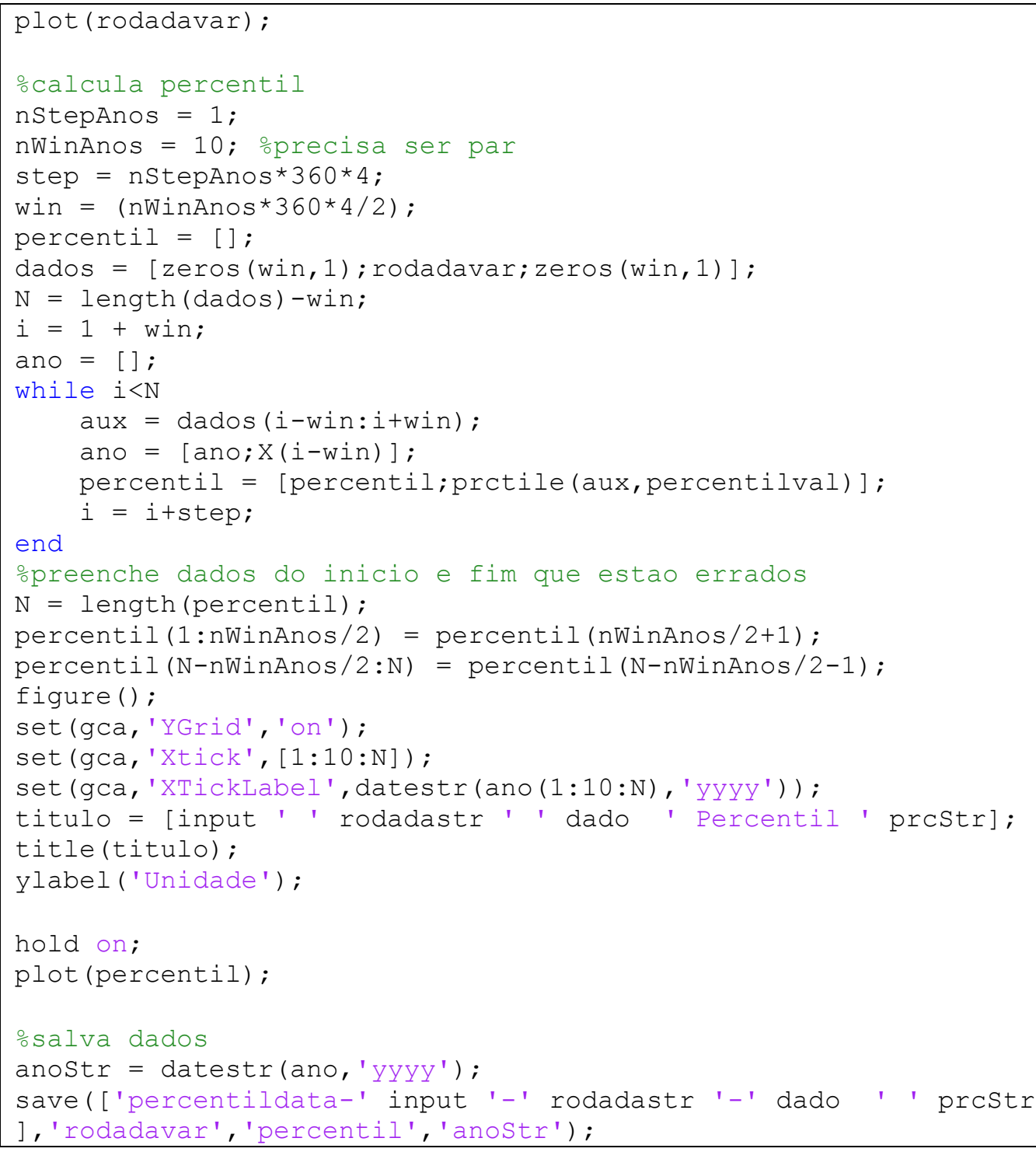


APÊNDICE B - ESCOAMENTO SUPERFICIAL E HISTOGRAMA

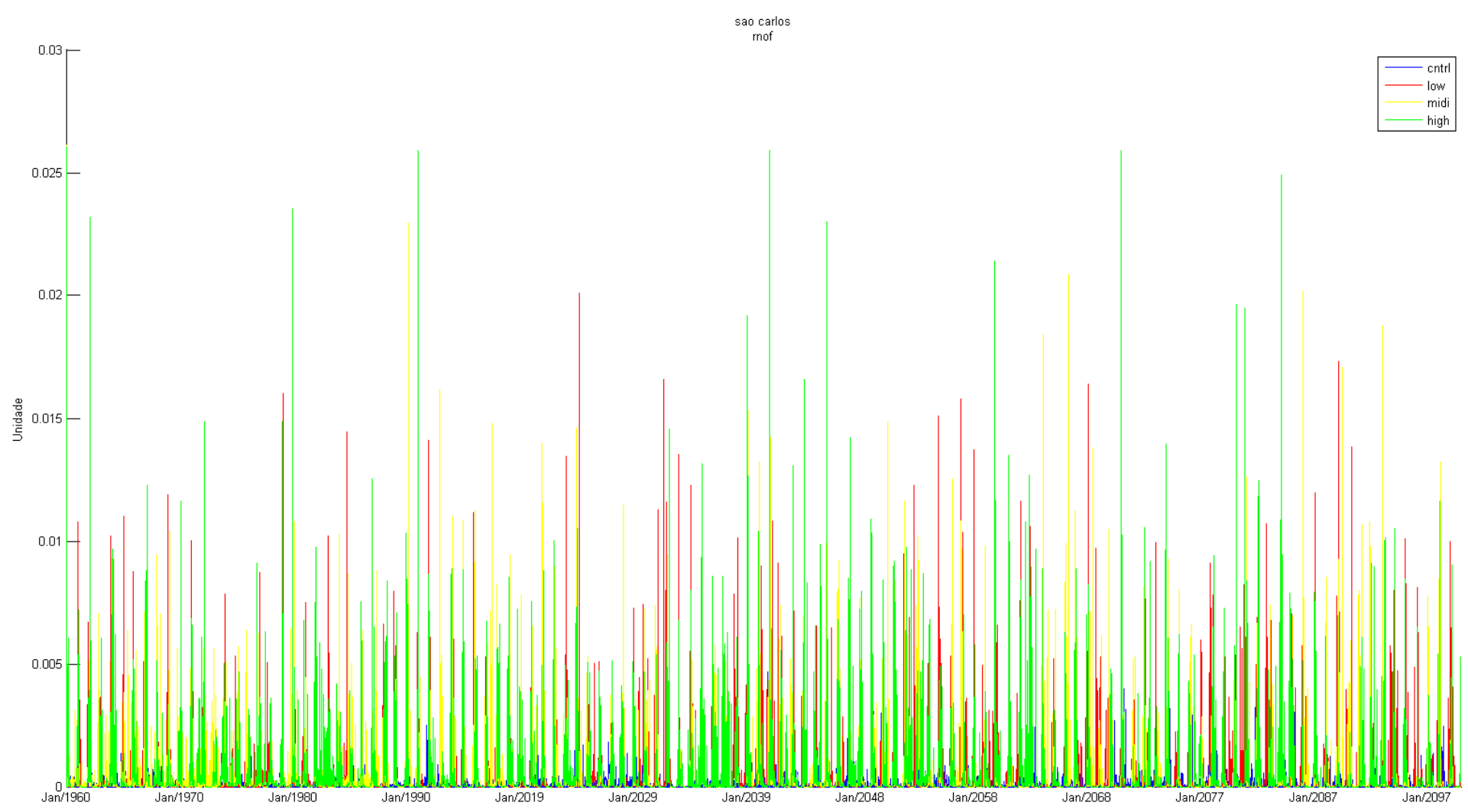

Figura 50 - Escoamento superficial simulado pelo INPE. 


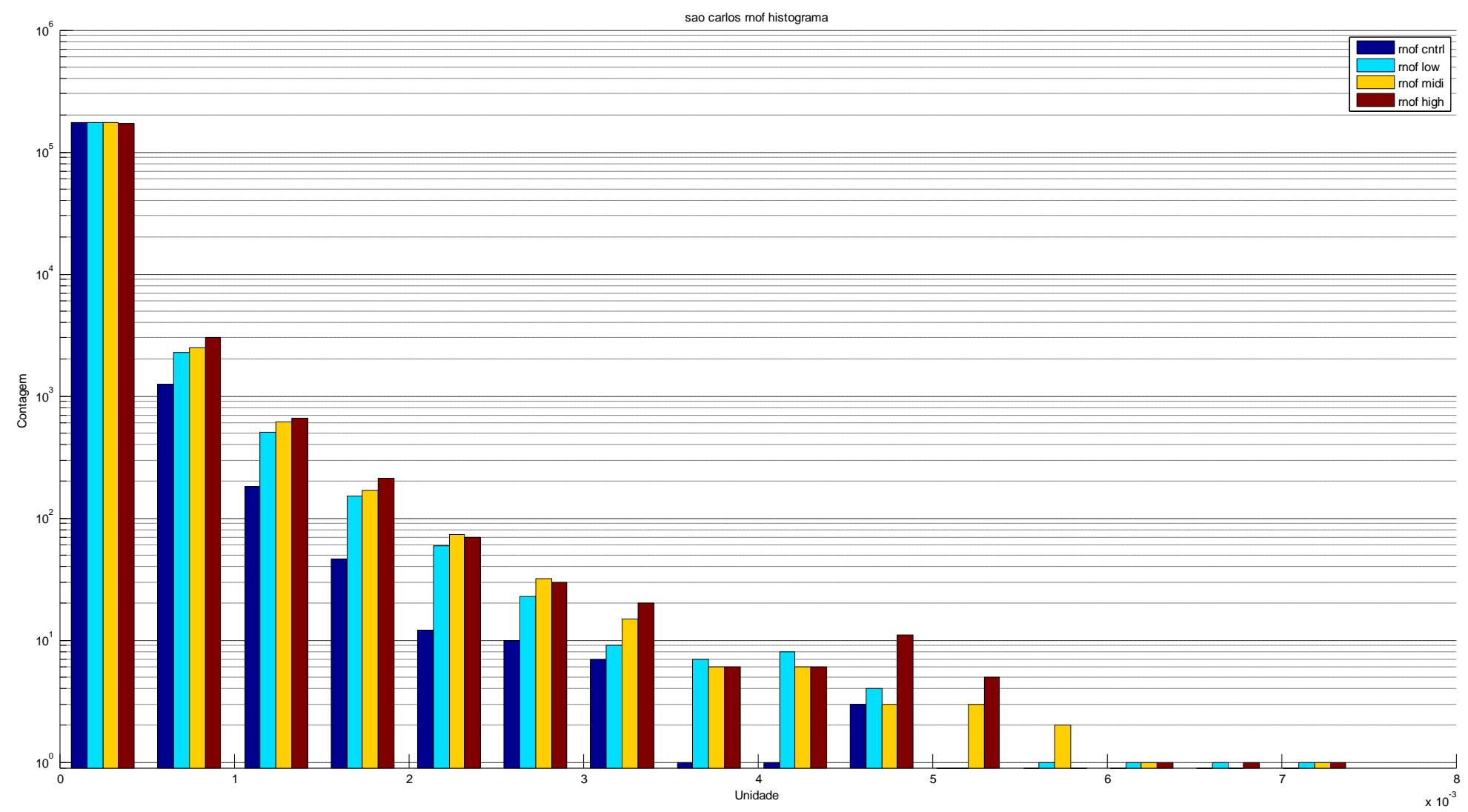

Figura 51 - Histograma do escoamento superficial simulado pelo INPE. 


\section{APÊNDICE C - ÍNDICE DE RESILIÊNCIA}
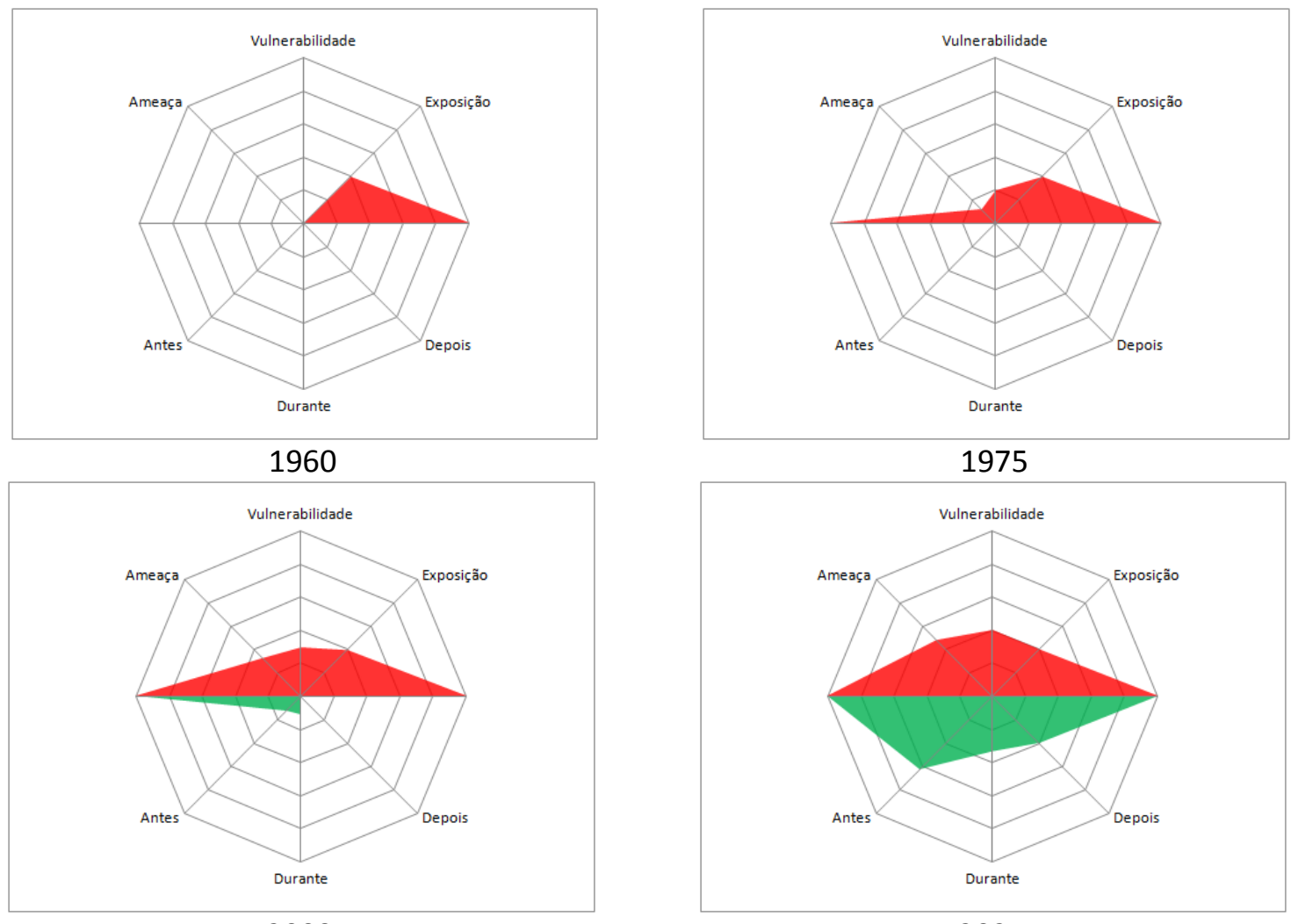

1975

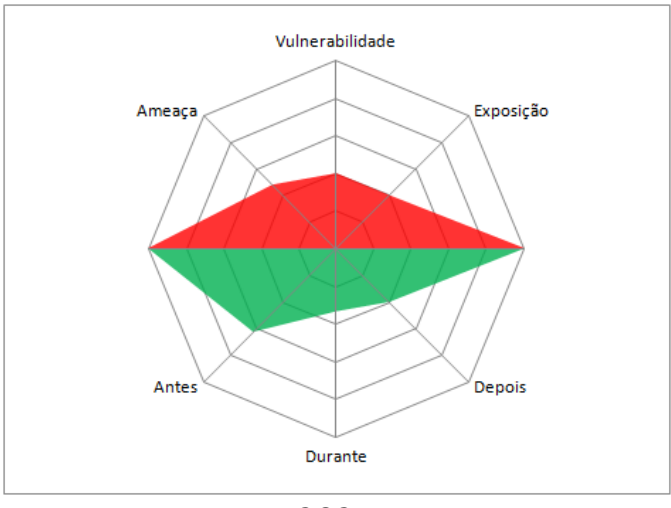

2003

2025
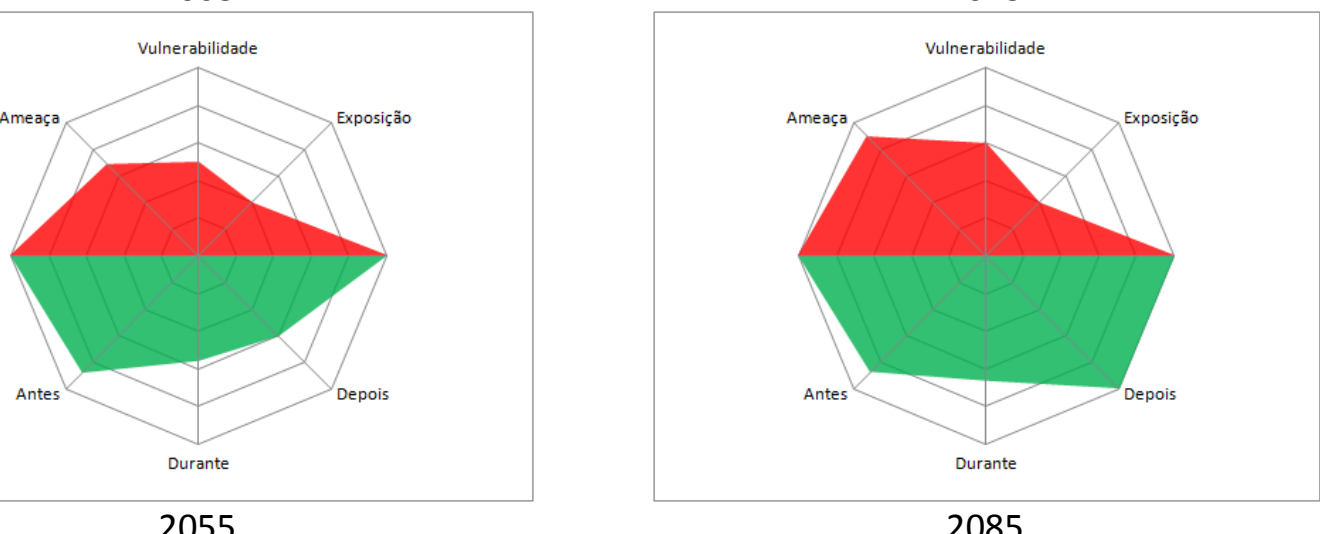

2055

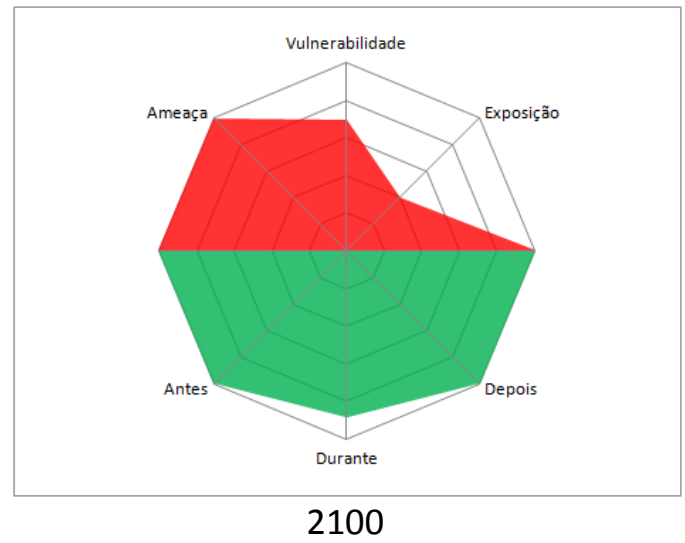

Figura 52 - Índice de resiliência para Kartódromo. 


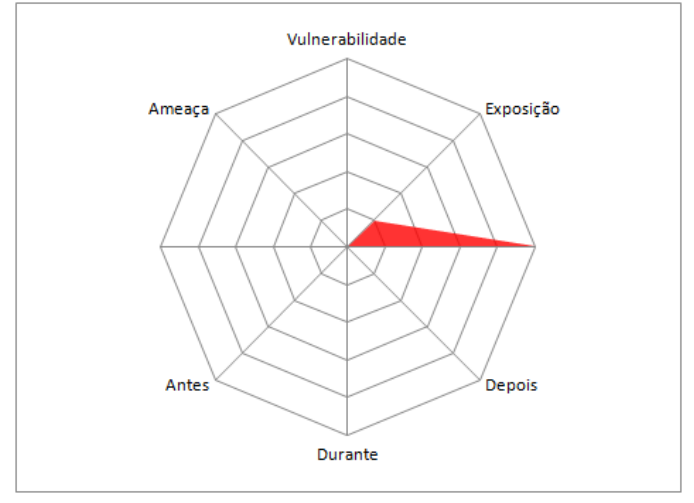

1960

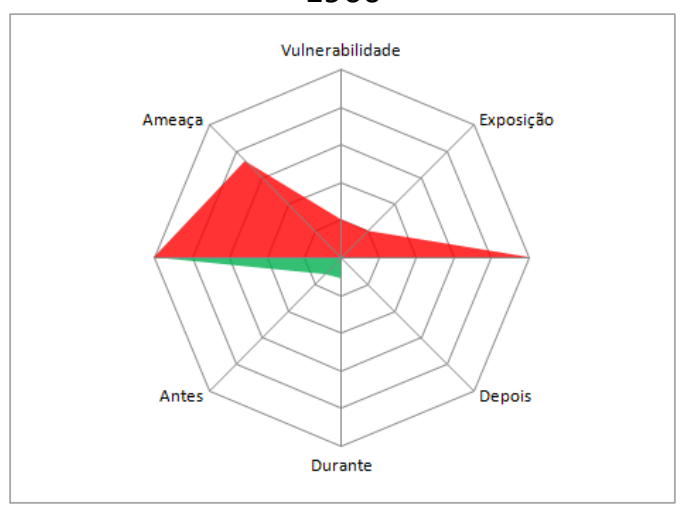

2003

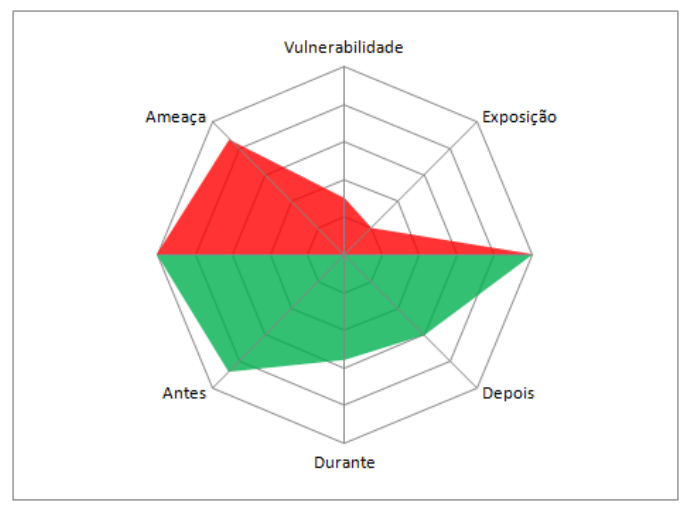

2055

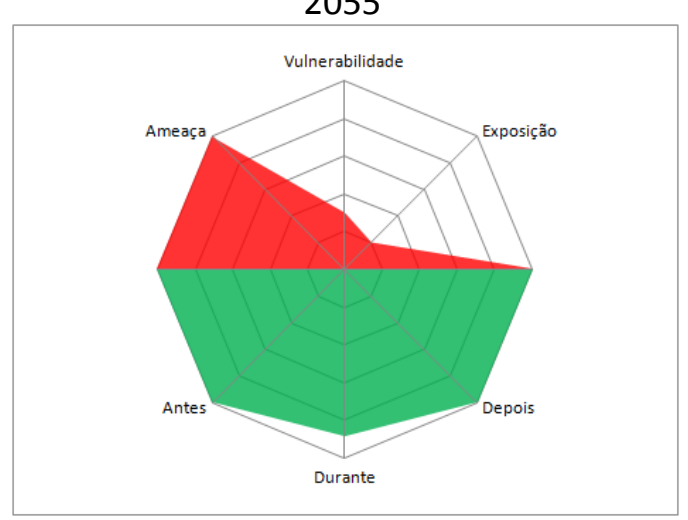

2100

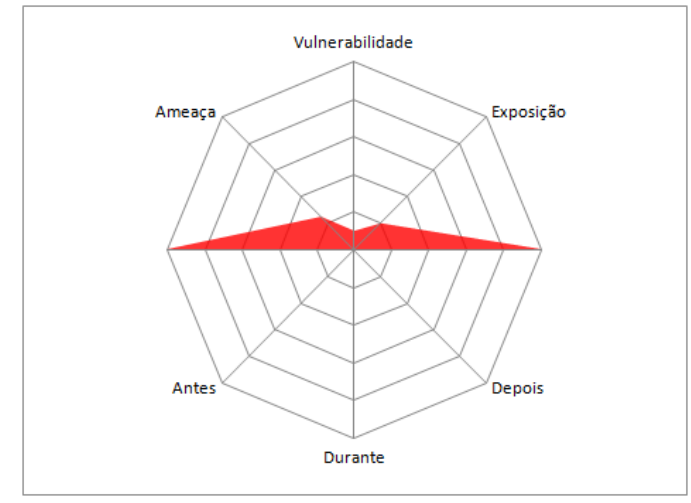

1975

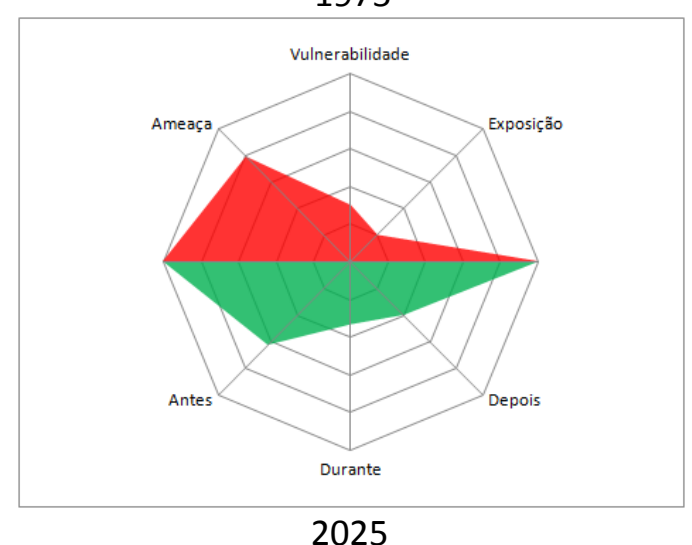

2025

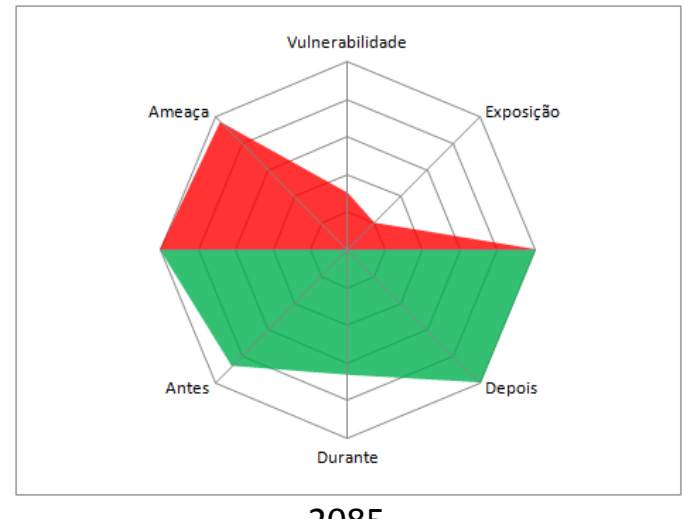

2085

Figura 53 - Índice de resiliência para Mercado Municipal. 


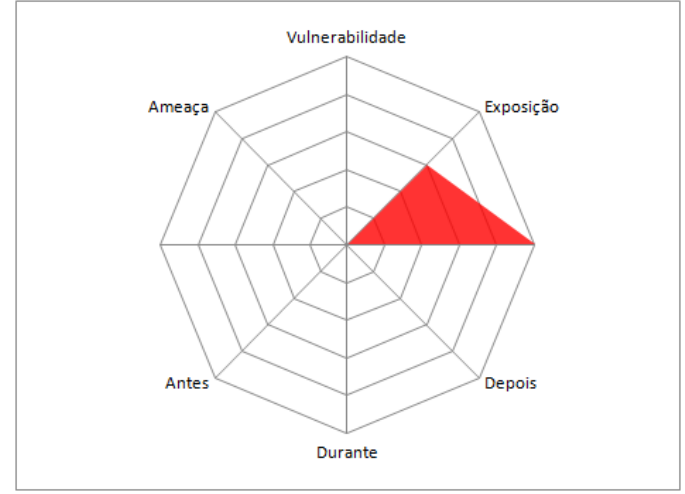

1960

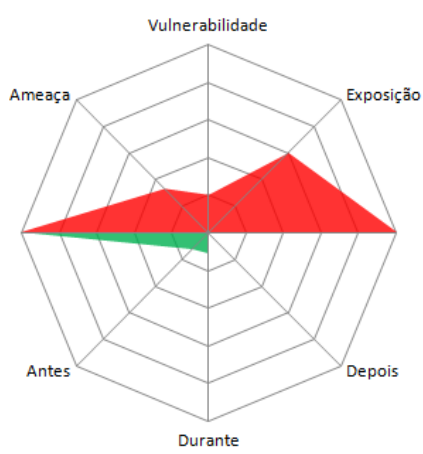

2003

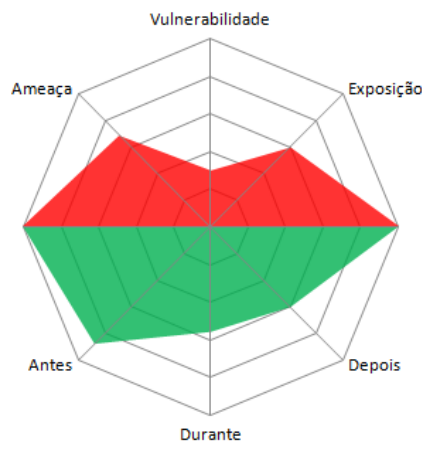

2055

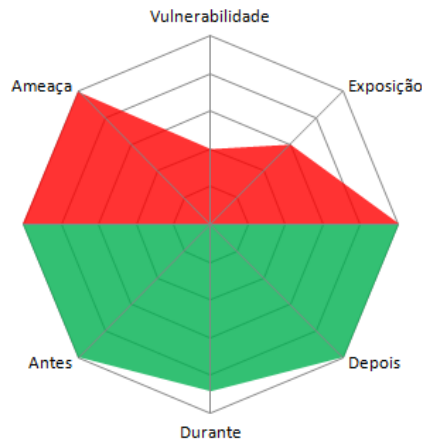

2100

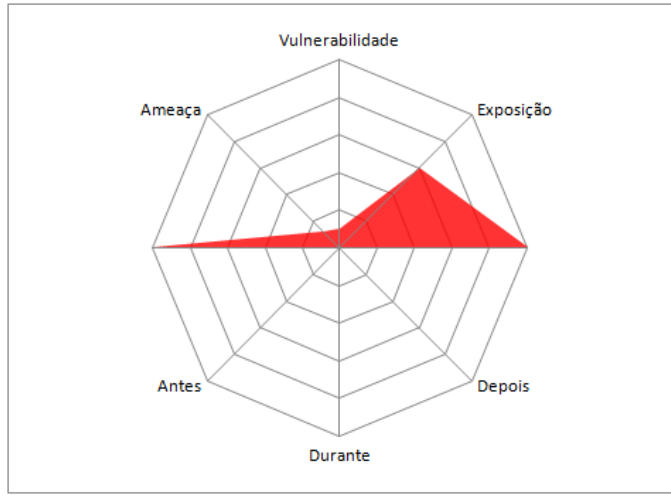

1975

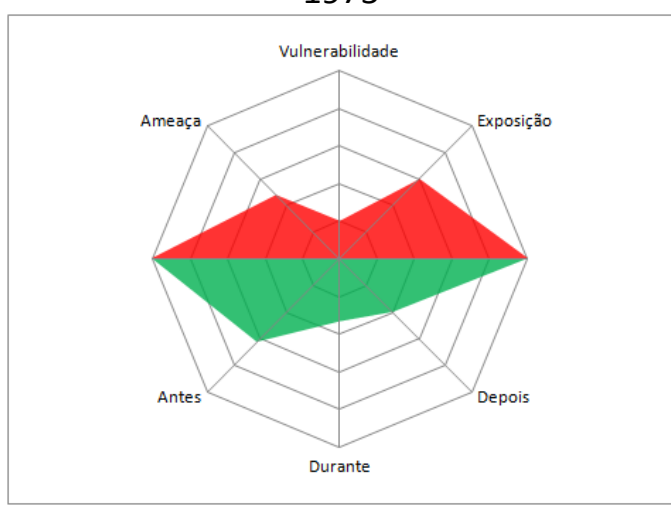

2025

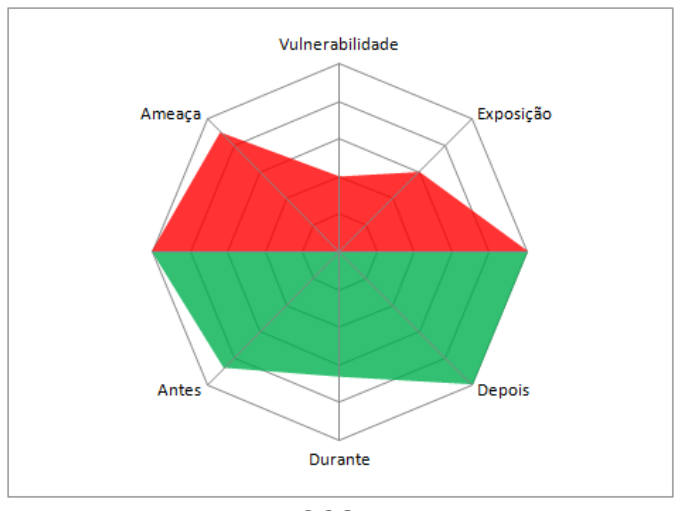

2085

Figura 54 - Índice de resiliência para Alto do Monjolinho. 


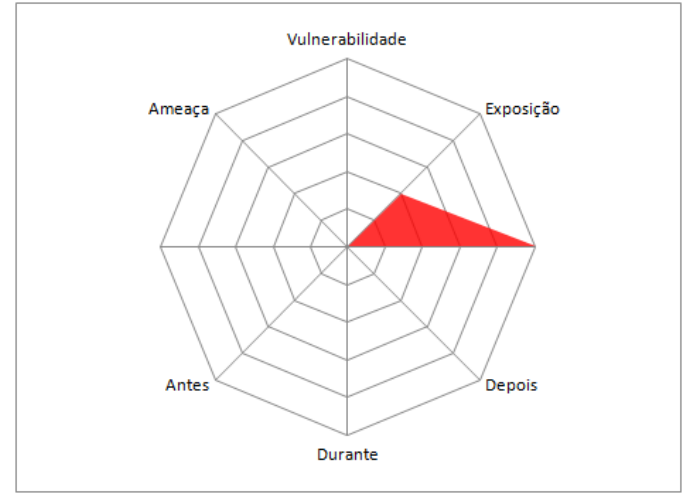

1960

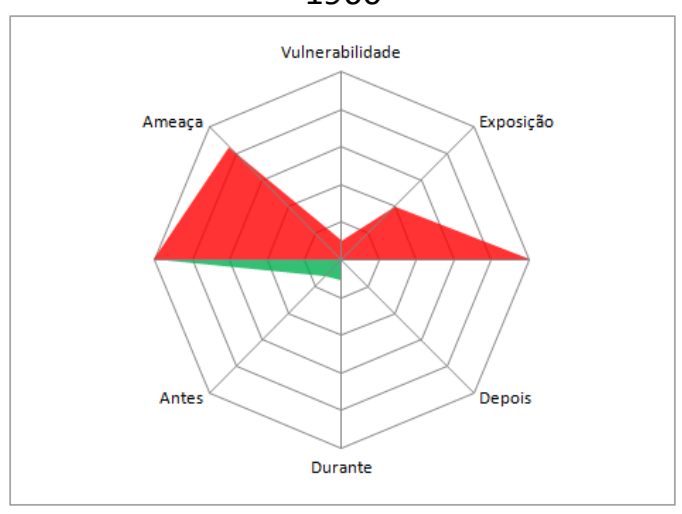

2003

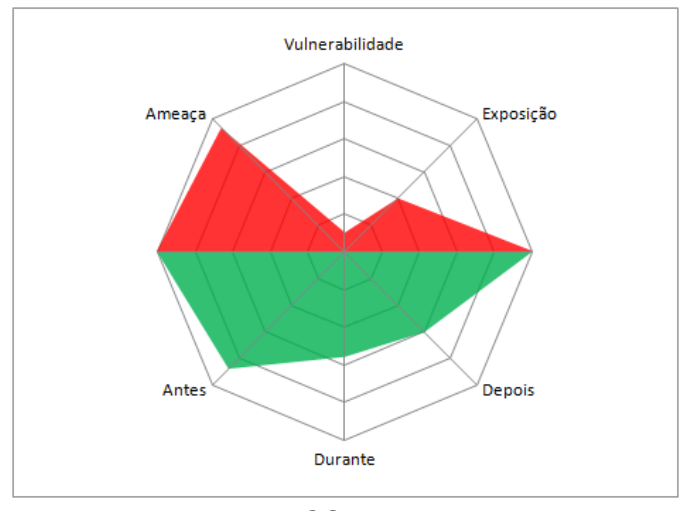

2055

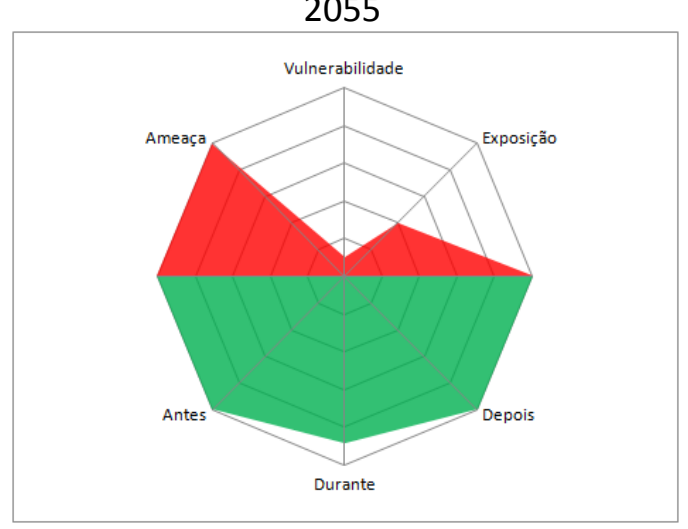

2100

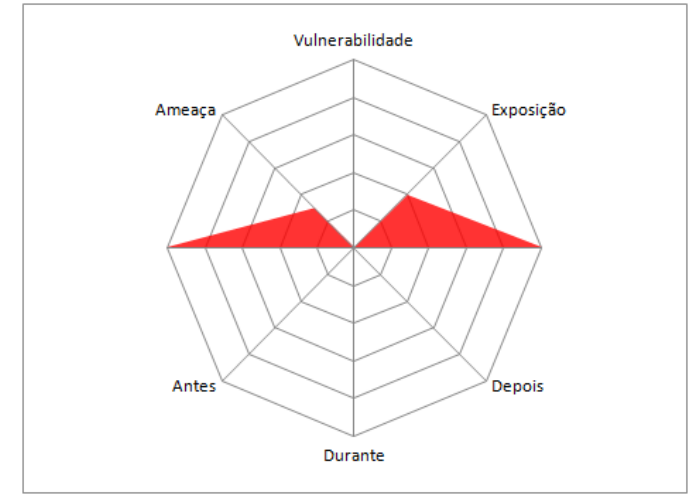

1975

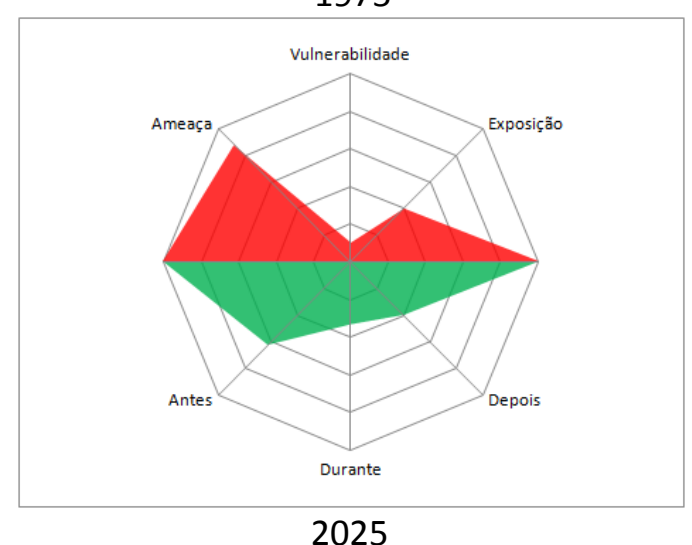

2025

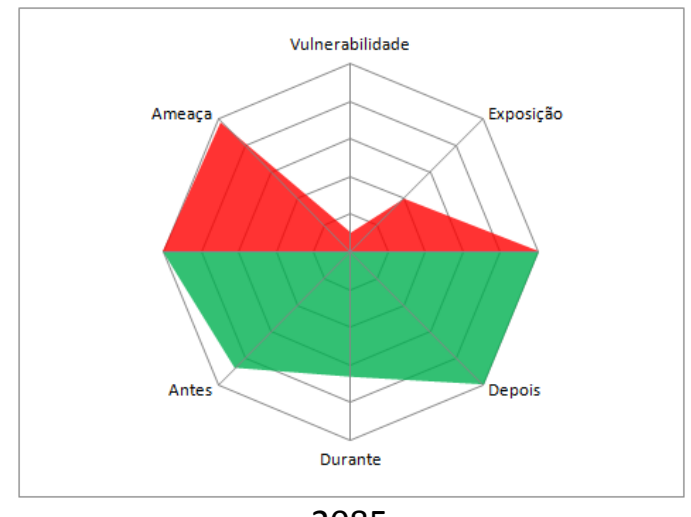

2085

Figura 55 - Índice de resiliência para Rodoviária. 


\section{ANEXO A - TABELA DE PRECIPITAÇÃO HISTÓRICA}

Tabela 21 - Datas com ocorrência de precipitação diária maior que 70 mm para São Carlos.

\begin{tabular}{|c|c|c|c|c|}
\hline Data & Precipitação diária & Estação & Latitude & Longitude \\
\hline 05/03/1942 & 100,8 & D4-045 & $22^{\circ} 02^{\prime} \mathrm{S}$ & $47^{\circ} 58^{\prime} W$ \\
\hline $12 / 03 / 1942$ & 88 & D4-045 & $22^{\circ} 02^{\prime} \mathrm{S}$ & $47^{\circ} 58^{\prime} W$ \\
\hline 12/10/1943 & 99 & D4-045 & $22^{\circ} 02^{\prime} \mathrm{S}$ & $47^{\circ} 58^{\prime} W$ \\
\hline $16 / 01 / 1945$ & 90 & D4-045 & $22^{\circ} 02^{\prime} \mathrm{S}$ & $47^{\circ} 58^{\prime} W$ \\
\hline $13 / 11 / 1953$ & 81,4 & D4-045 & $22^{\circ} 02^{\prime} \mathrm{S}$ & $47^{\circ} 58^{\prime} W$ \\
\hline $01 / 12 / 1953$ & 70 & D4-045 & $22^{\circ} 02^{\prime} \mathrm{S}$ & $47^{\circ} 58^{\prime} W$ \\
\hline 05/01/1954 & 91,2 & D04-17 & $22^{\circ} 01^{\prime} \mathrm{S}$ & $47^{\circ} 53^{\prime} W$ \\
\hline 02/05/1956 & 81,8 & D04-17 & $22^{\circ} 01^{\prime} \mathrm{S}$ & $47^{\circ} 53^{\prime} W$ \\
\hline $12 / 06 / 1956$ & 80 & D04-17 & $22^{\circ} 01^{\prime} \mathrm{S}$ & $47^{\circ} 53^{\prime} W$ \\
\hline $15 / 01 / 1957$ & 106,4 & D04-17 & $22^{\circ} 01^{\prime} \mathrm{S}$ & $47^{\circ} 53^{\prime} W$ \\
\hline 02/04/1957 & 104,2 & D04-17 & $22^{\circ} 01^{\prime} \mathrm{S}$ & $47^{\circ} 53^{\prime} W$ \\
\hline 20/01/1958 & 99 & D04-17 & $22^{\circ} 01^{\prime} \mathrm{S}$ & $47^{\circ} 53^{\prime} W$ \\
\hline $11 / 12 / 1958$ & 70,4 & D04-17 & $22^{\circ} 01^{\prime} \mathrm{S}$ & $47^{\circ} 53^{\prime} W$ \\
\hline 09/01/1960 & 77 & D04-17 & $22^{\circ} 01^{\prime} \mathrm{S}$ & $47^{\circ} 53^{\prime} W$ \\
\hline 06/01/1960 & 71,6 & D04-17 & $22^{\circ} 01^{\prime} \mathrm{S}$ & $47^{\circ} 53^{\prime} W$ \\
\hline $16 / 12 / 1960$ & 76,2 & D04-17 & $22^{\circ} 01^{\prime} \mathrm{S}$ & $47^{\circ} 53^{\prime} W$ \\
\hline $19 / 12 / 1960$ & 72,6 & D04-17 & $22^{\circ} 01^{\prime} \mathrm{S}$ & $47^{\circ} 53^{\prime} W$ \\
\hline $21 / 12 / 1960$ & 91,4 & D04-17 & $22^{\circ} 01^{\prime} \mathrm{S}$ & $47^{\circ} 53^{\prime} W$ \\
\hline $12 / 02 / 1961$ & 75,2 & D04-17 & $22^{\circ} 01^{\prime} \mathrm{S}$ & $47^{\circ} 53^{\prime} W$ \\
\hline $30 / 12 / 1962$ & 71,5 & D04-17 & $22^{\circ} 01^{\prime} \mathrm{S}$ & $47^{\circ} 53^{\prime} W$ \\
\hline $20 / 01 / 1965$ & 76,6 & D04-17 & $22^{\circ} 01^{\prime} \mathrm{S}$ & $47^{\circ} 53^{\prime} W$ \\
\hline $23 / 02 / 1965$ & 110,1 & D04-17 & $22^{\circ} 01^{\prime} \mathrm{S}$ & $47^{\circ} 53^{\prime} W$ \\
\hline $27 / 02 / 1965$ & 73 & D04-17 & $22^{\circ} 01^{\prime} \mathrm{S}$ & $47^{\circ} 53^{\prime} W$ \\
\hline $10 / 12 / 1965$ & 86,4 & D04-17 & $22^{\circ} 01^{\prime} \mathrm{S}$ & $47^{\circ} 53^{\prime} W$ \\
\hline $23 / 12 / 1966$ & 99,1 & D04-17 & $22^{\circ} 01^{\prime} \mathrm{S}$ & $47^{\circ} 53^{\prime} W$ \\
\hline $13 / 01 / 1968$ & 75,2 & D04-17 & $22^{\circ} 01^{\prime} \mathrm{S}$ & $47^{\circ} 53^{\prime} W$ \\
\hline 27/11/1968 & 98,2 & D04-17 & $22^{\circ} 01^{\prime} \mathrm{S}$ & $47^{\circ} 53^{\prime} W$ \\
\hline 13/01/1969 & 75,2 & D04-17 & $22^{\circ} 01^{\prime} \mathrm{S}$ & $47^{\circ} 53^{\prime} W$ \\
\hline $16 / 01 / 1970$ & 103,6 & D4-075 & $22^{\circ} 01^{\prime} \mathrm{S}$ & $47^{\circ} 53^{\prime} W$ \\
\hline $18 / 01 / 1970$ & 102 & D4-075 & $22^{\circ} 01^{\prime} \mathrm{S}$ & $47^{\circ} 53^{\prime} \mathrm{W}$ \\
\hline $17 / 01 / 1970$ & 92,2 & D4-075 & $22^{\circ} 01^{\prime} \mathrm{S}$ & $47^{\circ} 53^{\prime} W$ \\
\hline $14 / 03 / 1970$ & 71,8 & D4-075 & $22^{\circ} 01^{\prime} \mathrm{S}$ & $47^{\circ} 53^{\prime} W$ \\
\hline 24/02/1972 & 109,8 & D4-075 & $22^{\circ} 01^{\prime} \mathrm{S}$ & $47^{\circ} 53^{\prime} W$ \\
\hline 13/07/1972 & 82,8 & D4-075 & $22^{\circ} 01^{\prime} \mathrm{S}$ & $47^{\circ} 53^{\prime} W$ \\
\hline $11 / 10 / 1972$ & 72,5 & D4-075 & $22^{\circ} 01^{\prime} \mathrm{S}$ & $47^{\circ} 53^{\prime} W$ \\
\hline $05 / 02 / 1973$ & 83,6 & D4-075 & $22^{\circ} 01^{\prime} \mathrm{S}$ & $47^{\circ} 53^{\prime} W$ \\
\hline 07/12/1973 & 93,3 & D4-075 & $22^{\circ} 01^{\prime} \mathrm{S}$ & $47^{\circ} 53^{\prime} W$ \\
\hline 01/01/1974 & 149 & D4-075 & $22^{\circ} 01^{\prime} \mathrm{S}$ & $47^{\circ} 53^{\prime} W$ \\
\hline 06/06/1976 & 94 & D4-075 & $22^{\circ} 01^{\prime} \mathrm{S}$ & $47^{\circ} 53^{\prime} W$ \\
\hline $14 / 09 / 1976$ & 73,2 & D4-075 & $22^{\circ} 01^{\prime} \mathrm{S}$ & $47^{\circ} 53^{\prime} W$ \\
\hline 03/12/1977 & 70,5 & D4-075 & $22^{\circ} 01^{\prime} \mathrm{S}$ & $47^{\circ} 53^{\prime} W$ \\
\hline $18 / 01 / 1980$ & 71,7 & D4-075 & $22^{\circ} 01^{\prime} \mathrm{S}$ & $47^{\circ} 53^{\prime} W$ \\
\hline $13 / 02 / 1980$ & 122,4 & D4-075 & $22^{\circ} 01^{\prime} \mathrm{S}$ & $47^{\circ} 53^{\prime} W$ \\
\hline $18 / 02 / 1980$ & 95,6 & D4-075 & $22^{\circ} 01^{\prime} \mathrm{S}$ & $47^{\circ} 53^{\prime} W$ \\
\hline 20/10/1981 & 93,2 & D4-075 & $22^{\circ} 01^{\prime} \mathrm{S}$ & $47^{\circ} 53^{\prime} W$ \\
\hline
\end{tabular}




\begin{tabular}{|c|c|c|c|c|}
\hline 06/03/1983 & 70,5 & D4-075 & $22^{\circ} 01^{\prime} \mathrm{S}$ & $47^{\circ} 53^{\prime} \mathrm{W}$ \\
\hline $31 / 05 / 1983$ & 78,5 & D4-075 & $22^{\circ} 01^{\prime} \mathrm{S}$ & $47^{\circ} 53^{\prime} \mathrm{W}$ \\
\hline $14 / 12 / 1983$ & 92,6 & D4-075 & $22^{\circ} 01^{\prime} \mathrm{S}$ & $47^{\circ} 53^{\prime} \mathrm{W}$ \\
\hline $15 / 12 / 1984$ & 70,9 & D4-075 & $22^{\circ} 01^{\prime} \mathrm{S}$ & $47^{\circ} 53^{\prime} \mathrm{W}$ \\
\hline 03/11/1985 & 124,4 & D4-075 & $22^{\circ} 01^{\prime} \mathrm{S}$ & $47^{\circ} 53^{\prime} \mathrm{W}$ \\
\hline $02 / 12 / 1986$ & 86,5 & D4-075 & $22^{\circ} 01^{\prime} \mathrm{S}$ & $47^{\circ} 53^{\prime} \mathrm{W}$ \\
\hline $28 / 01 / 1987$ & 102,7 & D4-075 & $22^{\circ} 01^{\prime} \mathrm{S}$ & $47^{\circ} 53^{\prime} \mathrm{W}$ \\
\hline $16 / 11 / 1987$ & 78,8 & D4-075 & $22^{\circ} 01^{\prime} \mathrm{S}$ & $47^{\circ} 53^{\prime} \mathrm{W}$ \\
\hline 05/12/1987 & 70,8 & D4-075 & $22^{\circ} 01^{\prime} \mathrm{S}$ & $47^{\circ} 53^{\prime} \mathrm{W}$ \\
\hline $13 / 12 / 1989$ & 70,5 & D4-075 & $22^{\circ} 01^{\prime} \mathrm{S}$ & $47^{\circ} 53^{\prime} \mathrm{W}$ \\
\hline 04/01/1990 & 79,8 & D4-075 & $22^{\circ} 01^{\prime} \mathrm{S}$ & $47^{\circ} 53^{\prime} \mathrm{W}$ \\
\hline 03/01/1996 & 135,7 & D4-075 & $22^{\circ} 01^{\prime} \mathrm{S}$ & $47^{\circ} 53^{\prime} \mathrm{W}$ \\
\hline $28 / 02 / 1996$ & 92 & D4-075 & $22^{\circ} 01^{\prime} \mathrm{S}$ & $47^{\circ} 53^{\prime} \mathrm{W}$ \\
\hline
\end{tabular}

Fonte: Mendes et al. (2004) 